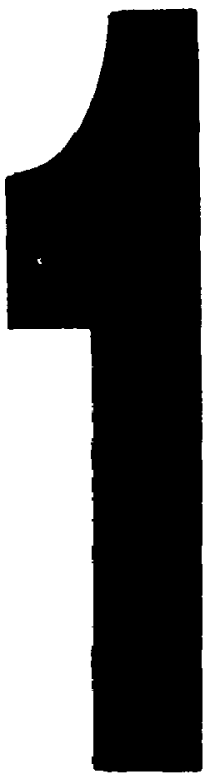

PM-1 31/2"x4" PHOTOGRAPHIC MICROCOPY TARGET NBS 1010a ANSI/ISO \#2 EQUIVALENT

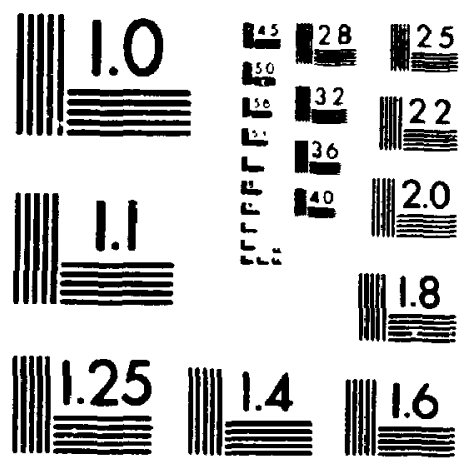

PRECISIONSM RESOLUTION TARGETS 
The quality of this microform is heavily dependent upon the quality of the original thesis submitted for microfilming. Every effort has been made to ensure the highest quality of reproduction possible.

If pages are missing, contact the university which granted the degree.

Some pages may have indistinct print especially if the original pages were typed with a poor typewriter ribbon or if the university sent us an inferior photocopy.

Reproduction in full or in part of this microform is governed by the Canadian Copyright Act, R.S.C. 1970, c. C-30, and subsequent amendments.
La qualité de cette microforme dépend grandement de la qualité de la thèse soumise au microfilmage. Nous avons tout fait pour assurer une qualité supérieure de reproduction.

S'il manque des pages, veuillez communiquer avec l'université qui a conféré le grade.

La qualité d'impression de certaines pages peut laisser à désirer, surtout si les pages originales ont été dactylographiées à l'aide d'un ruban usé ou si l'université nous a fait parvenir une photocopie de qualité inférieure.

La reproduction, même partielle, de cette microforme est soumise à la Loi canadienne sur le droit d'auteur, SRC 1970, c. C-30, et ses amendements subséquents. 


\title{
Assessment of Seismic Analysis Methods for Unreinforced Stone Masonry Towers
}

\author{
by \\ Yuhua Lu \\ B.E. (Bridge Engineering) \\ Tongji University. Shanghai, 1988
}

\begin{abstract}
A thesis submitted to
The faculty of Graduate Studies and Research

In partial fulfullment of the requirements

For the degree of

Master of Engineering

Department of Civil and Environmental Engineering

Carleton University, Ottawa
\end{abstract}

April 1995

The master of Engineering Program in Civil and Environmental

Engineering is a joint program with the University of Ottawa, administered by the Ottawa-Carleton Institute for Civil Engineering

(C) copyright

1995. Yuhua Lu 
National Library

of Canada

Acquisitions and

Bıblicgraphic Services Branch

395 Wellinyton Street

Onawa. Ontario

K1A ON4
Bibliothéque natıoriale

du Canada

Direction des acquisitions et des services bibliographiques

395. rue Wellington

Ontawa (Ontario)

KIA ON4
THE AUTHOR HAS GRANTED AN IRREVOCABLE NON-EXCLUSIVE LICENCE ALLOWING THE NATIONAL LIBRARY OF CANADA TO REPRODUCE, LOAN, DISTRIBUTE OR SELL COPIES OF HIS/HER THESIS BY ANY MEANS AND IN ANY FORM OR FORMAT, MAKING THIS THESIS AVAILABLE TO INTERESTED PERSONS.
L'AUTEUR A ACCORDE UNE LICENCE IRREVOCABLE ET NON EXCLUSIVE PERMETTANT A LA BIBLIOTHEQUE NATIONALE DU CANADA DE REPRODUIRE, PRETER, DISTRIBUER OU VENDRE DES COPIES DE SA THESE DE QUELQUE MANIERE ET SOUS QUELQUE FORME QUE CE SOIT POUR METTRE DES EXEMPLAIRES DE CETTE TAESE A LA DISPOSITION DES PERSONNE INTERESSEES

L'AUTEUR CONSERVE LA PROPRIETE DU DROIT D'AUTEUR QUI PROTEGE SA THESE. NI LA THESE NI DES EXTRAITS SUBSTANTIELS DE CELLECI NE DOIVENT ETRE IMPRIMES OU AUTREMENT REPRODUITS SANS SON AUTORISATION.

ISBN $\quad 0-612-03028-8$ 
Name

i/ $1 / \operatorname{los}_{c}: \dot{c}$

$\angle 61$

Dissertation Abstracts International is arranged by brood, general subject categaries Please select the one subject which most nearly describes the content of your dissertation Enter the corresponding four-digit code in the spaces provided

SUBJECT COOE

Subject Categories

\section{THE HUMANITIES AND SOCIAL SCIENCES}

\section{COMMUNICATIONS AND THE ARTS}

Architecture

Ant Histary

Cinemo

Fine Arts

Information Science

Journalism

library Science

Moss Commun cotions

Music

Speech Communication

Theoter

\section{EDUCATION}

Genera!

Administration

Adult and Continuing

Agricultura

Bilingual and Miulicultura

Business

Community College

Curriculum and Instruction

Early Childhood

Elementory

Guidance ond Counsel:ng

Heaith

History of

Home Economic

Industrial

Language and Liperalure

Mothematics

Music

Philosophy of

Physical

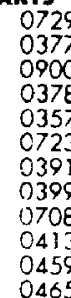

0465

0515

0514

0516

0273

0282

$0<88$

0275

0527

052

0277

0519

0680

0745

C520
0278
0521

0521

280

0522

0998

0523
Psychology

Reoding

Religious

Sciences

Secondary

Social Sciences

Sociology of

Special

Teacher Trainıng

Technology

Tests and heosurements

Vocational

LANGUAGE, IITERATURE AND LINGUISTICS

Longuage

Geners
Ancient
linguistics
Modern
erature
General
Classical
Comporative
Medieval
Modern
Africari
American
Asion
Canadion (English)
Canadian (French)
English
Germanic
Latin American
Middle Eastern
Roniunce
Slovic ond East Europeon

0679

0289

0290

0291

0401

0295

0297

0298

0316

0591

0352

0355

0593

031 :

0312

0315
0313

Slovic ond East Europeon
PHILOSOPHY, RELIGION AND

THEOLOGY

Philosophy

Religion.

Biblical Siudies

Clergy

History of

Philosophy of

Theology

SOCIAL SCIEMCES

americon Stud es

Anthropology

Archoeology

Cutura

Bus.ness Administration

Generul

Accounting

Banking

Manogement

Morketing

Conadion Studies

Economic:

General

Agriculiurai

Commerre business

Finance

History

Lobor

$$
\text { Theory }
$$

Folklore

Geogrephy

Gerontology

History

General
0422

0318

0321

0320

0320
0322
0469

0.323

$0 ? 24$

0326

0327

0310

0272

0770

0454

0385

0501

0503

0505

0508

0509

051

0358

0360

0578

\section{THE SCIENCES AND ENGINEERING}

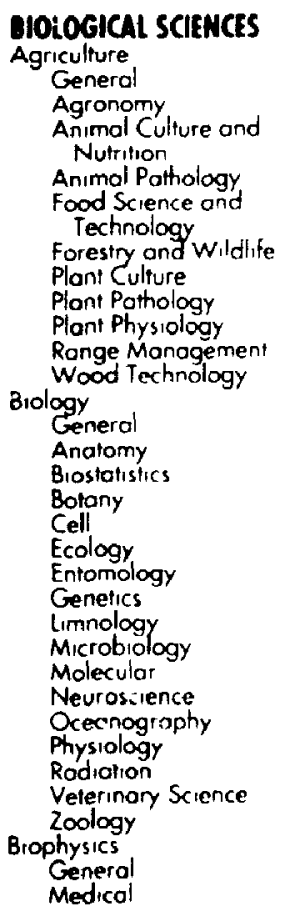

EARTH SCIENCES

Biogeochemistry

Geochemistiry

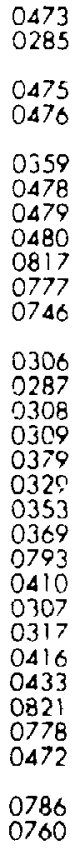

0760

0425
0996
Geodesy

Geophysucs

Hydrology

Minerology

Poleobotany

Paleoecology

Poleozoology

Polynology

Physical Geography

Physical Oceonography

HEALTH ANO ENVIRONMENTAL SCIENCES

Environmental Sriences

Heoith Sciences

General

Chemother opy

Denistry

Educalion

Hospitol Maragement

Humon Development

Immunology

Medicine and Surgery

Mental Meolit

Nursing

Otstetrics and Gynecology

Occupolional Healih and

Therapy

Ophthalmology

Pothology

Pharmacology

Pharmacy

Public Health

Radiology
0370
0372

$03 / 3$

0388

04) 1

0345

0420

0418

0427

0368
0415

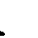

0768

0566

0300

$\mathrm{C} 992$
0567

0350

0769

0758

0982

0.564

0347

0.569

0570

0380

0354

0381

0571

0419

0572
0382

0382
0573

0573
0574

0575
0575

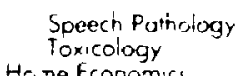

Ho ne fconomics

\section{PHYSICAL SCIENCES}

Pure Sciences

Chemisty

General
Agriculiural

Analytical

Brochemistry

inorganis

Nuclear

Organic

Pharmocentical

Phusica

Polyme

Rodia:

Mathemat's:

Physics

General

Acoustics

Astronomy and

Astrophysics

Amospheric Science

Aromic

Electronics and Electricity

Flementory Porticles and

High Energy

Flud and Plasmo

Molecular

Nuclear

Optics

Radiotion

Solid Siate

Stotistics

Applied Sciences

Applied Mechanics

Computer Science 


\section{Carleton University Ottawa, Canada K1S 5.J7}

Thesis contains black \& white illustrations which when microfilmed may lose their significance. The hardcopy of the thesis is available upon request from carleton University Library. 


\section{Department of Civil and Environmental Engineering}

The Undersigned Recommend to the Faculty of Graduate Studies and Research Acceptance of the Thesis

Assessment of Seismic Analysis Methods for Unreinforced Stone Masonry Towers

subrnitted by

Yuhua Lu

In partial fulfillment of the requirements for the degree of Master of Enguneering

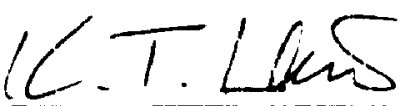

for J. L. Humar. Chair of Department of Civil and Environmental Engineering

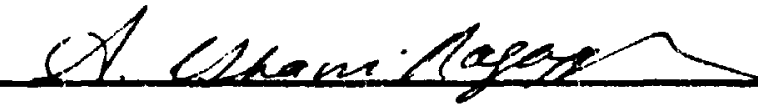

A. G. Razaqpur. Department of Civil and Environmental Engineering. Thesis Co-Supervisor

\section{Sainchidius}

S. E. Chidiac, Structure Laboratory, IRC-NRCC Thesis Co-Supervisor

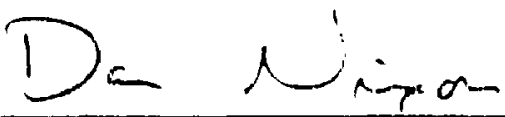

External Examiner

Carleton University Ottawa, Ontario, Canada

May 1995 


\section{Abstract}

This thesis investigates the Impact of structural analysis methods in predicting the seismic response of unreinforced stone masonry structures. Towards thn: goal. an existing stcne masonry tower. whose dynamic properties have been measured, was selected as a basis for the investigation.

Three different structural idealizations of the tower were considered: the simplified method, the frame analysis method and the finite element method. The dynamic modulus of alasticity for the stone masonry was determined by calibrating the first dynamic mode from each method of analysis against the corresponding measured values, from the ambient vibration tes The dynamic properties, namely the natural frequencies and dynamic mode shapes were then computed and compared wilh the reported measured dynamic values. The results revealed that only the finite element model was able to accurately predict the dynamic properties of the load bearing stone masonry tower with openings and flexible diaphragms.

The mathematical models are further evaluated by assessing both equivalent static and dynamic analysis techniques. For the dynamic analysis. different levels of attificially generated tume history ground motson representing 200.500 and 2000 year return penod were used. For the equivalent static method. the computed lateral force according to NBC 1990 was used. The results of the seismic resionse showed that the finite element method yielded consistent and reasonable it ass and displacement values The simplified method was found to produce small displacement and stress values. thus resulting in a non-conservative assessment. On the other hand. the frame model falled to reproduce the dynamic properties of the stone masonry tower. Hence this resulted in an erroneous prediction of the location of maximum stresses and displacements. 


\section{Acknowledgments}

I would like to express my gratitude to both of my supervisors, Prof. A. G. Razaqpur and Dr. S. E. Chidiac, for their ample guidance, advice and useful suggestions.

I would like to acknowledge Dr. J. H. Rainer, Dr. A. H. Maurenbrecher, Messrs. W. Guan and J. Marans, and Ms. L. R. Dessureault of IRC for their useful discussions and help.

I am also grateful to the Institute for Research in Construction. NRC and to the Department of Civil and Environmental Engineering for providing their facilities and financial assistance during the course of this study.

Finally, I would like to express my gratitude to my wife for her support and understanding throughout the course of this study. 


\section{Table of Contents}

Abstract . . . . . . . . . . . . . . . . . . . . . iii

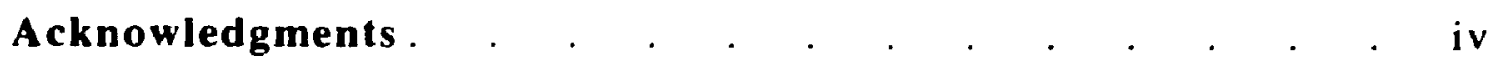

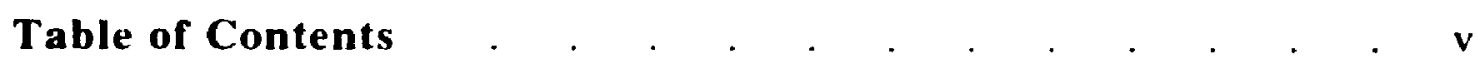

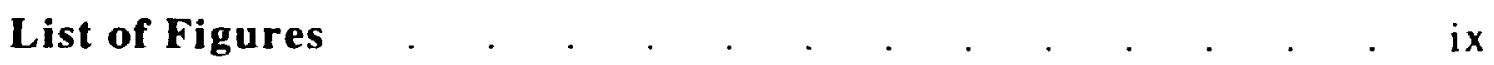

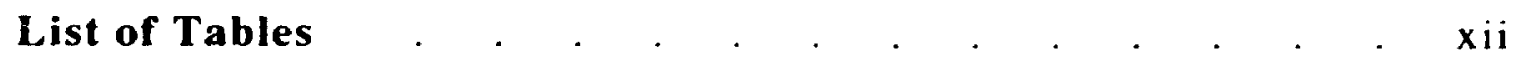

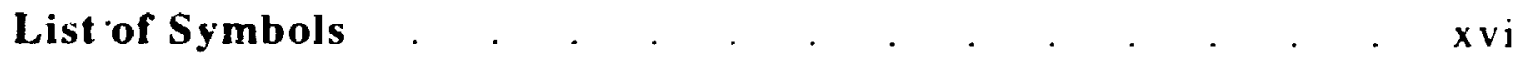

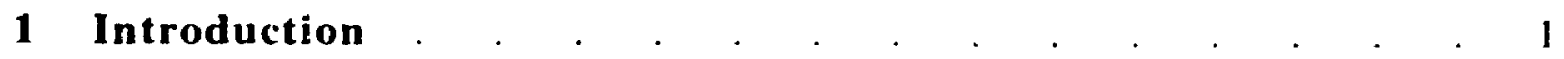

1.1 General. . . . . . . . . . . . . . 1

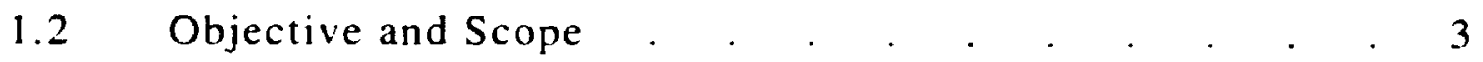

2 Literature Review $\quad . \quad$. $\quad . \quad$. . . . . . . . . . . . . 4

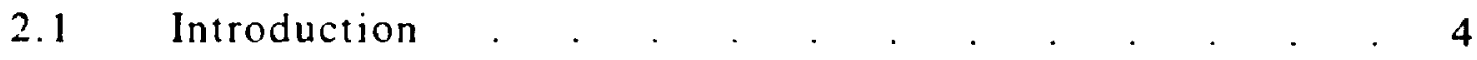

2.2 Seismic Performance

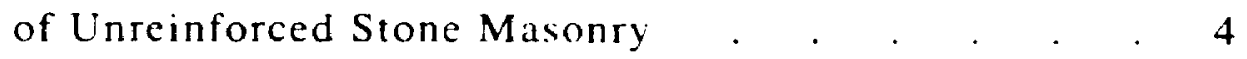

2.2.1 Observed Past Performance . . . . . . . . 5

2.2.2 Dinamic experimental Tests. . . . . . $\quad . \quad . \quad .99$

2.3 Material Characteristics . . . . . . . . . 10

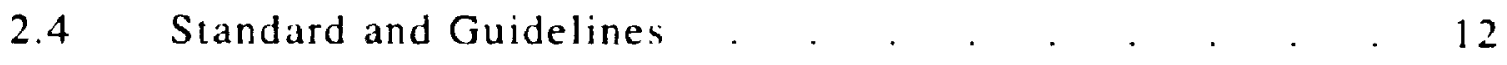

2.5 Analytical Modeling . . . . . . . . . . . . 13

2.6 Summary . . . . . . . . . . . . . . . . . 16

\section{Description of the}

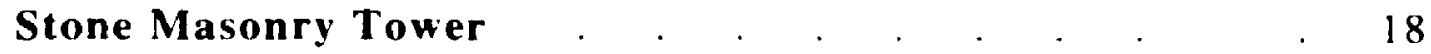

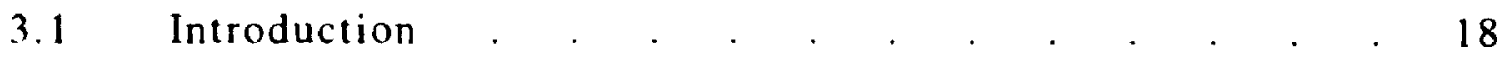

3.2 General Description . . . . . . . . . . 18

3.3 Structural Components. . . . . . . . . . . . . 20

3.3.1 Foundation and Wall . . . . . . . . . . 20

3.3.2 Stone Turrets . . . . . . . . . . . . . . . . 21 
3.3.3 Floors. . . . . . . . . . . . . . . 21

3.3.4 Roof . . . . . . . . . . . . . . . . 30

3.4 Structural Condition of the Tower . . . . . . . . . 31

4 Dynamic Characteristics of the Tower $\quad . \quad$. $\quad . \quad$. $\quad . \quad$. $\quad .32$

4.1 General . . . . . . . . . . . . . 32

4.2 On-site Measurement . . . . . . . . . . . 32

4.3 Simplified Method of Analysis . . . . . . . . . . 36

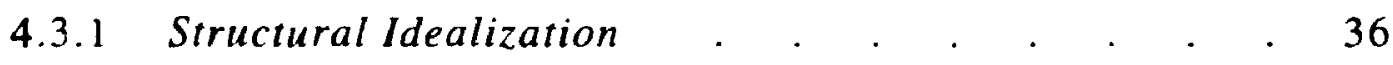

4.3.2 Analytical Procedure and Results . . . . . . . . 39

4.3.3 Boundary Conditions and Material Properties . . . 40

4.4 Frame Analysis Method . . . . . . . . . 41

4.4.1 Program ETABS . . . . . . . . . . . . . . . 41

4.4.2 Structural Idealization $\quad . \quad$. . . . . . . . . . . . . 46

4.4.2.1 Stone Masonry Wall _. . . . . . . . 46

4.4.2.2 Clay Brick Wall . . . . . . . . . . 52

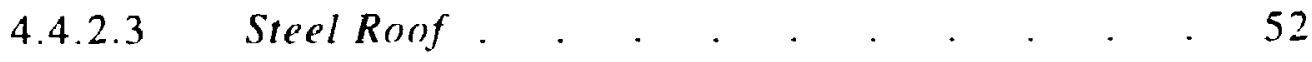

4.4.3 Model Evaluation and Analytical Results . . . . . 52

4.4.3.1 Effects of Rigid Diaphragm . . . . . . 54

4.4.3.2 Effects of Membrane Element . . . . . 55

4.4.3.3 Effects of Conninction
Between the Roof and the Walls . . . . 57

4.4.3.4 Effects of the Surrounding Building . . . 58

4.4.4 Boundary Conditions and Material Properties . . . 65

4.5 Finite Element Method. . . . . . . . . . 67

4.5.1 Finite Element Program AFEMS . . . . . . 67

4.5.1.1 Description of Finite Elements

Used to Model the Tower . . . 68 
4.5.1.2 Dynamic Analysis

Method Applied by AFEMS . . . . . . 71

4.5.2 Structural Idealization. . . . . . . . . . . . . . . 72

4.5.2.1 Stone Masonry Walls . . . . . . . . 73

4.5.2.2 Diaphragm . . . . . . . . . 77

4.5.2.3 Clay Brick Wall . . . . . . . . 77

4.5.2.4 Steel Roof . . . . . . . . . . . . 78

4.5.3 Model Evaluation and Results . . . . . . . . . . 78

4.5.4 Boundary Condition and Material Properties . . . 81

4.6 Discussion . . . . . . . . . . . . . . . . . 81

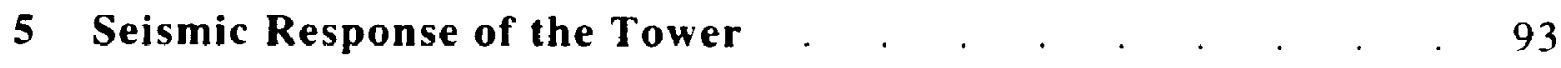

5.1 General . . . . . . . . . . . . . . . 93

5.2 Computation of Seismic Forces. . . . . . . . . . . . 93

5.2.1 Equivalent Lateral Seismic Forces . . . . . . . . 94

52.2 Inertia Forces Introduced by the Ground Motion . . 96

5.3 Response of Analytical Model . . . . . . . . 101

5.3.1 Simplified Model . . . . . . . . . . 101

5.3.1.1 Calculation of Lateral Displacement . . . . 101

5.3.1.2 Calculation of Compressive and Tensile Stresses. 101

5.3.13 Calculation of Shear Stress . . . . . . . 103

5.3.2 Frame Model . . . . . . . . . . . . . . 106

5.3.3 Finite Element Model . . . . . . . . . . 110

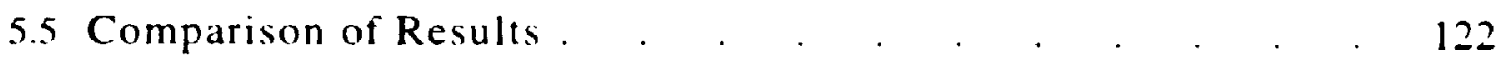

5.5.1 Comparison of Lateral Displacement . . . . . . . 122

5.5.1.1 Displacement in the East-West Direction . . . 122

5.5.1.2 Displacement in the North-South Direction. . . 124 
5.5.2 Comparison of Base Shears . . . . . . . . . 125

5.5.3 Comparison of Acceleration . . . . . . . . . . 126

5.5.4 Comparison of Maximum

Normal and Shear Stresses. . . . . . . . . 128

5.6 Observations . . . . . . . . . . . . . . . 135

6 Conclusions and Recommendations . . . . . . . . . 136

6.1 Conclusions . . . . . . . . . . . . . . . . . 136

6.2 Recommendations . . . . . . . . . . . 138

References . . . . . . . . . . . . . . . 139

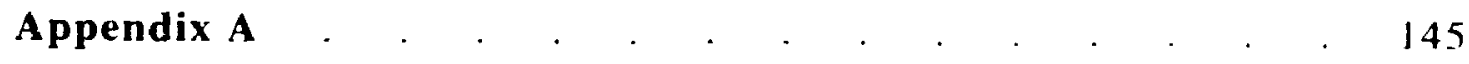




\section{List of Figures}

3.1 Section A-A (looking North: see Fig 3.3) . . . . . . . . . 19

3.2(a) Enlarged upper part of section A-A . . . . . . . . . . $\quad 22$

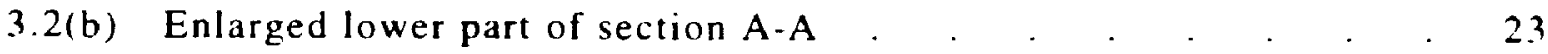

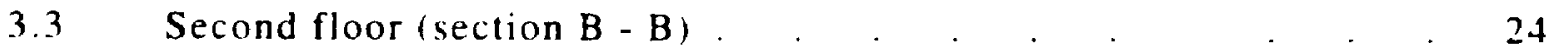

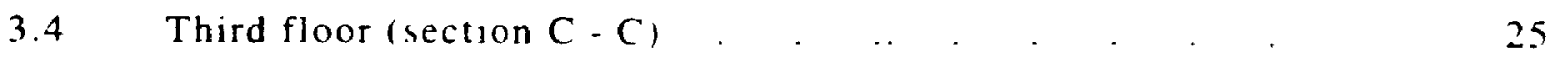

3.5 Sixth floor $(\operatorname{section} F-F) \quad . \quad \ldots 26$

$\begin{array}{lll}3.6 & \text { Eighth floor (section } \mathrm{H}-\mathrm{H}) & 27\end{array}$

3.7 Tenth floor (section J - J) . . . . . . . . . . . 28

3.8 Top of brick wall (section $\mathrm{K}-\mathrm{K}) \quad$. . . . 29

3.9 Arrangement of the various elements of the roof . . . . 30

41 First mode obtaned from the ambient whration tent 3.3

42 Second mode obtained from the ambient wbration teal

4.3 Third mode obtalned from the ambient wbration test 34

4.4 Forth mode ohtaned from the ambient wbration test . . 35

4.5 Fifth mode obianed from the ambient wbration test . . . . . 35

46 Model of the tower

(a) Lumped man (b) Degrees of freedom . 37

4.7 Space frame model for the wower $\quad$ it

4.8 Elevation and plan views of the frame model . 45

4.9 (a) Typical undow shape (b) Structural idealization $\quad 47$

4.10 (a) Plan view of sixth floor

(b) Structural idealization of sixth floor. . . . . 48

4.11 Structural idealization of beam-column connection . . 49

4.12 Typical cross section of

turret at helght where opening exit 
4.13 Detail frame model at eight floor of the tower . . . . . 51

4.14 The single cell rectangular tower . . . . . . . . . . . 53

4.15 $1.5 \mathrm{~m}$ thick rectangular shaft with four openings . . . . . $\quad 57$

4.16 Modes of free standing model

(a): Second translational mode in $\mathrm{N}$ - S direction

(b): Third translational mode in $\mathbf{N}-\mathrm{S}$ direction

4.17 First mode of frame model (North-South direction) . . . . 61

4.18 second mode of frame model (West-East direction) _ . . . . 61

4.19 Third mode of frame model (North-South direction) . . . . . 62

4.20 Fourth mode of frame model (Rotational direction) . . . . . . 62

4.21 Fifth mods of frame model (West-East direction) . . . . . . . 63

4.22 Sixth mode of frame model (North-South direction) . . . . $\quad 63$

4.23 Seventh mode of frame model (North-South direction). . . . $\quad 64$

4.24 Eighth mode of frame model (West-East direction) _ . . . 64

4.25 Ninth mode of frame model (Rotational direction) . . . . . . $\quad 65$

4.26 External constrains at fifth floor in frame model . . . . . . 66

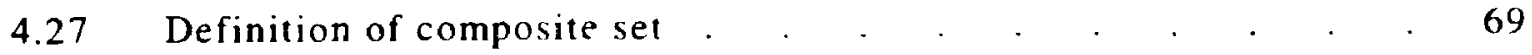

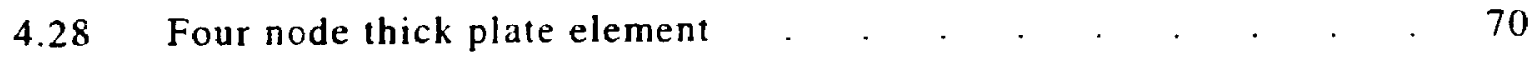

4.29 Beam element . . . . . . . . . . . . . . . . 70

.30 Truss element.$\quad$. . . . . . . . . . . . . . . . 71

4.31 Finite element model for the tower . . . . . . . . . . 74

4.32 Elevation and plan views of finite element model . . . . . . 75

4.33 Mesh of lintel . . . . . . . . . . . . . . . . . . . 76

4.34 Plan view of stone masoriry section modeling . . . . . . . . 77

4.35 Modeling of steel angles _. . . . . . . . . . . . . . . . 78

4.36 Fundamental mode shape of FEM model . . . . . . . 85

4.37 Second mode shape of FEM model _ . . . . . . . . . . . 86 
4.38 Third mode shape of FEM model _. . . . . . . . . . . $\quad$. 87

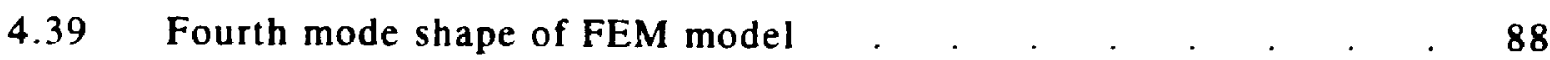

$4.40 \quad$ Fifth mode shape of FEM model . $\quad . \quad$. . . . . . . . . $\quad$. 89

4.41 Sixth mode shape of FEM model . . . . . . . . . . . . . . 90

4.42 Seventh mode shape of FEM mode! . . . . . . . . . . . 91

4.43 Eighth mode shape of FEM model _. . . . . . . . . . . $\quad 92$

5.1 Generated ground motions representing 500 year return period. . . . . . . 97

5.2 Response spectra for 500 year return period seismic ground motions . . . . . . . . . 98

5.3 Auto-spectrum of the ground motion containing high frequency . . . . . . . . . . 99

5.4 Auto-Spectrum of the ground motion containing low frequency . . . . . . . . 100

5.5 frequency content of time history response at the top of the stone masonry . . . . . 111

5.6 frequency content of time history response at the top of the steel roof . . . . . . 111

5.7 Maximum normal and shear stresses due to equivalent lateral force;

5.8 Maximum stresses from high frequency content of time history ground motions (frame model). . . . . . . 131

5.9 Maximum stresses from low frequency content of time history ground motions (frame model).

5.10 Maximum stresses from high frequency content of time history ground motions (FEM model) . . . . . $\quad 133$

5.11 Maximum stresses from low frequency content of time history ground motions (FEM model). 


\section{List of Tables}

4.! Natural frequencies and mode shapes from the ambient vibration test . . . . . . . 33

4.2 Parameters used for the simplified method . . . . . . . 38

4.3 Computed natural periods of the tower using the simplified method . . . . . . . 39

4.4 First mode period of the tower based on NBCC 1990 . . . 40

4.5 Material properties used in the simplified method . . . . 41

4.6 Frequencies carried out from two-storey to ten-storey model and from FEM $(\mathrm{Hz})$. . . . . . 55

4.7 Frequencies of shaft with openings . . . . . . . . . . 57

4.8 Effects oi connection between brick wall and steel angles . . 58

4.9 Effect of surrounding building connection on the natural frequencies of the tower . . 59

4.10 Material properties applied in frame analysis . . . . . 66

4.11 Frequencies from free and constrained model with same material properties . . . . . . . 79

4.12 Frequencies from free and constrained models and from experimental data . . . . . . $\quad .80$

4.13 Frequencies adopted from finite element aralysis . . . . 80

4.14 Material properties used for finite element analysis . $\quad 81$

4.15 Frequencies and mode shapes

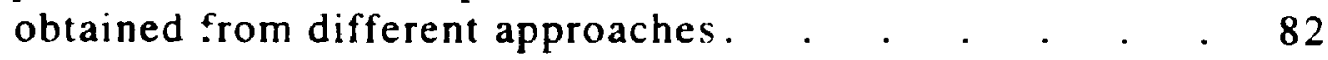

5.1 Values of parameters used to calculate $V_{e} \quad . \quad . \quad . \quad . \quad .95$

5.2 Lateral inertia force along the height and the associated weights 
5.3 Pertinent characteristics of the ground motions. . . . . 98

5.4 Lateral displacements of the simplified model due to equivalent static load. . . . . . . . 101

5.5 Maximum compressive stress obtained from hand calculation. . . . . . . . . . 102

5.6 Maximum tensile stress obtained from hand calculation. $. \quad . \quad . \quad . \quad . \quad . \quad . \quad 103$

5.7 Shear stresses in North-South direction . . . . . . 105

5.8 Shear stress in East-West direction. . . . . . . . 106

5.9 Computed base shear (MN) for 500 year return period seismic motion . . . . . . . . 107

5.10 Maximum horizontal displacement obtained from frame analysis: North - South Direction (Units: mm) . . 107

5.11 Maximum horizontal displacement obtained from frame analysis: West - East Direction (Units: mm) . . . 107

5.12 Maximum compressive stress obtained from frame analysis: North-South Direction (Units: MPa) . 108

5.13 Maximum compressive stress obtained from frame analysis: East-West Direction (Units: MPa) . . . 108

5.14 Maximum tensile stress obtained from frame analysis: North-South Direction (Units: MPa) . . 109

5.15 Maximum tensile stress obtained from frame analysis: East-West Direction L'nits: MPa) . . . 109

5.16 Maximum shear stress obtained from frame analysis:North-South Direction (Units: MPa) . . 110

5.17 Maximum shear stress obtained from frame analysis: East-West Direction (Units: MPa) . . . 110

5.18 Maximum horizontal displacement obtained from FEM analysis: North-South direction (l)its: $\mathrm{mm}$ ). 
5.19 Maximum horizontal displacement obtained from

FEM analysis: East-West direction (Units: $\mathbf{m m}$ ) . . . 113

5.20 Maximum compression stress obtained

from FEM analysis: North-South direction

(Units: MPa, limestone for Tower and Turret) . . . 114

5.21 Maximum compression stress obtained

from FEM analysis: East-West direction

(Units: MPa, limestone for Tower and Turret) . . . 115

5.22 Maximum tensile stress obtained

from FEM analysis: North-South direction

(Units: MPa, limestone for Tower and Turret).

5.23 Maximum tensile stress obtained

from FEM analysis: East-West direction

(Units: MPa, limestone for Tower and Turret)

5.24 Maximum shear stress obtained

from FEM analysis: North-South direction

(Units: MPa, limestone for Tower and Turret).

5.25 Maximum shear stress obtained

from FEM analysis: East-West direction

(Units: MPa, limestone for Tower and Turret).

5.26 Maximum tensile stress for sandstone obiained from

FEM analysis: North-South direction (Units: MPa) . . 120

5.27 Maximum tensile stress for sandstone obtained from

FEM analysis: East-West direction (Units: MPa) . . . 121

5.28 Horizontal displacement from three

methods for 500 year return period (Units:mm) . . . 123

5.29 caled horizontal displacement

for 500 year return period (Units: $\mathrm{mm}$ ) . . . . . . . 123

5.30 Lateral displacement of the top of stone

masonry relative to the roof of surrounding

building from FEM and FA (Units: $\mathrm{mm}$ ) 
5.31 Lateral displacement at the top of the roof relative to the top of stone masonry from FEM and FA (Units: mm) . . . 125

5.32 Maximum absolute acceleration from

FA and FEM model of 500 year return period: East-West direction (Units: g) . . . . . 126

5.33 Maximum absolute acceleration from

FA and FEM model of 500 year return period: North-South direction (Units: g) . . . . 127

A 2.1 Material properties applied in the simplified method . . 146

A 2.2 Flexural displacement . . . . . . . . . . . 152

A 2.3 Shear displacement. . . . . . . . . . . . 153

A 2.4 Fundamental period (Units: second) . . . . . . . . 153

A 2.5 Torsional displacement. . . . . . . . . . . . . 154

A 2.6 Torsional period (Units: second) . . . . . . . . . 154

A 2.7 Natural frequencies obtained from simplified method . . . 155 


\section{List of Symbols}

A

$A_{o}$

$a_{1}$

b

c

$\omega_{n}$

$C_{n}$

$\delta_{i}-\ldots$

Ds

$e_{x}$

E

$F_{1}$

F

$F$,

$F_{x}$

g

$h_{1}$

$h_{x}$

$h_{n}$

H,

I

$I_{b}$ cross-sectional area

area surrounded by center line of wall

length for each separated component

width of the cross section of wall $i$

viscous damping matrix

damped natural frequency for mode $n$

generalized viscous modal damping coefficient for mode $n$

esastic deflecion due to the applied lateral force $f_{1}$ in storey $i$

dimension of frame which constitutes the main lateral load-

resisting system

dimension between the location of the resultant of all forces at

and above the level being considered and the center of the rigidity at the level being considered

Modulus of elasticity

any lateral force associated with weight $\boldsymbol{W}_{\boldsymbol{i}}$,

foundation factor

lateral force on top of the structure

lateral seismic force at floor $x$

gravity acceleration

height of storey $i$

height of storey $x$

total story height

height of segment for segment $i$

seismic importance factor

moment of inertia of the section 
I.

$I(x)$

J

$J_{\text {closed }}$

$J_{\text {open }}$

$k$

$\boldsymbol{K}_{n}$

$\xi_{n}$

$m$

M

$M(x)$

$M_{n}$

$M_{t r}$

$M$,

$p$

P

$P G A$

$P_{n}$

$Q$

$Q$

$R$

$S$

$s$

$S_{h}$

$S$,

$s^{*}$

$t$ moment of inertia of the section $i$

function of moment of inertia along height of interest

torsional constant

torsional constant for closed section

torsional constant for open section

stiffness matrix

generalized stiffness for mode $n$

damping ratio for mode $n$

mass matrix

bending moment

function of bending moment along height of interest

normal-coordinate generalızed mass for mode $n$

torsional moment at story $x$

torsional moment

matrix of applied forces

axial load

peak ground acceleration

generalized load for mode $n$

shear force at each level

applied shear force for segment $i$

force modification factor

seismic response factor

first moment of area

sectional modulus

sectional modulus along walls at storey $i$

sectional modulus

width of the wall at poin of interest 


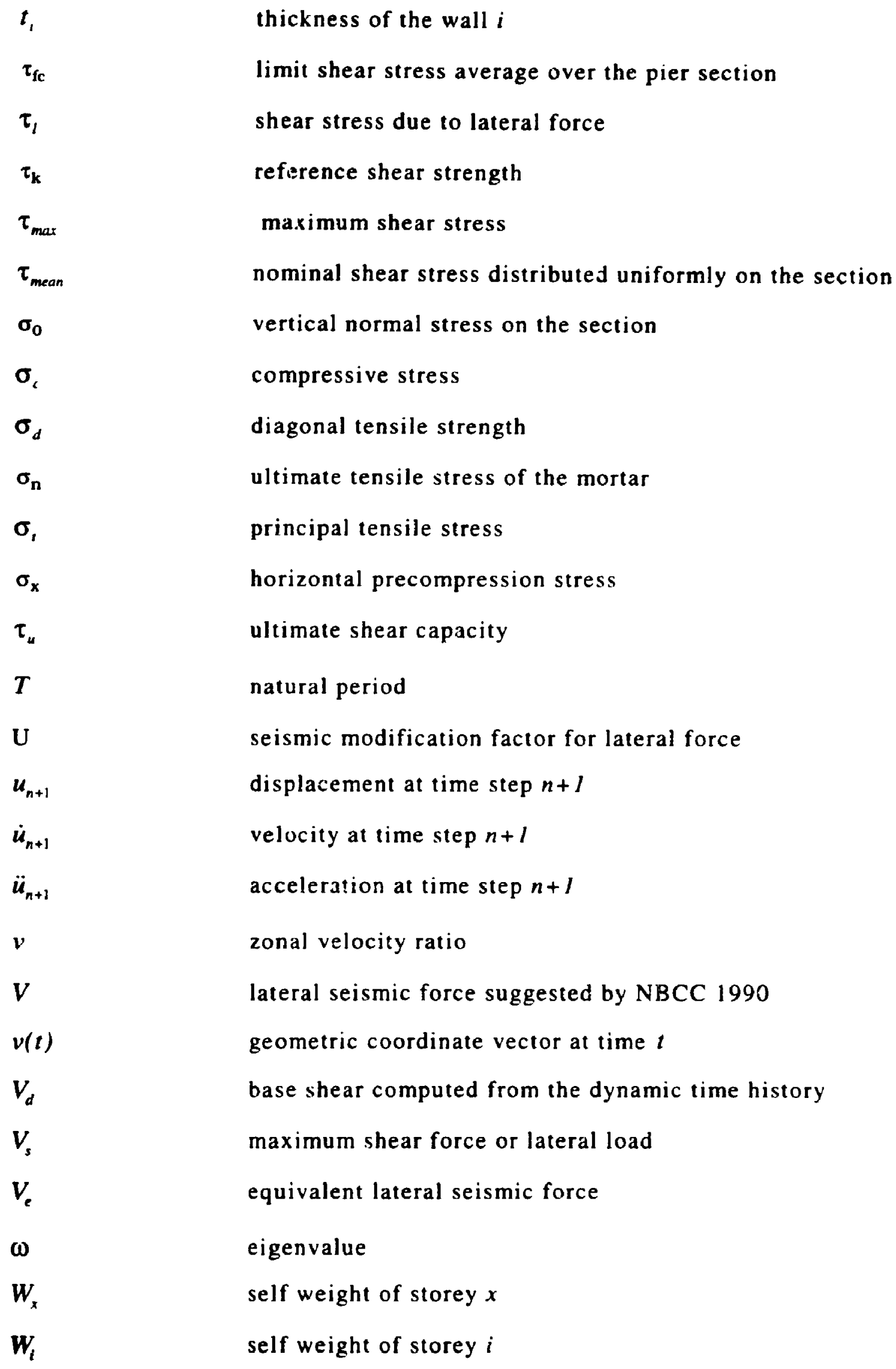

$\tau_{\text {fc }}$

$\tau_{l}$

$\tau_{k}$

$\tau_{\text {max }}$

$\tau_{\text {mean }}$

$\sigma_{0}$

$\sigma$

$\sigma_{d}$

$\sigma_{\mathbf{n}}$

$\sigma$

$\sigma_{x}$

$\tau_{u}$

$T$

$\mathbf{U}$

$u_{n+1}$

$\dot{u}_{n+1}$

$\ddot{u}_{n+l}$

$\boldsymbol{v}$

$V$

$v(t)$

$V_{d}$

$V_{s}$

V

$\omega$

$W_{x}$

$W_{i}$

limit shear stress average over the pier section

shear stress due to lateral force

refirence shear strength

maximum shear stress

nominal shear stress distributed uniformly on the section

vertical normal stress on the section

compressive stress

diagonal tensile strength

ultimate tensile stress of the mortar

principal tensile stress

horizontal precompression stress

ultimate shear capacity

natural period

seismic modification factor for lateral force

displacement at time step $n+I$

velocity at time step $n+l$

acceleration at time step $n+I$

zonal velocity ratio

lateral seismic force suggested by NBCC 1990

geometric coordinate vector at time $t$

base shear computed from the dynamic time history

maximum shear force or lateral load

equivalent lateral seismic force

eigenvalue

self weight of storey $x$

self weight of storey $i$ 


$\begin{array}{ll}W & \text { weight of the whole structure } \\ \delta_{0} & \text { elastic displacement } \\ \delta_{1} & \text { total displacement at storey } i \\ \delta_{1,} & \text { lateral flexural displacement } \\ \delta_{t_{s}} & \text { lateral shear displacement } \\ \delta_{m} & \text { ultimate displacement of pier } \\ \phi_{n} & \text { mode-shape vector for mode } n \\ \rho & \text { mass density } \\ \gamma & \text { Poisson's Ratio } \\ \mu & \text { ductility of stone pier } \\ \mu_{r} & \text { ratio of dynamic base shear to equivalent static base shear } \\ \Phi_{m} & \text { eigenvectors for } n \text { mode } \\ \Phi_{n} & \text { eigenvectors for m mode }\end{array}$




\section{CHAPTER 1}

\section{INTRODUCTION}

\subsection{General}

Unreinforced stone masonry structures have existed for centuries all over the world. Some of them were built to express national or local pride, others although not intended as monuments, have also withstood the challenge of time. Although by their survival, these structures have demonstrated adequate capacity to resist all kinds of load including earthquake, historically, they were constructed without any consideration to lateral loads and in particular seismic loads. Following the aftermath of several earthquakes that shocked parts of Europe and America, the vulnerability of unreinforced masonry to seismic ground motion has to bc addressed. Since most existing stone masonry structures are now classified as "heritage" buildings, and in most cases they serve as public buildings, such as libraries, schools, government offices, churches, etc., the assessment of their seismic safety is becoming even more important.

In North America, most existing unreinforced masonry buildings were constructed of multi-wythe load bearing clay brick wall with flexible diaphragms, with the exceptions of natural stone units and adobe. The adobe which represents sun-dried mud brick is mainly located in the southırn part of USA, Mexico, etc. The unreinforced stone masonry type of construction exists in the eastern part of Canada, and the unreinforced clay brick type of construction is distributed all over North America.

Recent earthquakes in North America, beginning with the May 2, 1983 Coalinga Earthquake of magnitude 6.7, the October 28, 1983 Borah Peak Idaho 
Earthquake of magnitude 7.3, the April 24, 1984 Morgan Hill Earthquake of magnitude 8.1, the October 1, 1987 Whittier Narrow Earthquake of magnitude 5.9, the November 25, 1988 Saguenay Earthquake of magnitude 6.0, and finally the October 17. 1989 Loma Prieta Earthquake of magnitude 7.1(Bruneau and Boussabah 1991), have greatly risen the awareness of the risk associated with unreinforced masonry buildings. To address seismic safety issues of such structures, a multiyear project was sponsored by the National Science Foundation in the USA to review the existing construction practices and to develop a methodology to mitigate the seismic hazard inherent to the unreinforced masonry buildings. The research was conducted by a joint venture of specialists and is known as the $A B K$ ( $A B K$ 1984). Although the ABK study was comprehensive. its scope did not extend to cover thick masonry and walls constructed with natural stone units. The Federal Emergency Management Agency, FEMA(FEMA 1989), has since sponsored the Building Seismic Safety Council to incorporate the findings of ABK. Canadian researchers have since published two documents pertaining to seismic rehabilitation, IRC-NRCC (1992). Although these guidelines are instrumental to establish a general consensus on the seismic behavior of masonry structure, they rely largely on simple model to establish the performance level. Furthermore, they are mostly an extension of the work reported by $A B K$.

The applicability of simple models to adequately predict the seismic performance of unreinforced stone masonry structures located in a moderate earthquake zone requires further study. Also a better understanding of the seismic performance of unreinforced masonry structures will undoubtedly translate into economical saving and the preservation of existing heritage structures. 


\subsection{Objective and Scope}

The objective of this thesis is to evaluate the adequacy of different existing numerical methods for analyzing the seismic response of unreinforced load-bearing stone masonry structures.

In pursuing that objective, a stone masonry tower located in a moderate seismic zone is chosen as a case study for assessing the various methods. More specifically, a simplified method, suitable for hand calculations, the space frame analysis method and the spatial finite element method (FEM) will be used to perform the analysis.

In each case, the dynamic characteristics of the tower is first computed, then the seismic response is determined, using both the equivalent static and dynamic methods. The analysis is limited to linear elastic behavior in order to focus more on the applicability of the mathematical model. Thus the impact of structural engineering modeling decisions are assessed by comparing the results from those mathematical models. The findings are expected to reveal which mathematical method is most suitable for modeling the dynamic behavior of unreinforced stone masonry. This should also provide useful information on the applicability of the equivalent static method and in a broad sense on the use of general guid.lines for the seismic rehabilitation of existing unreinforced stone masonry buildings. 


\section{CHAPTER 2}

\section{LITERATURE REVIEW}

\subsection{Introduction}

Historically, lateral load requirement for earthquake design have been shown to be inadequate and only in the last thirty years significant progress were made towa.ds appropriately and safely designing high-rise buildings for earthquake resistance. The need for structural integrity which is an essential requirement has been demonstrated also is not historically included in the design requirement (Corley 1991). Further, studıes in the understanding of seismic performance and assessment of heritage structures have been minute compared with building constructed of modern material. To this end, a brief examination of the past performance of heritage buildings in particular stone masonry to earthquake loads is merited. The applicability of the assessrient methods that have been proposed to examine the seismic adequacy of heritage building also needs to be revened. Both of above aspects are the subjects of this chapter along with a brief examination of the methods proposed to characterize the seismic response of stone masonry

\subsection{Seismic Performance of Unreinforced Stone Masonry}

In this section, the selsmic behavior of unreinforced stone masonry under seismic excitation is summarized. The key parameters that are reported to affect its response are also identified on the basis of reported past performance and laboratory testing. 


\subsubsection{Observed Past Performance}

The performance of stone masonry to the three medium to strong earthquakes(1974-1976) in Slovenia were reported by Turnsek(1978). The damage caused to masonry building were mainly cracking at wall junctions, pulling away of walls from main structure and collapse of head walls. Turnsek(1978) pointed out that the damage is attributed to the flexibility of the soft wooden floors that led to the unsynchronized oscillation of the walls and causing damage to the structures. Further, the presence of a flexible diaphragm does not uniformly distribute the inertial forces generated by the earthquake and thus reduces the seismic capacity of the building as a whole. The preceding observation was verified through a $1: 5$ scale model of a single storey stone masonry building.

The 1977 earthquake in Romania with a magnitude of 7.2 on the Richter scale was reported by Tezcan(1978). The local stone masonry buildings in Romania are usu-lly two to four stories high massive structures constructed sometime between the 18 th century and World War 1. According to Tezcan(1978), these structures withstood the shock quite well. In some century-old masonry, the earthquake apparently widened the cracks in the load bearing walls. The later cracks had been caused by earlier earthquakes, but despite the cracks these buildings withstood the earthquake well.

The 1981 earthquakes in central Greece which consisted of a main shock of magnitude 6.7 on the Richter scale and several after-shock of magnitude 5.0-6.3 were reported by Carydis(1982). Stone masonry buildings built after the 1928 earthquake and those that had been repaired to the requirements of recent seismic codes withstood the shock well. Some of the observed damage was attributed to the various additions(both in plan and elevation) $t^{2}$ ough renovation, such as introduction of openings in walls or remove of masonry walls and their replacement 
by slender steel columns without any horizontal stiffening elements. In some cases, stiff buildings found on very soft soil suffered almost no damage even in the epicentral region, while some old hotels and houses on good soil were damaged beyond repair. In some region, many masonry walls were built as two exterior faces infilled with rubble and earth. Clay mortar without any cementing material was used. These buildings were extensively damaged. In Athens, the 140 years old Athens Cathedral suffered numerous cracks over arches, but parapets and ornamentation were not damaged. The Cathedral has survived all previous earthquakes, including the 1894 earthquake that led to the collapse of all the surrounding buildings.

Erguray and Erdik(1984) presented the Turkish experience on the earthquake performance of stone masonry buildings and concluded that the performance of such structures have been discouraging. Later. Erdik(1990) reported on the observed earthquake damage to rural stone masonry buildings. He noted that the quality of masonry is actually an important factor that influences the seismic performance, but there are other factors of equal importance that must be addressed, namely

- mortar quality

- inadequate connection of roof beams to the bearing walls

- poor transverse connection

- lack of in-plane ductility

- inappropriate corner detalling

- excessive opening in a wall

In 1985 Mexico city suffered an earthquake of magnitude 8.1 on the Richter scale with the epicenter located $400 \mathrm{~km}$ west of the city. According to Klingner(1987), buildings ranging from 7 to 20 story high were either severely 
damaged or led to collapse. On the other hand, many century old stone masonry churches, residences and commercial buildings suffered in general very little damage. The unexpected behavior was confirmed and it was suggested by the International Masonry Institute(undated): "This may have been less a function of their general structural integrity than of the fact that their fundamental periods of vibration were shorter than the characteristic periods of the lake zone ground motion."

As reported by Allen(1989), the 1988 Saguenay earthquake in Canada caused cracking of window soffits in a thick stone masonry church under maximum acceleration of approximately $0.2 \mathrm{~g}$. Allen(1989) further stated that the damage was caused by forces in the plane of the wall, amplified by stress concentration, and were often associated with changes in building stiffness. The loss of the wall's stability was not observed. Only in a few cases partial collapse of veneer and of block partitions were reported, and the main contributing factor was concluded to be lack of adequate ties to the structure.

Karantoni(1992) reported on the magnitude 6.0 earthquake which hit Kalamata, Greece in September 1986. Peak horizontal ground acceleration ranged from $0.22 \mathrm{~g}$ to $0.3 \mathrm{~g}$. Masonry buildings in Kalamata were typically $50-150$ years old, comprising two storey and a basement, with exterior load-bearing walls made of plastered uncoursed rubble-stone masonry. Walls usually did not have any tie beams. The buildings typically have light wood floors on timber joists, weakly anchored to the exterior walls in the direction of the joists and the wood sheathing. Almost half of these buildings suffered partial collapse or other itreparable damage and had to be demolished. The main types of observed damage were: 
- Diagonal tension cracking in the piers, in one or both stories. If window sills were integral with the adjacent piers, diagonal cracking often extended into the heavy spandrels.

- Vertical cracking of spandrels over the windows or door heads, mainly in the top story.

- Separation of the longitudinal walls from the transverse walls, along a nearly vertical line at the corner pier of the second storey.

- Out-of-plane collapse of a second-storey wall or of the upper part of the wall.

Since there are different descriptions for earthquake severity and damage levels given in the various reports, it is difficult to make comparisons between building performances, but nevertheless, some common observed failure modes can be summarized as:

- In-plane failure: generally include diagonal and sliding shear failure and tensile failure due to overturning.

- Out-of-plane failure: pull away of the whole wall or collapse of part of wall for one or several levels

- Combination of in-plane and out-of-plane failure: lack of in-plane ductility. leading to diagonal cracks, and subsequent separation of walls and eventual out-of-plane collapse.

- Flexible diaphragm: flexible diaphragm leads to oscillating movements and collapse of the walls and roof.

Even though the inherent weakness of stone masonry structure to seismic loads is documented, their level of safety has been shown to vary significantly. As indicated by Tomazevic(1982). "Quantitative data about the seismic resistance of a 
building cannot be determined unless additional investigation to establish the structural characteristics and the material properties are carried out."

\subsubsection{Dynamic Experimental Test}

In 1978 Turnsek (1978) built and tested two 1:5 scale models of one-storey stone masonry building on a laboratory suaking table. The purpose of the study was to obtain insight into and understanding of the seismic resistance of stone masonry buildings with a soft diaphragm. One of the buildings had a steel tied roof while the other did not. The model without tied roof failed due to the collapse of head-wall while the tied model was found to fail due to the collapse of one parallel to the shaking direction, with the head-wall still intact. The results supported his assumption that most of the damages in the 1974-1976 Slovenia earthquake, such as cracking at joints between walls, pulling away of walls and collapse of head-walls, was due to soft wood diaphragms, which did not show stiff action in the horizontal direction and led to the unsynchronized oscillations of individual walls.

Tomazevic and Sheppard(1982) conducted shaking table tests on laboratorymade specimens of limestr.ne blocks with mortar and with workmanship typical of the old masonry buildings. The study focused on the strength characteristics of stone masonry walls. It was concluded that the strength characteristics of stone masonry walls vary widely in their original state. Their resistance to horizontal loading is very low, so that damage to or even the collapse of stone masonry building can be expected in moderate earthquake, and collapse on a large scale in severe earthquake.

Dynamic analysis of masonry structures through non-destructive methods such as ambient vibration, has been conducted by severa! researchers(Tomazevic 
and Anicic 1989. Modena 1991), as well as studies involving forced vibration using low excitation forces(UNESCO 1982 and 1983). The analysis results from those forced vibration test records such as displacement, velocity and acceleration of the system, supply the dynamic modal parameter and were used for calibration.

\subsection{Material Characteristics}

The resistance of the stone masonry walls to the action of horizontal forces depends on the quality of construction. An experimental investigation by Benedetti and Castellani (1980) resulted in the development of a method to determine the failure mechanism and section capacity of walls. Two potential modes of failure were identified, namely shear and flexural type. The limit for the shear mechanism is defined by

$$
\tau_{\mathrm{fc}}=\tau_{\mathrm{k}} \sqrt{1+\frac{\sigma_{0}+\sigma_{x}}{1.5 \tau_{k}}+\frac{\sigma_{0} \sigma_{x}}{2.25 \tau_{k}}} ; \quad \tau_{k}=\frac{\sigma_{n}}{1.5}
$$

where $\tau_{k}, \tau_{f c}, \sigma_{o}, \sigma_{x}$ and $\sigma_{n}$ are the reference shear strength, the limit shear stress average over the pier section, vertical normal stress on the section. horizontal precompression stress and the ultimate tensile stress of the mortar, respectively. For flexural mechanism, failure occurred at the toe of the pier due to overturning moment.

The failure characteristics of a full scale model was studied by Xia and Chen (1984). They observed that the natural frequencies decreased by $32 \%$ and $16 \%$ for the two perpendicular directions after the occurrence of penetration cracks. The damping ratio for tested buildings varied from $2.3 \%$ to $10 \%$. The dynamic modulus was found on the average to be 1.5 times the static one. Both the compressive strength and Poisson's ratio were not influenced by the inertia force. 
In 1984, Benedetti et. al. reported on a second experimental investigation of a single pier. They characterized the shear mode failure by early flexural crack at the base of the pier followed by a diagonal crack. They also observed that the first crack occurred when the shear force, $v$ was between $85 \%$ and $100 \%$ of the maximum value for height to width ratio up to 1.5 . The shear force, $V$, was computed using

$$
\mathrm{V}=\mathrm{A} \tau_{\mathrm{k}} \sqrt{1+\frac{\sigma_{0}}{15 \tau_{\mathrm{k}}}} ; \quad \tau_{k}=\frac{\sigma_{d}}{1.5}
$$

where $A$ and $\sigma_{d}$ are pier cross section area and diagonal tensile strength respectively. The ultimate capacity was, however, found to be controlled by the magnitude of the displacement, j.e. by

$$
\delta_{\mathrm{m}}=\mu \delta_{0}
$$

where $\delta_{m}, \mu$ and $\delta_{0}$ are the ultimate displacement of the pier, the ductility and its elastic displacement, respectively. Using this procedure, Benedetti(1984) demonstrated good agreement between the experimental results and the predicted seismic resistance.

Angotti et. al.(1988) used the equivalent static method in conjunction with seismic coefficient (the ratio between the lateral load and the weight) to examine the influence of both the geometrical and material characteristics on the ultimate seismic capacity. In their analysis, they assumed that the floors were rigid and properly anchored to the walls and that the ultimate strength was controlled by the shear strength, but they did not consider out-of-plan failure or other failures which may cause collapse such as anchorage failure of the diaphragm. Their results suggested that the seismic capacity of a masonry building is largely influenced by the material characteristics, in particular the shear strength. 
Tomazevic and Velechovsky(1992) conducted an experimental investigation to explain the factors that control the level of damage caused by earthquakes. The damage patterns and failure mechanisms obtained during the model tests were found to be similar to those observed in buildings after earthquakes. They concluded that the type of failure mechanisms of masonry walls stibjected to seismic loads depends largely on the ratio of shear and flexural stress to the compression stress in the wall.

\subsection{Standard and Guidelines}

Clause 4.1.9 of National Building Code of Canada(NBCC) provides the definition and calculation procedures for live loads due to earthquake. It suggests that the base shear. $V$. due to earthquake be computed from

$$
V=\left(V_{e} / R\right) U
$$

where $U$ equal to $0.6, R$ and $V_{e}$ are the force modification fact and the equivalent lateral seismic force representing the elastic response respectively. $V_{e}$ will be calculated ds

$$
V_{e}=v \cdot S \cdot I \cdot F \cdot W
$$

where $v, S, I, F$ and $W$ are zonal velocity rato, seismac response factor, seismic importance factor, foundation factor and weight of the structure, respectively.

It is suggested that $V_{e}$. be distributed through the height of structure proportional to the tributary mass. The code provides suggestion for determining the natural period of the fundamental mode and formulas for computing the overturning moment, torsional moment. The code also define the limitation of deflections and provides special provisions regarding some particular structures in clause 4.1 .9 .2 and clause $4,1,9.3$ 
ABK-joint venture $(1981,1984)$ has conducted research to develop a methodology to mitigate the seismic hazard inherent to the unreinforced masonry buildings. The methodology was primarily based on common features during the investigation of low rise commercial buildings with wooden floors and large multistorey important building with cast-in-place concrete floors. Accordingly some recommendations were made which included limits of height/thickness for out-ofplane stability ratio, demand/capacity ratio for diaphragm and anchorage between diaphragm and wall. They also concluded that the equivalent static procedures is not satisfactory to define the dynamic and highly nonlinear response of unreinforced masonry buildings. However, these limits were base on the examination of brick wall with height/thickness ratio from 14 to 25 and the assumption of soil amplification and infinite in-plane rigidity.

\subsection{Analytical Modeling}

Sinha (1978) proposed a simplified model based on fracture lines to calculate the ultimate pressure that can be applied to any brittle material having both strength and stiffness orthotropies. This model can be applied to unreinforced stone masonry in order to predict its failure load.

An analytical model was developed by Adham and Ewing(1978) to study the response of a flexible diaphragm when subjected to high seismic excitation. The results have shown that because the diaphragm is highly nonlinear, it attenuates the input earthquake accelerations and thus reduces the transmitted shear force to the masonry wall.

Traditionally, researchers have used a shear failure criterion based on diagonal tension capacity. The normal tensile stress capacity of masonry, $\sigma_{1}$, is equal to the maximum shear stress at failure, $\tau_{\max }$, where $\tau_{\text {max }}=1.5 \tau_{\text {mean }}$ for a 
rectangular section under pure shear. The ultimate shear capacity of unreinforced panel under shear and axial compression can be derived by using the well-known classical expression for principal tensile stress (Mayes and Clough, 1975) and (Turnsek, 1978)

$$
\sigma_{1}=\frac{\sigma_{c}}{2}+\sqrt{\left(\frac{\sigma_{c}}{2}\right)^{2}+\left(\tau_{u}\right)^{2}}=\sigma_{t}=\tau_{\text {max }}=\tau_{\text {mean }}
$$

where $\sigma_{c}$ is the compressive stress, and $\tau_{u}$ is ultimate shear capacity which can be expressed as

$$
\tau_{u}=1.5 \tau_{\text {mean }} \sqrt{1-\frac{\sigma_{c}}{1.5 \tau_{\text {mean }}}}
$$

The maximum lateral load, $V$, that could be applied to the wall is

$$
V=\frac{\tau_{u} A}{1.5}
$$

As recommended by Mayes and Clough(1975), both the above and the Coulomb friction equation need to be checked. Generally, the first one refers to high bond mortar. the second reflects that bond and friction between the mortar joints could potentially govern at low axial compression.

Dionsio Bernal(1992) developed a single degree of freedom model(SDOF) to check safety against dynamic instability, but his method is limited to regular shapes which can be easily transformed to a 2-D model and most of his criteria need to be modified for stone URM.

Vestroni et. al.(1991) suggested the use of finite element method linearelastic model to determine the value of the spectral earthquake intensity which can be supported by a structure with only slight strengthening work. In other words, one should determine the seismic level, before damage occurs, which can lead to 
global failure, and use the nonlinear generalized single degree-of-freedom model for safety investigation.

Seible and Kingsley(1991) proposed three approaches to model masonry structure, namely the lumped parameter model (LPM), the structural component model(SCM) and the finite element model (FEM). They found that the LPM is a valuable tool to obtain a basic understanding of the dynamic response of a structure, but it heavily relied on the correct definition of the component hysteresis which must include not only the nonlinear material behavior but also the effects resulting from true geometry of the structure, such as changes in axial load level due to overturning, uplift and coupling. Meanwhile LPM is not suitable for predicting local or global failure mechanisms, or distress levels in individual structural components. The SCM, in which a plane wall was modeled with beam and column elements, was considered as the most powerful tool to asses the detailed linear behavior of the structural system under static and dynamic loads, but it still relies on knowledge of the true member end force/deformation relation, and on developments based on consistent nonlinear theories. Nonlinear inelastic behavior and the smeared crack theory were adopted for a small scale planar finite element model to investigate the behavior and response characteristics of components and sub-assemblies, and was found satisfactory with both monotonic and cyclic loads histories. Complex multi-story structures analysis by nonlinear FEM was suggested to be computationally demanding and possible numerical difficulties may arise.

The objective of Karantoni and Fardis's study(1992) was to asses the ability of three different linear elastic methods to predict both the location and severity of seismic damage of stone masonry under a given seismic excitation. The three methods are the crude shear-beam type of approximation which neglects out-of- 
plane bending and considers only the stiffness of walls parallel to seismic input, the 3-D space frame model (SFM) where pier and spandrel are modeled as wide prismatic beam elements rigidly connected, and the 2-D four nodes thick plate finite element discretization (FEM). Static equivalent lateral load was applied to the three models for the comparison purposes. Only the FEM model was assessed by eigenvalue/eigenvector and response spectrum computation. By comparing the analysis results with actual existing damage, they concluded that FEM accounts for both in-plane and out-of-plane action, and it can capture the key features of the response, and can provide a fairly close prediction of the distribution and severity of damage. SFM overestimates the principal tensile stress while the shear-beam model accounts only for in-plane action and it underestimates seismic stresses and gives unreliable damage patterns. There was no discussion about the dynamic characteristics of each model which can be very critical when excited by ground motion. Thus, a more detailed comparison among those three methods based on a dynamic time history input would be valuable from the designer's point of view.

\subsection{Summary}

This literature survey has revealed limited knowledge on how to assess the seismic performance of stone masonry buildings. The past performance of those structures is somewhat confusing since they have exhibited vulnerability to some earthquake and were unshaken by others. Further, no guidelines were found on the use of the analytical methods to assess the seismic resistance of such structures. On that basis. this study was initiated to investigate the applicability of existing analytical methods to estimate the response of heritage buildings to earthquake loading. In particular, the simplified method, the stiffness and the finite element method will be evaluated using both equivalent static and dynamic analysis. The 
outcome should provide guidance on the choice of method of analysis for the quantification of stone masonry seismic resistance. 


\section{CHAPTER 3}

\section{DESCRIPTION OF THE STONE MASONRY TOWER}

\subsection{Introduction}

The safety evaluation of a heritage structure must reflect its present condition, including the current deformation and damage (Groci 1992). Traditionally, historical survey and visual investigation have been used as methods of evaluation. However, mathematical modeling is being increasingly used to predict the deformations and the overall behavior of such structure and thus to provide an assessment of their safety level. In this study, a simplified model, a frame model and a finite element model are applied as mathematical tools to investigate the applicability to the assessment of the seismic response of a heritage building. In this chapter. the selected structure will be briefly described and its principal structural element will be identified

\subsection{General Description}

The selected tower is an unreinforced stone masonry bearing wall structure with nine floor systems covered with a steel frame roof. The two wythes stone masonry walls consist of limestone at inner face as structural component and sandstone at the outer face as decoration. Its lower five levels are attached by a building on three sides, while its remaining height is free standing. The total height of the tower is $81.55 \mathrm{~m}$ of which the roof is $32.6 \mathrm{~m}$ high. A overall view of elevation of the tower is presented in Fig. 3.1. Its floor plan is basically 
rectangular with dimensions of approximately $9 \mathrm{~m} \times 12 \mathrm{~m}$. At two corners of the rectangle are situsied octagonal turrets which are integrally built in with the tower.

A set of detailed geometric drawings of the tower is presented from Fig. 3.2 to Fig. 3.8 based on the original drawings and on-site surveys. The drawings represent one elevation and the plans of some typical floors. The indicated thicknesses of the walls have been recently checked by means of direct measurements and by ground penetrating radar(Chidiac 1993).

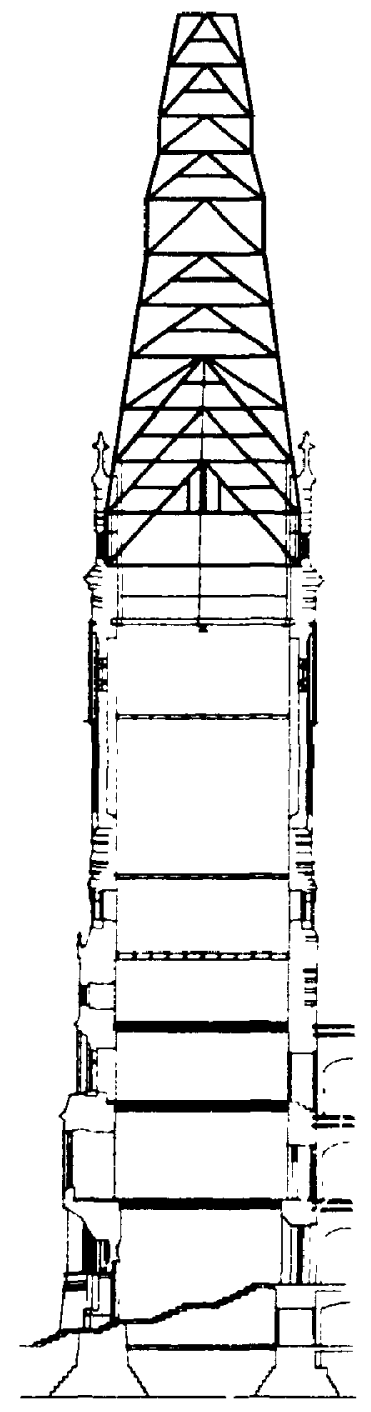

Fig. 3.1 Section A-A (looking North: see Fig. 3.3, Chidiar et. al. 1993) 


\subsection{Structural Components}

\subsubsection{Foundation and Wall}

The tower is believed to be built directly on bedrock with a step masonry footing as shown in Fig. 3.2(b).

By reference to Fig. 3.2(a) and (b), we observe that the walls of the tower are made of stone masonry from the base of the tower to the base of the steel roof while $2.39 \mathrm{~m}$ above the ninth floor, the walls are made of clay brick masonry and are $2.94 \mathrm{~m} \mathrm{high}$.

The stone masonry wall consists of two wythes. The inner layer comprises limestone blocks with an average height varying from $340 \mathrm{~mm}$ to $620 \mathrm{~mm}$ and a maximum observed length of $1800 \mathrm{~mm}$. The outer layer or veneer is constructed from sandstone blocks with an average thickness of $100 \mathrm{~mm}$ to $300 \mathrm{~mm}$. The thickness of the stone walls is $1.8 \mathrm{~m}$ from the ground level (Fig. 3.3) to the third level, then changes io $1.5 \mathrm{~m}$ from the third level to the sixth, as shown in Figs. 3.4 and 3.5 respectively. Figure 3.5 also shows the small openings and indentions along the stone masonry walls between the sixth floor and the sererin floor. As indicated in Figures 3.6 and 3.7, the seventh floor to the top of the stone masonry. the thickness of the stone masonry walis is $1.4 \mathrm{~m}$. Figure 3.6 also shows the size of the large openings between the seventh floor and the ninth floor. The preceding values have been confirmed using a ground penetrating radar. The walls on the west side of the sixth floor and on the south side of the seventh floor were found to contain irregular stone or rubble through their thickness(Chidiac et. al. 1993).

The face of the interior stone masonry is exposed above the fifth floor level. The walls consist of limestone blocks of nearly uniform height within one course. The sandstone veneer consists mostly of rectangular blocks attached to the 
limestone. At the top of the stone masonry lies the solid clay brick wall of $2.94 \mathrm{~m}$ high as shown both in Figs. 3.2 and 3.7. The base of the steel roof also rests on top of the stone masonry but at the outside of clay brick walls (Figs. 3.7 and 3.8).

\subsubsection{Stone Turrets}

Figure 3.3 shows the second floor plan which includes the plan view of the two octagonal stone turrets of the tower. The continuity of the octagonal is interrupted by the openings of the doors and windows. Unlike the dimensions of the main walls of the tower, which remain almost unchanged with height, the diameter of the turrets becomes smaller from the bottom to the top. As shown in Figures 3.3 to 3.7 , the outer diameter of the turret $5.55 \mathrm{~m}$ at the second floor level becomes $5.08 \mathrm{~m}$ at the third floor, $4.32 \mathrm{~m}$ at the sixth floor, and finally $3.96 \mathrm{~m}$ at the ninth floor. The thickness of the turrets varies from $1.5 \mathrm{~m}$ at the first level to $1.2 \mathrm{~m}$ at the top of the stone masonry. There are a number of openings in the turret: which serve mainly as the entrance from the turrets to the main floors of the tower or as windows. Some typical openings and doors are shown in Figs. 3.4 and 3.5.

\subsubsection{Floors}

The first floor of the tower is a concrete diaphragm with a thickness of approximately $200 \mathrm{~mm}$ (Fig. 3.2b). The three floor diaphragms at the 3rd, 4th and 5th floor levels are brick arches spanning between steel joists as shown in Fig. 3.2b. Above the fifth floor, wooden planks replace the brick and are resting on the steel joists (Figs. 3.2a and 3.2b). The connections between the joists and the wall are not visible except at the ninth floor level. There the joists are essentially simply supported with each end extending $210 \mathrm{~mm}$ into the wall (Fig. 3.2a). 
A large iron beam made of tiveted plates, as shown in Figs. 3.1 and 3.2a, is located under the ninth floor, and is simply supported on large stone corbels.

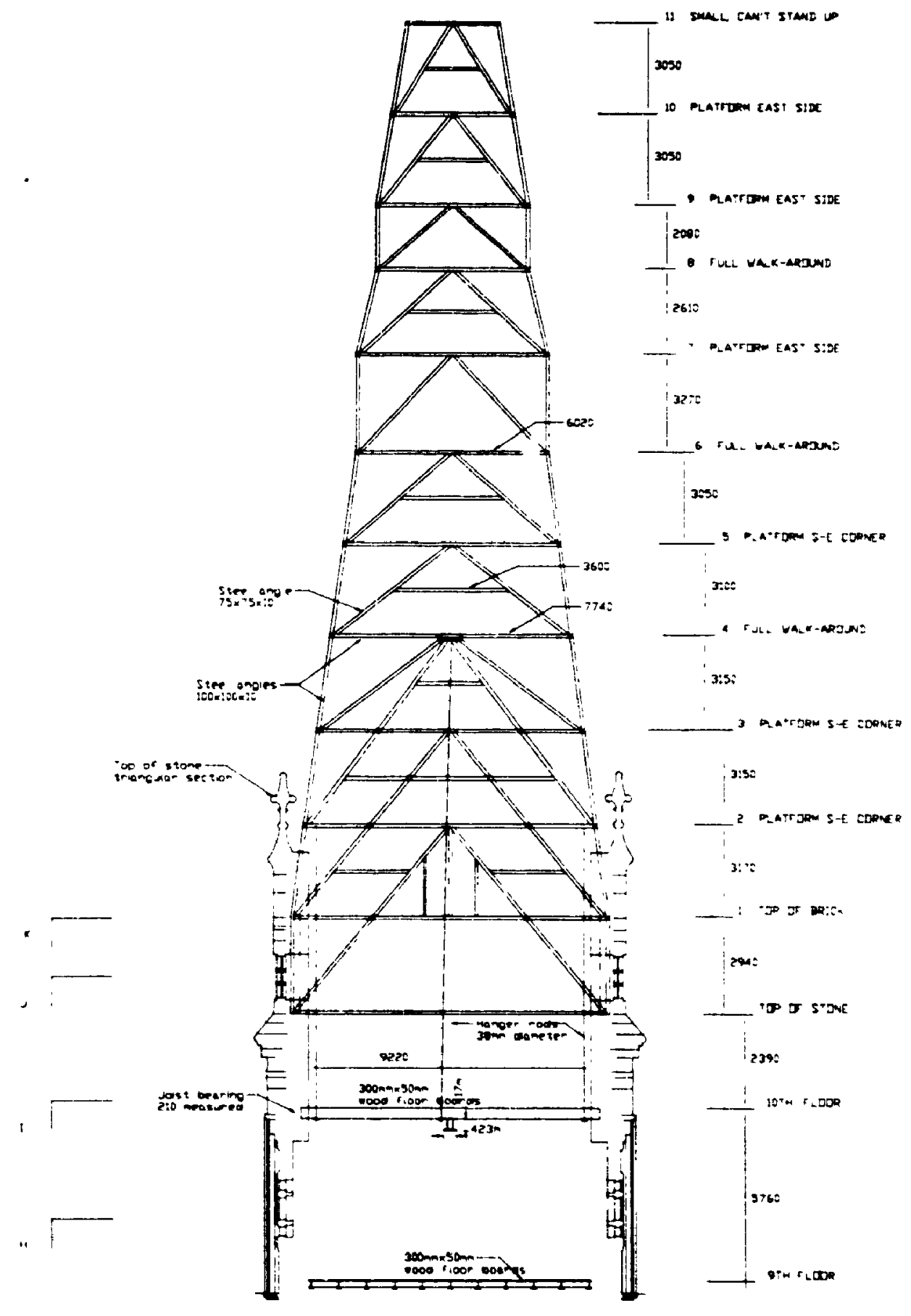

Fig. 3.2(a) Enlargad upper part of section A-A (Chidiac et. al. 1993) 


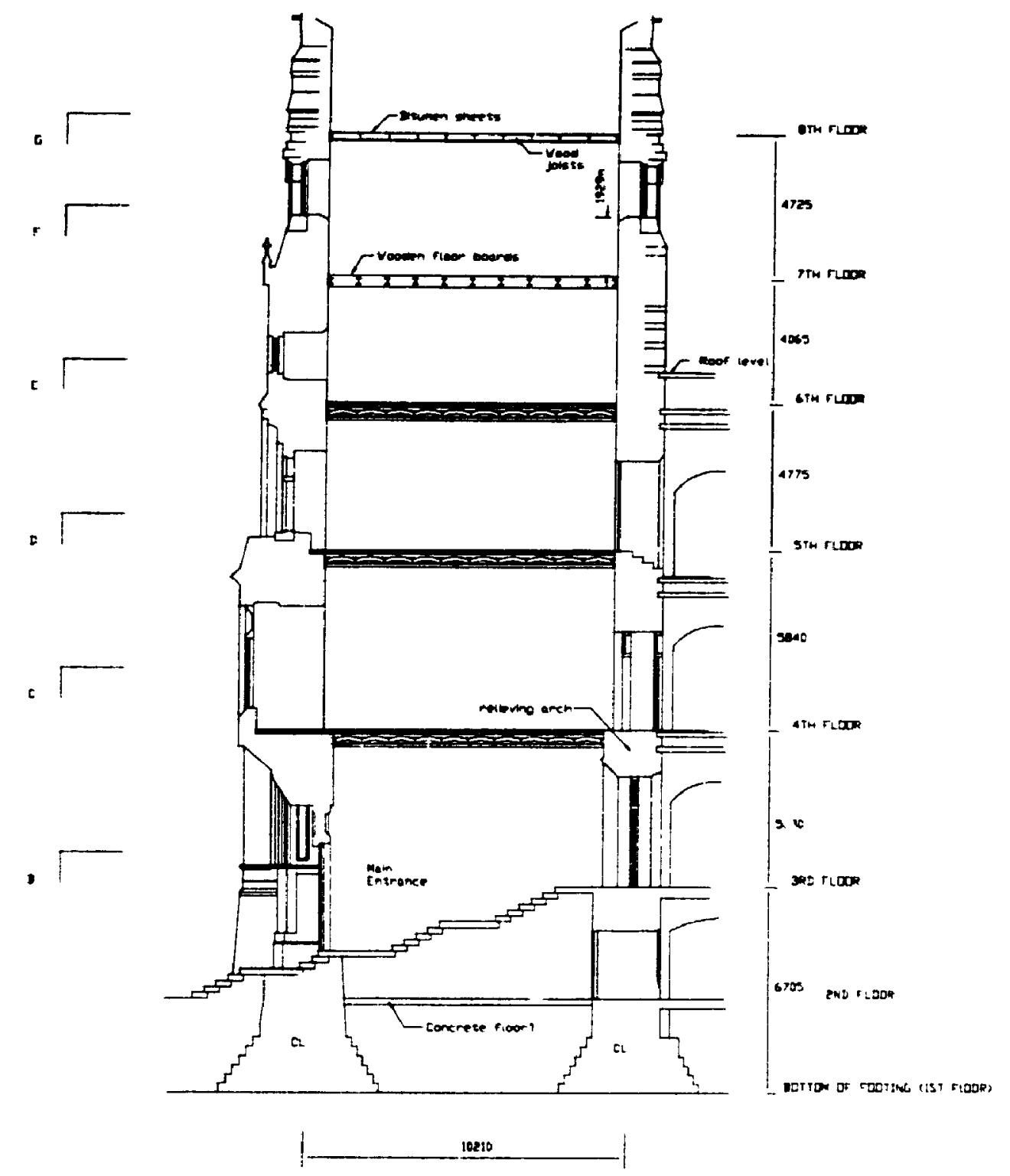

Fig. 3.2(b) Enlarged lower part of section A-A(Chidiac et. al. 1993) 


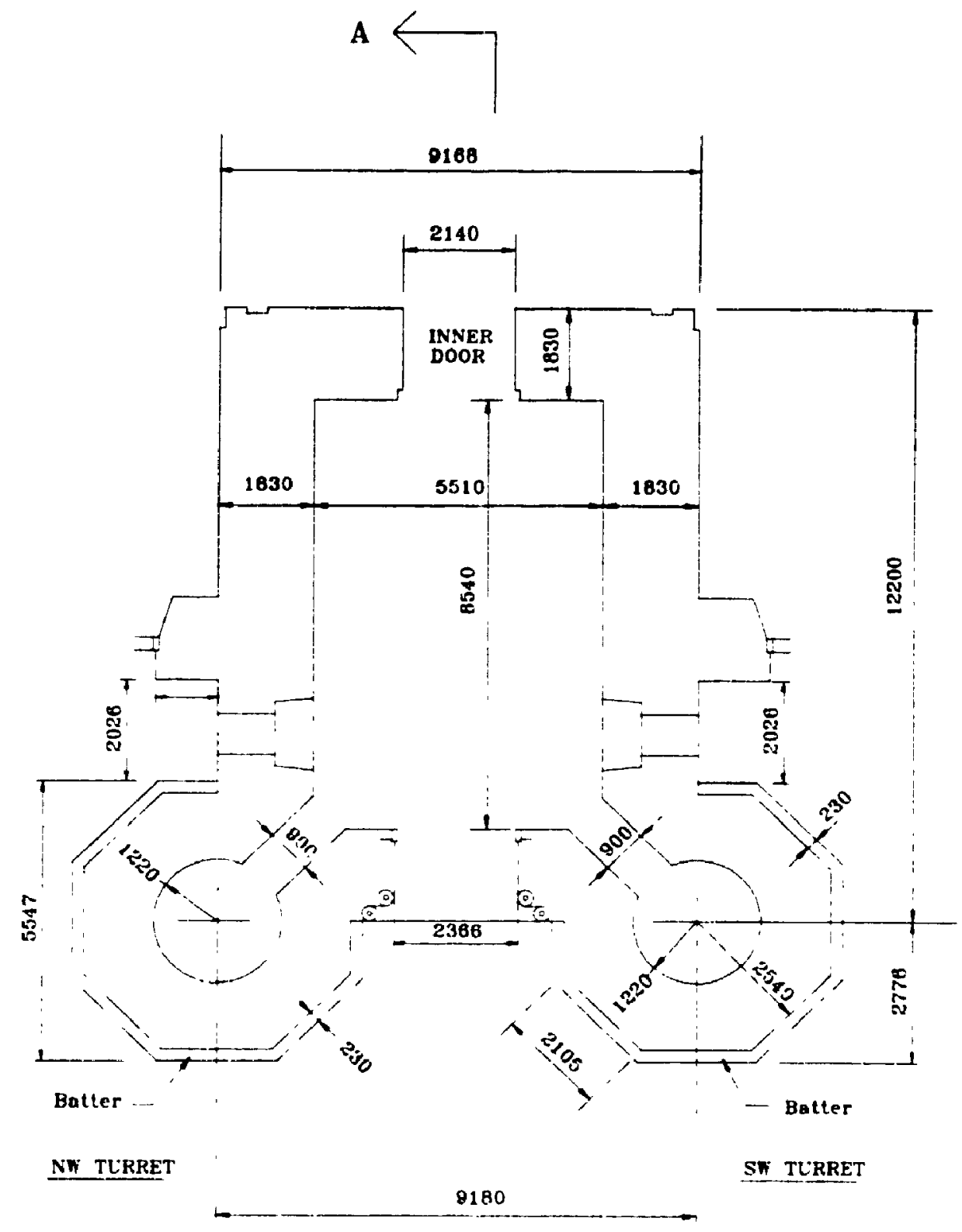

$A<$

Fig. 3.3 Third floor - Main entrance (section B -B Chidiac et. al. 1993) 


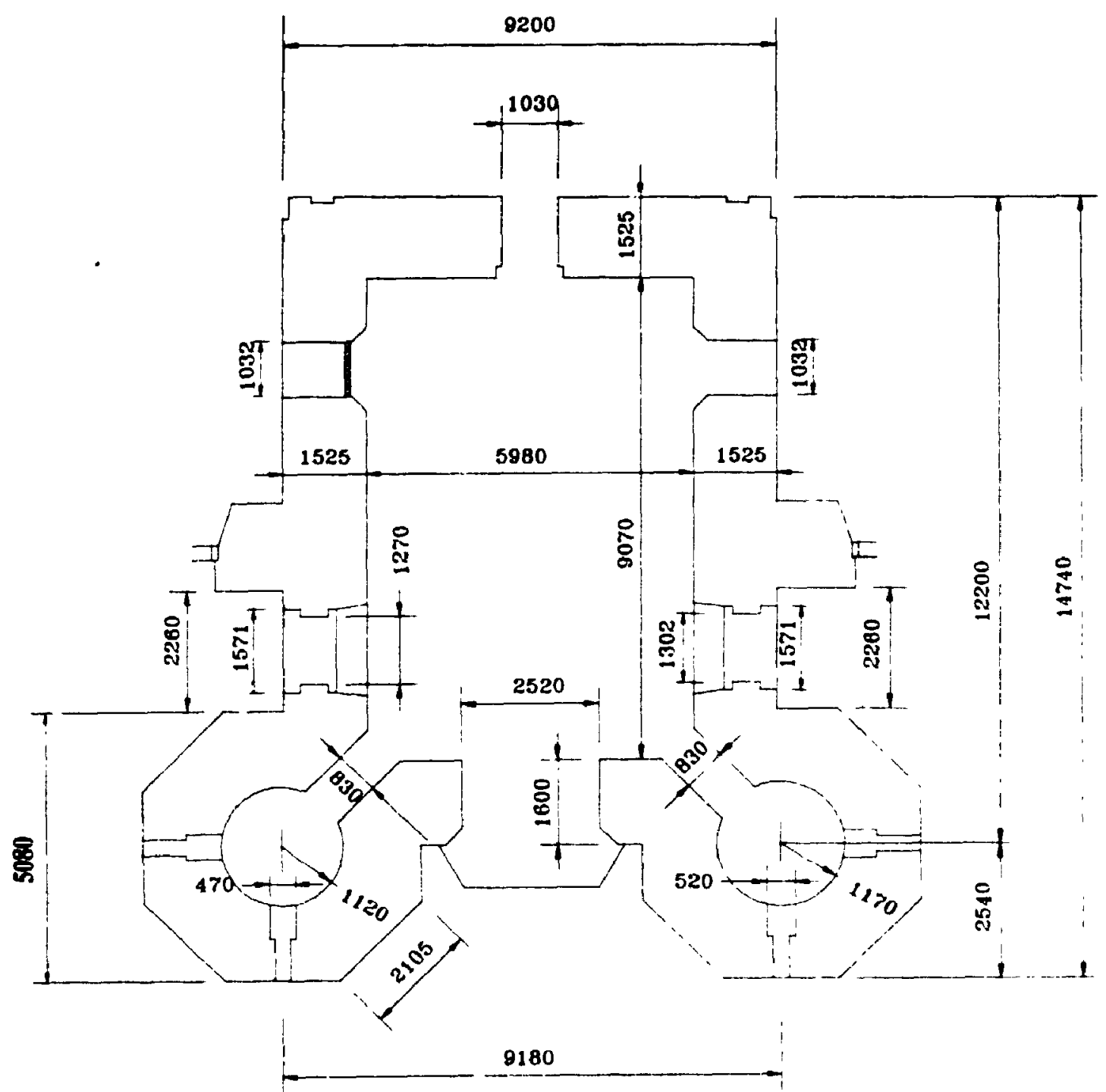

Fig. 3.4 Fourth floor ( section C - C, Chidiac et. al. 1993) 


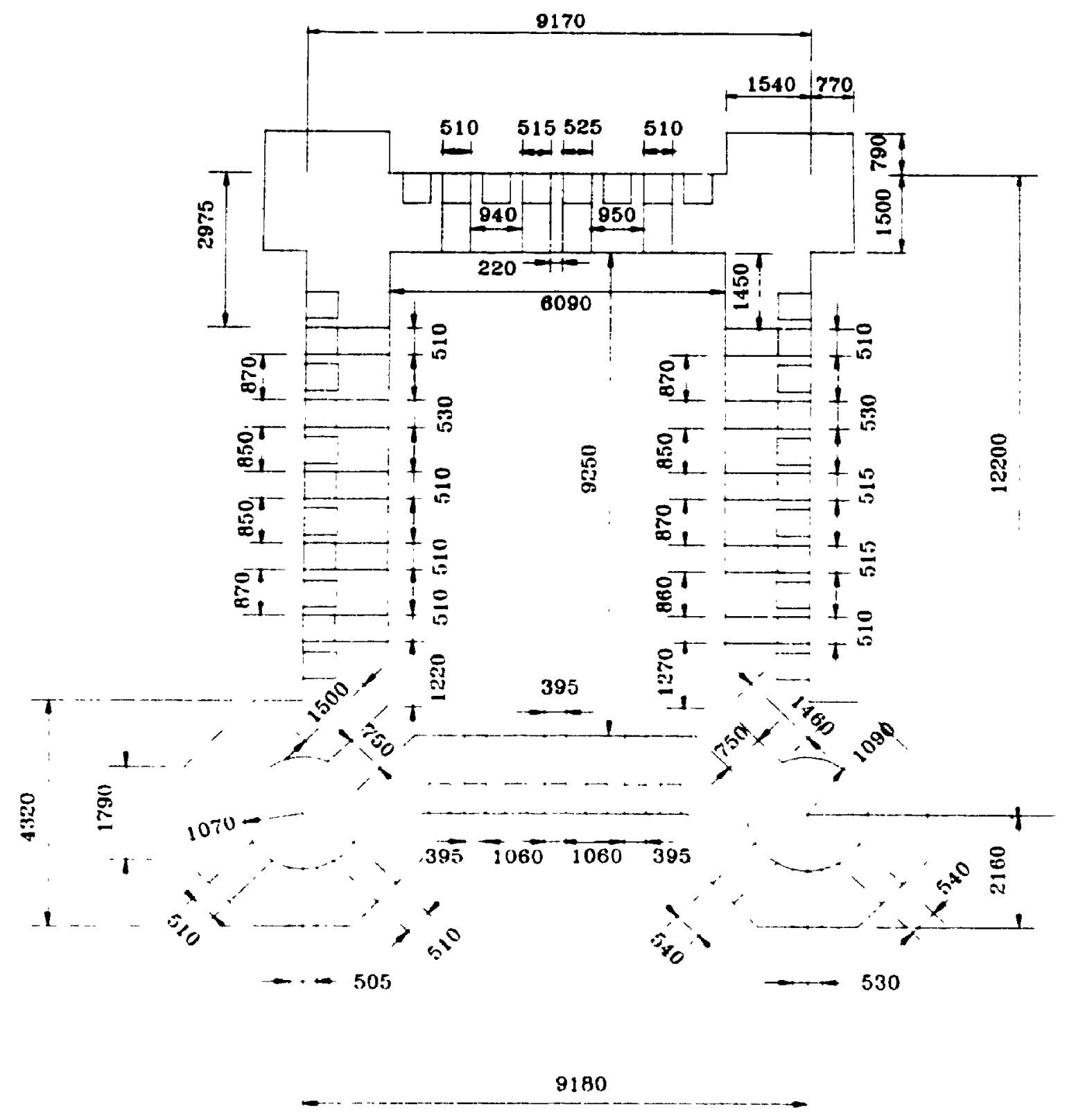

Fig. 3.5 Seventh floor ( section F - F, Chidiac et. al. 1993) 


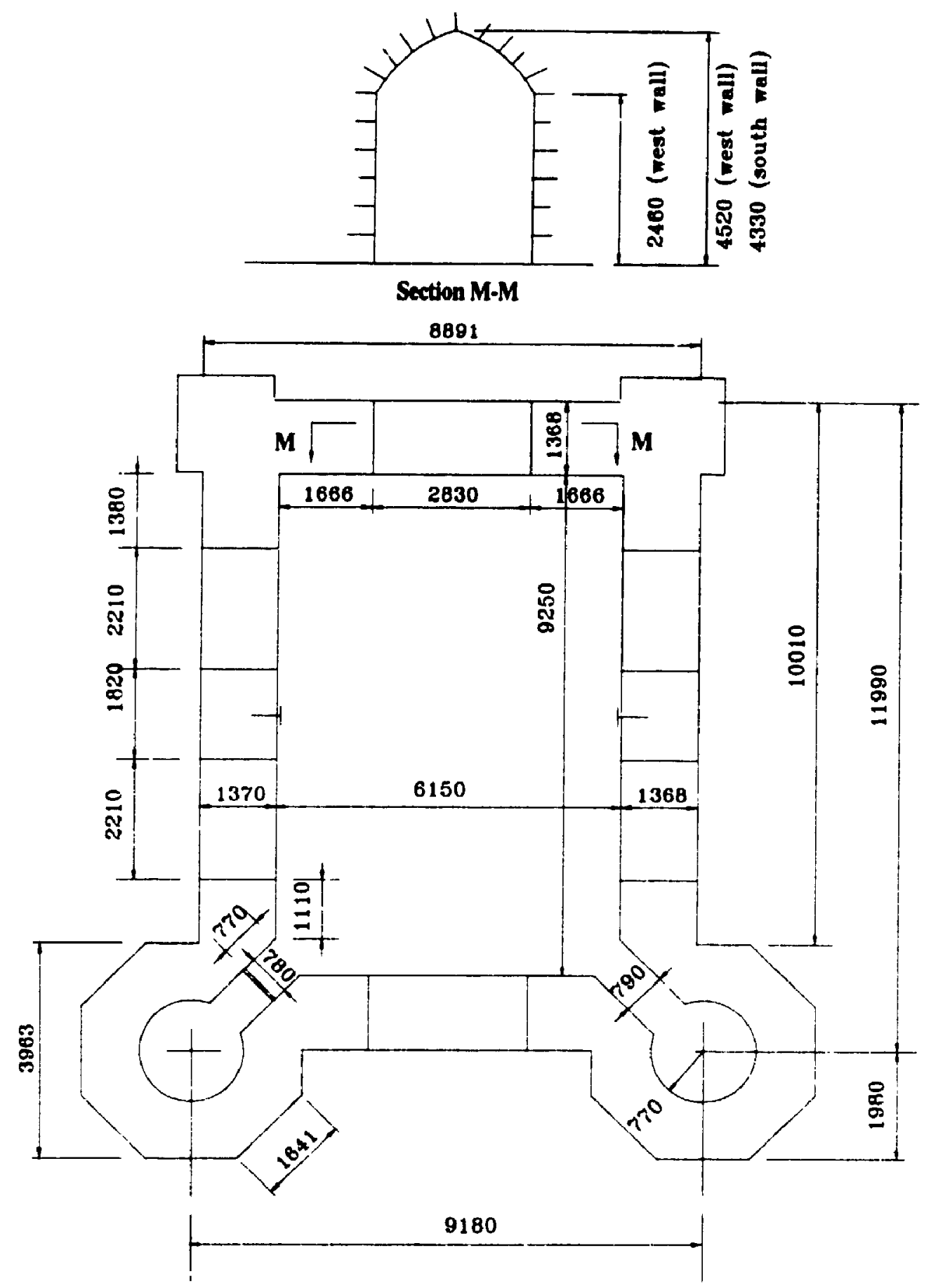

Fig. 3.6 Ninth floor ( section H - H, Chidiac et. al. 1993 ) 


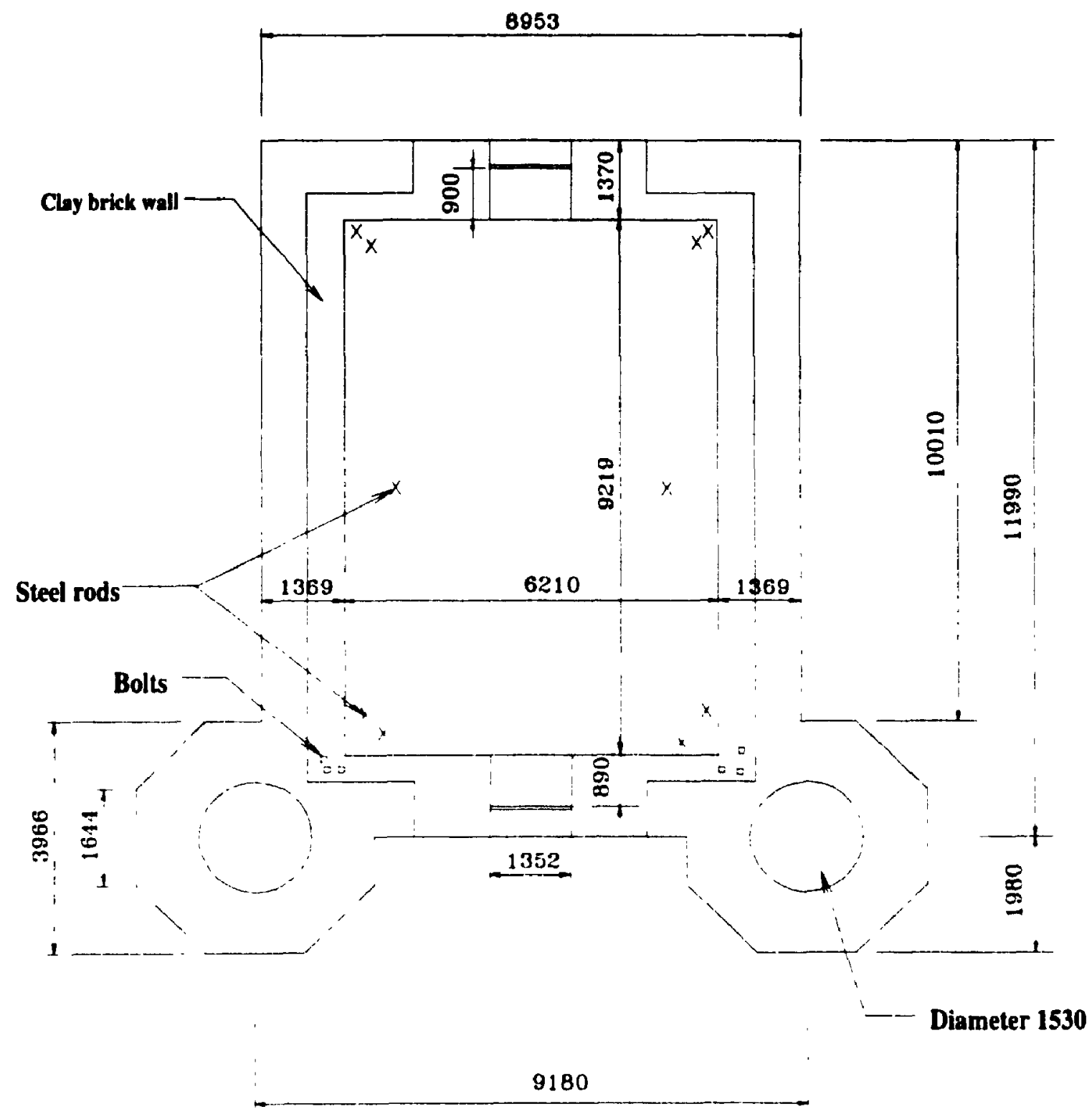

Fig. 3.7 Eleventh floor ( section J - J, Chidiac et. al. 1993 ) 


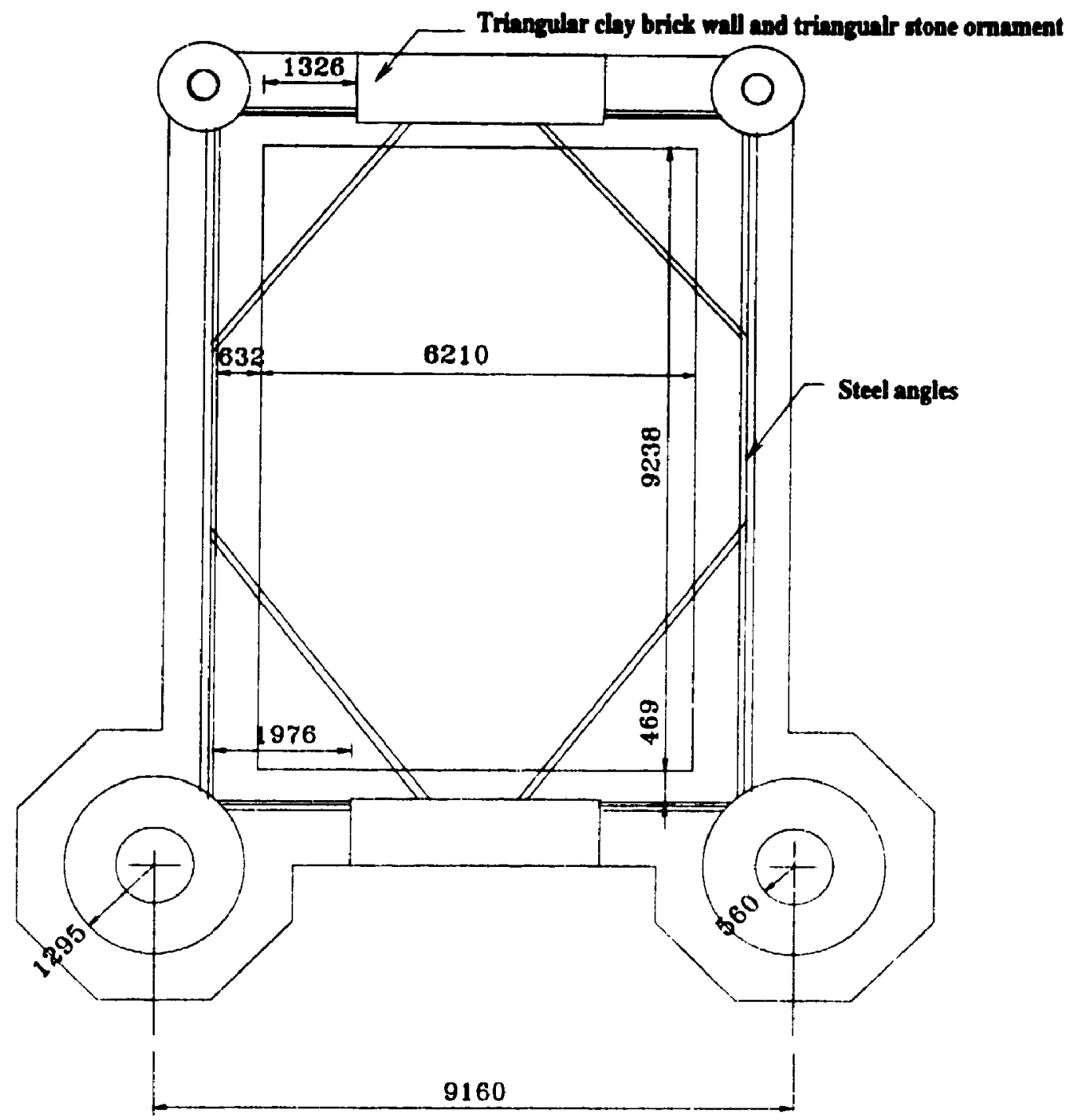

Fig. 3.8 Top of brick wall ( section K - K, Chidiac et. al. 1993 ) 


\subsubsection{Roof}

The roof essentially consists of a space frame made of steel angles $(100 \times 100 \times 10 \mathrm{~mm}$ or $75 \times 75 \times 10 \mathrm{~mm})$, steel straps $(65 \times 10 \mathrm{~mm})$, wood joists $(150 \times 105 \mathrm{~mm})$ and wooden planks. The steel angles form a space frame structure, as shown in Figs. 3.2(a) and 3.8, with vertical steel straps (spacing $600 \mathrm{~mm}$ ) bolted to the outside of the steel angles. Similarly, the vertical wood joist at $600 \mathrm{~mm}$ spacing are attached directly to the outside face of the straps. Finally, thin wooden planks are attached to the joists form the sheathing. Fig. 3.9 show schematically the arrangement of the various elements of the roof.

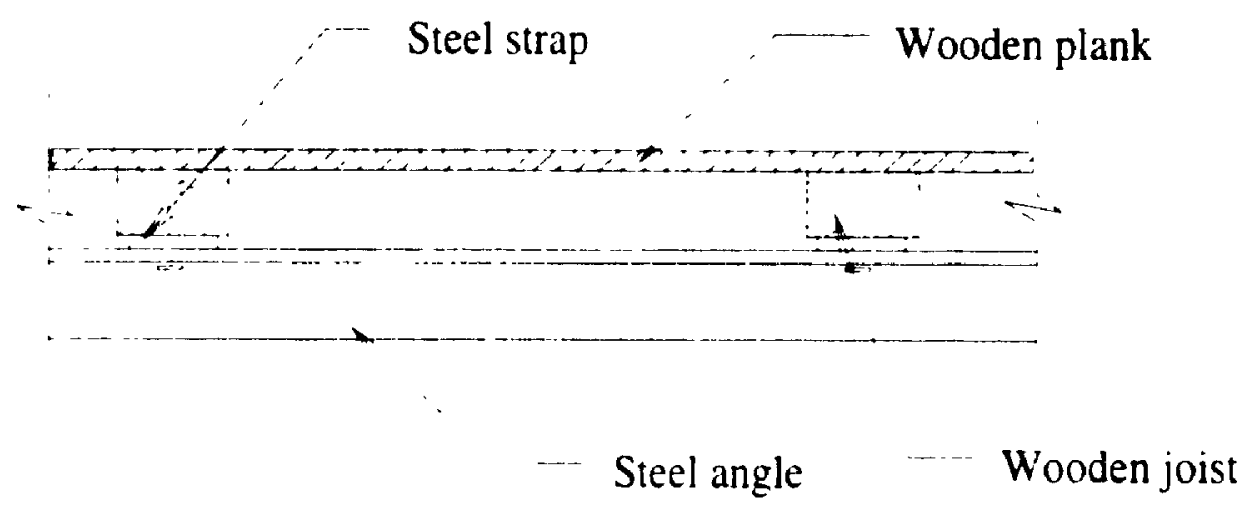

\section{Fig. 3.9 Arrangement of the various elements of the roof}

The roof structure is connected to the stone masonry tower at its corners. This is confirmed at one losation where three connecting bolts are visible. Further more, as shown in Fig. 3.7 ten $38 \mathrm{~mm}$ diameter steel rods tie down the roof to the steel joists on the ninth floor. The rods are in loose condition and will not carry any tensile force, other than their own weight, unless the roof hifts up. 


\subsection{Structural Condition of the Tower}

From visual inspection the tower is generally in good condition and only minor distress signs can be observed. In the soffits stones of the arches above over the top of the three window openings on the sixth floor, single vertical cracks are visible. These cracks do not appear to be extending right through the thickness of the stone. The mortar at the unoccupied part of the tower has a dry, chalky consistency due to water infiltration.

Some joints appear to have been repointed with Portland cement mortar. This intervention is likely to cause spoiling of the mortar in the event of load redistribution. Only minor corrosion can be observed at the bottom of the steel roof frame. On the other hand, straps coming out of the interior mortar joints in the main walls of the tower and at some other locations in the two west turrets of the tower are in poor condition due to corrosion. 


\section{CHAPTER 4}

\section{DYNAMIC CHARACTERISTICS OF THE TOWER}

\subsection{General}

The first step in assessing the dynamic behavior of a structure when subjected to seismic ground motion is the determination of its dynamic properties. The natural frequencies, mode shapes and damping of the structure are prerequisites for determining the forces affecting a heritage building. However, the calculation of natural frequencies and mode shapes is not easy because parameters such as material properties and structural connections are generally not known precisely. Nevertheless, in this chapter, the different numerical methods, namely the simplified methed, the frame analysis and the finite element method are examined to assess their suitability for calculating the dynamic properties of the thick stone masonry tower presented in Chapter 3. The measured first five natural frequencies and mode shapes of the tower are used as a basis for the comparison. The first measured dynamic mode is also used as a calit rator for the three models.

\subsection{On-site Measurement}

On-site ambient vibration tests were conducted by Chidiac et. al. (1995) The first five modes and their associated mode shapes were achieved and are presented in Fig. 4.1 to 4.5. A general description of the modes along with the values corresponding to each mode is presented in Table 4.1 
Table 4.1 Natural frequencies and mode shapes from the ambient vibration test (Chidiac et. al. 1995)

\begin{tabular}{|c|c|l|}
\hline Mode Number & $\begin{array}{c}\text { Frequency } \\
\mathrm{Hz}\end{array}$ & \multicolumn{1}{|c|}{ Description of mode shapes } \\
\hline 1 & 1.77 & $\begin{array}{l}\text { North-South lateral } \\
\text { Large relative motion of steel roof in the N-S direction } \\
\text { Significant motion at the base of the steel roof } \\
\text { relative to the top of the stone masonry }\end{array}$ \\
\hline 2 & 2.13 & $\begin{array}{l}\text { East-West lateral } \\
\text { Discontinuity at the base of the steel roof is more } \\
\text { pronounced in the E-W direction }\end{array}$ \\
\hline 3 & 2.76 & $\begin{array}{l}\text { Torsional about Z-axis } \\
\text { Twis'.ng and lateral motion, and expansion of the base } \\
\text { of the steel roof }\end{array}$ \\
\hline 4 & 2.92 & $\begin{array}{l}\text { Torsional about Z-axis } \\
\text { North-South lateral motion of the steel portion }\end{array}$ \\
\hline 5 & 308 & Similar to mode 4 with different resonant frequency \\
\hline
\end{tabular}
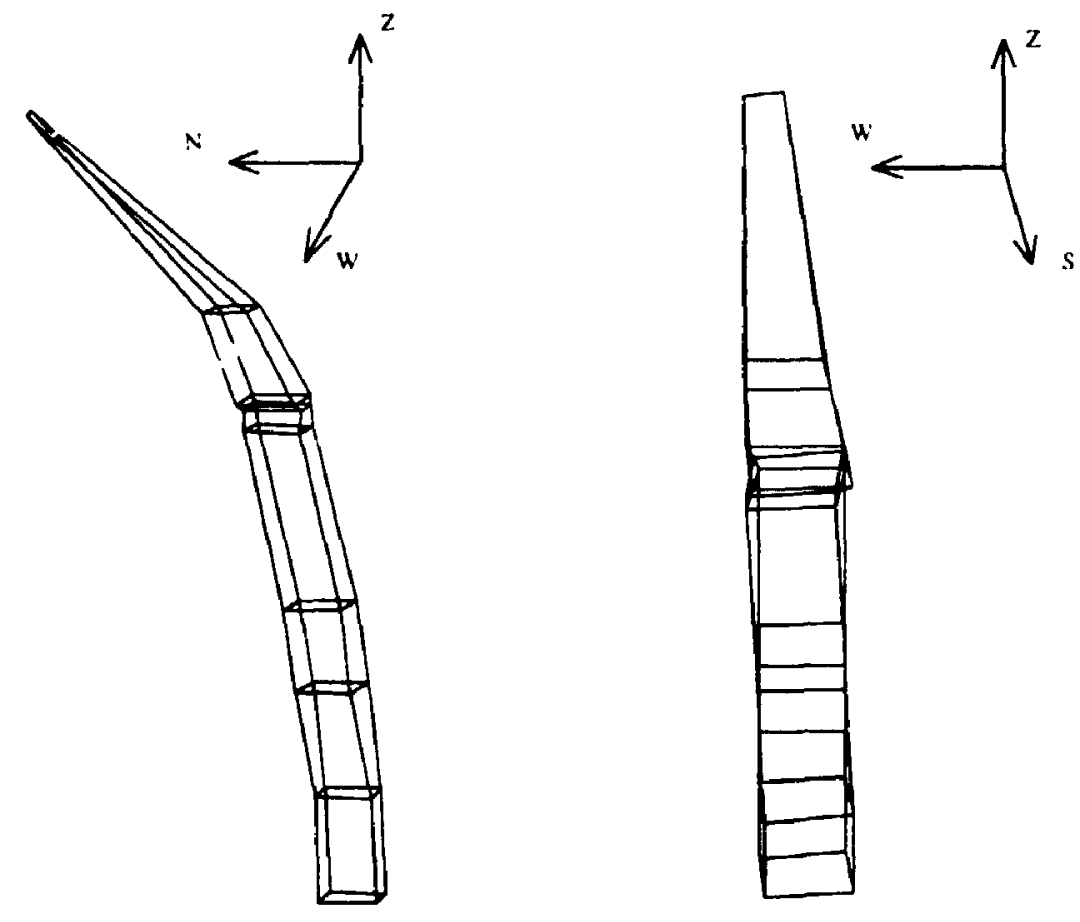

Fig. 4.1 First mode obtained from the ambient vibration test (Chidiac et. al. 1993) 

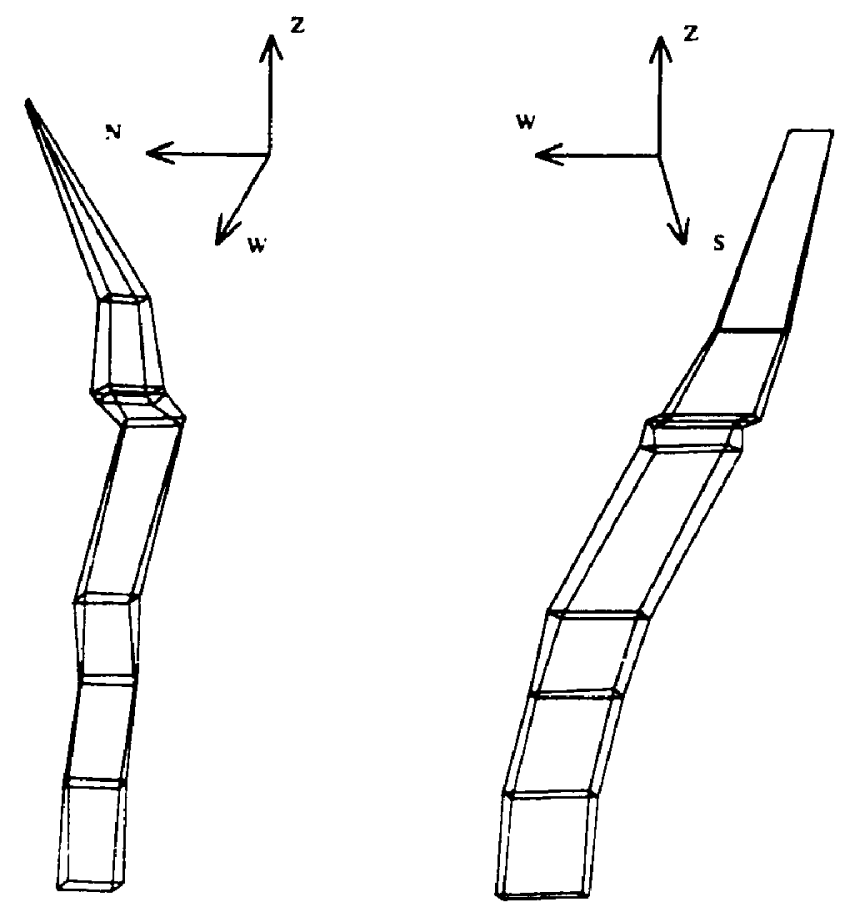

Fig. 4.2 Second mode obtained from the ambient vibration test (Chidiac et. al. 1993)
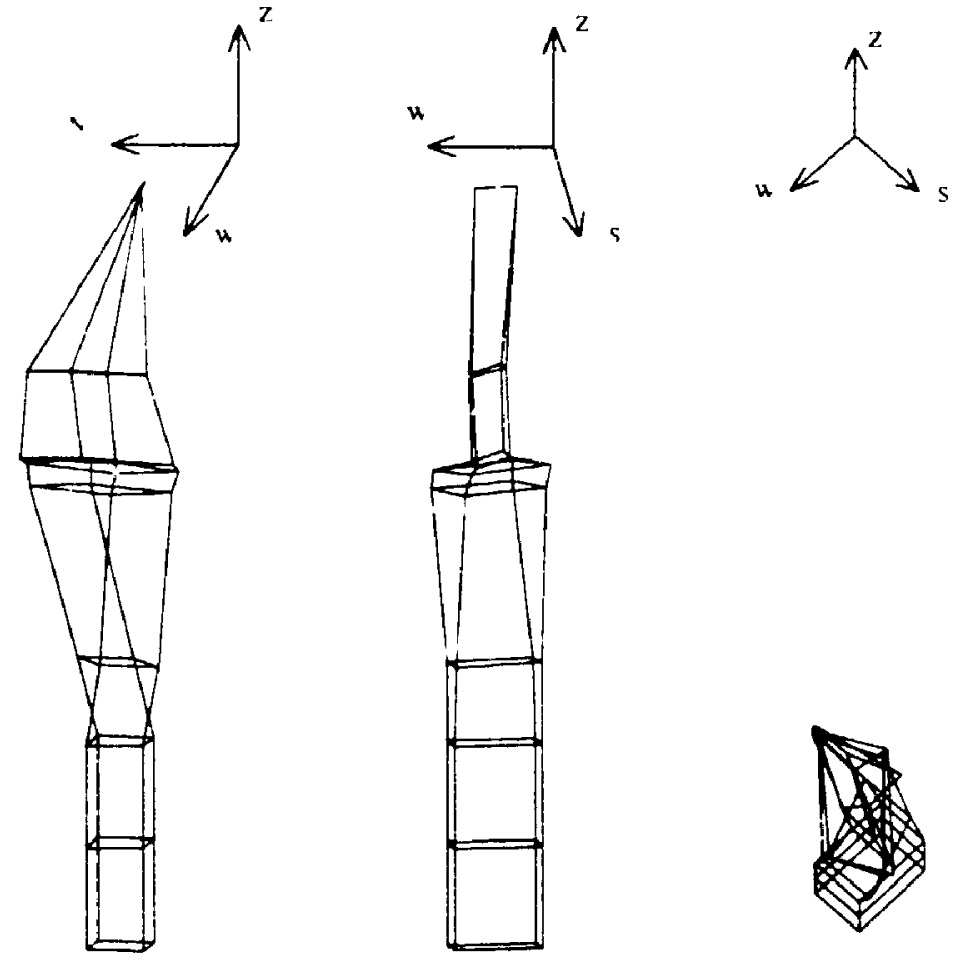

Fig. 4.3 Third mode obtained from the ambient vibration test (Chidiac et. al. 1993) 

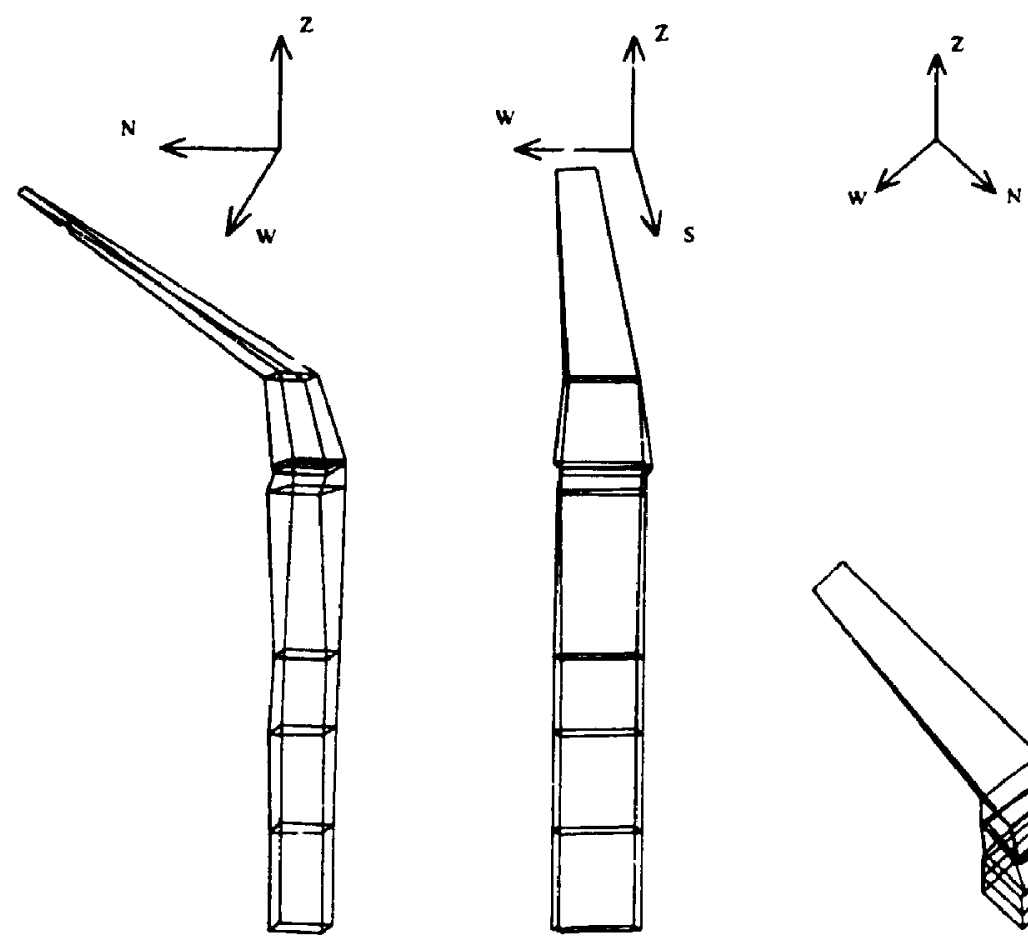

Fig. 4.4 Fourth mode obtained from the ambient vibration test (Chidiac et. al. 1993)
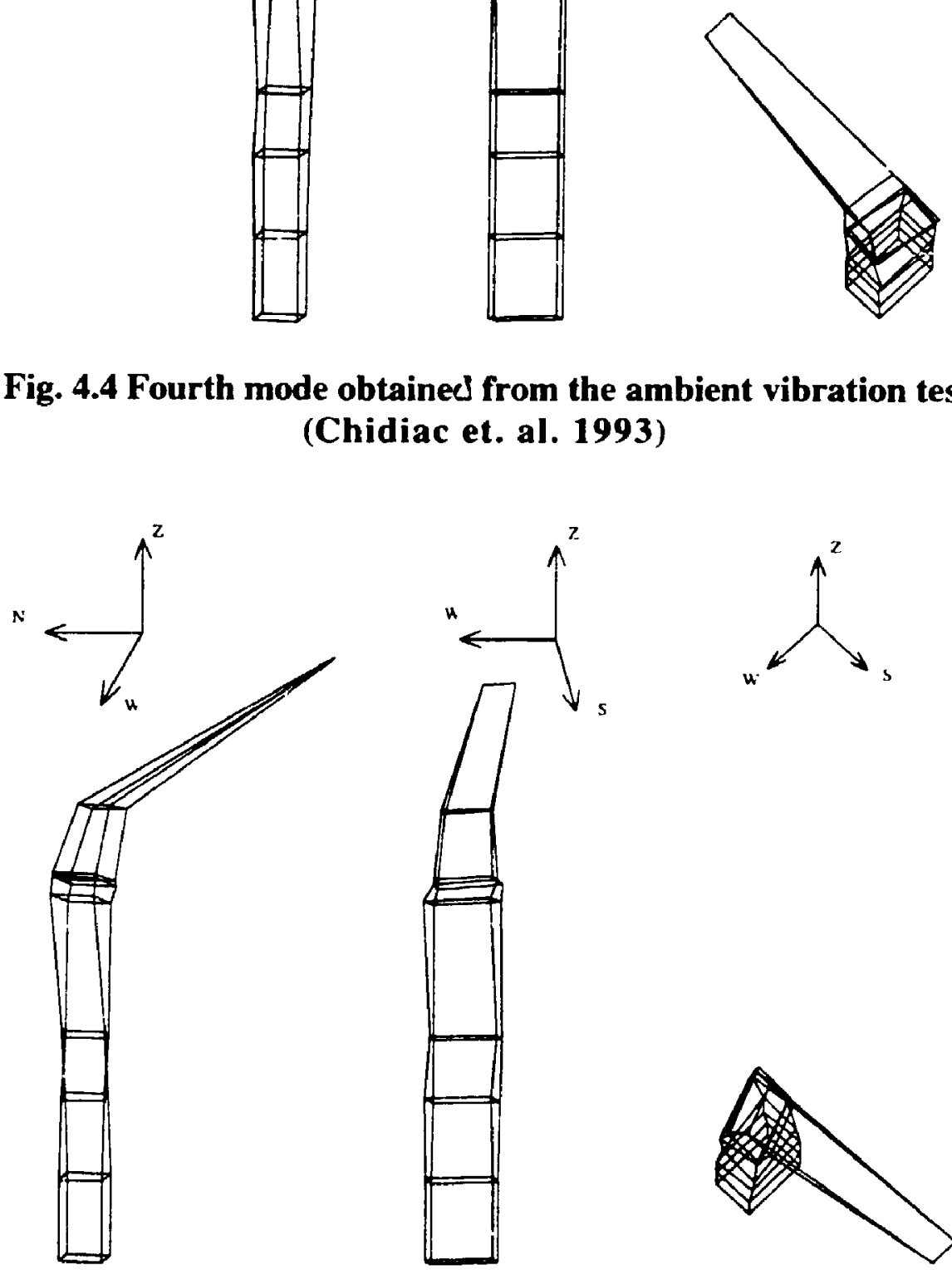

Fig. 4.5 Fifth mode obtained from the ambient vibration test (Chidiac et. al. 1993) 


\subsection{Simplified Method of Analysis}

For a complex structure such as the tower with complex boundary condition, the modes of deformation are not straight forward. However, for the simplified method of analysis, the analysis will focus only on the translational mode in two directions and on the first rotational mode. The corresponding elastic deformations are approximately obtained based on the displacement computed from the equivalent lateral force suggested by the National Building Code of Canada (NBCC 1990).

\subsubsection{Structural Idealization}

According to NBCC 1990, the lateral force at each level shall be calculated in proportion to its height and mass. Since the tower has continuous walls along its height and since the mass of its floors is negligible compared with the mass of its stone masonry wall. it can be idealized as a continuous shaft structure with sectional properties changing along the height. Thus a discrete model was constructed consisting of five segments to accommodate any abrupt changes in both geometry and/or material properties.

The steel frame and clay brick are considered as one segment each because of their different material properties and relatively small mass. The model of the tower is first modeled as three segments. comprising for the steel frame at the top. th. clay brick and the stone masonry. respectively. The model was then continuously refined by subdividing the stone masonry part of the tower into smaller parts in order to better accommodate the sudden changes in the section geometry till the difference in the results of two consecutive models was less than $1 \%$ and thus considered as converged results. The adopted model for the analysis is illustrated in Fig. 4.6. 


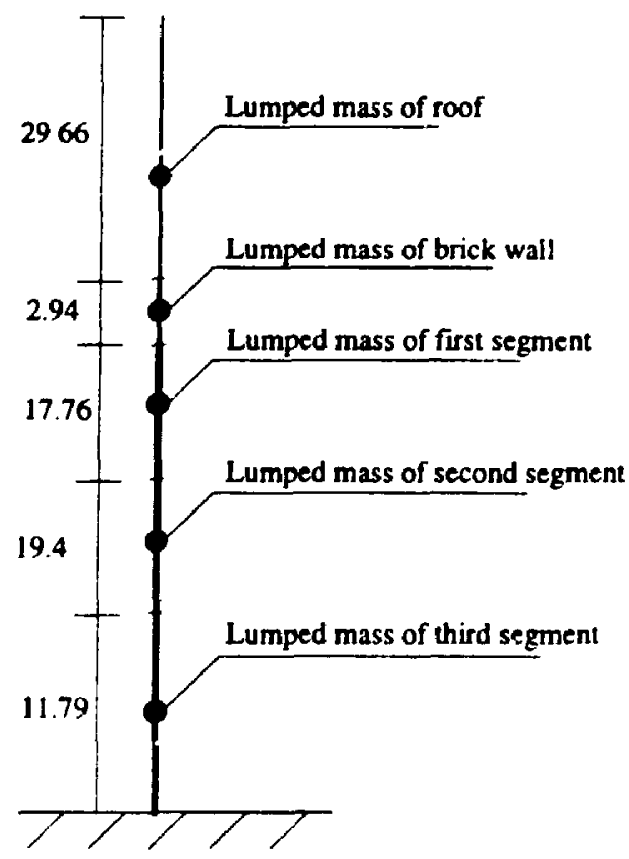

(a)

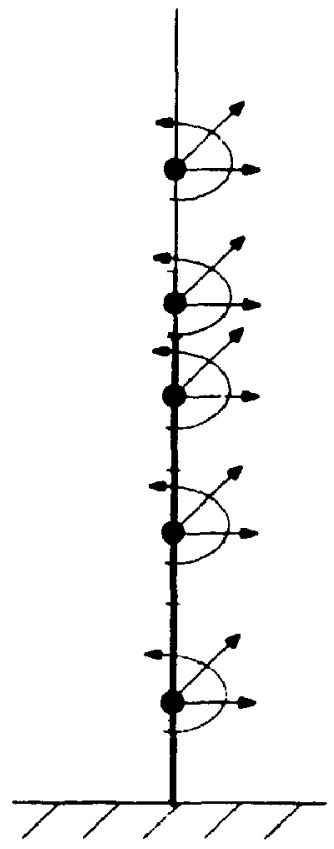

(b)

\section{Fig. 4.6 Model of the tower:(a) Lumped mass (b) Degrees of freedom}

The model consists of five nodes with three degrees of freedom, two out-ofplane translations and one rotation resulting in a total of fifteen degrees of freedom. The simplifying assumptions employed to model the tower are as follow: First, the stiffness of the steel frame was approximated by idealizing the rouf as a triangular truss structure pin-ended at the top and the bottom. The as-built section properties were used for the truss model. Using a frame model, the idealization of the steel roof was found to result in an error in the stiffness of less than $20 \%$ when compared with a space truss model built according to the original geometry. Given its small potential energy contribution, in comparison to the rest of the tower, no further refinement for the idealized roof structure was deemed necessary. By applying a unit force at the top of the roof, while keeping its bottom fixed and by computing the resultant lateral displacement, the stiffness of the steel roof was determined. Because of its triangular shape, the mass center of the steel frame is 
located at 0.38 of its height from the base of the steel frame. As a further simplification in the analysis, the roof was represented by a beam with uniform cross section. The stiffness of both the stone and brick masonry walls was computed based on their sectional dimensions. The stiffness includes bending, torsion and shear as the contributing factors of the deformation. Appendix A provides the procedure to compute the stiffness and deformed shape, and the relevant properties are listed in Table 4.2

Table 4.2 - Parameters used for the simplified method

\begin{tabular}{|c|c|c|c|c|c|c|}
\hline $\begin{array}{l}\text { Storey } \\
\text { Level }\end{array}$ & $\begin{array}{l}\text { Heıght } \\
\text { (m) }\end{array}$ & $\begin{array}{c}\text { Weight } \\
\text { per Storey } \\
\text { (kN) }\end{array}$ & $\begin{array}{l}\text { Helght } \\
\text { of Storey } \\
\text { (m) }\end{array}$ & $\begin{array}{c}\text { Moment of } \\
\text { Inertia } \\
m^{4}\end{array}$ & $\begin{array}{c}\text { W of } \\
\text { Segment } \\
(\mathrm{kN})\end{array}$ & $\begin{array}{l}\text { Height of } \\
\text { Mass Centre } \\
\text { (m) }\end{array}$ \\
\hline Steel Cap & 81.55 & 386.00 & 29.66 & 0.04 & 386 & 6316 \\
\hline Clay Brick & 51.89 & 2360.00 & 2.94 & 178.00 & 2360 & 5042 \\
\hline 10th & 48.95 & 3804.70 & 2.38 & \multirow{3}{*}{68466} & \multirow{3}{*}{22209} & \multirow{3}{*}{40.59} \\
\hline $9 \mathrm{th}$ & 4657 & 7458.10 & 5.78 & & & \\
\hline $8 \mathrm{th}$ & 40.79 & 10946.10 & 9.60 & & & \\
\hline $7 \mathrm{th}$ & 31.19 & 6275.50 & 4.73 & \multirow{4}{*}{952.00} & \multirow{4}{*}{36181} & \multirow{4}{*}{21.29} \\
\hline $6 \mathrm{th}$ & 26.47 & 10242.70 & 4.07 & & & \\
\hline 5th & 22.40 & 9412.20 & 4.78 & & & \\
\hline $4 \mathrm{th}$ & 17.63 & 10250.30 & 584 & & & \\
\hline 3rd & 11.79 & 9761.90 & 5.08 & \multirow{3}{*}{1342.70} & \multirow{3}{*}{29692} & \multirow{3}{*}{5.28} \\
\hline 2nd & 671 & 11311.60 & 3.83 & & & \\
\hline $1 \mathrm{st}$ & 287 & 8618.50 & 287 & & & \\
\hline
\end{tabular}

The computational procedure for the first rotational mode requires a revised model since its deformational behavior is different from the translational mode and is controlled by different sectional properties. The steel cap and the clay brick wall are assumed symmetrical in both directions, thus the excited torsional moment is considered zero. The stone portions of the tower is modeled as follows: The first segment is from the base to the sixth floor. and the third segment is from ninth floor to the top of stone masonry. These two are modeled as closed section. The second segment, the one in between the first and third, was modeled as an open section due to the large window openings in the wall. 


\subsubsection{Analytical Procedure and Results}

Following the recommendations of NBCC 1990, the natural period of the tower $T$, can be approximated using Rayleigh's approximation method. Accordingly

$$
T=2 \pi \sqrt{\frac{\sum_{i=1}^{n} W_{i} \delta_{i}^{2}}{g \times \sum_{i=1}^{n} F_{i} \delta_{1}}}
$$

where $F$, represents the distributed lateral force associated with the lumped weight $W_{i}$, and $\delta_{i}$, is the elastic deflection due to the applied lateral force $F_{1}$ in storey $i$. The lateral forces are distributed along the height of the tower in accordance with

$$
F_{1}=\frac{V W_{1} h_{l}}{\sum_{i=1}^{n} W_{\imath} h_{\imath}}
$$

where $n$ is the total number of floors, and $h_{1}$ is the height from the base to the storey $i$.

The detailed calculation procedures are listed in Appendix $A$ and the calculated natural periods are given in Table 4.3

Table 4.3 - Computed natural periods of the tower using the simplified method

\begin{tabular}{|c|c|}
\hline $\begin{array}{c}\text { Description of } \\
\text { Mode Shapes }\end{array}$ & $\begin{array}{c}\text { Natural Period, } T \\
\text { (s) }\end{array}$ \\
\hline North-South lateral & 0.568 \\
\hline West-East lateral & 0.475 \\
\hline Rotational about Z-axis & 0.32 \\
\hline
\end{tabular}


The NBCC 1990 also requires that the computed period be less than or equal to 1.2 times the period computed_based on the following empirical formula

$$
T=\frac{0.09 h_{n}}{\sqrt{D_{s}}}
$$

in which $h_{n}$ and $D_{s}$ the are the total height of the building and the dimension of the frame that constitutes the main lateral load-resisting system in a direction parallel to the applied forces. Both parameters are expressed in meters. Although the formula is strictly applicable to moment resisting frame building structures, the computed natural period as given in Table 4.4 complies with the requirement of the NBCC 1990.

\section{Table 4.4 - First natural period of the tower based on NBCC 1990}

\begin{tabular}{|c|c|}
\hline Equation & $\begin{array}{c}\text { Natural Period. T } \\
(\mathrm{s})\end{array}$ \\
\hline Eq 4.1 & 0.568 \\
\hline Eq 4.3 & 1.2 \\
\hline
\end{tabular}

\subsubsection{Boundary Conditions and Material Properties}

Although the actual tower is partly attached to the surrounding building below the fifth floor on its north, south and east faces, it is difficult to model the boundary condition using hand calculations. Towards that end, the tower is modeled as a free standing cantilever fixed at its base.

The material properties used to characterize the dynamic behavior of the tower are given in Table 4.5. The value of the modulus of elasticity for the stone masonry was adjusted until the computed first natural frequency became essentially equal to its corresponding measured value. 
Table 4.5 - Material properties used in the simplified method

\begin{tabular}{|c|c|c|c|}
\hline \multirow{2}{*}{ Material } & Modulus of Elasticity & Mass Density & Poisson's Ratio \\
\cline { 2 - 4 } & $(\mathrm{GPa})$ & $\mathrm{kg} / \mathrm{m}^{3}$ & \\
\hline Stone masonry & 6 & 2716 & 0.2 \\
\hline Steel & 200 & 7800 & 0.3 \\
\hline Brick wall & 28 & 1800 & 0.2 \\
\hline
\end{tabular}

\subsection{Frame Analysis Method}

A space frame analysis program (ETABS 1991), based on the stiffness method of analysis and mode displacement superposition, was used to asses the dynamic characteristics of the tower. In this analysis, the tower is treated as a three dimensional space frame, including shear wall elements, rigid offsets and rigid floor diaphragms.

\subsubsection{Program ETABS}

The computer program ETABS, developed and marketed by Computers and Structures Inc. of Berkeley, California (ETABS 1991), was selected for this study because of its wide acceptance by practicing structural engineers for siatic and dynamic analysis of building structures. Some of the features pertaining to the dynamic analysis of the tower are:

(1) 3-D beam and column elements, comprising two nodes and each node with six degrees of freedom. These elements can model extension, flexure (including shear deformations), and torsion.

(2) Wall panel element, formulated on the basis of an isoporametric membrane element, contains in-plane degrees of freedom, namely in-plane translation in both directions and in-plane rotation. 
(3) Diaphragms are treated only as in-plane infinitely rigid member with one rotational degree of freedom.

(4) For the dynamic analysis of buildings, the building mass is lumped at the location of the diaphragm.

(5) The program uses the stiffness method of structural analysis and mode displacement superposition method to calculate the dynamic response of buildings. The procedure to calculate the dynamic characteristics and response of the structure are briefly described below:

(a) The stiffness matrix and a diagonal mass matrix based on lumped mass are assembled.

(b) Both eigenvectors and eigenvalues are determined using matrix iteration from the equation of motion for a freely vibrating undamped system

$m \ddot{i}+k v=0$

where $m$ and $k$ are the mass matrix and the stiffness matrix. respectively, and $v$ is the coordinate vector. Equation 4.4 leads to the frequency equation of the system as

$\left|k-\omega^{2} m\right|=0$

where $\omega^{2}$, the eigenvalues, yield the free vibration frequencies. The corresponding mode shapes known as eigenvectors are given by the displacement vector.

(c) The mode displacement superposition for viscous damped system is derived from the equation of motion

$m \ddot{v}(t)+c \dot{v}(t)+k v(t)=p(t)$

where $c$ and $p$ are the viscous damping matrix and the matrix of applied forces respectively. 
(e) Using the orthogonality relationship

$$
\Phi_{m}^{T} m \Phi_{n}=0 \quad \Phi_{m}^{T} k \Phi_{n}=0 \quad \Phi_{m}^{T} c \Phi_{n}=0
$$

where $m \neq n$ and $\Phi_{m}$ and $\Phi_{n}$ are the eigenvectors for $m$ and $n$ mode respectively, and using normal-coordinate transformation, an uncoupled form of the damped equation of motion can be derived. where

$M_{n} \ddot{Y}_{n}(t)+C_{n} \dot{Y}_{n}(t)+K_{n} Y_{n}(t)=P_{n}(t)$

in which $M_{n}, C_{n}, K_{n}$ and $P_{n}$ are respectively normal-coordinate generalized mass, generalized viscous modal damping coefficient, generalized stilfness and generalized load for mode $n . Y_{n}$, the $n$th generalized coordinate vector, in the time domain, can be expressed by the Duhamel integral (Clough and Penzien 1993)

$$
Y_{n}(t)=\frac{1}{M_{n} \omega_{n}} \int_{0}^{t} P_{n}(\Gamma) \exp \left[-\xi_{n} \omega_{n}(t-\Gamma)\right] \sin \omega_{D_{n}}(t-\Gamma) d \Gamma
$$

while $\xi_{n}$ is the damping ratio for mode $n$.

(c) Having generaied the total response for each mode $Y_{n}(t)$, the structural displacements are convertes back to the geometric coordinates using

$$
v(t)=\sum_{n=1}^{N} \phi_{n} Y_{n}(t)
$$

Detailed information regarding ETABS can be obtained from User's ManualETABS 1991. It should be pointed out that the analysis of the dynamic response of structures using the mode displacement superposition was briefly presented for completeness sake only since it can be found in many standard references such as Humar (1990), Clough and Penzien (1993). 
The computer program ETABS is aimed at prartical applications with time and resource constraints in mind. Accordingly, the validity of the results will depend on the extent to which the structure at hand resembles the majority of modern buildings geometry and structural characteristics.

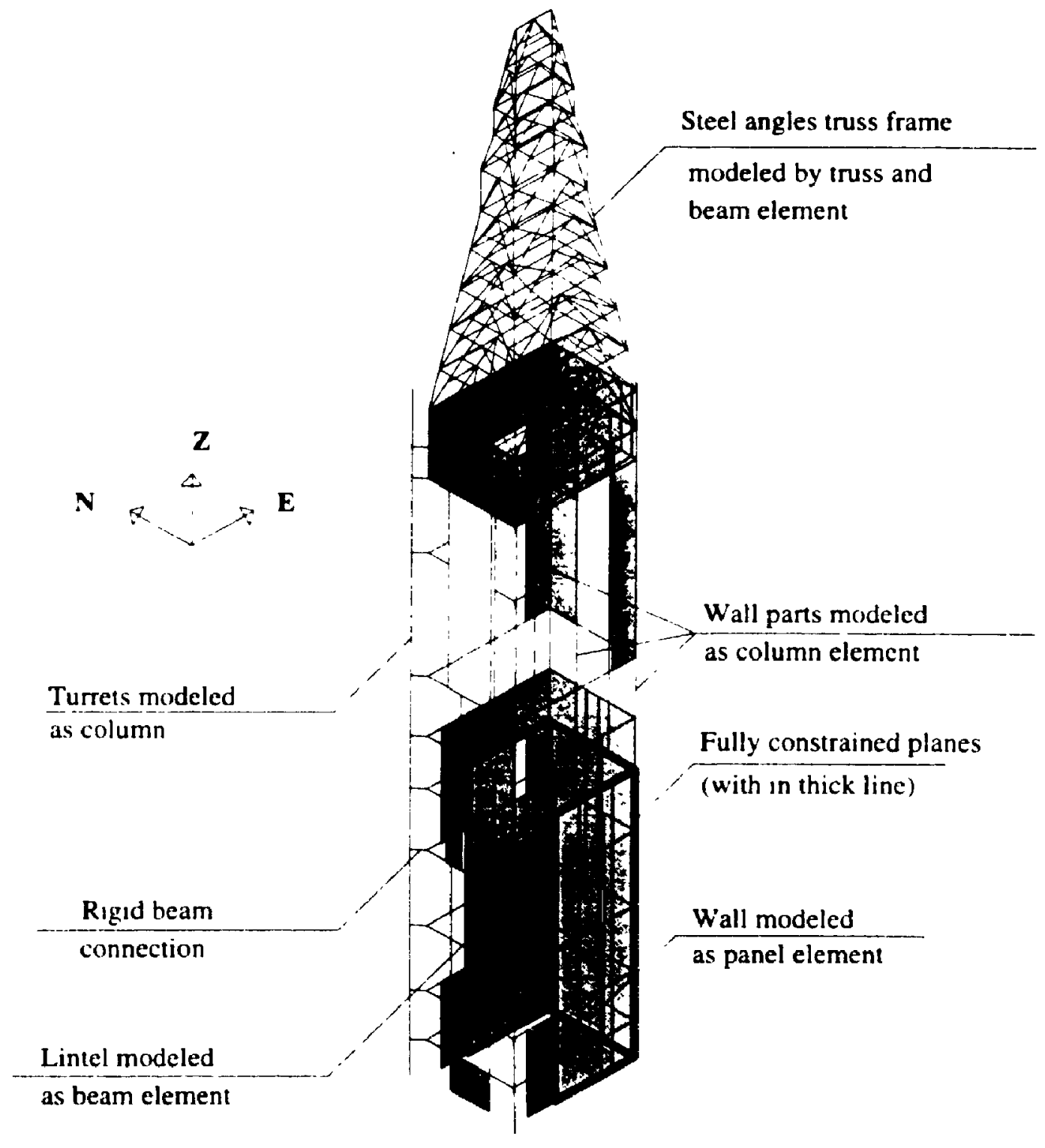

Fig. 4.7 Space frame model for the tower 


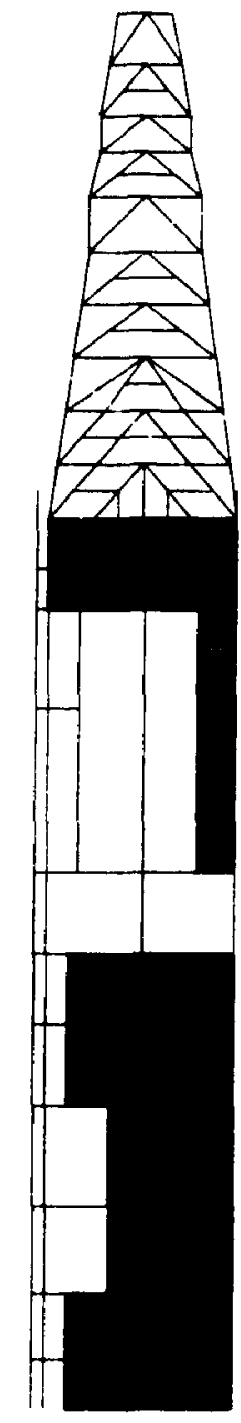

Southview of frame model

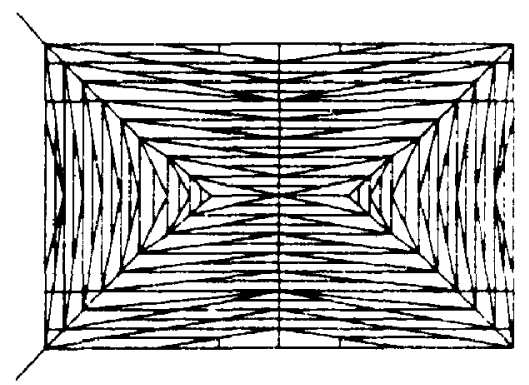

Plan veiw of the frame model

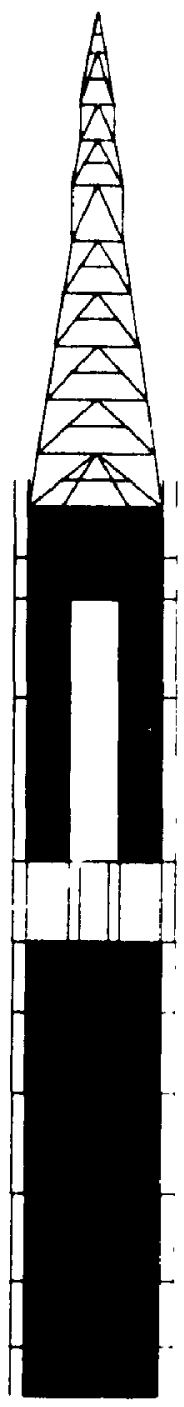

Westview of frame model 


\subsubsection{Structural Idealization}

Figure 4.7 illustrates the idealized model of the structure used in the current analysis. Figure 4.8 gives the elevation and plan view of the morel. The model comprises 256 3-D brace elements (can be either pin or continuous ended), 305 beam elements, 160 rigid beam e!ements and 115 planar panel elements. Further details regarding the modeling of the various parts are given below.

\subsubsection{Stone Masonry Wall}

Because the thickness of the walls and the size of the stairwells vary with height, but within each floor they are essentially constant, each floor is modeled by a combination of prismatic beam, column and panel elements. The panes element is mostly used to model the masonry wall, with the exceptions of the turrets and those walls surrounding the large openings. All the openings are accounted for and the majority are modeled by placing two panel elements on each side of the opening and then using a beam element to connect the two panels at their top and bottom. The windows in the turrets were accounted for by using a reduced cross-sectional area and moment of inertia for the columns representing the turrets. It should be noted that the actual windows have arch lintels as shown in Fig. 4.9, but in the current analysis due to the Iımitation of the program ETABS, this arch action is not accounted for. Obviously, this idealization may produce spurious tensile stresses due to bending in the beam representing the arch.

Since the walls have large size window opening from the seventh floor to ninth floor, they were modeled as columns rather than panels. For the same reason, the west side masonry walls next to the openings at first. second and third floor levels were modeled as columns. 


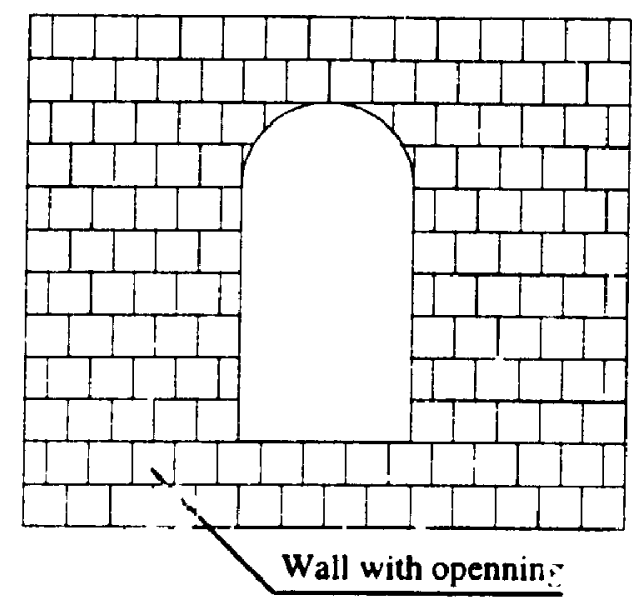

( a )

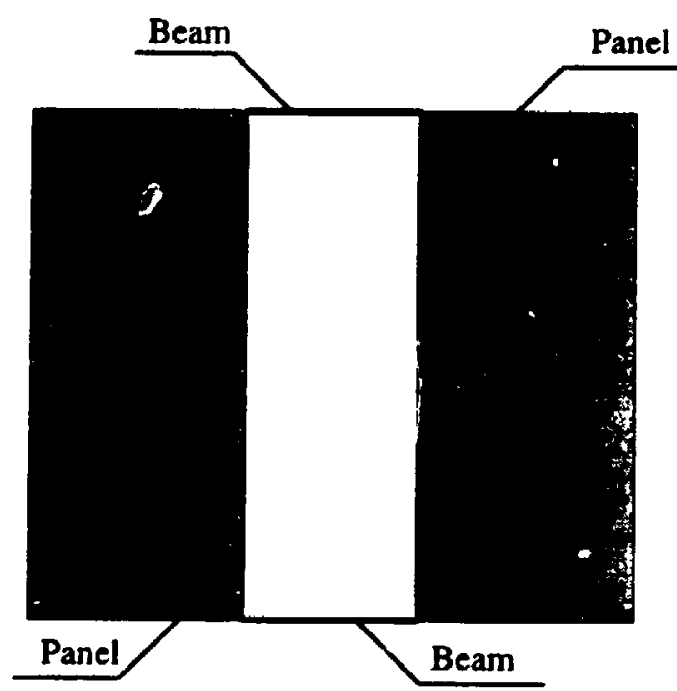

( b )

Fig. 4.9 (a) Typical window shape (b) Structural idealization

From a height of $26.485 \mathrm{~m}$ to $31.21 \mathrm{~m}$, there are a total of seventeen $0.51 \times 2.1 \mathrm{~m}$ openings distributed along the four faces. In addition, there are twenty-one indentions reaching a depth of $0.55 \mathrm{~m}$ from the outer face, and alternating with the latter openings. Instead of modeling each opening separately, it was decided to use on!y one or two beam elements to model each face of the tower at the latter elevation. Fig. 4.10(a) shows a typical plan of the sixth floor of the tower, while Fig. 4.10(b) shows tise struct:al idealization of the same a. za in accordance with the previuus description. It should be mentioned that modeling the individual lintel beams may result in grossly idealized condition because such beams would have a depth of $2 \mathrm{~m}$ and a length of $0.5 \mathrm{~m}$. On the other hand, the program does not allow modeling the section as panel element on top of openings. 


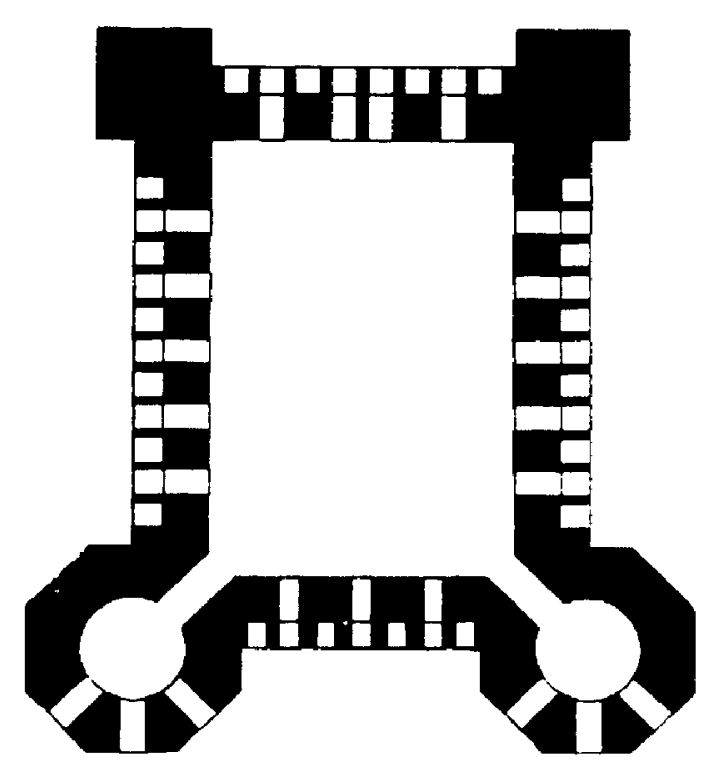

(a)

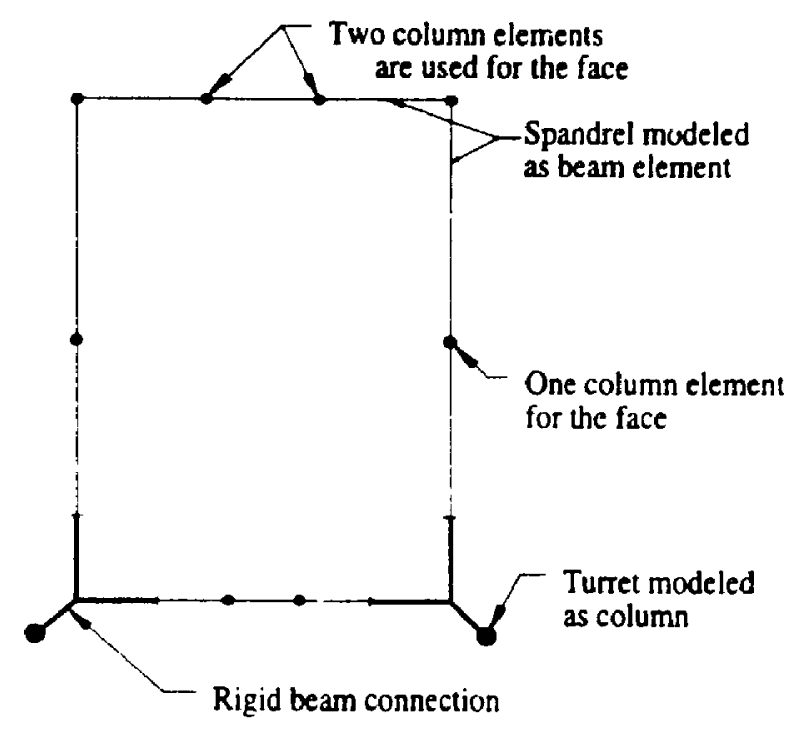

(b)

Fig. 4.10 (a) Plan view of sixth floor (b) Structural idealization of sixth floor

Rigid offset was introduced at every beam-column connection. To illustrate the point, consider a typical joint in Fig. 4.11 where $L$ is the beam length measured from face to face of columns and $a$ is the distance between the column center and column face. This joint can be modeled as a beam element connecting to a column element, where we notice that length a is the distance from the column surface to its center line. The rigid offsets are the distances from the joints to the surface of the assumed supports, and beam and column stiffness formulation assumes no member flexural or shear deformations within the rigid offset length. A reduction factor " $z$ " of magnitude $1 / 2$ was used to reduce the length of the rigid offset. In other words, the length of rigid offset was reduced from a to $(1-z)^{*} a$. Thus the effective length of the heam became $L+z^{*} a$ instead of $L+a$ or $L$. It should be noted that not using an offset reduction factor will result in an under estımate the stiffness of the beam while assuming the beam to be spanning from face to face of the column will overestimas the same stiffness. Hence tle reduction factor $i / 2$ is a compromise between those two extremes. 


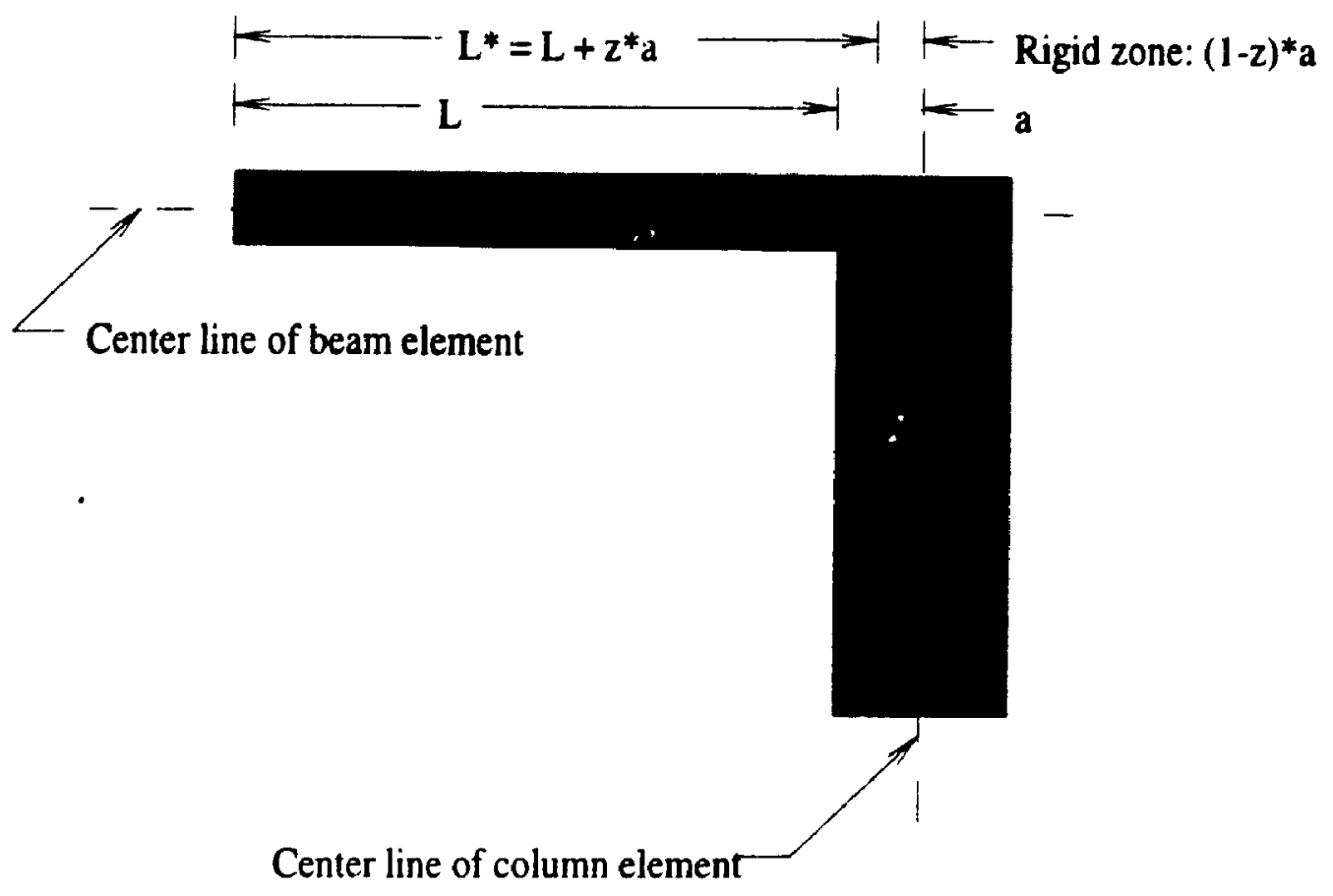

Fig. 4.11 Structural idealization of beam-column connection

The two turrets, whose typical cross section is shown in Fig. 4.12, were modeled as columns using their pertinent sectional properties. However, since the turrets have a number of small windows and doors, the modeling of the sectional properties becomes difficult. Hence, it was decided to determine the flexural stiffness by neglecting the small windows, but not the opening of the doors. The torsional moment of inertia can not be computed through the same kind of approximation because each turret actually forms a closed section, except where there are doors and windows. Since the torsional moment of inertia differs significantly between a closed and an open section, and since the height of doors is usually around $2 \mathrm{~m}$, which is almost half of the storey height, effect of the openings on the horizontal stiffness of the columns can not be ignored. To account for the open-closed section, an equivalent torsional constant was derived. 


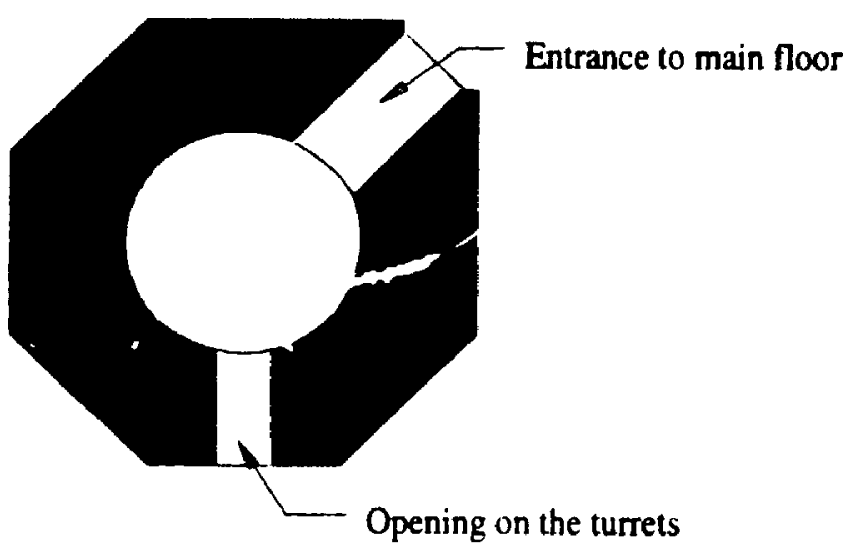

Fig. 4.12 Typical cross section of turret at height where opening exits

Consider the column element in Fig. 4.12 consisting of open and closed segments. The torsional stiffness of this composite column can be derived from first principlas. Let $K$ represent the torsional stiffness of this column, then

$$
K \theta=M,
$$

where $\theta$ is the angle of twist at the free end and $M_{t}$ is the applied torsional moment. From basic mechanics, Equation 4.11 yields

$$
\theta=\frac{M_{t}}{G} \sum_{i=1}^{n} \frac{L_{t}}{J_{i}}
$$

where $L_{1}, J_{i}$ are the length and torsional constant of segment $i, G$ is the shear modulus and $n$ is the total number of segments. For a clnsed section $J_{\text {ctosed }}$ is given by

$$
J_{\text {lurerd }}=\frac{\Omega^{2}}{\oint_{\mathrm{r}} \frac{d s}{t}}
$$

where $\Omega$ is twice the area surrounded by center line of the walls and $t$ is the wall thickness. For an open thin-walled section, its torsional constant, $J_{\text {open }}$ is given by

$$
J_{\text {opren }}=\frac{1}{3} \sum_{i=1}^{n} b_{i} t_{i}
$$


where $b_{1}$ and $t_{1}$ are, respectively, the $v$ idth and the thickness of the cross-section of wall $i$. Hence the total stiffness of the column can be obtained from

$$
K=\frac{G}{\sum_{i=1}^{n} L_{i} / J_{i}}
$$

Although the masonry wall is composed of two wythes, the facing sandstone and the inner limestone, the two wythes are treated as a single unit using the mechanical properties of the limestone (Section 4.3.2). This is reasonable since the sandstone thickness ranges from $0.15 \mathrm{~m}$ to $0.3 \mathrm{~m}$ in contrast to the limestone whose thickness is approximately $2.7 \mathrm{~m}$ at the bottom and $1.2 \mathrm{~m}$ at the top. It should also be noted that the two stone are assumed to have the same elastic modulus, but different densities. An illustration of the model represents the masonry is drawn in Fig. 4.13 shows typical discretization of the masonry elements.
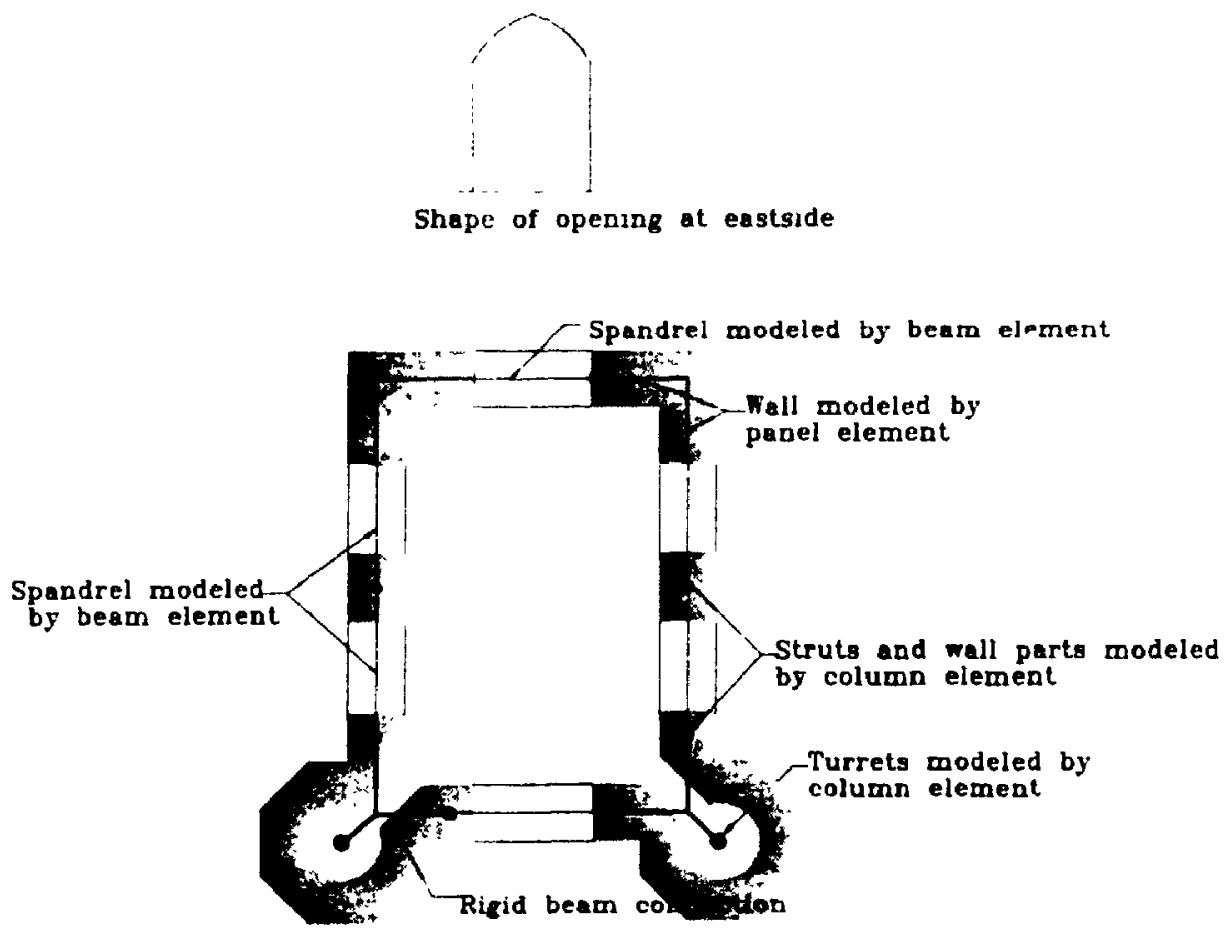

Fig. 4.13 Detail frame model at eight floor of the tower 


\subsubsection{Clay Brick Wall}

The panel element is used to model the clay brick wall which sits on top of the limestone from the 10 th floor to the 11 th floor with a height of $2.94 \mathrm{~m}$. In the model, the clay brick is assumed joined to the limestone at every node and only attached to the steel angles that pass through its cross section. Modeling the connection between the steel angles and the brick walls is found to be difficult because details of the connection are not available and also ETABS does not allow flexible connection.

\subsubsection{Steel Roof}

The roof structure is modeled as a steel space frame beginning from the 10 th to the 20 th floor of the tower. To compensate for the mass of the roof, rigid diaphragms were added and fully connected to its edges. It should be noted that the horizontal beam and bracing members of the space frame were modeled as pinconnected nembers whereas. : vertical beams were assumed to be rigidly connected. The steel tie rods that are used to tie down the roof were not included in the model since ETABS does not have the capability to model inactive structural member which could become active under certain loading conditions.

\subsubsection{Model Evaluation and Analytical Results}

Before proceeding with the analysis, there are a few assumptions in the modeling of the tower that require further investigation. First the tower does not have rigid floors from the second floor upwards, however, rigid diaphragms were included in the model in order to lump the mass of the walls at proper heights. The consequence of his assumption was investigated using a shaft with a uniform cross 
section. The results of the ETABS mojel were compared to a finite element model using thick shell element with uniformly distributed mass. Second, the influence of modeling the masonry with a membrane panel element that has no out-of-plane resistance was also studied. Third, the influence of the interconnection between the limestone, clay brick and steel roof was examined. Finally the assumed boundary condition of the tower to compensate for the surrounding building was evaluated. The final adopted model will be obtained following the foregoing evaluations. The dynamic characteristics of the model will be computed by adjusting the first natural frequency of the model to be equal to the corresponding experimental value. The adjustment will be effected through the adjustment of elastic modulus of stone masonry.

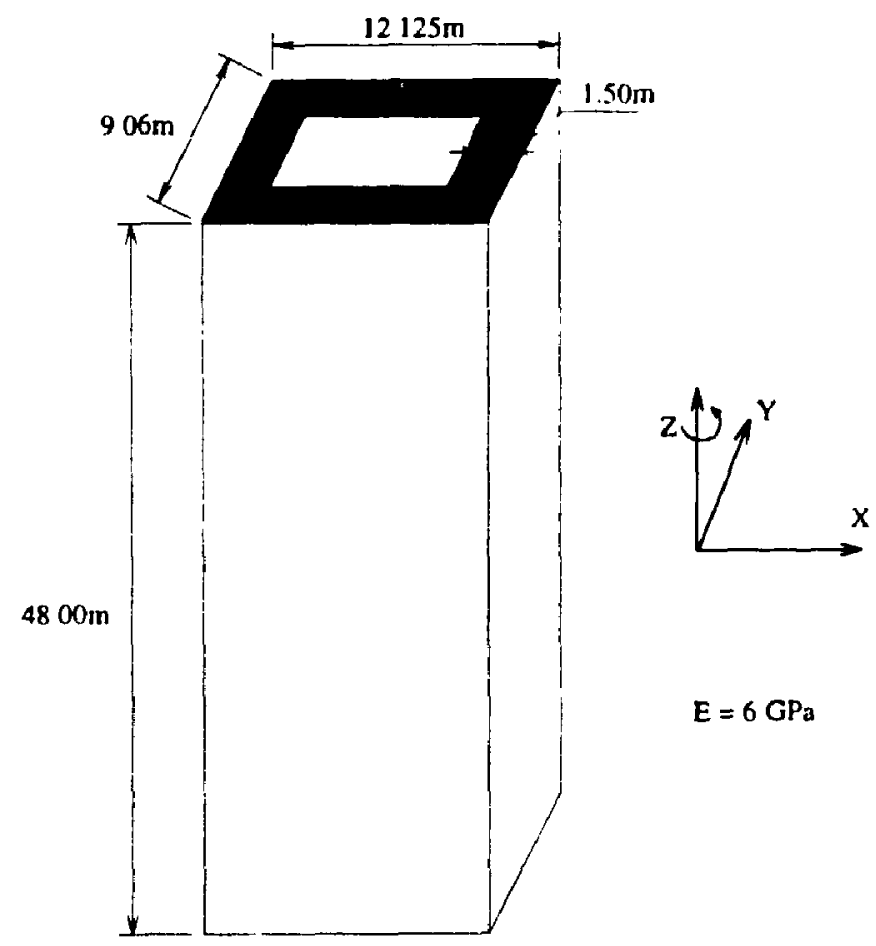

Fig. 4.14 The single cell rectangular tower 


\title{
4.4.3.1 Effects of Rigid Diaphragm
}

\begin{abstract}
A single cell rectangular tower is shown in Fig. 4.14 which was used to examine the influence of the rigid diaphragms on its overall dynamic characteristics. Although the example does not contain any diaphragms, floor diaphragms were added at various levels in order to lump the mass. The same tower was then analyzed by the finite element method using the thick shell element and having the mass uniformly distributed along its height. The natural frequencies obtained from the two analyses are given in Table 4.6. Close examination of the results reveals that the response is sensitive to the number of diaphragms. especially as the deformation pattern becomes more complex, as is the case in higher dynamic modes. For instance, the sixth mode from FEM analysis is the second pure torsional mode whereas the sixth mode from the five storey and the $t: n$ storey model of ETABS is triple bending. The second torsional mode for tha five and ten storey model is the seventh mode. It is thus believed that rigid diaphragms provide additional constraint against torsion, albeit the first torsional mode is practically unaffected and precludes relative motion between the opposite walls of the tower while the FEM model shows such movement. On the other hand, using two story to model the tower yields quite well the frequencies for the first and second bending and the torsional modes, but it can not reproduce the additional modes.
\end{abstract}




\section{Table 4.6 - Frequencies carried out from two-storey to ten-storey model and from ETABS (units: $\mathbf{H z}$ )}

\begin{tabular}{|c|c|c|c|c|}
\hline Mode & Two-story & Five-story & Ten-story & FEM \\
\hline 1 & $0.96(\mathrm{Y})$ & $1.01(\mathrm{Y})$ & $1.01(\mathrm{Y})$ & $0.97(\mathrm{Y})$ \\
\hline 2 & $1.22(\mathrm{X})$ & $1.28(\mathrm{X})$ & $1.3(\mathrm{X})$ & $1.24(\mathrm{X})$ \\
\hline 3 & $3.61(\mathrm{Z})$ & $3.69(\mathrm{Z})$ & $3.7(\mathrm{Z})$ & $3.75(\mathrm{Z})$ \\
\hline 4 & $4.47(\mathrm{Y})$ & $4.76(\mathrm{Y})$ & $4.73(\mathrm{Y})$ & $4.47(\mathrm{Y})$ \\
\hline 5 & $5.43(\mathrm{X})$ & $5.86(\mathrm{X})$ & $5.95(\mathrm{X})$ & $5.56(\mathrm{X})$ \\
\hline 6 & $8.72(\mathrm{Z})$ & $10.05(\mathrm{Y})$ & $10.27(\mathrm{Y})$ & $7.1(\mathrm{Z})$ \\
\hline
\end{tabular}

$\mathrm{Z}$ is torsional axis

\subsubsection{Effects of Membrane Element}

We notice in Table 4.6 that the first five natural frequencies of the twostorey model are very close to those from the FEM model which indicates that the membrane element is capable of simulating the behavior of close rectangular sections satisfactorily. However, the actual tower is a structure containing numerous openings, especially at higher floor levels where large openings exist. Consequently the in-plane stiffness is reduced significantly while the out-of-plane stiffness becomes considerably important. To assess the effect of such openings, a rectangular shaft with four openings on one side, and $1.5 \mathrm{~m}$ wall thickness as shown in Fig. 4.15, was considered. Two models were built for the shaft, by ETABS using beam and membrane elements and the other by FEM using thick shell elements. The results are shown in Table 4.7. It is obvious that the modes representing bending about the $\mathrm{X}$-direction are not appreciably affected because the out-of-plane stiffness in the X-direction is relatively small compared with the in-plane stiffness in the same direction. On the other hand, the results from FEM indicate that the fundamental natural ficguency is more than double the value obtained from ETABS. Also the double bending mode and the triple bending mode in the $Y$ - 
direction, and the first tcrsional mode are much higher in the FEM case. Further more, the results in Table 4.7 indicate that the double bending mode in FEM is the fourth mode while in ETABS, it is the third mode. This indicates that when the out-of-plane stiffness is neglected, the stiffness in the Y-direction is greatly affected so that the fourth mode shifts to the third mode. On the other hand, the torsional mode only changes $13 \%$, compared to $43 \%$ change of double bending mode. This is because the torsional mode mostly depends on the in-plane stiffness, hence the reduced torsional frequency from ETABS is due to the fact that the beam stiffness is neglected in the ETABS model.

Although the preceding results are from a particular case study, nevertheless the indicated differences depend on the in-plane and out-of-plane stiffness ratio. The results imply that the ratio of in-plane to out-of-plane stiffness in an open section is important and they also indicate that the out-of-plane stiffness of thick wall structures can be significant and should not be neglected. It is also found that beam elements in the ETABS model do not model the necessary out-of-plane resistance of the system. The reason is attributed to the fact that the out-ofplane(diaphragm) stiffness of beams are not transferred to the perpendicular wall elements. Further investigation showed that if the thickness of the wall was reduced to $0.25 \mathrm{~m}$ or $0.15 \mathrm{~m}$, the values for the frequency and mode shapes from ETABS would correspond to those from FEM, except that the out-of-plane deformational mode of wall becomes the lower modes in FEM. Further, if rigid diaphragms are introduced into the FEM model, the two models give almost identical natural frequencies and mode shapes. The results of this test indicate that ETABS may not be suitable to represent the dynamic characteristics of stone masonry with openings. 
Table 4.7 - Frequencies of shaft with openings

\begin{tabular}{|c|c|c|}
\hline Mode & $\begin{array}{c}\text { ETABS } \\
\mathrm{Hz}\end{array}$ & $\begin{array}{c}\text { FEM } \\
\mathrm{Hz}\end{array}$ \\
\hline 1 & $0.30(\mathrm{Y})$ & $0.70(\mathrm{Y})$ \\
\hline 2 & $1.11(\mathrm{X})$ & $1.12(\mathrm{X})$ \\
\hline 3 & $1.69(\mathrm{Y})$ & $2.27(\mathrm{Z})$ \\
\hline 4 & $1.97(\mathrm{Z})$ & $2.97(\mathrm{Y})$ \\
\hline 5 & $4.40(\mathrm{Y})$ & $5.35(\mathrm{Y})$ \\
\hline 6 & $5.87(\mathrm{X})$ & $5.64(\mathrm{X})$ \\
\hline
\end{tabular}

("Z" direction means torsional direction)

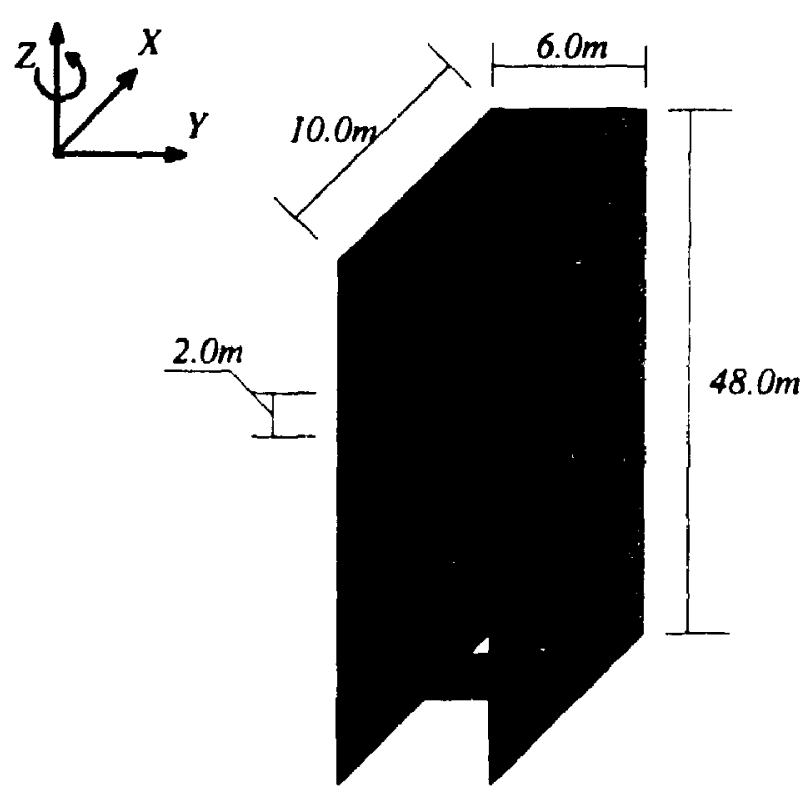

Fig. 4.15: $1.5 \mathrm{~m}$ thick rectangular shaft with four openings

\subsubsection{Effects of Connection Between the Roof and the Walls}

The visual inspection of the clay brick wall, ihe limestone and the steel roof connection did not reveal their degree of interconnection and detailed information is not available in the archives. Thus, the effects of various scenario of 
connections need to be examined. Three different cases were selected: namely, the clay brick connected along its entire periphery to the steel angles that extend from the roof, the clay brick connected at its corners only to the steel angles extending from the roof, and the clay brick not connected at all to the steel angles that extend from the roof. The results of the free vibration analysis for the three assumptions are given in Table 4.8 .

We observed in Table 4.8 that for the first six modes, the natural frequencies based on the three assumptions are nearly the same. Since all three mode shapes yield identical results, one can assume that the clay brick wall is joined to the steel angles at its corners only. As expected, the overall influence of the different types of connection on the dynamic characteristics of the model is small, but the local stresses of the structural components, such as steel angles, will be affected to a greater extent because there will be large movements at the roof level wher the lower modes are excited.

\section{Table 4.8 - Effects of connection between brick wall and steel angles}

\begin{tabular}{|c|c|c|c|}
\hline Mode & $\begin{array}{c}\text { Free } \\
(\mathrm{Hz})\end{array}$ & $\begin{array}{c}\text { Corner Connection } \\
(\mathrm{Hz})\end{array}$ & $\begin{array}{c}\text { Full Connection } \\
(\mathrm{Hz})\end{array}$ \\
\hline 1 & 1.11 & 1.11 & 1.11 \\
\hline 2 & 1.26 & 1.26 & 1.26 \\
\hline 3 & 2.23 & 2.3 & 2.31 \\
\hline 4 & 2.42 & 2.43 & 2.43 \\
\hline 5 & 3.41 & 3.43 & 2.43 \\
\hline 6 & 3.64 & 3.77 & 3.77 \\
\hline
\end{tabular}

\subsubsection{Effects of the Surrounding Building}

The tower in its present state is connected on its three sides with a fourstorey building. Thus in principle, the dynamic characteristics of the tower can not 
be isolated from those of the overall structure. However, due to the difficulties associated in modeling the actual contribution of the surrounding buildings, it was assumed that the tower is either a free standing structure independent of the surrounding building or it is fully constrained at those locations where it is joined to the building, with the building being totally rigid. The fully restrained and free standing analysis will constitute the lower bound and upper bound of the actual structural response. The effects of these simplified boundary conditions are summarized in Table 4.9. By restricting the movement of the tower where the two structures are joined, its frequency increased as expected.

\section{Table 4.9 - Effect of surrounding building connection on the natural frequencies of the tower}

\begin{tabular}{|c|c|c|}
\hline Mode & $\begin{array}{c}\text { Free } \\
(\mathrm{Hz})\end{array}$ & $\begin{array}{c}\text { Constrained } \\
(\mathrm{Hz})\end{array}$ \\
\hline 1 & $1.11(\mathrm{Y})$ & $1.74(\mathrm{Y})$ \\
\hline 2 & $1.26(\mathrm{X})$ & $1.84(\mathrm{X})$ \\
\hline 3 & $2.3(\mathrm{Y})$ & $2.29(\mathrm{Y})$ \\
\hline 4 & $2.43(\mathrm{Z})$ & $3.00(\mathrm{Z})$ \\
\hline 5 & $3.43(\mathrm{Y})$ & $3.70(\mathrm{X})$ \\
\hline 6 & $3.77(\mathrm{X})$ & $6.41(\mathrm{Y})$ \\
\hline
\end{tabular}

$\mathrm{Z}$ is torsional axis

The results in Table 4.9 show that both the modes of deformation and the frequencies are affected when constiaints are introduced. The frequencies of the first two bending modes and of the first torsional mode increased substantially due to the constraint at the lower level. However, the second mode in the $\mathrm{Y}$ direction is essentially unaffected, and is believed to be due to its small deformation at lower 
levels as shown in Fig. 4.16. Note that the triple bending mode shape in the $Y$ direction is constrained at the lower level to the extent that it becomes the sixth mode instead of the fifth mode, and its fraquency is almosi doubled. To select the appropriate boundary conditions, the results obtained from the two cases are compared to the experimentally extracted mode shapes and frequency The constrained model was found to compare favorably with the experimental data. consequently, it is selected to represent the dynamic behavior of the tower in subsequent frame analysis. The first nine mode shapes of the final adopted model are illustrated in Fig. 4.17 to Fig. 4.25.

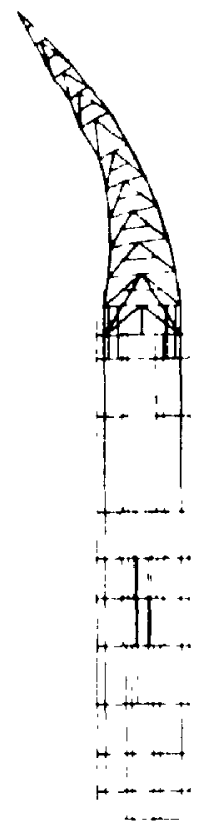

(a)

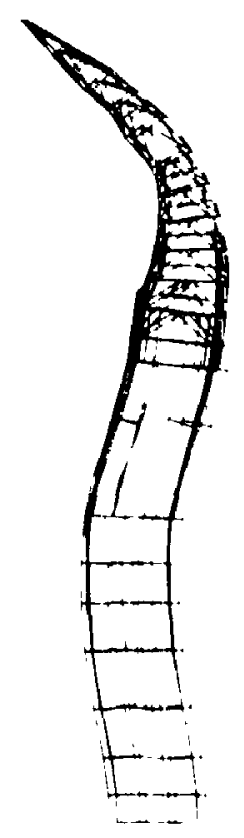

(b)

Fig. 4.16 Modes of free standing model (a):Second translational mode in $Y$ direction (b): Third translational mode in $Y$ direction 


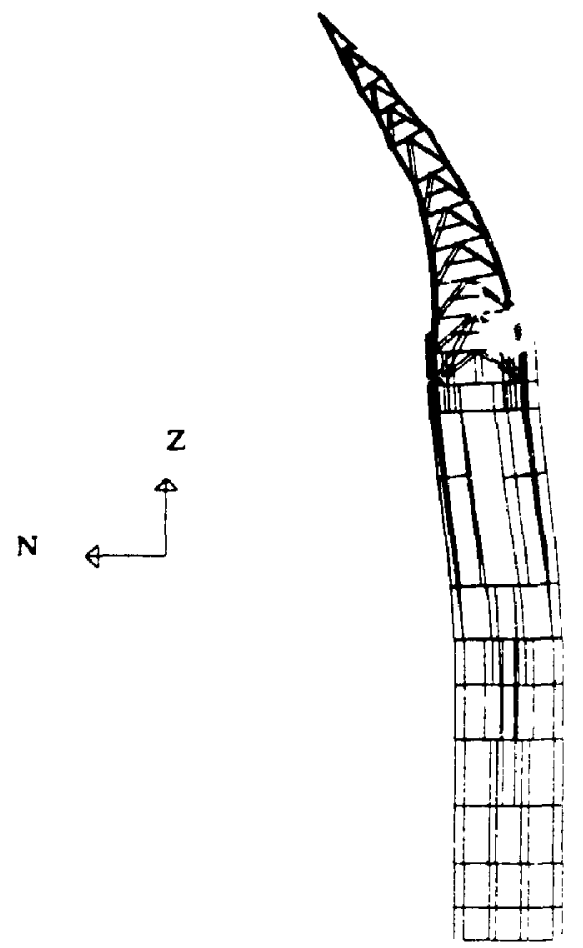

Fig. 4.17 rirst mode of frame model Nort.h-South direction

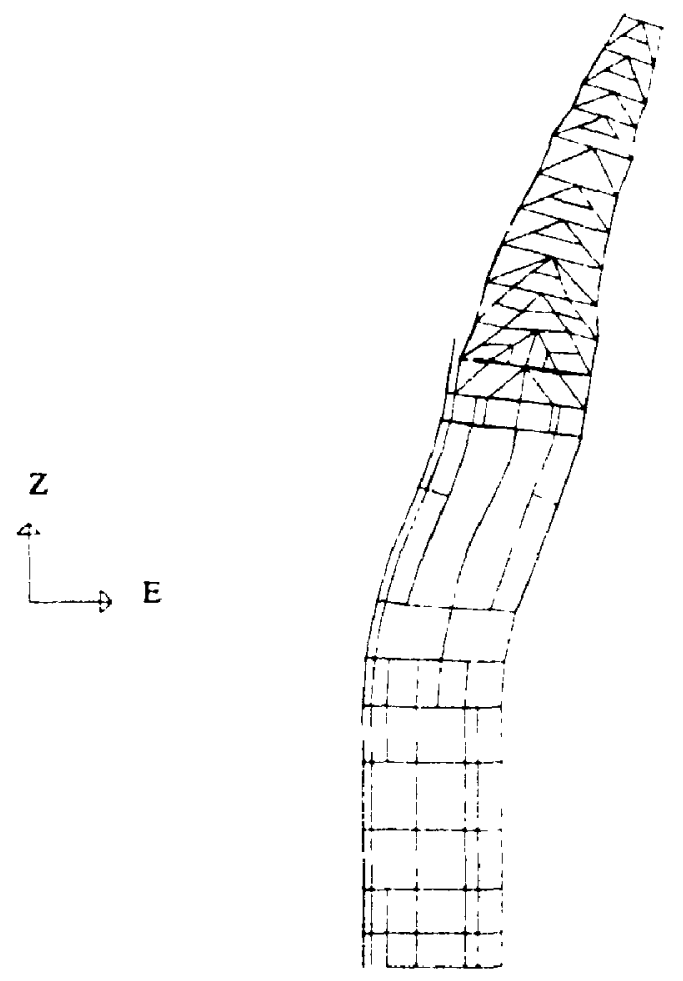

Fig. 4.18 Second mode of frame model East-West direction 


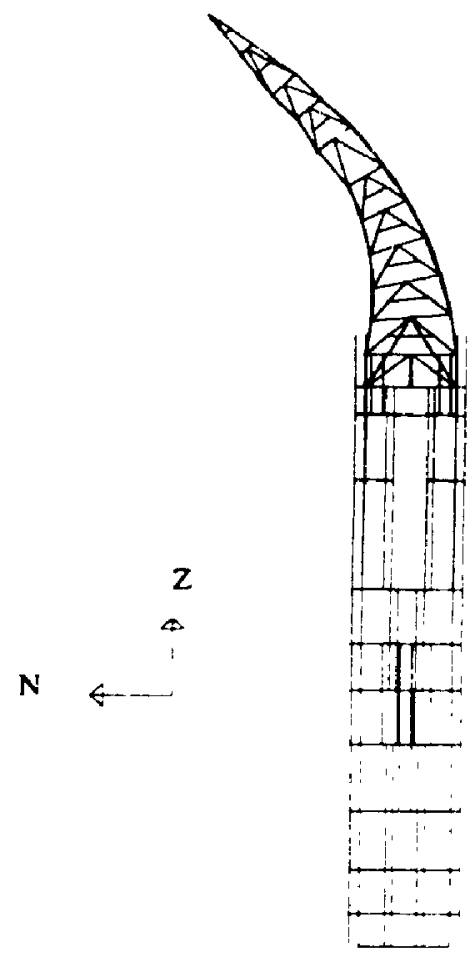

Fig. 4.i9 I hird mode of frame model North-South direction

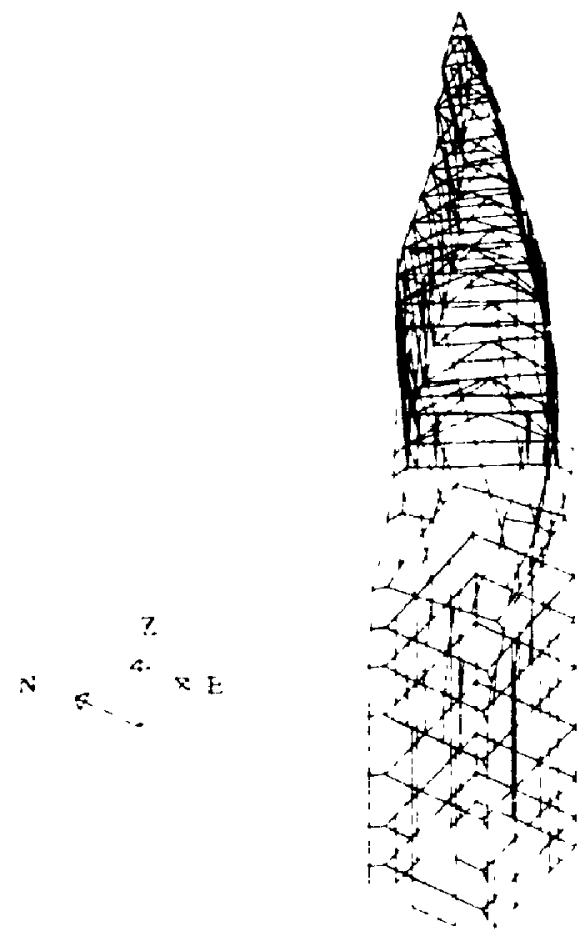

Fig. 4.20 Fourth mode of frame model Tr.isional direction 


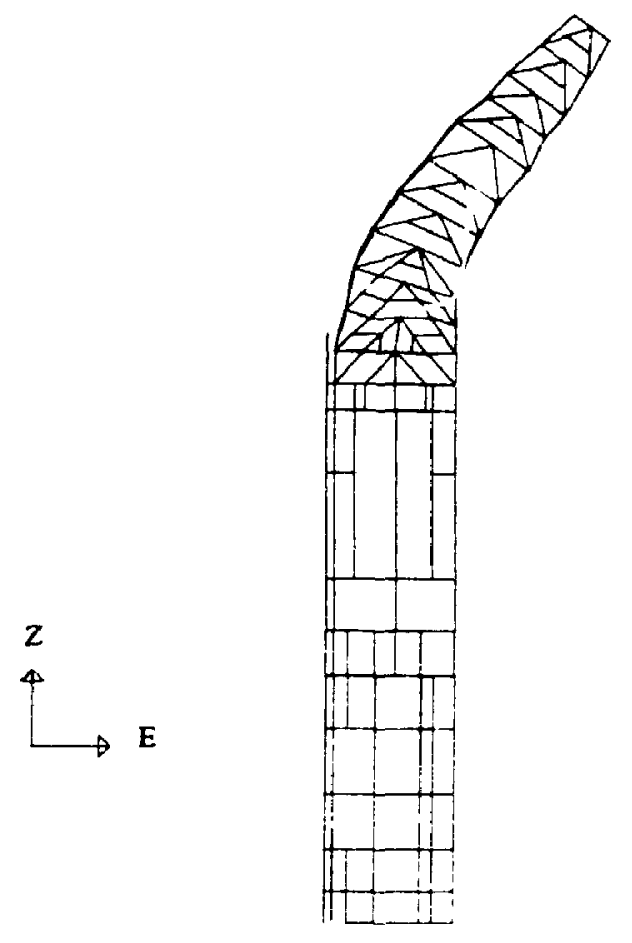

Fig, 4.21 Fifth mode of frame model East-West direction

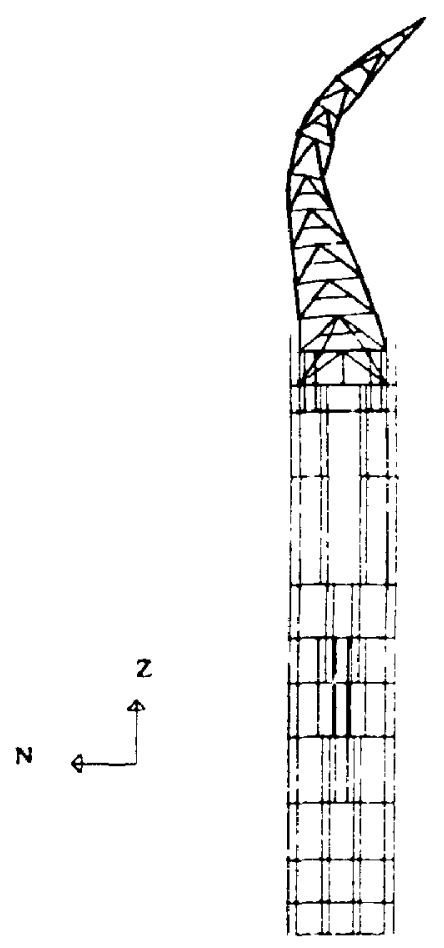

Fig. 4.22 Sixth mode of frame model North-South direction 


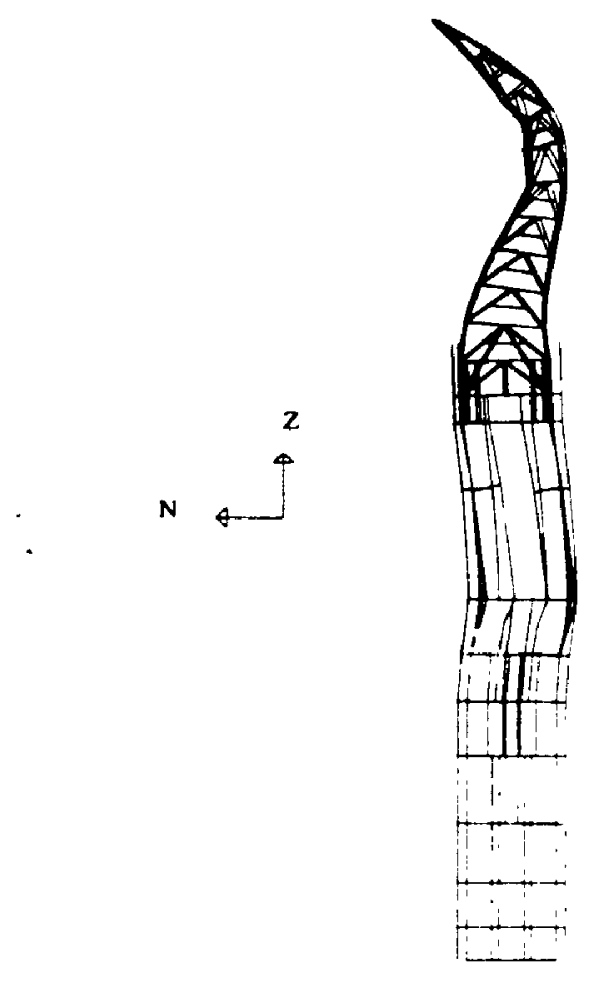

Fig. 4.23 Seventh mode of frame model North-South direction

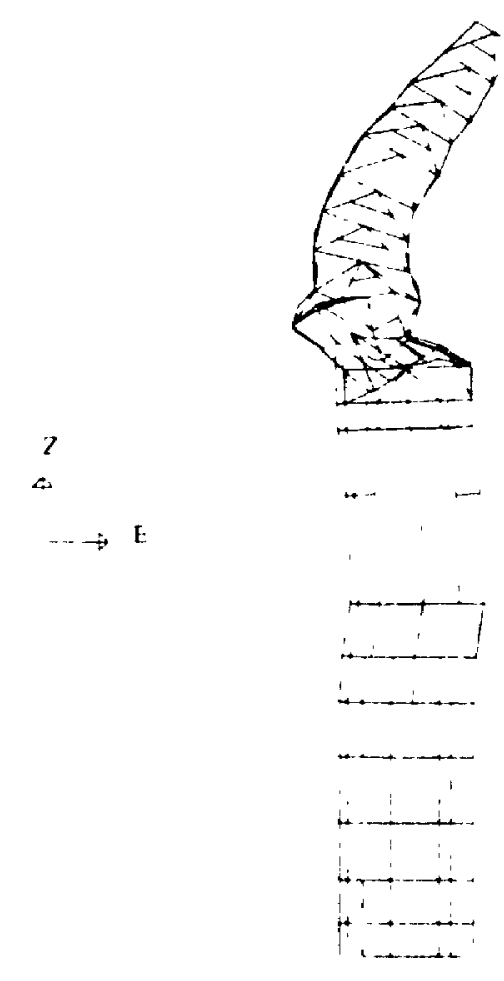

Fig. 4.24 Eighth mode of írame model East-West direction 

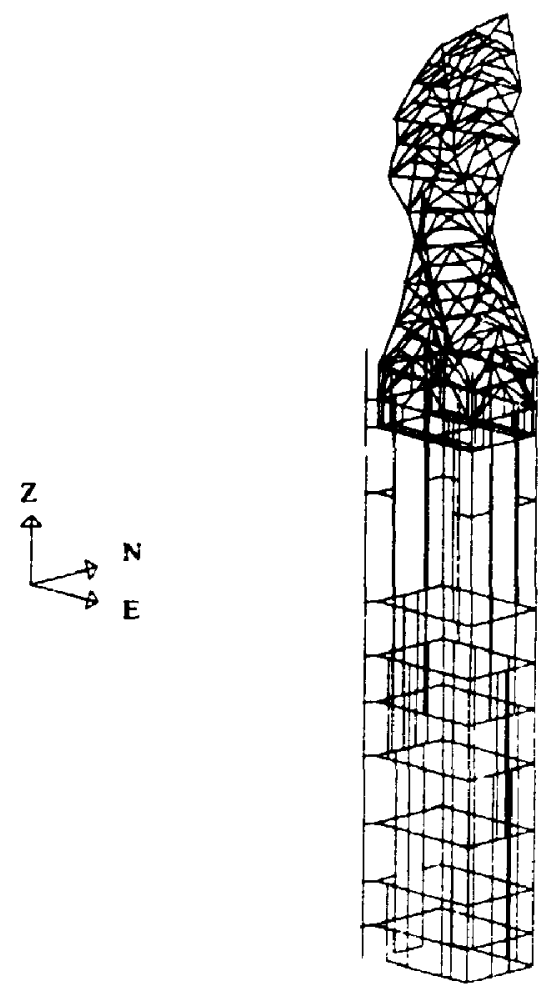

Fig. 4.25 Ninth mode of frame model Rotational direction

\subsubsection{Boundary Conditions and Material Properties}

The tower will be assumed fully constrained at the locations where it is connected to the surrounding building as illustrated in Fig. 4.26. The assumption is derived from the results of the previous section.

The material properties used in the current analysis are given in Table 4.10. As noted earlier, the material properties of all the structural members are kept constant with the exception of the stone masonry's modulus of elasticity. The latter is obtained by calibrating the first natural frequency to the corresponding experimentally extracted value. 
Table 4.10 - Material properties applied in frame analysis

\begin{tabular}{|c|c|c|c|}
\hline \multirow{2}{*}{ Material } & Modulus of Elasticity & Mass Density & Poisson's Ratio \\
\cline { 2 - 4 } & $(\mathrm{GPa})$ & $\mathrm{Kg} / \mathrm{m}^{3}$ & \\
\hline Stone masonry & 5 & 2600 & 0.2 \\
\hline Steel & 200 & 7800 & 0.3 \\
\hline Brick wall & 28 & 1800 & 0.2 \\
\hline
\end{tabular}

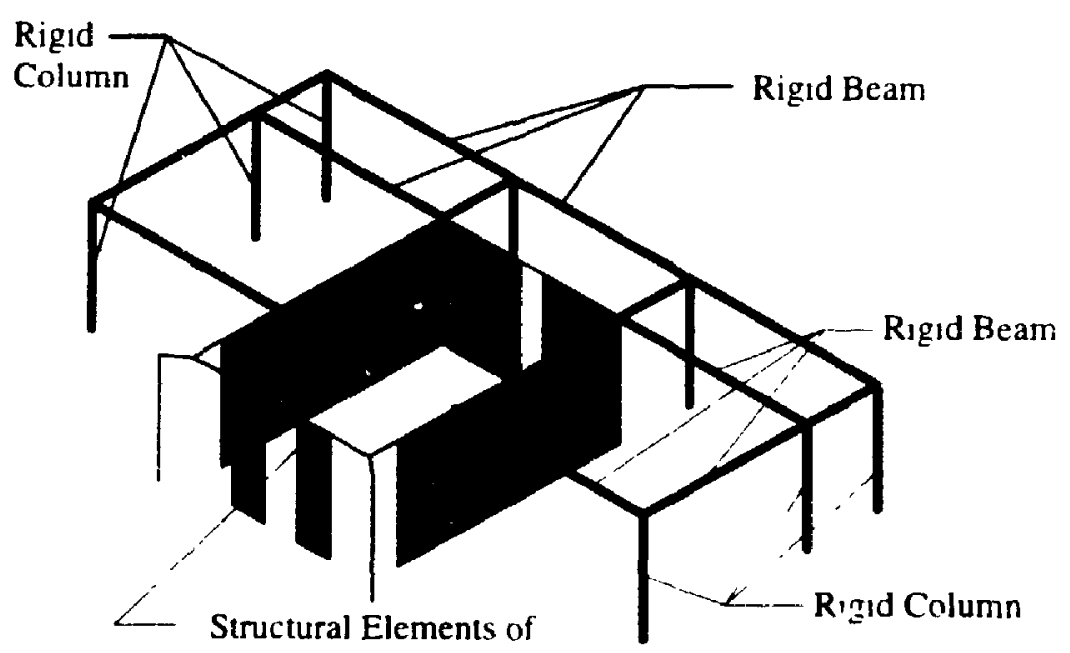
the tower itself

Fig. 4.26 External constrains at fifth floor in frame model 


\subsection{Finite Element Method}

In this section, the tower is analyzed as a spatial structure using a general finite element program. The purpose is to examine the influence of further refinement in modeling on the dynamic characteristics of the tower. The finite element method is chosen because of its wide application and acceptance in solving civil engineering problems. The results in the form of natural frequencies and mode shapes will be compared with the corresponding experimental data. Again, the objective of this task is to select the most appropriate finite element model to characterize the dynamic response of the tower.

\subsubsection{Finite Element Program AFEMS}

AFEMS (Automatic Finite Element Modeling \& Solution) (AFEMS 1992), developed for commercial applications and marketed by FEM Engineering Corporation of Inglewood, California, is used here to model the tower. AFEMS, being a general purpose finite element program with static and dynamic capabilities, is one of the many commercial programs that can be used to study the dynamic characteristics of a given structure. Here AFFiMS was employed because it was readily available. Some of its main features are briefly listed:

(1) AFEMS is a modular finite element program that can be used to perform both static and dynamic analysis on one, two and three dimensional problems. It also includes modules for heat transfer and fluid flow analysis. For the stress analysis module, it can model both geometric and material non-linearity. 
(2) AFEMS element library includes two-dimensional continuum, threedimensional continuum, general constraint, truss, pipe, beam, elbow, plate, shell, rigid bar, rigid mass, spring, damper, gap, and friction elements.

(3) Types of loading that can be used include the point loads, distributed loads, transient motion, thermal loads and prescribed boundaries. It also features line or surface contact boundary.

(4) The dynamic analysis includes mode shape and frequency extraction, modal analysis, response spectrum generation and analysis, and time integration for time-dependent or independent excitation force.

\subsubsection{Description of Finite Elements Used to Model the Tower}

The types of finite elements employed in the this study are the four-node composite shell element. four-node plate bending element, beam element and truss element. A brief description of each element is given here. further information can te obtained from user's operation manual(AFEMS 1992)

(1) Four-node composite shell element

The four-node composite shell element is an extension of the general finite element thick shell element. In its formulation, the element is a conforming :ment with five degree of freedom at each node, namely translation in three directions and rotation about the $\mathrm{X}$ and $\mathrm{Y}$ axis. Being a shell element, it can represent both in-plane and out-of-plane deformations. including shear deformations. The composite shell element is one of the techniques available to model laysred shells. The element is illustrated in Fig 4.27 where a plate is divided into $n$ layers, with each layer being measured from a reference surface. The displacement field is only computed at the reference surface but it includes the effect of the geometry of the plate through its 
thickness. Higher order quantities, i.e. stress field, are computed at the integration point of every layer and averaged at the node position for each layer.

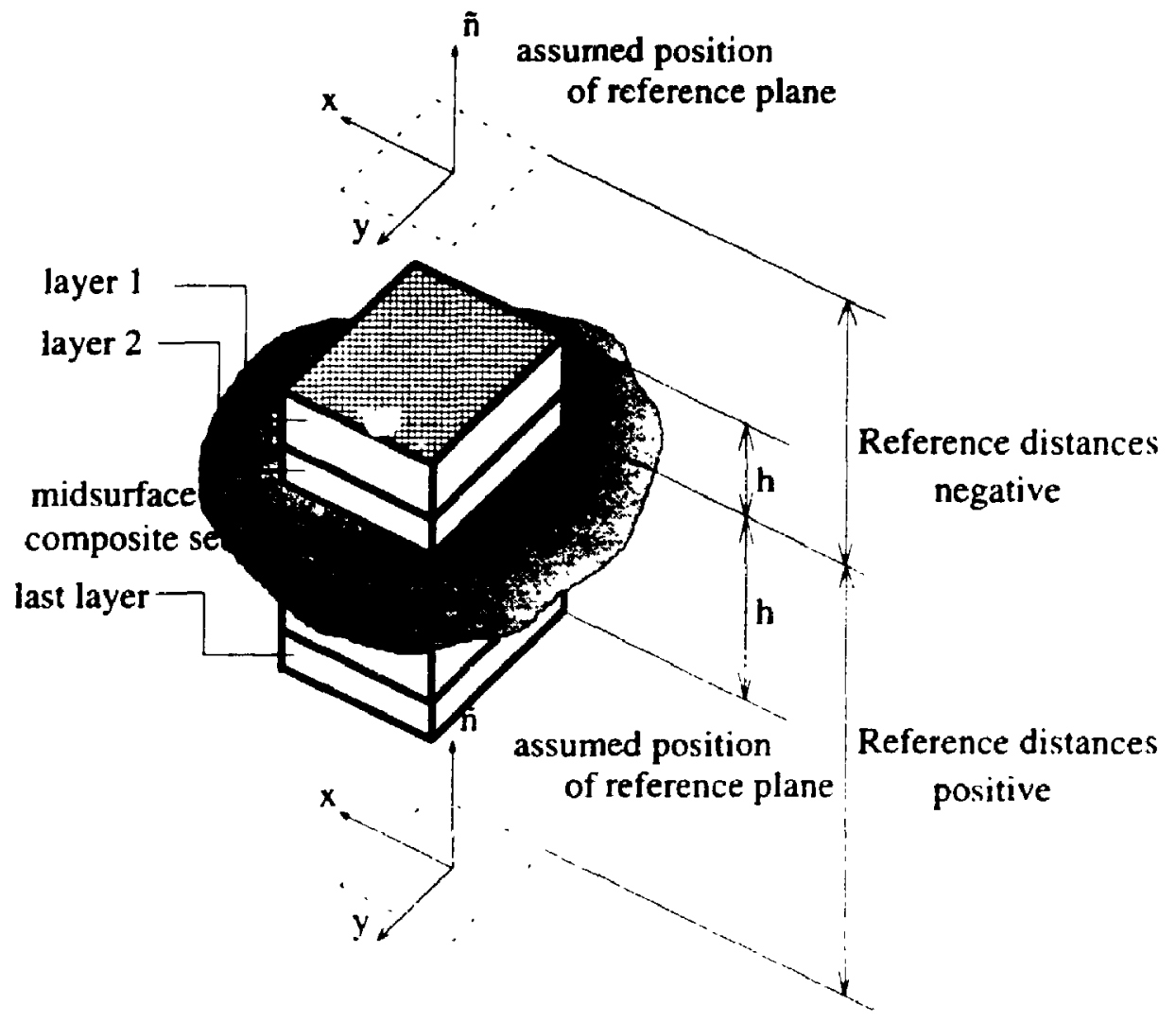

Fig 4.27 Definition of composite set

(2) Four-node plate bending element

The four-node plate bending element, named PLATE4, is constructed by four grid points and has both bending and membrane capabilities. There are five degrees of freedom at each grid point, namely iranslation in $X, Y, Z$ directions and rotation in $X$ and $Y$ directions. All four nodes of this element must be located in the same plane, as illustrated in Fig 428. 


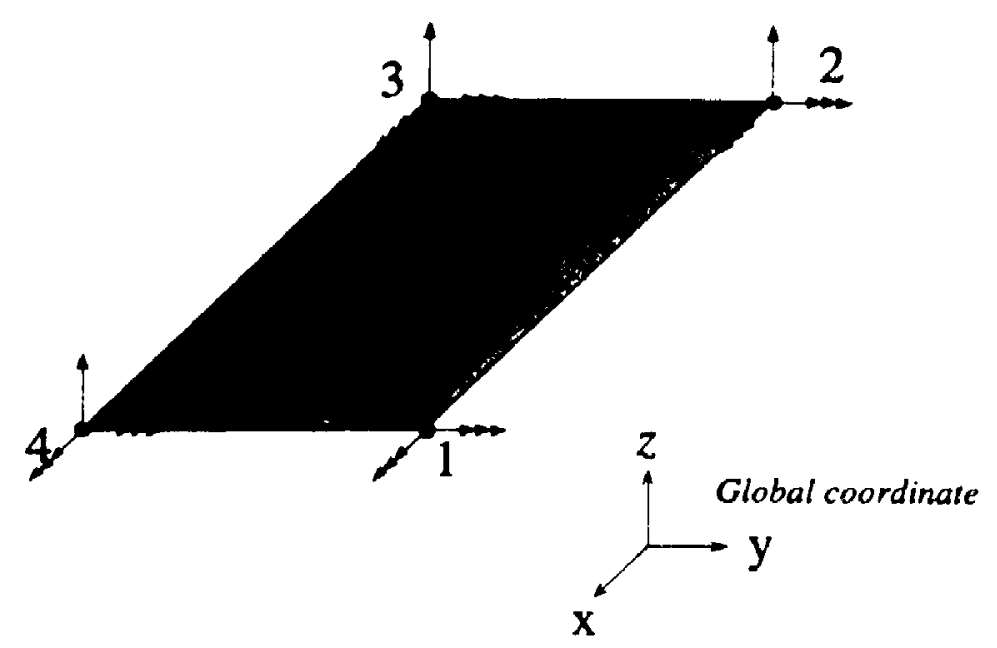

Fig 4.28 Four node thick plate element

(3) Beam element

The 3-D elastic beam element is a 2 -node uniaxial element with tension, compression, torsion and bending capabilities. Six degrees of freedom. three translations and three rotations, are avalable at each node. When defining the beam element, a third node is required to specify the orientation of its principal axis. The element is illustrated in Fig 4.29.

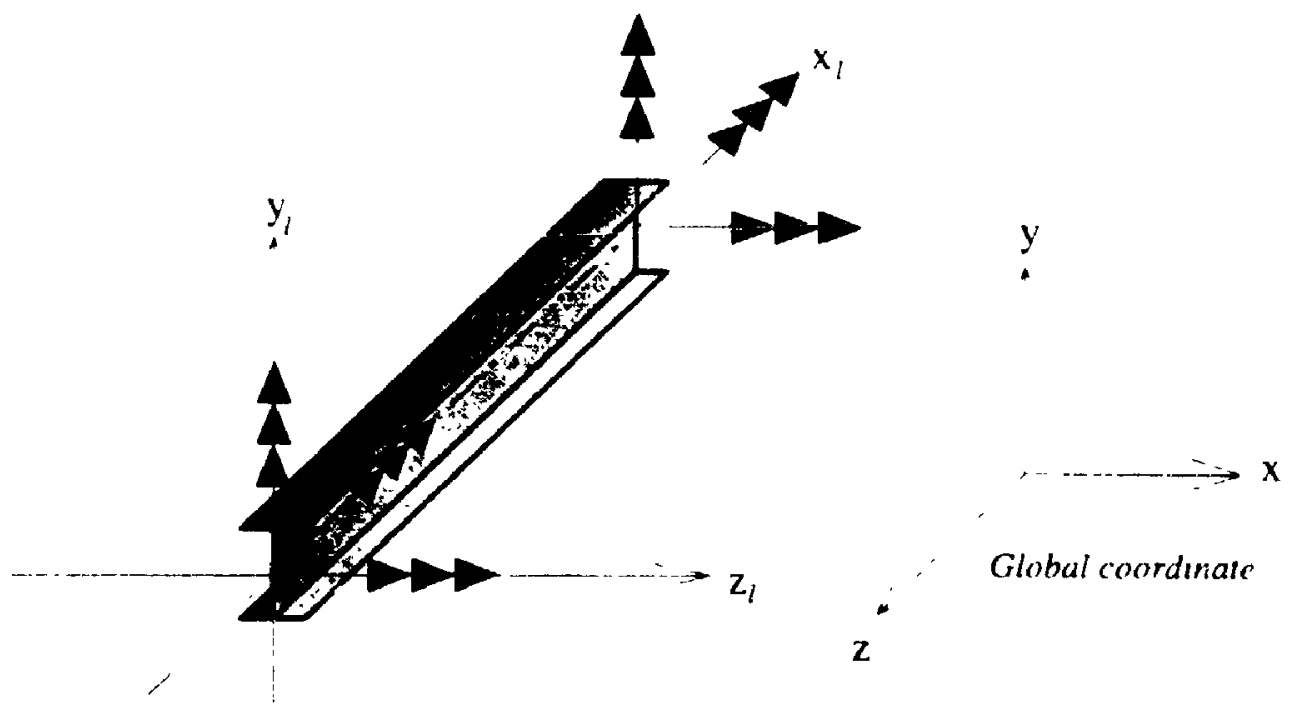

Fig 4.29 Beam element 
(4)

\section{Truss element}

The 3-D truss element is a uniaxial tension-compression element with three degrees of freedom at each node, namely translations in the $X, Y$ and $Z$ directions, as illustrated in Fig 4.30.

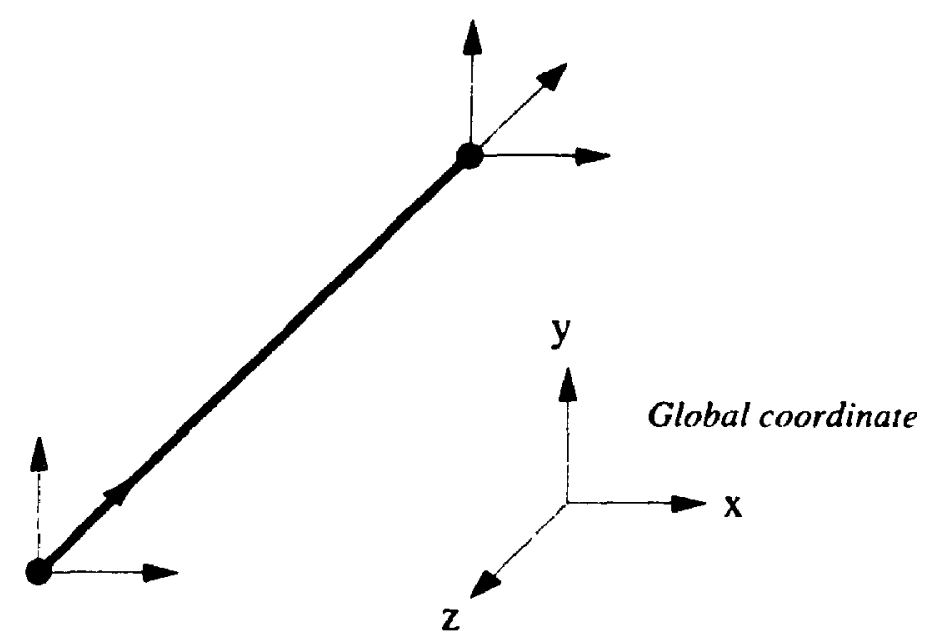

Fig 4.30 Truss element

\subsubsection{Dynamic Analysis Method Applied by AFEMS}

AFEMS provides different methods to solve dynamic problem. For this study, the eigenvalues and eigenvectors are first computed using matrix iteration, and the time integration procedure was selected to capture the seismic response of the tower. Again a brief description of the latter is provided here since many text books such as Humar (1990) and Clough (1992) provide detailed explanation and presentation of the procedure.

The solution is based on the average acceleration method where the acceleration along each coordinate of the system is assumed to remain constant over the small time intervai. The value is the average of those at the beginning and 
end of the interval. The relationships between the response parameters at time step $n$ and $n+1$ are similar to their scalar counterparts, i.e.

$$
\begin{aligned}
& \ddot{u}_{n+1}=-\ddot{u}_{n}+\frac{4}{\Delta t^{2}}\left(u_{n+1}-u_{n}-\Delta t \dot{u}_{n}\right) \\
& \dot{u}_{n+1}=-\dot{u}_{n}+\frac{2}{\Delta t}\left(u_{n+1}-u_{n}\right)
\end{aligned}
$$

where $\Delta t$ is the time interval. A third relationship is obtained from the equation of motion at'time step $n+1$

$$
M \ddot{u}_{n+1}+C \dot{u}_{n+1}+K u_{n+1}=p_{n+1}
$$

Substitution for $\ddot{u}_{n+1}$ and $\dot{u}_{n+1}$ from equation 4.16 and equation 4.17 into equation 4.18 gives

$$
\left(\frac{4}{\Delta t^{2}} M+\frac{2}{\Delta t} C+K\right) u_{n+1}=p_{n+1}+M\left(\frac{4}{\Delta t^{2}} u_{n}+\frac{4}{\Delta t} \dot{u}_{n}+\ddot{u}_{n}\right)+C\left(\frac{2}{\Delta t} u_{n}+\dot{u}_{n}\right)
$$

Equation 4.19 is solved for $u_{n+1}$ and the resulting value is substituted in Eqs. 4.16 and 4.17 , respectively. In this case. an effective stiffness matrix, given as the first term of equation 4.19 , is used in stead of the original stiffness matrix $K$.

\subsubsection{Structural Idealization}

The finite element model representing the tower is shown in Fig 4.31 which is assembled in accordance with the description to follow. The elevation view and plan views of the model are presented in Fig 4.32 .

The finite element mesh in Fig 4.31 consists of four different finite element types, with a total of 7073 elements and 6907 nodes. Due to the complex geometric variations within the walls and turrets. a number of assumptions had to be made in order to simplify the analysis. The assumptions will be described in the pertinent sections that follow. 


\subsubsection{Stone Masonry Walls}

The stone masonry parts of the tower were modeled using a combination of four-node composite thick shell element aud thick plate bending element. Although field measurements have revealed that the thickness of the sandstone layer ranges from $150 \mathrm{~mm}$ to $350 \mathrm{~mm}$, it was approximated in the analysis with a uniform thickness of $200 \mathrm{~mm}$. The thickness of the limestone was subtracted from the total thickness of the wall along the height of the tower.

Theoretically, the deformational behavior of the tower is best represented by a three dimensional analysis. However, even to crudely represent the out-of-plane behavior of the tower, a minimum of three 3-D elements are needed across the thickness. This will result in a large amount of degrees of freedom and a very large sparse stiffness matrix whose computational requirements are prohibitive. Instead. the walls were modeled by CSHELL4 elements.

The element consists of two layers, representing limestone and sandstone, respectively. The elements planar dimensions vary from $0.5 \times 0.5 \mathrm{~m}$ to $1.0 \times 1.0 \mathrm{~m}$, with the exception of the elements at the seventh floor level where a refined mesh of $0.22 \times 0.4 \mathrm{~m}$ elements were used. The latter is needed to represent the geometry without distorting the element while properly modeling all the openings of the structure. The curved lintel beams located on top of entrances and window openings were modeled as shown in Fig 4.33. Once agaın, the modeling of curved members by straight elements can introduce spurious transverse bending action at the nodes, however, with sufficient refinement, this effect is expected to diminish. 


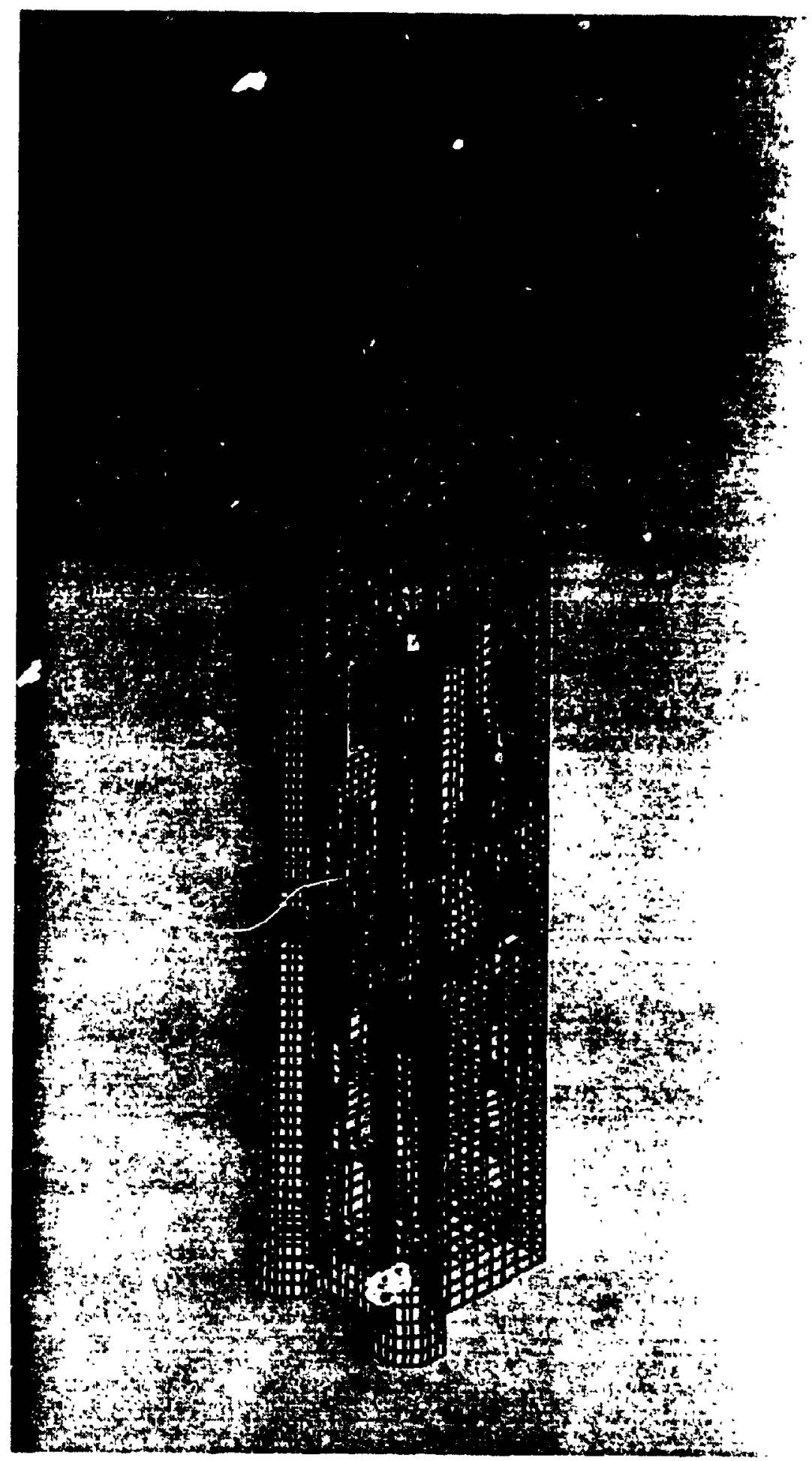

Fig 4.31 Finite element model for the tower 


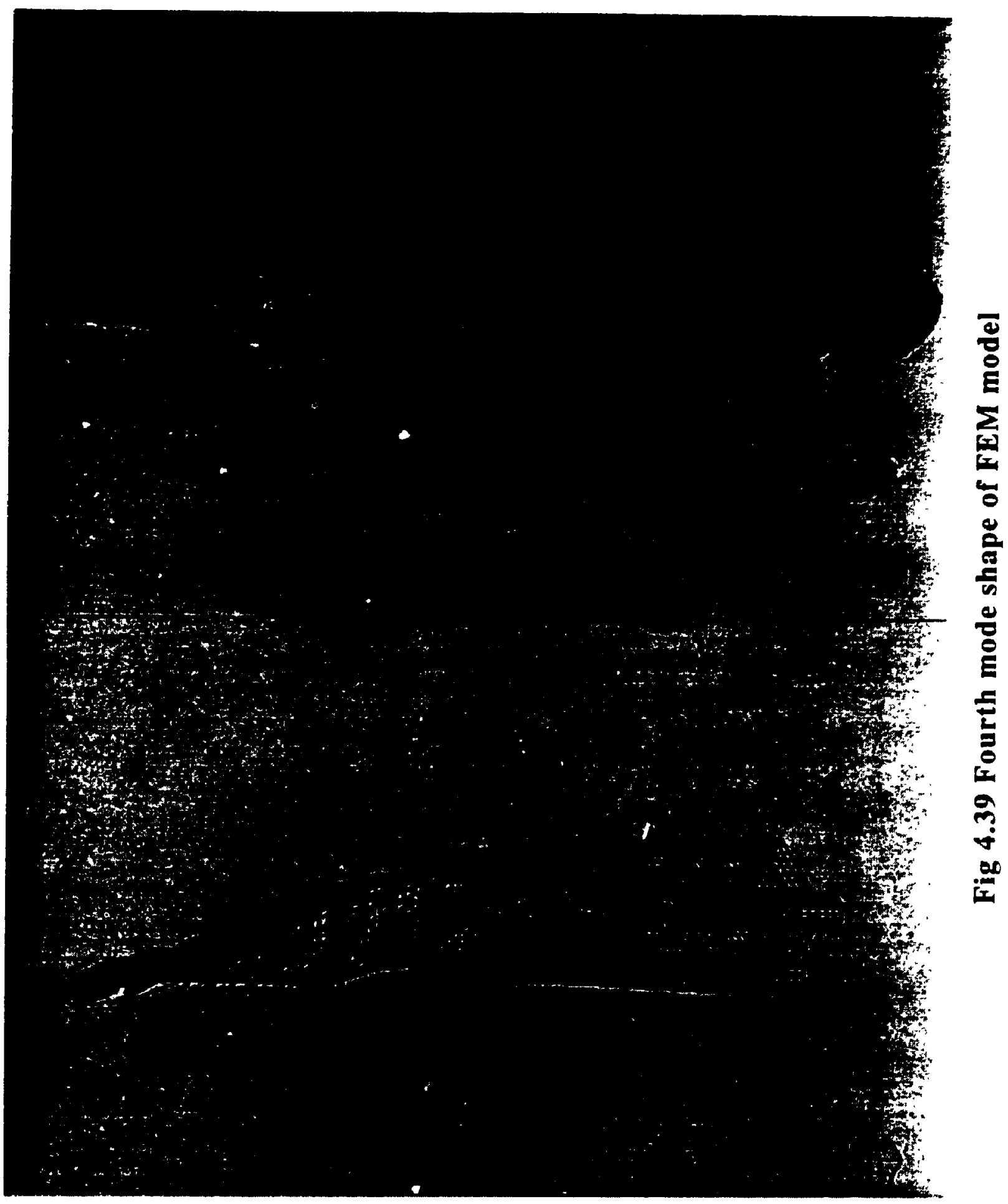




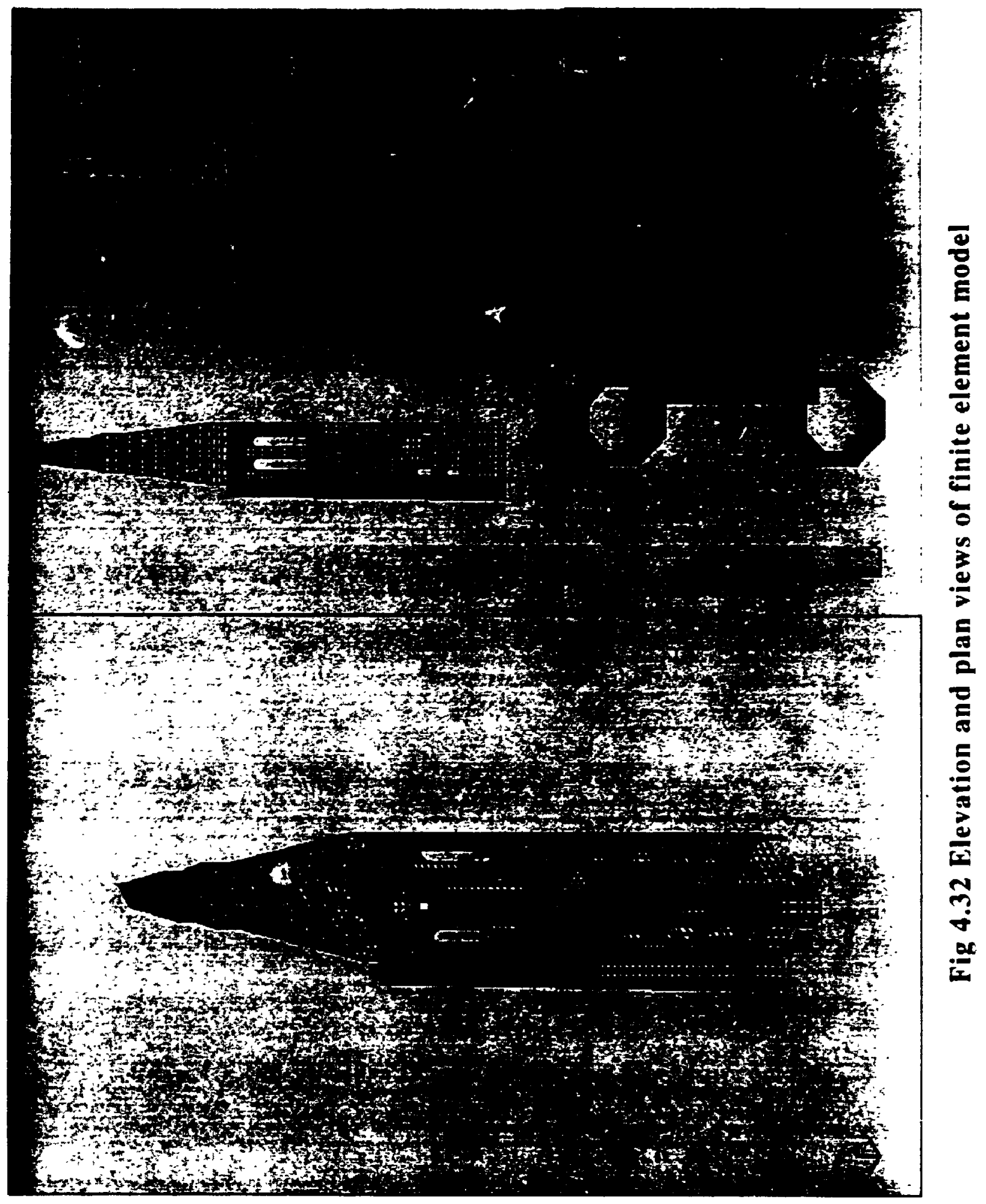


As stated in Chapter 3, the tower is a very complex structure with geometry changes along the height. Among those changes, one is the change in the thickness of stone masonry wall. For the walls on the four sides of the tower, there are two major changes in their thickness, the first occurs at the fourth level and the second at the seventh level. Although the changes in the cross section occur gradually within two to three meters of height, to simplify the model, the walls were modeled with a sudden change in their thickness.

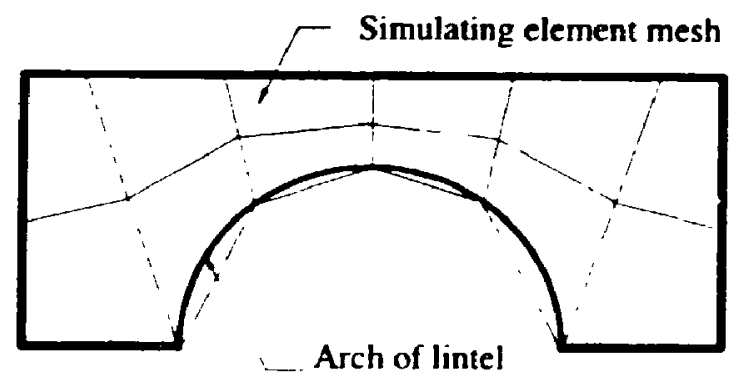

Fig 4.33 Mesh of lintel

The turrets were also idealized by CSHELL4 element. However, unlike the walis of the tower, the change of turret's diameter along the height is significant. Given that the details of the rapid geometrical changes of the turrets at certain stories are not available, an inclined reference surface built through the midd!e surfaces of top and bottom wall was employed which is believed to provide an adequate representation of the turrets. Although the turrets have an octagonal shape on the exterior and a circular one on the inside, the section was assumed to be an octagon on both faces. All the spenings on the turrets were accounted for, however, to reduce computational effort, the arch action of the openings in turrets was not represented, in other words, all the openings on turrets were idealized as rectangular sections. A plan view section of the finite element model is presented in Fig 4.34. 


\subsubsection{Diaphragms}

The concrete floor located at the first fioor was modeled by thick plate bending elements. The diaphragms at the second, third and fourth levels. consisting of iron joists in one direction and of cast-in-place concrete slabs, provide a reasonable in-plane stiffness to the diaphragm. However, since the diaphragms are tied to the rest of the building, it was decided to investigate their effect as part of the boundary condition of the surrounding building. The diaphragms above the fifth floor were neglected because of their weak in plane stiffness and their loose connection with the stone wall.

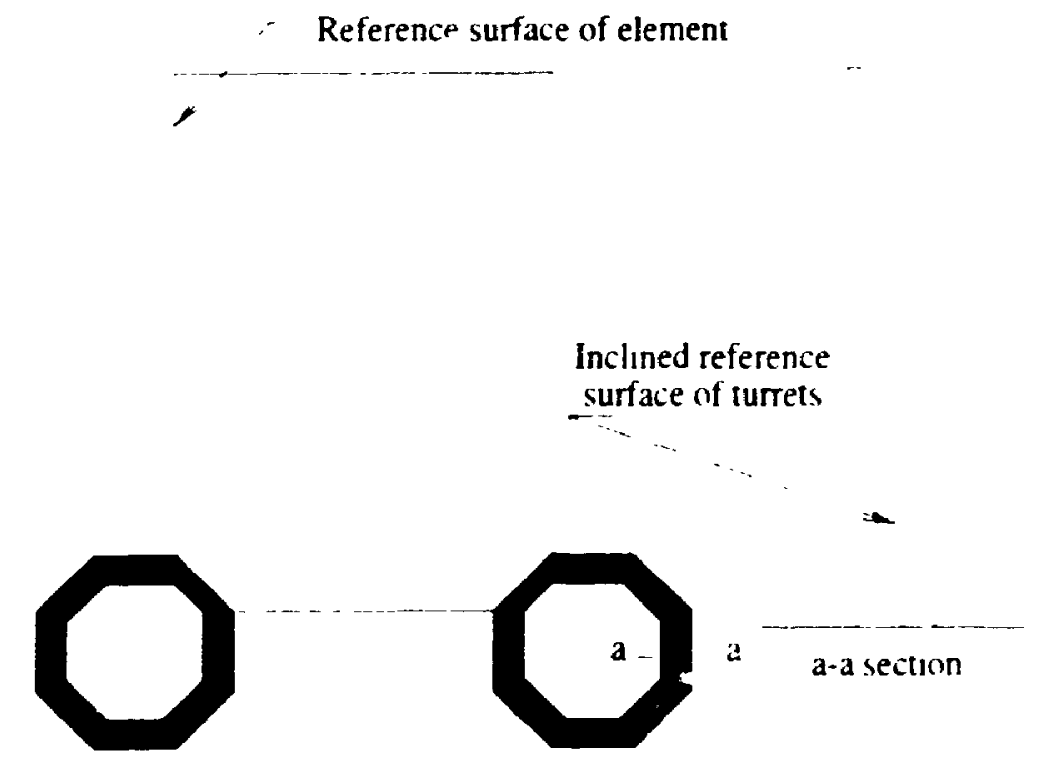

Fig 4.34 Plan view of stone masonry section modeling

\subsubsection{Clay Brick Wall}

The rational behind the introduction of the clay brick wall located on the 10th floor and resting on top of the limestone masonry is not exactly known. However, it is believed to provide an additional out-of-plane resistance to the inner face of the steel frame. To investigate potential weakness at the base of the steel 
roof, it is decided to exclude the clay brick from the model. The resulting deformation at the base of the steel roof is expected to provide information on the structural contribution of the clay brick wall.

\subsubsection{Steel Roof}

The roof structure consists of mainly two structural parts, the space truss structure and the wood planks covered by copper sheathing. Both the wood and copper sheathing were modeled by four-node composite shell element and in accordance with their actual geometry. The main vertical and horizontal steel angles were treated as continuous beam members. Although the horizontal steel

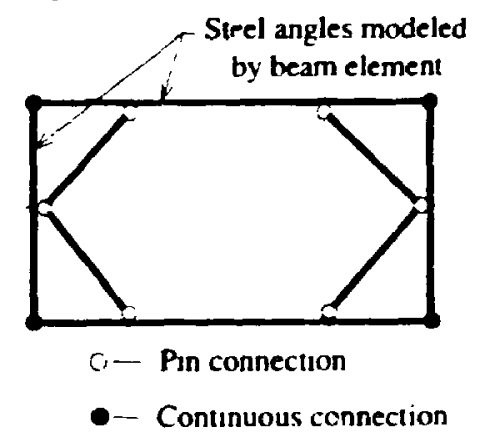

Fig. 4.35 Modeling of steel angles angles on the surface are pin connected, they are usually attached to other steel angles at the middle or quarter points of their spans which makes the modeling difficult (see Fig 4.35). If a steel angle is divided into several truss elements to include the bracing elements, problems can arise due to the rigid body motion since the local stiffness in the orthogonal direction becomes zero. To bypass this problem with minimal efforts, the steel angles were modeled as illustrated in Fig 4.35. Again, the steel tie rods are not included in the model.

\subsubsection{Model Evaluation and Results}

As stated earlier in the modeling of the tower by the frame analysis method, the isolation of the tower from the rest of the building is a sigrificant factor and its consequences need to be assessed. Hence once again it is assumed in the finite 
element modeling that the tower is either free standing or totally constrained at each node that is in contact with the surrounding building. The results of the analysis are summarized in Table 4.11. From the results, it is obvious that the frequencies of the lateral and rotational modes increase by more than $31 \%$. however the expansion mode of the stone wall changed by only $9 \%$. By investigating the mode shapes of the structure, the expansion mode of the wall was found to have large relative movement at the top of the stone masonry, but it decreased rapidly downward. Therefore, constraints below the fifth level have little effect on the expansion mode. Similarly, the expansion modes of the roof structure are practically unaffected by the change in the boundary conditions. By calibrating the fundamental frequency against the corresponding experimental value. the resulting modulus of elasticity for tile free standing tower can be taken as $10 \mathrm{GPa}$. The natural frequencies obtained from the two cases of analysis and the corresponding experimental data are summarized in Table 4.12

Table 4.11 - Frequencies from free and constrained model with same material properties

\begin{tabular}{|c|c|c|c|c|}
\hline \multirow{2}{*}{ Mode number } & \multicolumn{2}{|c|}{ Free } & \multicolumn{2}{c|}{ Constrained } \\
\cline { 2 - 5 } & $\mathrm{Hz}$ & Direction & $\mathrm{Hz}$ & Direction \\
\hline 1 & 1.03 & $\mathrm{~N}-\mathrm{S}$ & 1.77 & $\mathrm{~N}-\mathrm{S}$ \\
\hline 2 & 1.20 & $\mathrm{E}-\mathrm{W}$ & 2.15 & $\mathrm{E}-\mathrm{W}$ \\
\hline 3 & 2.35 & Torsional & 2.77 & Expansion(cap) \\
\hline 4 & 2.77 & Expansion(cap) & 3.09 & Torsional \\
\hline 5 & 3.14 & $\mathrm{~N}-\mathrm{S}$ & 4.13 & Expansion(wall) \\
\hline 6 & 3.79 & Expansion(uall) & 4.14 & Expansion(cap) \\
\hline 7 & 3.83 & E-W & 4.62 & Expansion(cap) \\
\hline 8 & 4.14 & Expansion(cap) & 4.78 & $\mathrm{~N}-\mathrm{S}$ \\
\hline
\end{tabular}


Due to the limited number of recording stations, in particular for the steel roof, the expansion modes were not captured in the experiments. These modes can not be compared with any experimental data.

The natural frequencies computed using the finite element analysis are listed in Table 4.13. The corresponding mode shapes are illustrated from Fig 4.36 to Fig 4.43 .

Table 4.12 - Frequencies from free and constrained models and from experimental data

\begin{tabular}{|c|c|c|c|c|c|c|}
\hline \multirow{2}{*}{ Mode number } & \multicolumn{2}{|c|}{ Free } & \multicolumn{2}{c|}{ Constrained } & \multicolumn{2}{c|}{ Experimental } \\
\cline { 2 - 6 } & $\mathrm{Hz}$ & Direction & $\mathrm{Hz}$ & Direction & $\mathrm{H} z$ & Direction \\
\hline 1 & 1.74 & $\mathrm{~N}-\mathrm{S}$ & 1.77 & $\mathrm{~N}-\mathrm{S}$ & 1.77 & $\mathrm{~N}-\mathrm{S}$ \\
\hline 2 & 2.04 & $\mathrm{E}-\mathrm{W}$ & 2.15 & $\mathrm{E}-\mathrm{W}$ & 2.13 & $\mathrm{E}-\mathrm{W}$ \\
\hline 3 & 2.78 & Expansion(cap) & 2.77 & Expansion(cap) & 2.76 & Torsional \\
\hline 4 & 3.96 & Torsional & 3.09 & Torsional & 2.92 & Torsional \\
\hline 5 & 4.14 & Expansion(cap) & 4.13 & Expansion(wall) & 3.08 & Torsional \\
\hline 6 & 4.62 & Expansion(cap) & 4.14 & Expansion(cap) & & \\
\hline 7 & 5.29 & $\mathrm{~N}-\mathrm{S}$ & 4.62 & Expansion(cap) & & \\
\hline 8 & 6.25 & Expansion(wall) & 4.78 & $\mathrm{~N}-\mathrm{S}$ & & \\
\hline
\end{tabular}

Table 4.13 - Frequencies adopted from finite element analysis

\begin{tabular}{|c|c|c|}
\hline Mode number & \multicolumn{2}{|c|}{ FEM analysis } \\
\cline { 2 - 3 } & $\mathrm{Hz}$ & Direction \\
\hline 1 & 1.77 & $\mathrm{~N}-\mathrm{S}$ \\
\hline 2 & 2.15 & $\mathrm{E}-\mathrm{W}$ \\
\hline 3 & 2.77 & Expansion (cap) \\
\hline 4 & 3.09 & Torsional \\
\hline 5 & 4.13 & Expansion (wall) \\
\hline 6 & 4.14 & Expansion (cap) \\
\hline 7 & 4.62 & Expansion (cap) \\
\hline 8 & 4.78 & $\mathrm{~N}-\mathrm{S}$ \\
\hline
\end{tabular}




\subsubsection{Boundary Conditions and Material Properties}

Two types of boundary conditions were investigated, namely the surrounding building being totally rigid or very flexible. Comparing the results of the two analyses with experimental data, the former is considered to oe a better assumption. Thus, the tower is assumed fully constrained at each grid point that is connected to the surrounding building. The material properties employeri in the finite element analysis are listed in Table 4.14. The modulus of elasticity for the stone masonry was varied until the first natural frequency became equal to the corresponding measured value. The other properties are defined according to reported values in literature.

Table 4.14 - Material properties used for finite element analysis

\begin{tabular}{|c|c|c|c|}
\hline Material & $\begin{array}{c}\text { Young Modulus } \\
\text { GPa }\end{array}$ & $\begin{array}{c}\text { Mass Density } \\
\tilde{K} / \mathrm{m}^{2}\end{array}$ & Poisson's Ratio \\
\hline Lime stone masonry & 3.5 & 2716 & 0.2 \\
\hline Sand stone masonry & 3.5 & 2600 & 0.2 \\
\hline Steel & 200 & 7800 & 0.3 \\
\hline Copper & 110 & 8900 & 0.3 \\
\hline Wood & 7 & 450 & 0.3 \\
\hline
\end{tabular}

\subsection{Discussion}

Although the first natural frequency from each of the three models was calibrated against the measured data. the results among the three different 
approaches differ not only in terms of the eigenvalues of higher modes, but also in the eigenvectors

\section{Table 4.15 - Frequencies and mode shapes obtained from different approaches}

\begin{tabular}{|c|c|c|c|c|c|c|c|c|}
\hline \multirow{2}{*}{ Mode number } & $\begin{array}{c}\text { Simplified method } \\
\text { E=6 GPa }\end{array}$ & \multicolumn{2}{c|}{$\begin{array}{c}\text { Frame analysis } \\
\text { E=5 GPa }\end{array}$} & \multicolumn{2}{c|}{$\begin{array}{c}\text { FEM aralysis } \\
\text { E=3.5 GPa }\end{array}$} & \multicolumn{2}{c|}{ Experimental } \\
\cline { 2 - 9 } & $\mathrm{Hz}$ & Direction & $\mathrm{Hz}$ & Direction & $\mathrm{Hz}$ & Direction & Hz & Direction \\
\hline 1 & 1.76 & $\mathrm{~N}-\mathrm{S}$ & 1.74 & $\mathrm{~N}-\mathrm{S}$ & 1.77 & $\mathrm{~N}-\mathrm{S}$ & 1.77 & $\mathrm{~N}-\mathrm{S}$ \\
\hline 2 & 2.11 & $\mathrm{E}-\mathrm{W}$ & 1.84 & $\mathrm{E}-\mathrm{W}$ & 2.15 & E-W & 2.13 & E-W \\
\hline 3 & 3.13 & Torsional & 2.29 & $\mathrm{~N}-\mathrm{S}$ & 2.77 & Expansion(cap) & 2.76 & Torsional \\
\hline 4 & & & 3.00 & Torsional & 3.09 & Torsional & 2.92 & Torsional \\
\hline 5 & & & 3.70 & E-W & 4.13 & Expansion(wall) & 3.08 & Torsional \\
\hline 6 & & & 6.41 & $\mathrm{~N}-\mathrm{S}$ & 4.14 & Expansion(cap) & & \\
\hline 7 & & & 7.37 & $\mathrm{~N}-\mathrm{S}$ & 4.62 & Expansion(cap) & & \\
\hline 8 & & 8.14 & E-W & 4.78 & N-S & & \\
\hline
\end{tabular}

For the simplified method, although effort has been made to include both shear and bending resistance, it is found that the modulins of elasticity is almost double that obtained from the FEM model. This is mostly due to the free standing assumption and partly due to the gross geometric assumptions. Further, due to the complexity of the geometric layout and the surrounding structure, it is difficult to determine the order of the eigenvectors, i.e. lateral or rotational, especially when determining high dynamic modes.

The results obtained using frame analysis show that the second natural frequency differs by $11 \%$ from its corresponding experimental value. The value for the fourth mode, which is the first rotational mode, corresponds to the fourth experimental dynamic mode. The third mode obtained from the frame analysis is double bending in the north-south direction, which does not correspond to any of the experimental modes. As stated earlier in the study of the effects of openings in Section 4.4.3.2, it was found that the fourth mode in the FEM model becomes the 
third mode in the frame model, partly due to the effect of the membrane elements which neglects the out-of-plare stiffness, thus reducing the stiffness in the respective direction. For the same reasons as pointed out in Section 4.4.3.2, the result of the third : .ode from ETABS is deemed to have shifted from the higher mode. Also due to the existence of rigid diaphragms in the frame analysis, which constrain the relative movement of walls at each diaphragm level, there is no expansion mode shape for any structural component, as was found in the FEM model. This mode can be very important in inducing the out-of-plane failure, as mentioned earlier in the literature review, if resonance occurs at that mode. Hence, the mode shapes from ETABS can not accurately represent the dynamic characteristics of a structure made up of thick stone masonry with large openings and flexible diaphragm.

The results from the finite element model are closer to the experimental data. When calibrated against the fundamental mode shape obtained from the ambient vibration test, the second mode obtained from FEM shows only 4\% difference from the test value. The third mode of the FEM model is the expansion mode of the steel roof which was not captured by the experiment due to the limited number of sensors, but a similar behavior was captured experimentally at the base of the roof at a frequency of $2.76 \mathrm{~Hz}$. The fourth mode of the FEM model is a torsional mode and corresponds to the fifth mode of the experimental data. The fifth mode of the FEM model shows the expansion mode of the structural components.

In summary, it is obvious that sophisticated finite element models can provide a better representation of the dynamic properties of the load bearing stone masonry structures with openings and flexible diaphragms. Further, by examining the values established for the modulus of elasticity from the calibration procedure. 
it is obvious that without the dynamic measurements, not even the finite element method one would be able to produce the proper dynamic characteristics of such structures. This implies that before any analytical model can be used reliably, at least its material properties i.e. dynamic properties, should first be calibrated against measured values. 


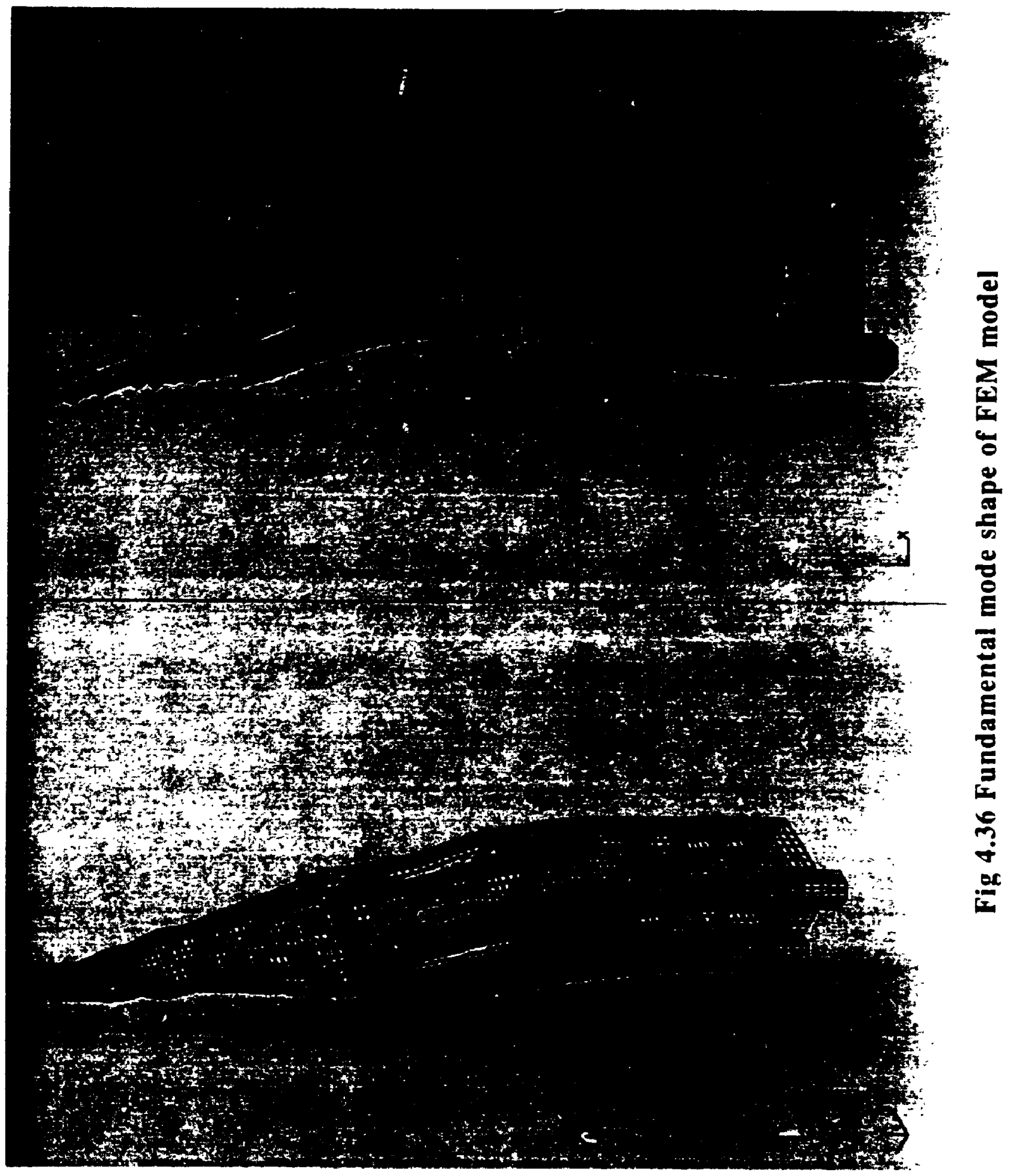




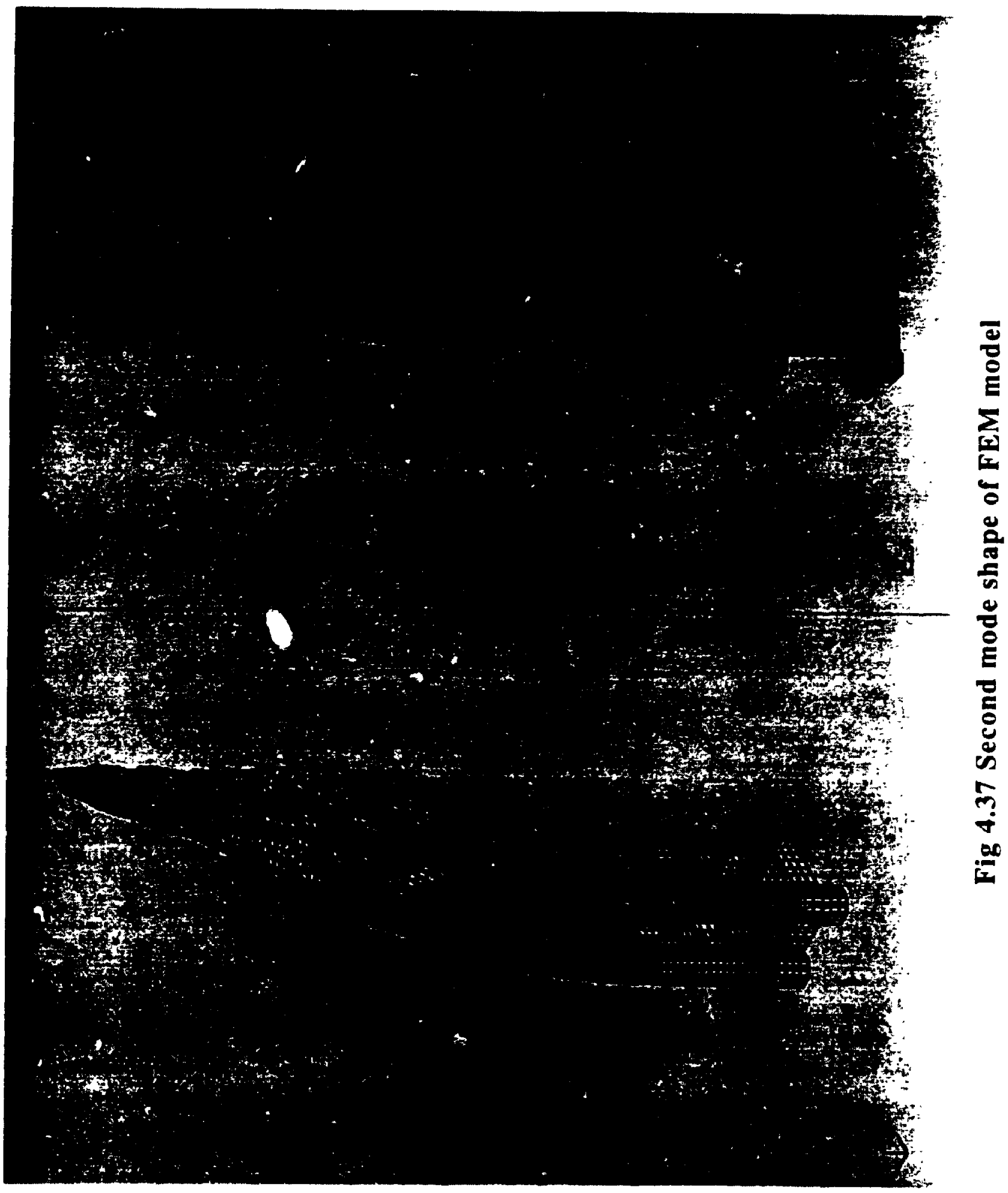




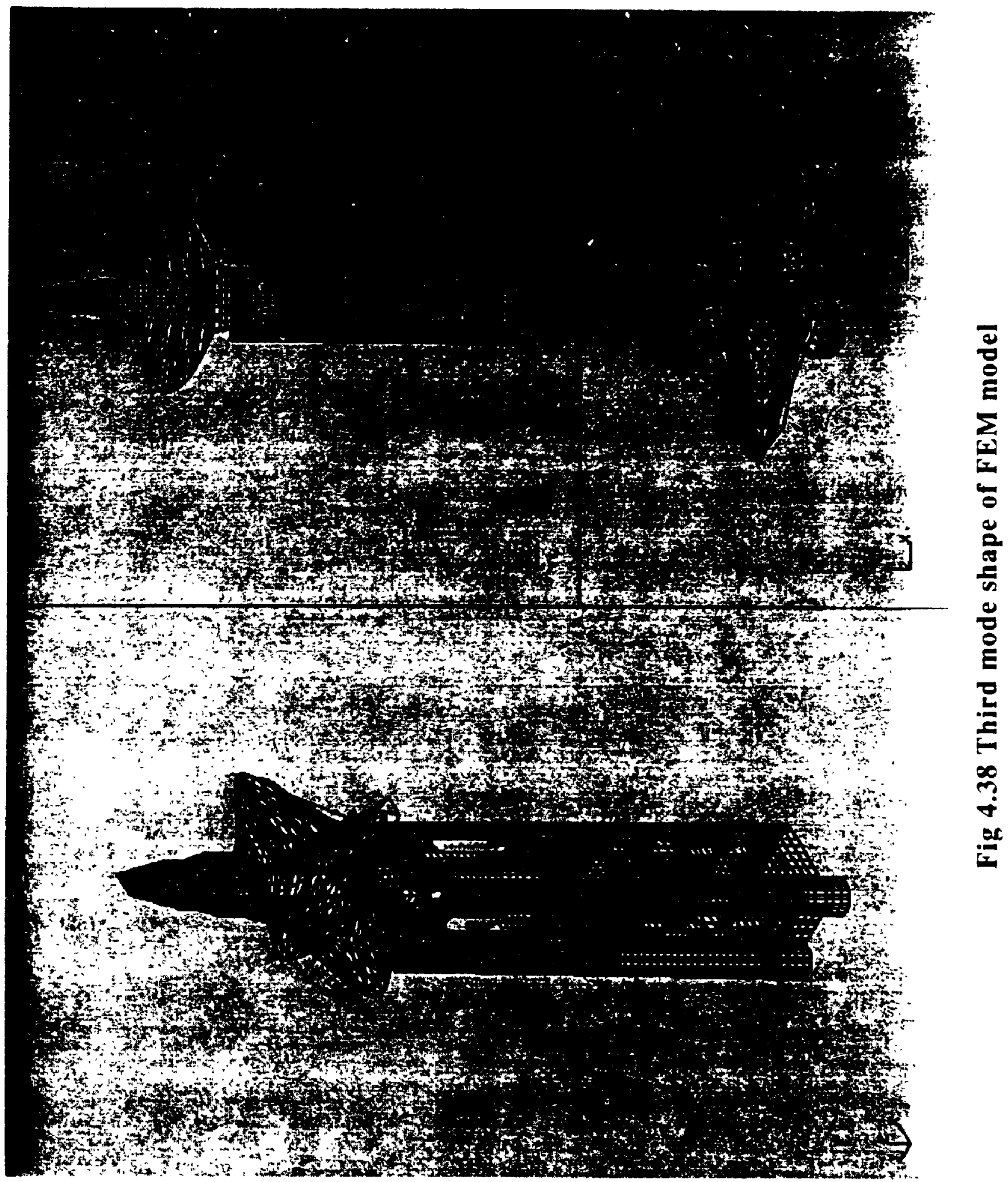




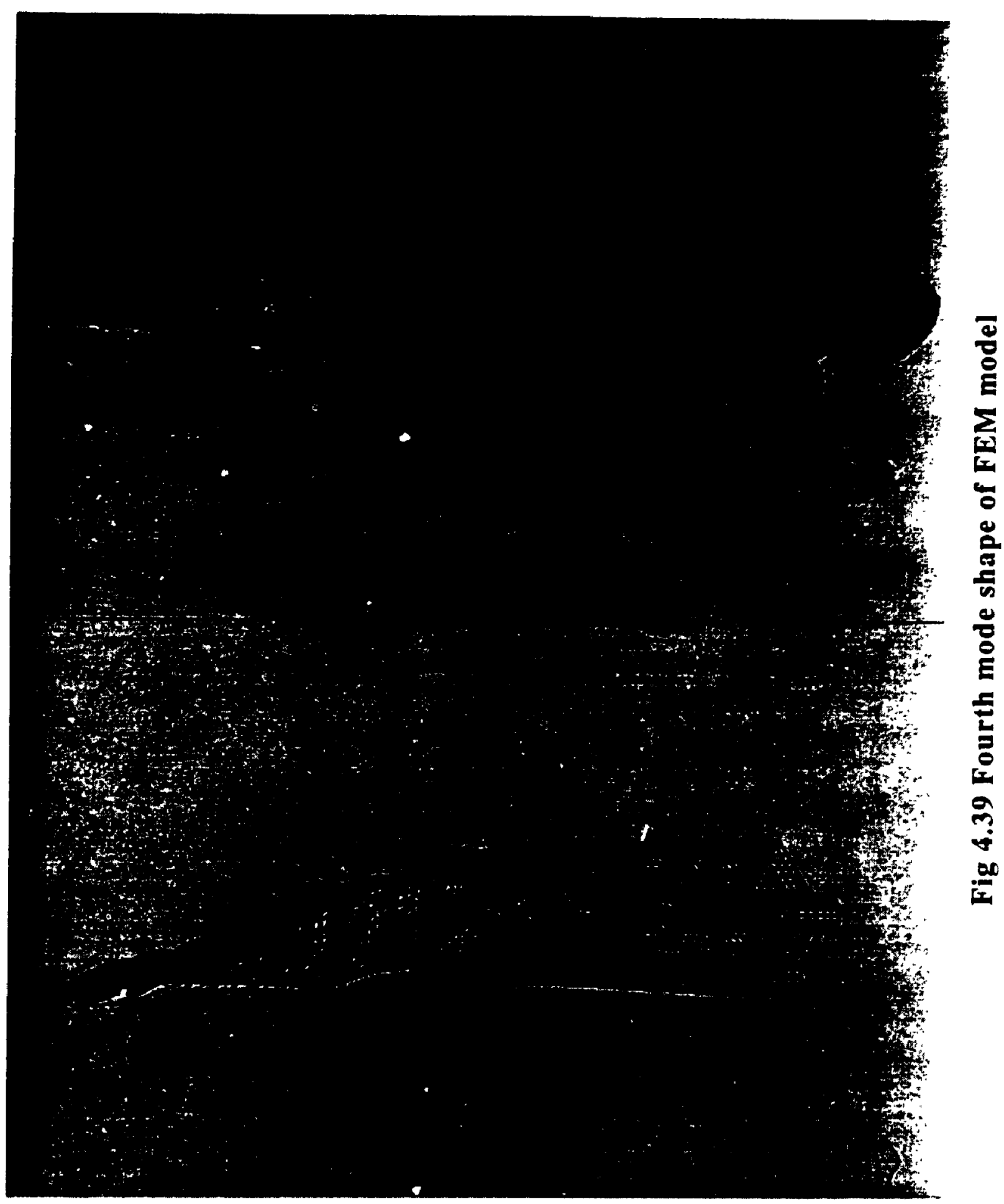




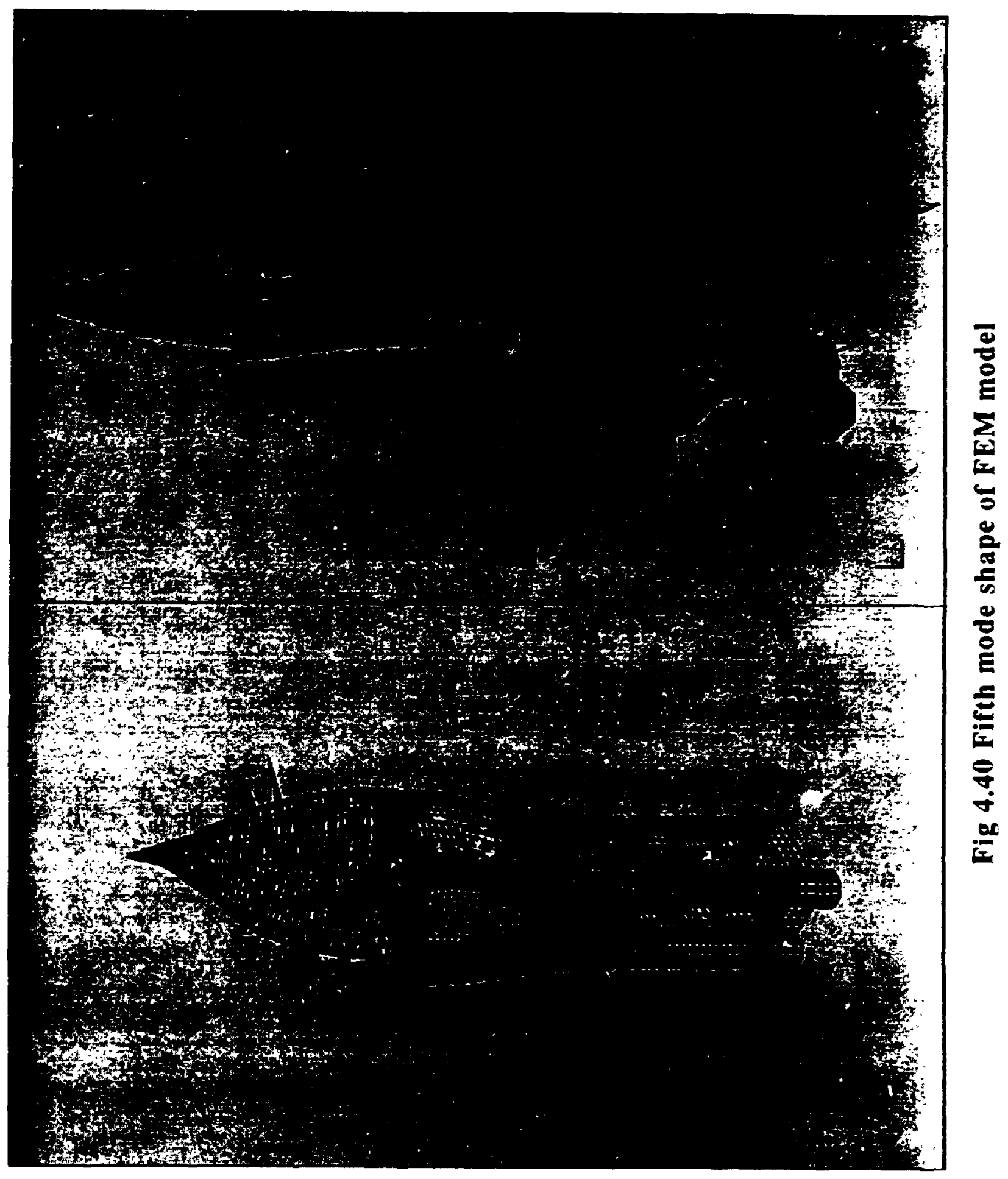




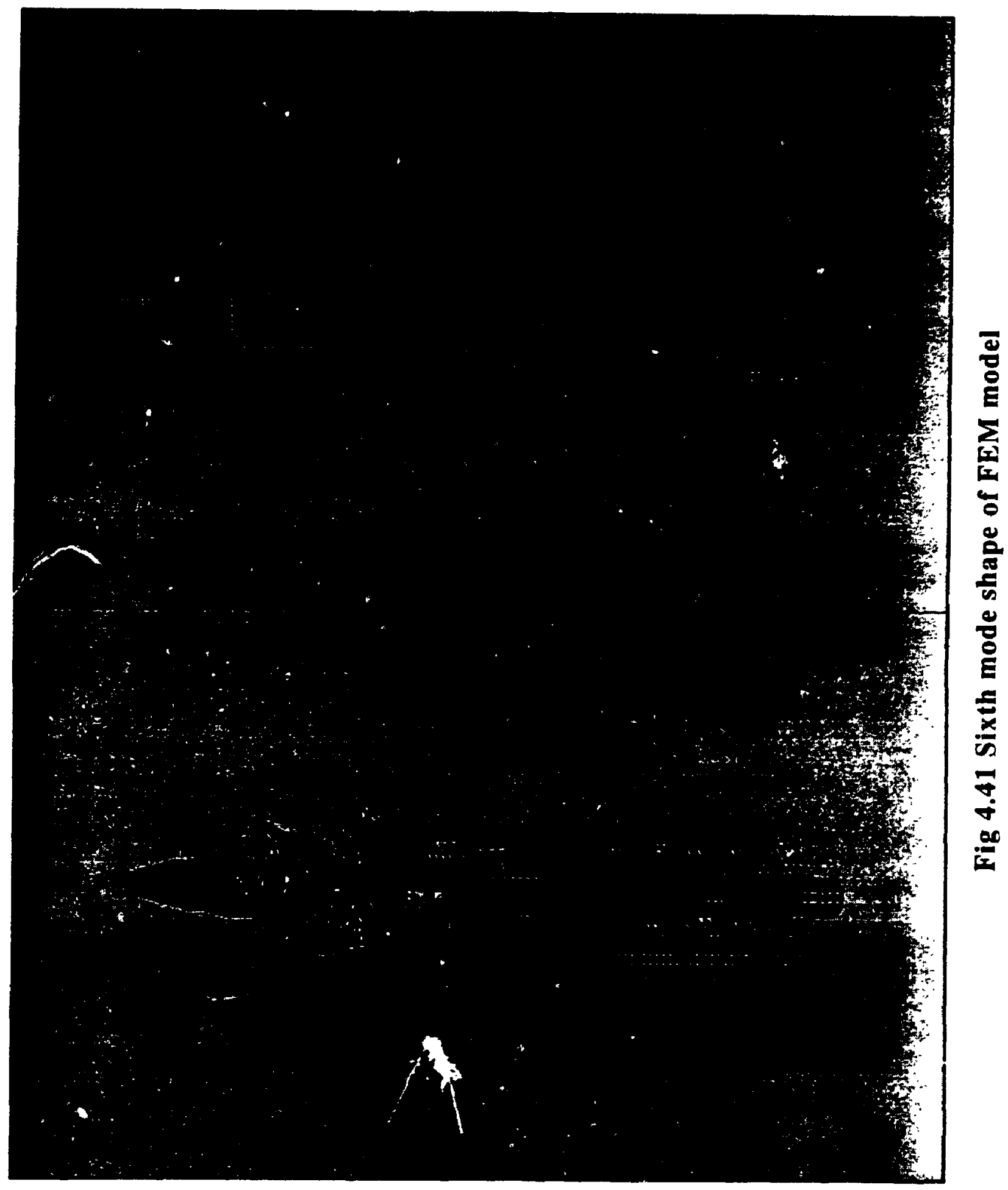




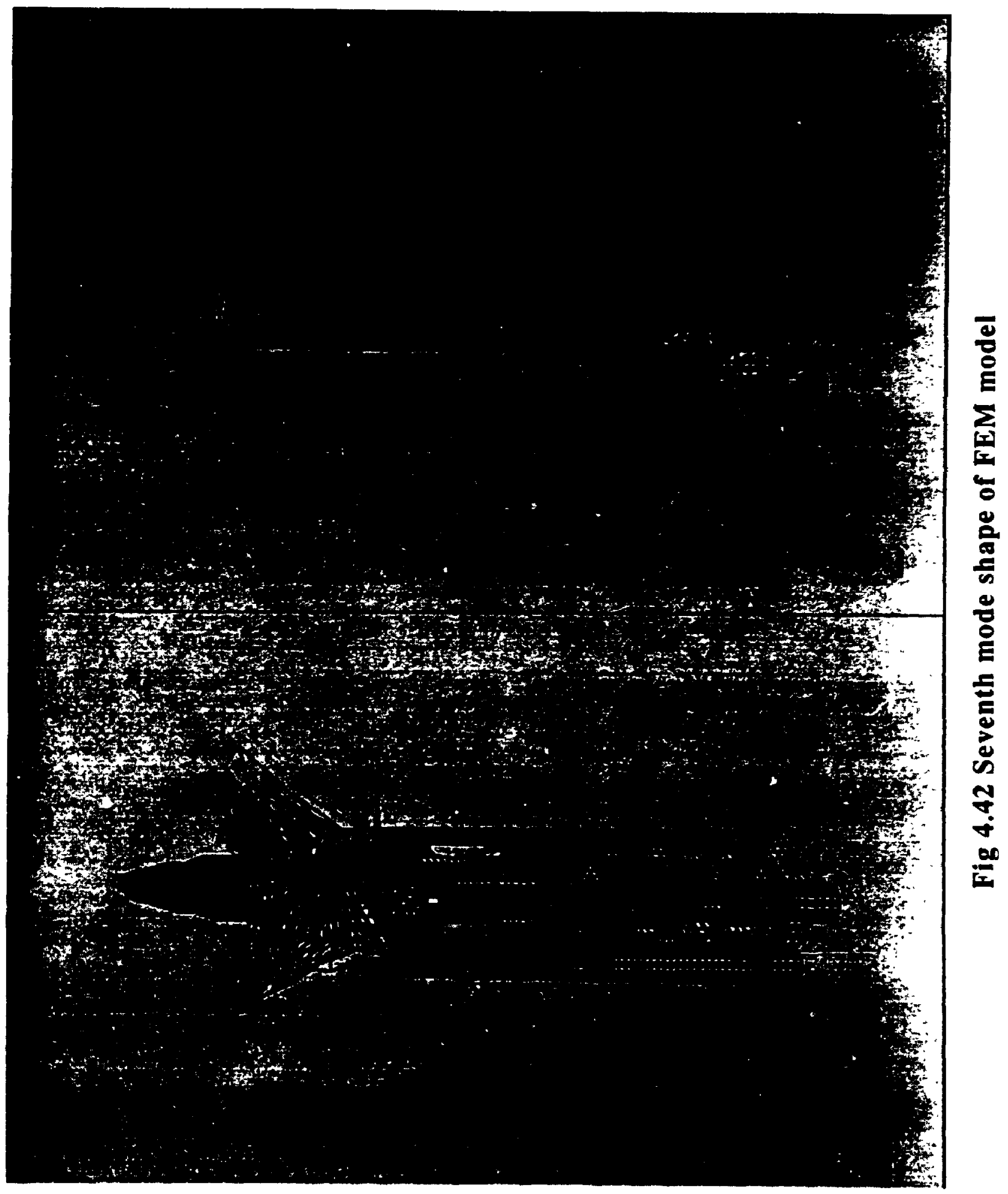




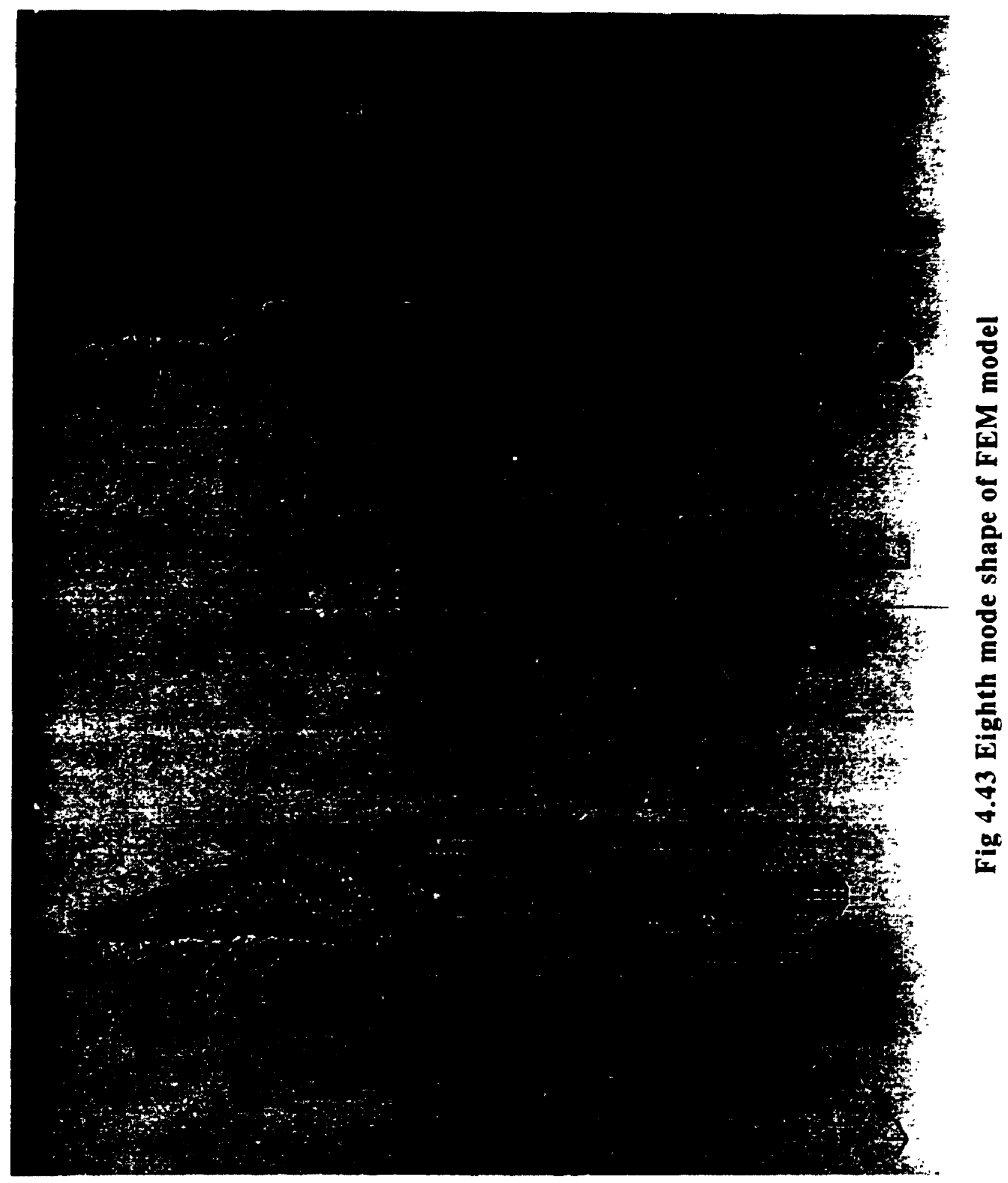




\section{CHAPTER 5}

\section{SEISMIC RESPONSE OF THE TOWER}

\subsection{General}

In the previous chapter, we have presented a detailed description of the different mathematical models used to represent the dynamic characteristics of the unreinforced stone masonry tower. The objective of this chapter is to evaluate the seismic response of the tower by using the simplified model, the frame model and the finite element model. Towards this end, two approaches were considered: an equivalent static analysis and a dynamic analysis. The former is carried out by the method provided in the NBCC 1990 and the latter by time history analysis using artificially generated ground motions. Given the limitations of the simplified model, its use will be limited tu the equivalent static analysis. This chapter describes first the computation of the seismic forces for the equivalent lateral seismic analysis and the inertia forces introduced by the ground motion in the time history analysis. The response obtained from the three mathematical models is then presented and lateral displacement. base shear. horizontal acceleration ard stresses will be compared.

\subsection{Computation of Seismic Forces}

In principle, the ground motion caused by earthquakes will generate inertia forces in the same direction for symmetrical structures and in more than one direction for the asymmetric ones. Also, depending on frequency content and duration of the ground motion and the natural frequencies of the structure. the 
inertia forces generally are amplified as the motion is transferred upward along the structure. Thus the computation of the seismic forces requires knowledge of the earthquake reccrd, the dynamic properties of the structure and the type of medium between the foundation of the structure and the bedrock. Since the quantification of all these parameters is not a simple task, the equivalent static method has been used as an alternative method to simplify the computation procedure for the seismic forces. Since the National Building Code of Canada (1990) has adopted the equivalent static method, we shall in this chapter address its applicability by comparing the results with those of the dynamic analysis.

\subsubsection{Equivalent Lateral Seismic Forces}

According to the NBCC 1990, the minimum lateral seismic force representing a return period of 500 years can be computed as (Clause 4.1.9.1(4))

$$
V=0.6 V_{e} / R
$$

in which $V_{e}$ is the equivalent lateral seismic force representing the elastic response, and $R$ is the force modification factor. For unreinforced masonry, the suggested value for $R$ is 1.0. $V_{e}$ is defined by Clause $4.1 .9 .1(5)$

$$
V_{e}=v \cdot S \cdot I \cdot F \cdot W
$$

where v, S, I, F and $W$ are zonal velocity ratio, seismic response factor, seismic importance factor, foundation factor and weight of the structure, respectively. The values of those parameters for the tower are given in Table 5.1.

The tower is located in moderate to low seismic zone and according to the Supplementary of NBCC 1990, the seismic regionalization defined for the city reveal a peak horizontal velocity of $0.098 \mathrm{~m} / \mathrm{s}$ and a peak horizontal acceleration of $0.2 \mathrm{~g}$ for a probability of annual exceedance equal to 0.0021 . This is equivalent to 
the probability of 10 percent in 50 years. The corresponding zonal velocity ratio is therefore found equal to 0.1 .

The fundamental period obtained from the experimental measurements is equal to $0.565 \mathrm{~s}$. The corresponding seismic response factor is then computed as 2.0 .

From the achives, it was found that the foundation walls bear directly on bedrock. thus according to the NBCC 1990, a value of 1.0 is given to the foundation fastor.

\section{Table 5.1 Values of parameters used to calculate $V_{\text {e }}$}

\begin{tabular}{|c|c|}
\hline Parameter & Value \\
\hline v & 0.1 \\
\hline I & 1 \\
\hline S & 2 \\
\hline F & 1 \\
\hline W & $90.4 \mathrm{MN}$ \\
\hline
\end{tabular}

The total base shear computed using Equation 5.1 is approximately $10.9 \mathrm{MN}$. Since the fundamental period $T$ is less than $0.7 \mathrm{~s}$. Th, NBCC 1990 states that there is no need to apply part of the base shear as a concentrated force at the top of the structure. Thus, the base shear is distributed along the height of the building in accordance with Clause 4.1.9.1(13)

$$
F_{i}=\frac{v W_{i} h_{i}}{\sum_{i=1}^{n} W_{i} h_{i}}
$$


where $n$ is the total number of floors, and $F_{x}$ represents the lateral seismic force at floor $x$. The resulting distributed lateral forces and the corresponding weights are listed in Table 5.2.

\section{Table 5.2 Lateral inertia force along the height and the associated weights}

\begin{tabular}{|c|c|c|}
\hline $\begin{array}{l}\text { Height } \\
\text { (m) }\end{array}$ & $\begin{array}{c}\text { Weight } \\
(\mathrm{kN})\end{array}$ & $\begin{array}{c}\text { Force } \\
(\mathrm{kN})\end{array}$ \\
\hline \multicolumn{3}{|l|}{81.55} \\
\hline 78.5 & 16.06 & 7.13 \\
\hline 75.45 & 20.85 & 8.90 \\
\hline 73.77 & 25.24 & 10.44 \\
\hline 70.76 & 28.83 & 11.55 \\
\hline 67.51 & 40.10 & 15.37 \\
\hline 64.46 & 41.00 & 15.00 \\
\hline 61.36 & 47.88 & 16.70 \\
\hline 58.21 & 59.06 & 19.58 \\
\hline 55.06 & 52.57 & 16.51 \\
\hline 51.89 & 420.78 & 124.76 \\
\hline 48.95 & 1607.00 & 449.24 \\
\hline 46.57 & 3805.00 & 1007.58 \\
\hline 40.79 & 7458.10 & 1806.22 \\
\hline 31.19 & 10946.10 & 2184.25 \\
\hline 26.465 & 6275.50 & 1003.04 \\
\hline 22.4 & 10242.80 & 1387.55 \\
\hline 17.625 & 9412.20 & 1044.37 \\
\hline 11.785 & 10250.30 & 835.72 \\
\hline 6.705 & 9761.90 & 500.38 \\
\hline 2.874 & 11311.70 & 300.39 \\
\hline 0 & 8618.50 & 68.67 \\
\hline
\end{tabular}

\subsubsection{Inertia Forces Introduced by the Ground Motion}

In order to perform dynamic analysis on the stone masonry tower, time histories that are representative of the site corresponding to appropriate annual probability of exceedance are needed. Since the generation of these records is 
beyond the scope of this study, three different time histories with annual exceedance probabilities of $0.005,0.002$ and 0.0005 were obtained from Chidiac et. al.(1993). A high frequency content and a low frequency content records were generated for each of the annual exceedance probabilities. Some of the pertinent characteristics of those ground motions are listed in Table 5.3. Only the time history ground motion records with their respective Fourier response spectra for high and low frequency content corresponding to a 500 year return period are shown in Figures 5.1 and 5.2. The different time history ground motions will be applied to both the frame model and the finite element model in the North-South and the East-West directions independently. It is further assumed that the ground motion will be transmitted to the building foundation without modificarion.

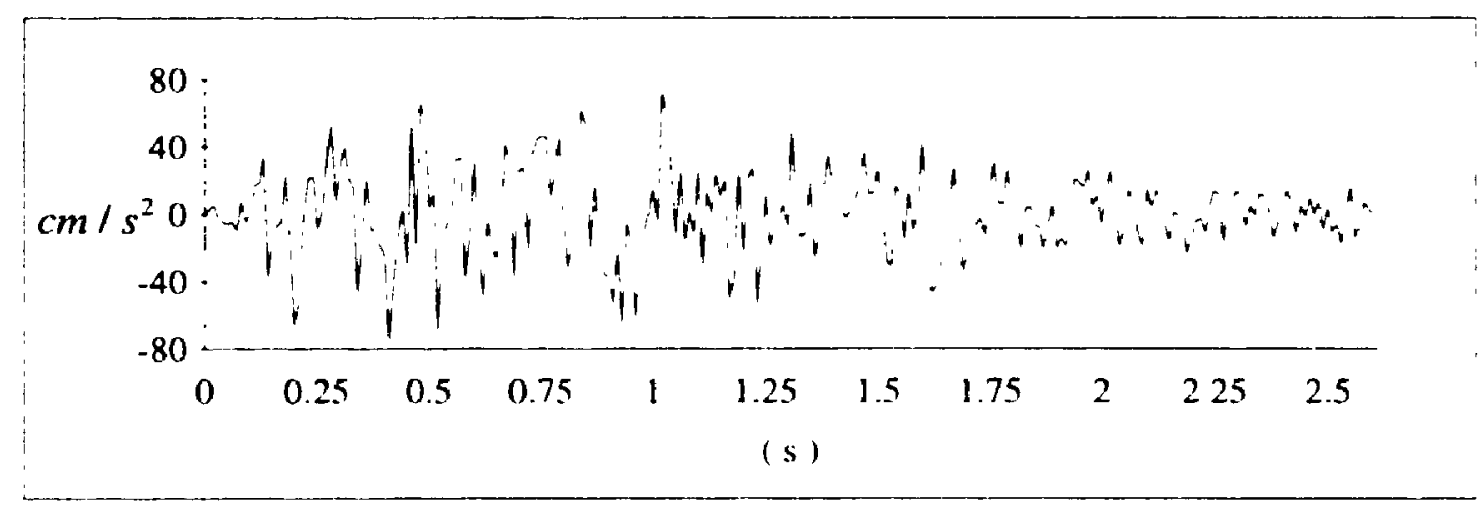

(a) High frequency content

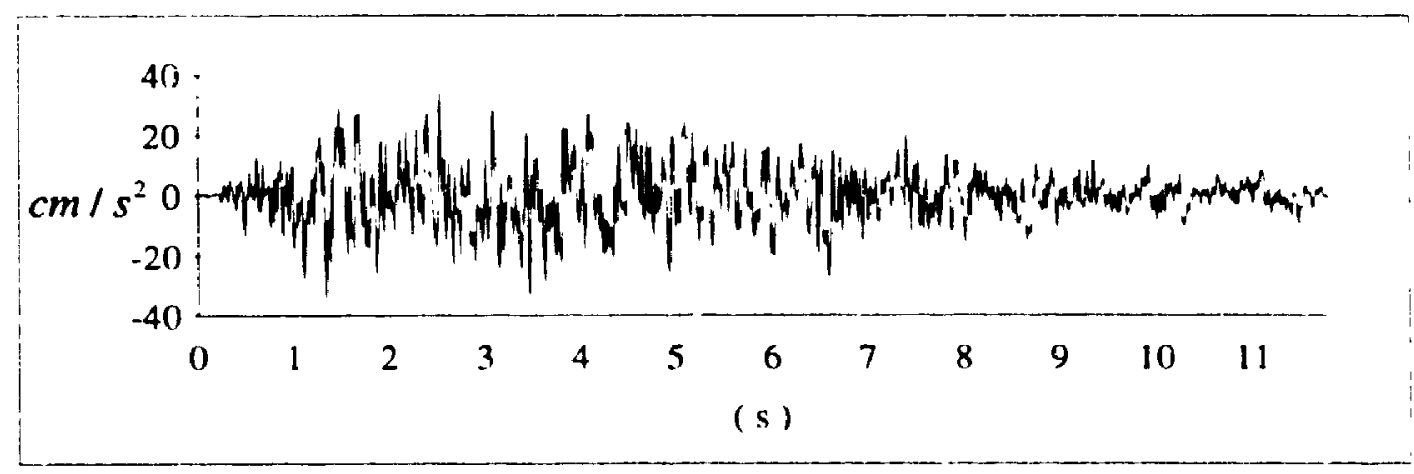

(b) Low frequency content

Fig. 5.1 Generated ground motions representing 500 year return period (Chidiac et. al. 1993) 
Table 5.3 Pertinent characteristics of the ground motions

\begin{tabular}{|c|c|c|c|c|c|c|}
\hline & \multicolumn{3}{|c|}{ Low Frequency Content } & \multicolumn{3}{c|}{ High Frequency Content } \\
\hline & $2000 \mathrm{y}$ & $500 \mathrm{y}$ & $200 \mathrm{y}$ & $2000 \mathrm{y}$ & $500 \mathrm{y}$ & $200 \mathrm{y}$ \\
\hline Duration (s) & 11.44 & 11.76 & 15.60 & 2.71 & 2.56 & 4.79 \\
\hline Max. Acceleration (g) & 0.09 & 0.03 & 0.01 & 0.20 & 0.08 & 0.02 \\
\hline
\end{tabular}

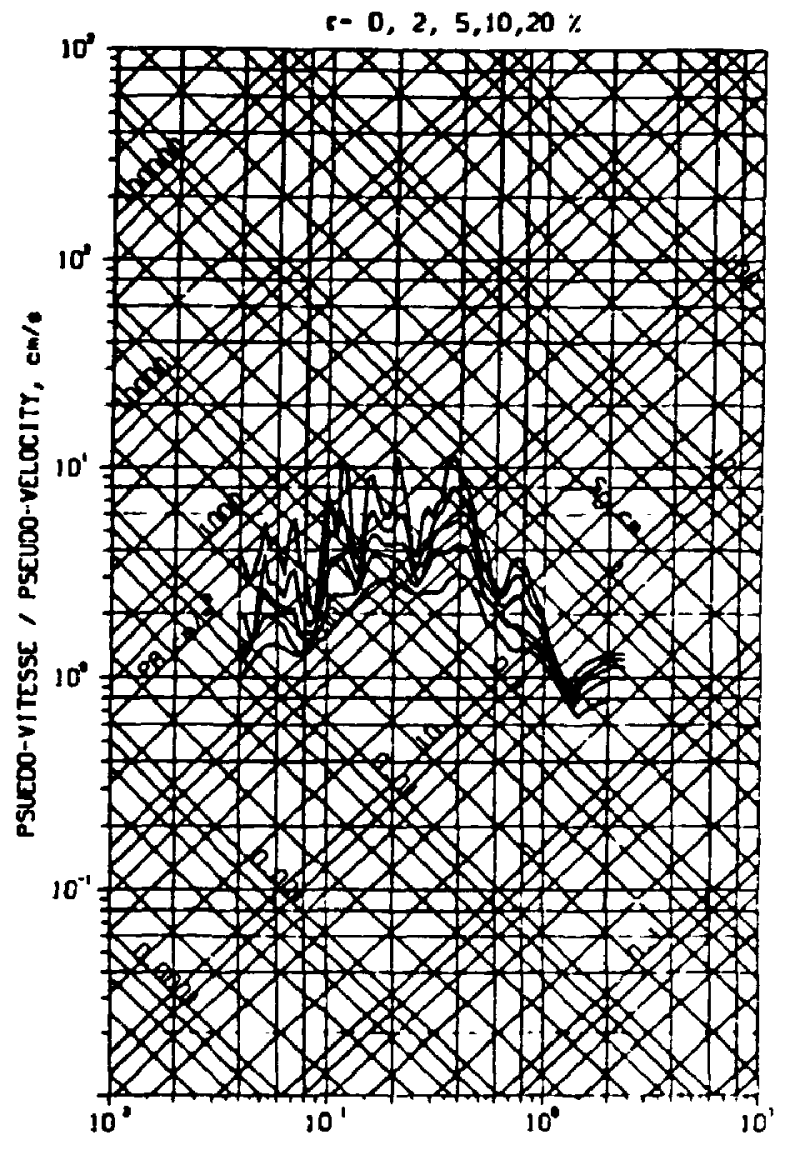

(a) High frequency content

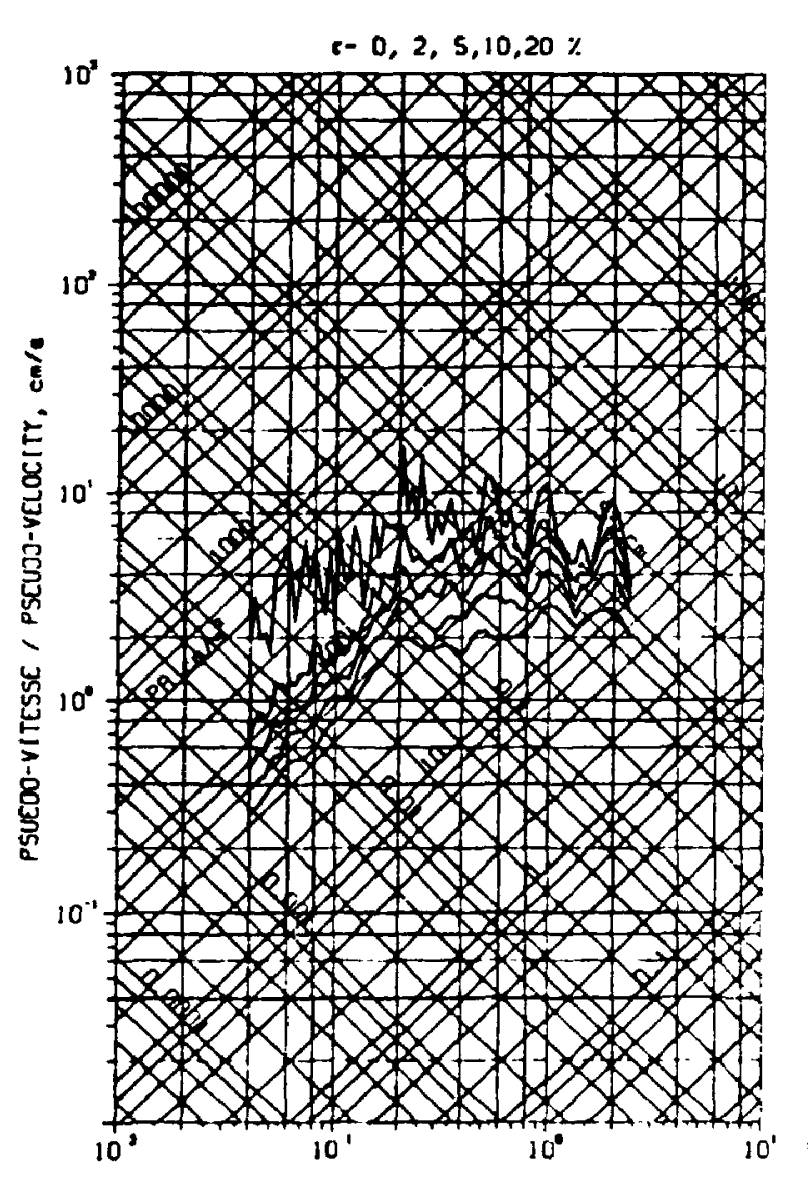

( s)

Fig. 5.2 Response spectra for $\mathbf{5 0 0}$ year return period seismic ground motions (Chidiac et. al. 1993)

The frequency content of t'ie ground motion was computed using Fast Fourier Transform. The resulting auto-spectra for the 200, 500 and 2000 year return period and for both high and low frequency content are shown in Fig. 5.3 and Fig. 5.4. In the same figures, the natural frequency of the tower is indicated with a solid line for the finite element model and a dotted line for the frame model. 


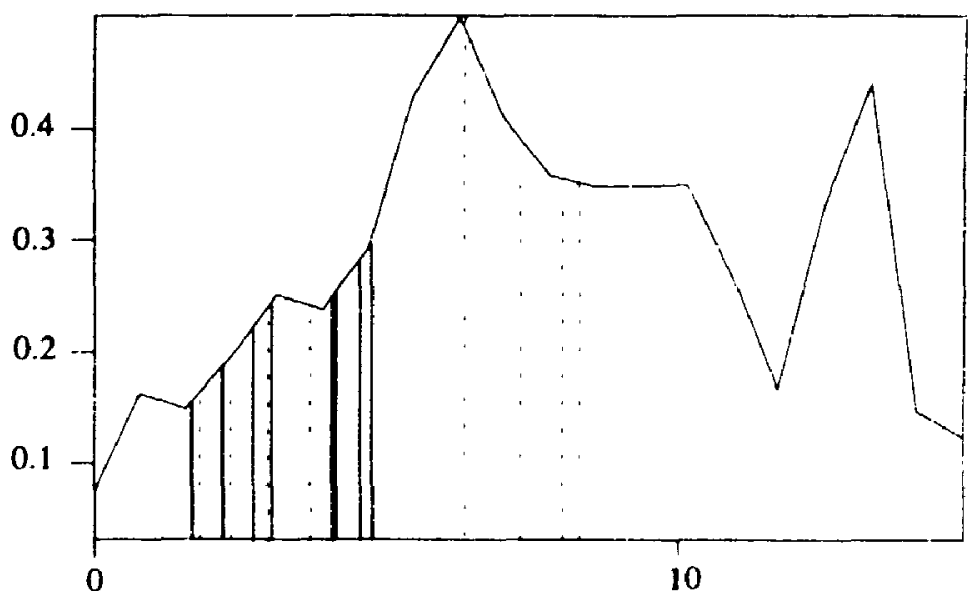

$[\mathrm{Hz}]$

(a)

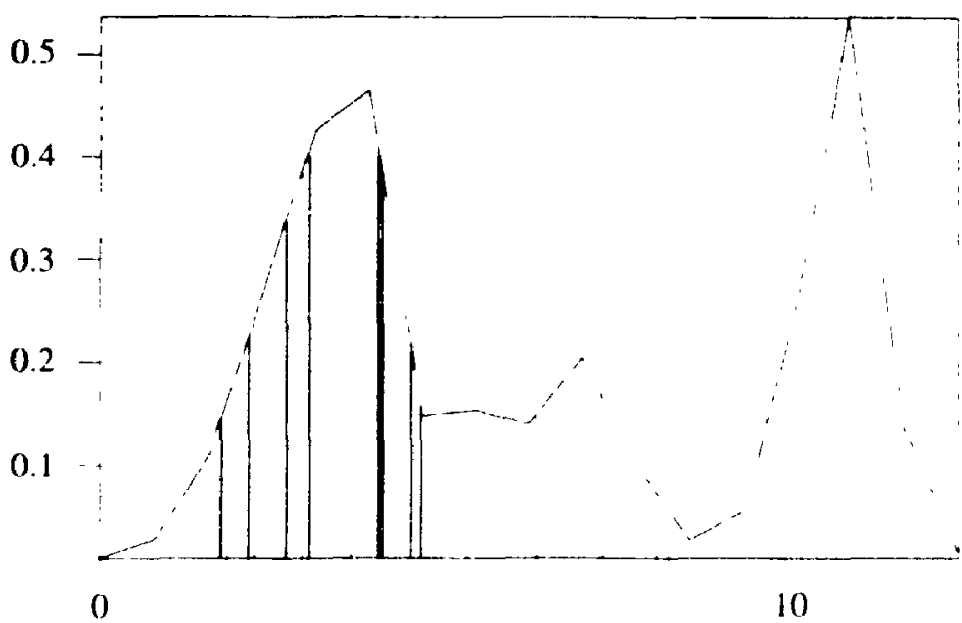

$[\mathrm{Hz}]$

(b)

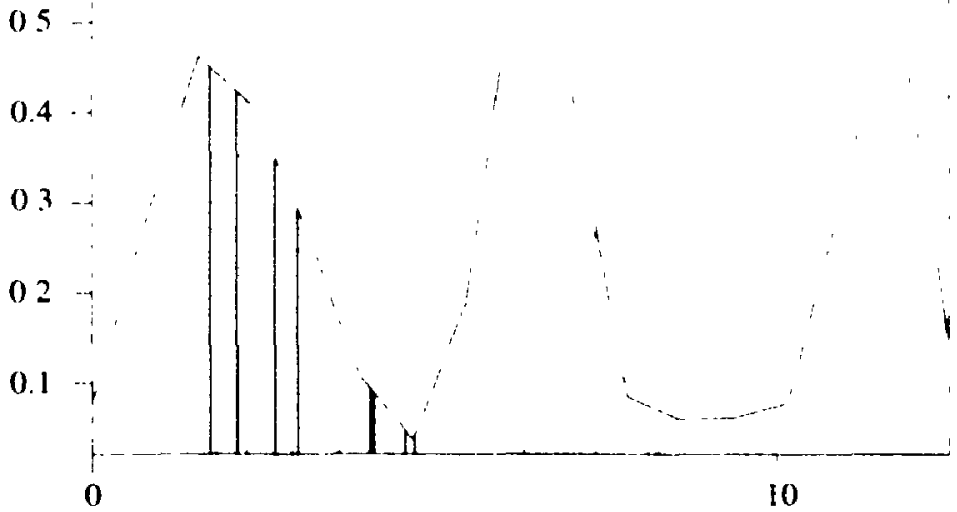

$[\mathrm{Hz}]$

(c)

Fig. 5.3 Fourier spectrum of the ground motion containing high frequency
(a) 200 return period
(b) 500 return period
(c) 2000 return period 


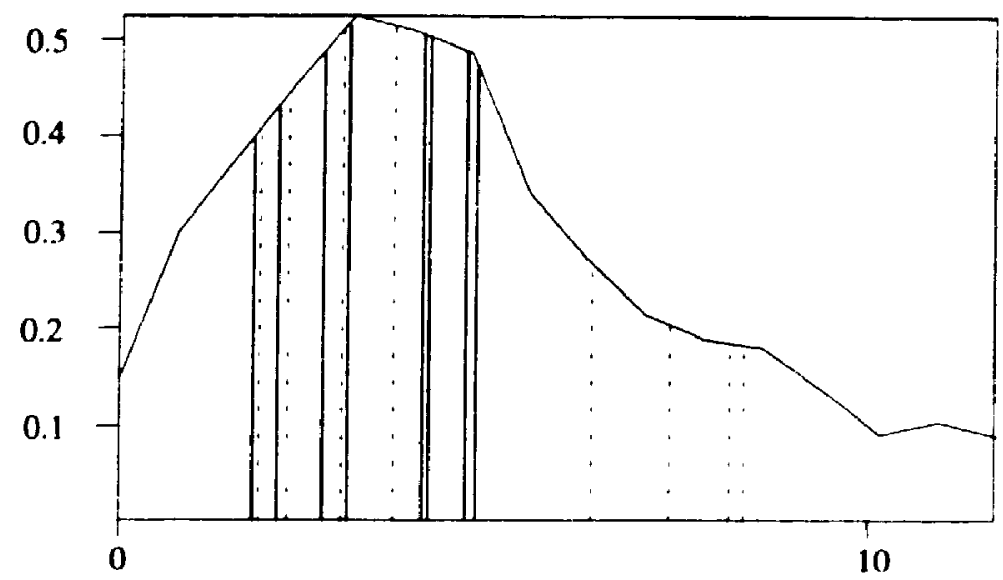

[Hz]

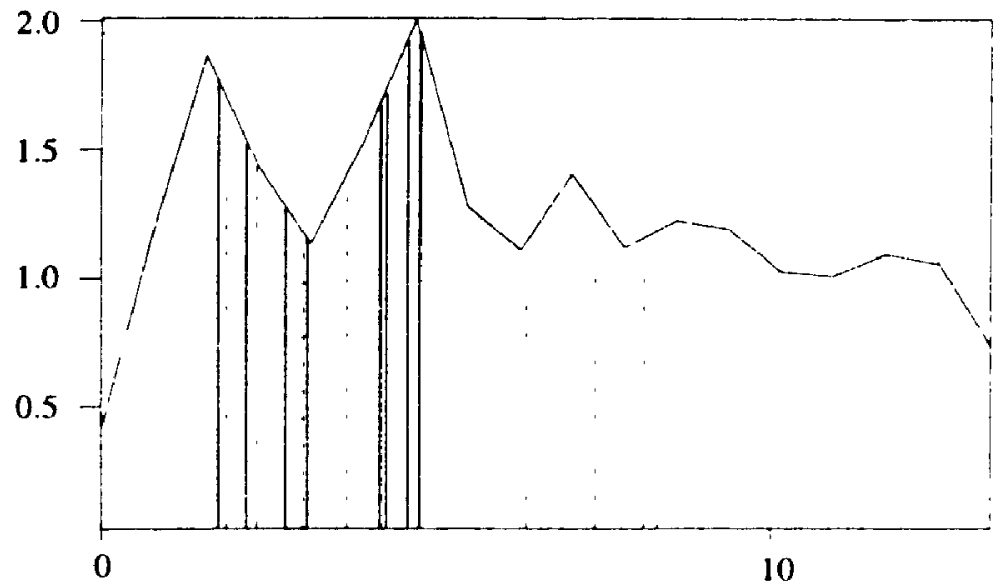

$[\mathrm{Hz}]$

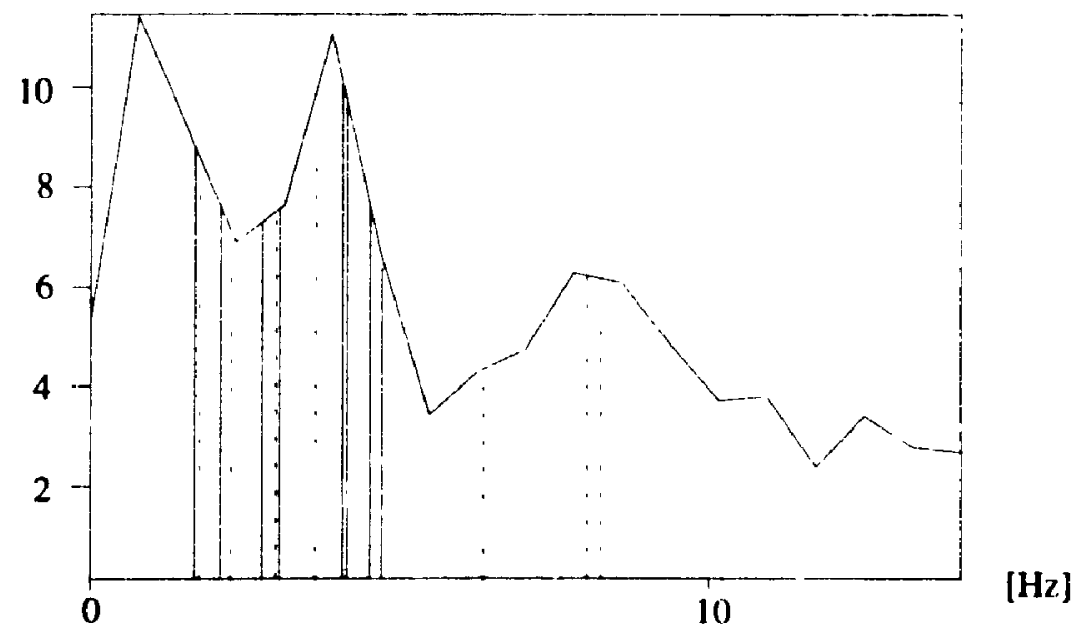

Fig. 5.4 Fourier spectrum of the ground motion containing low frequency (a) 200 return period (b) 500 return period (c) 2000 return period 


\subsection{Response of Analytical Models}

\subsubsection{Simplified Model}

The simplified model presented in Chapter 4 is subjected to the equivalent lateral static forces generated according to the NBCC 1990. Procedures employed in the calculation of the lateral displacement and stress field and the results are presented rext.

\subsubsection{Crlculation of Lateral Displacement}

The lateral displacements along the height are computed by subjectıng the simplified model to the equivalent static load presented in the previous section. The resulting displacements at four locations are listed Table 5.4.

Table 5.4 Lateral displacements of the simplified model due to equivalent static load

\begin{tabular}{|c|c|c|c|}
\hline $\begin{array}{c}\text { Elevation } \\
(\mathrm{m})\end{array}$ & Material & $\begin{array}{c}\text { East - West } \\
\delta(\mathrm{mm})\end{array}$ & $\begin{array}{c}\text { North-South } \\
\delta(\mathrm{mm})\end{array}$ \\
\hline 6.705 & Masonry & 0.06 & 0.22 \\
\hline 26.465 & Masonry & 3.6 & 7.60 \\
\hline 48.95 & Masonry & 24.9 & 40.43 \\
\hline 51.89 & Brick wall & 30.3 & 49.20 \\
\hline
\end{tabular}

\subsubsection{Calculation of Compressive and Tensile Stresses}

Assuming that the tower will deform similar to a column. then the longitudinal normal stress, $\sigma$, at any section along the tower can be computed from

$$
\sigma=\frac{P}{A} \pm \frac{M}{S_{b}}
$$


where $P$ and $M$ are the axial (dead) load and bending moment acting on the section respectively, $A$ is the net cross-section area of the tower and $S_{b}$ is its section motulus. Here the bending moment does not include the P-Delta effect. Using Equation 5.4, the compressive stresses and tensile stresses at various floor levels are listed in Tables 5.5 and 5.6, respectively, along with other pertinent information.

\section{Table 5.5 Maximum compressive stresses obtained from simplified method}

\begin{tabular}{|c|c|c|c|c|c|c|c|}
\hline \multicolumn{8}{|c|}{ North-South Direction } \\
\hline \multirow[t]{2}{*}{ Floor } & \multicolumn{2}{|c|}{ Elevation } & \multirow{2}{*}{$\begin{array}{c}P \\
(k N)\end{array}$} & \multirow{2}{*}{$\begin{array}{c}A \\
\left(m^{2}\right)\end{array}$} & \multirow{2}{*}{$\begin{array}{c}\mathbf{M} \\
(\mathrm{kN}-\mathrm{m})\end{array}$} & \multirow{2}{*}{$\begin{array}{c}S \\
\left(m^{3}\right)\end{array}$} & \multirow{2}{*}{$\begin{array}{c}\sigma \\
(\mathrm{MPa})\end{array}$} \\
\hline & Bottom & Top & & & & & \\
\hline 1 & 0 & 2.874 & $9.04 \mathrm{E}+(14$ & $1.13 \mathrm{E}+02$ & $3.45 \mathrm{E}+05$ & $3.00 \mathrm{E}+02$ & 1.95 \\
\hline 2 & 2.874 & 6.705 & $8.18 E+04$ & $1.11 \mathrm{E}+02$ & $3.14 \mathrm{E}+05$ & $2.08 \mathrm{E}+02$ & 2.25 \\
\hline 3 & 6.705 & 11.785 & $7.05 \mathrm{E}+04$ & $7.27 \mathrm{E}+01$ & $2.44 E+05$ & $1.68 \mathrm{E}+02$ & 2.42 \\
\hline 4 & 11.785 & 17.625 & $6.07 \mathrm{E}+04$ & $6.59 \mathrm{E}+01$ & $1.94 \mathrm{E}+05$ & $1.47 \mathrm{E}+02$ & 2.24 \\
\hline 5 & 17.625 & 22.4 & $5.05 \mathrm{E}+04$ & $7.41 \mathrm{E}+01$ & $1.40 \mathrm{E}+05$ & $1.31 E+02$ & 1.75 \\
\hline 6 & 22.4 & 26.465 & $4.11 \mathrm{E}+04$ & $9.47 \mathrm{E}+01$ & $1.02 \mathrm{E}+05$ & $1.41 E+02$ & 1.15 \\
\hline 7 & 26.465 & 31.19 & $3.08 \mathrm{E}+04$ & $4.99 \mathrm{E}+01$ & $7.44 E+04$ & $1.28 \mathrm{E}+02$ & 1.20 \\
\hline 8 & 31.19 & 40.79 & $2.46 \mathrm{E}+04$ & $4.28 \mathrm{E}+01$ & $2.13 E+04$ & $1.04 \mathrm{E}+02$ & 0.78 \\
\hline 9 & 40.79 & 46.57 & $1.36 \mathrm{E}+04$ & $4.85 E+01$ & $1.38 \mathrm{E}+04$ & $1.04 \mathrm{E}+02$ & 0.41 \\
\hline 10 & 46.57 & 48.95 & $6.16 \mathrm{E}+03$ & $6.01 E+01$ & $3.99 \mathrm{E}+03$ & $1.08 \mathrm{E}+02$ & 0.14 \\
\hline \multicolumn{8}{|c|}{ East-West Direction } \\
\hline \multirow[t]{2}{*}{ Floor } & \multicolumn{2}{|c|}{ Elevation } & $\mathbf{P}$ & A & $\mathbf{M}$ & $S$ & \\
\hline & Bottom & Top & $(\mathrm{kN})$ & $\left(m^{2}\right)$ & $(k N-m)$ & $\left(m^{3}\right)$ & (MPa) \\
\hline 1 & 0 & 2.874 & $9.04 E+04$ & $1.13 \Xi+02$ & $3.45 \mathrm{E}+05$ & $2.76 \mathrm{E}+02$ & 2.05 \\
\hline 2 & 2.874 & 6.705 & $8.18 \mathrm{E}+04$ & $1.11 \mathrm{E}+02$ & $3.14 \mathrm{E}+05$ & $2.37 \mathrm{E}+02$ & 2.07 \\
\hline 3 & 6.705 & 11.785 & $7.05 E+04$ & $7.27 \mathrm{E}+01$ & $2.44 E+05$ & $2.35 E+02$ & 2.01 \\
\hline 4 & 11.785 & 17.625 & $6.07 E+04$ & $6.59 \mathrm{E}+01$ & $1.94 \mathrm{E}+05$ & $2.22 \mathrm{E}+02$ & 1.80 \\
\hline 5 & 17.625 & 22.4 & $5.05 E+04$ & $7.41 E+01$ & $1.40 \mathrm{E}+05$ & $2.11 \mathrm{E}+02$ & 1.35 \\
\hline 6 & 22.4 & 26.465 & $4.11 E+04$ & $9.47 \mathrm{E}+\mathrm{O} 1$ & $1.02 E+05$ & $1.90 \mathrm{E}+02$ & 0.97 \\
\hline 7 & 26.465 & 31.19 & $3.08 E+04$ & $4.99 \mathrm{E}+01$ & $7.44 \mathrm{E}+04$ & $1.49 \mathrm{E}+02$ & 1.12 \\
\hline 8 & 31.19 & 40.79 & $2.46 \mathrm{E}+04$ & $4.28 E+01$ & $2.13 E+04$ & $1.22 E+02$ & 0.75 \\
\hline 9 & 40.79 & 46.57 & $1.36 \mathrm{E}+04$ & $4.85 \mathrm{E}+01$ & $1.38 \mathrm{E}+04$ & $1.22 \mathrm{E}+02$ & 0.39 \\
\hline 10 & 46.57 & 48.95 & $6.16 E+03$ & $6.01 E+01$ & $3.99 E+03$ & $. .50 \mathrm{E}+02$ & 0.13 \\
\hline
\end{tabular}




\section{Table 5.6 Maximum tensile stress obtained from simplified method}

\begin{tabular}{|c|c|c|c|c|c|c|c|}
\hline \multirow[t]{2}{*}{ Floor } & \multicolumn{2}{|c|}{ Elevation } & \multirow{2}{*}{$\begin{array}{c}P \\
(\mathrm{kN})\end{array}$} & \multirow{2}{*}{$\begin{array}{c}\text { A } \\
\left(m^{2}\right)\end{array}$} & \multirow{2}{*}{$\begin{array}{c}M \\
(k N-m)\end{array}$} & \multirow{2}{*}{$\begin{array}{c}S \\
\left(m^{3}\right)\end{array}$} & \multirow{2}{*}{$\begin{array}{c}J_{1} \\
(\mathrm{MPa})\end{array}$} \\
\hline & Bottom & Top & & & & & \\
\hline 1 & 0 & 2.874 & $9.04 E+04$ & $1.13 \mathrm{E}+02$ & $3.45 E+05$ & $3.00 \mathrm{E}+\mathrm{C2}$ & 0.35 \\
\hline 2 & 2.874 & 6.705 & $8.18 \mathrm{E}+04$ & $1.11 \mathrm{E}+02$ & $3.14 \mathrm{E}+05$ & $2.08 \mathrm{E}+02$ & 0.77 \\
\hline 3 & 6.705 & 11.785 & $7.05 E+04$ & $7.27 \mathrm{E}+01$ & $2.44 E+05$ & $1.68 \mathrm{E}+02$ & 0.48 \\
\hline 4 & 11.785 & 17.625 & $6.07 E+04$ & $6.59 \mathrm{E}+01$ & $1.94 E+05$ & $1.47 \mathrm{E}+02$ & 0.39 \\
\hline 5 & 17.625 & 22.4 & $5.05 \mathrm{E}+04$ & $7.41 \mathrm{E}+01$ & $1.40 \mathrm{E}+05$ & $1.31 \mathrm{E}+02$ & 0.39 \\
\hline 6 & 22.4 & 26.465 & $4.11 E+04$ & $9.47 \mathrm{E}+01$ & $1.02 E+05$ & $1.41 \mathrm{E}+02$ & 0.28 \\
\hline 7 & 26.465 & 31.19 & $3.08 E+04$ & $4.99 E+01$ & $7.44 E+04$ & $1.28 \mathrm{E}+02$ & 0.00 \\
\hline 8 & 31.19 & 40.79 & $246 \mathrm{E}+04$ & $4.28 \mathrm{E}+01$ & $2.13 E+04$ & $1.04 E+02$ & 0.00 \\
\hline 9 & 40.79 & 46.57 & $1.36 \mathrm{E}+04$ & $4.85 E+01$ & $1.38 \mathrm{E}+04$ & $1.04 \mathrm{E}+02$ & 0.00 \\
\hline 10 & 46.57 & 48.95 & $6.16 \mathrm{E}+03$ & $6.01 E+01$ & $3.99 E+03$ & $1.08 \mathrm{E}+02$ & 0.00 \\
\hline \multicolumn{8}{|c|}{ East-West Direction } \\
\hline \multirow[t]{2}{*}{ Floor } & \multicolumn{2}{|c|}{ Elevation } & $\mathbf{P}$ & A & $\mathbf{M}$ & $\mathbf{S}$ & $T_{1}$ \\
\hline & Bottom & Top & $(\mathrm{kN})$ & $\left(m^{2}\right)$ & $(\mathrm{kN}-\mathrm{m})$ & $\left(m^{3}\right)$ & $(\mathrm{MPa})$ \\
\hline 1 & 0 & 2.874 & $9.04 E+04$ & $1.13 E+02$ & $3.45 \mathrm{E}+05$ & $2.76 \mathrm{E}+02$ & 0.45 \\
\hline 2 & 2.874 & 6.705 & $8.18 E+04$ & $1.11 \mathrm{E}+02$ & $3.14 \mathrm{E}+05$ & $2.37 \mathrm{E}+02$ & 0.59 \\
\hline 3 & 6.705 & 11.785 & $7.05 \mathrm{E}+04$ & $7.27 \mathrm{E}+01$ & $2.44 \mathrm{E}+05$ & $2.35 \mathrm{E}+02$ & 0.07 \\
\hline 4 & 11.785 & 17.625 & $6.07 \mathrm{E}+04$ & $6.59 \mathrm{E}+01$ & $1.94 \mathrm{E}+05$ & $2.22 E+02$ & 0.00 \\
\hline 5 & 17.625 & 22.4 & $5.05 \mathrm{E}+04$ & $7.41 \mathrm{E}+01$ & $1.40 \mathrm{E}+05$ & $2.11 \mathrm{E}+02$ & 0.00 \\
\hline 6 & 22.4 & 26.465 & $4.11 \mathrm{E}+04$ & $9.47 \mathrm{E}+01$ & $1.02 E+05$ & $1.90 \mathrm{E}+02$ & 0.10 \\
\hline 7 & 26.465 & 31.19 & $3.08 \mathrm{E}+04$ & $4.99 E+01$ & $7.44 \mathrm{E}+04$ & $1.49 \mathrm{E}+02$ & 0.00 \\
\hline 8 & 31.19 & 40.79 & $2.46 \mathrm{E}+04$ & $4.28 E+01$ & $2.13 E+04$ & $1.22 E+02$ & 0.00 \\
\hline 9 & 40.79 & 46.57 & $1.36 \mathrm{E}+04$ & $4.85 \mathrm{E}+01$ & $1.38 E+04$ & $1.22 \mathrm{E}+02$ & 0.00 \\
\hline 10 & 46.57 & 48.95 & $6.16 \mathrm{E}+03$ & $6.01 E+01$ & $3.99 \mathrm{E}+03$ & $1.50 \mathrm{E}+02$ & 0.00 \\
\hline
\end{tabular}

\subsubsection{Calculation of Shear Stress}

Shear stresses at each floor level are calculated based on the total lateral force acting at that level. For the East-West direction, the listed foice acts along 
the shear center of the section whereas in the North-South direction due to the asymmetric geometry of the tower, the lateral inertia force does not act through the shear center of the section. Therefore for the latter, the total shear stress is the sum of the normal shear stresses and the shear stresses due to torsion.

According to NBCC-90, the torsional moment at each story shall be computed according to Clause 4.1.9.1.(22)

$$
M_{t x}=\left(F_{t}+\sum_{t=x}^{n} F_{t}\right) e_{x}
$$

where $F_{t}$ is lateral force acting at top of the structure, $F_{1}$ is the lateral force acting at the floor level and $n$ is the total number of the storey. $e_{x}$, the eccentricity, is to be simplified according to Clause 4.1.9.1.(23)

$$
e_{x}=1.5 e+0.10 D_{n}
$$

in which $e$ is the dimension between the location of the resultant of all forces at and above the level being considered and the center of the rigidity at the level being considered, and $D_{n}$ is the plan dimension of the building in the direction of the computed eccentricity. For a closed section, the shear stresses are calculated from

$$
\tau_{1}=\frac{M_{1}}{2 A_{n} t_{1}}
$$

where $A_{o}$ is the area surrounded by the center line of the wall and $t$, is the thickness at the wall section $i$ where the shear stress $\tau_{1}$, acts. Note that the shear flow along the thickness of the wall is assumed uniformly distributed. On the other hand, the shear stresses for an open section are computed from

$$
\tau_{t}=\frac{3 M_{t} t_{t}}{\sum a_{t} t_{t}^{3}}
$$

where $a_{1}$ is length of each separate component. 
The shear stress due to a shear force acting through the shear center is given obtained from

$$
\tau_{l}=\frac{Q S_{s}}{I_{b} t}
$$

where $Q, I_{b}, S_{s}$ and $t$ are the shear force at each level, the moment of inertia of the section, first moment of area and the width of the wall at point of interest respectively.

Using the preceding equations, the shear stresses due to the combination of lateral forces and torsional moments in the north-south direction were computed and are listed in Table 5.7, while those for East-West direction are shown in Table 5.8 .

Table 5.7 Shear stresses in North-South direction

\begin{tabular}{|c|c|c|c|c|c|c|}
\hline \multirow[t]{2}{*}{ Level } & \multicolumn{2}{|c|}{ Elevation $(\mathrm{m})$} & \multirow{2}{*}{$\begin{array}{c}Q \\
(\mathrm{kN})\end{array}$} & \multirow{2}{*}{$\begin{array}{c}\tau_{l} \\
(\mathrm{MPa})\end{array}$} & \multirow{2}{*}{$\begin{array}{c}\tau_{T} \\
(\mathrm{MPa})\end{array}$} & \multirow{2}{*}{$\begin{array}{c}\tau_{s}=\tau_{l}+\tau_{t} \\
(\mathrm{MPa})\end{array}$} \\
\hline & Buttom & Top & & & & \\
\hline 1 & 0 & 2.874 & 10833 & 0.63 & 0.11 & 1.10 \\
\hline 2 & 2.874 & 6.705 & 10765 & 0.62 & 0.19 & 1.21 \\
\hline 3 & 6.705 & 11.785 & 10464 & 0.60 & 0.19 & 1.19 \\
\hline 4 & 11.785 & 17.625 & 9964 & 0.61 & 0.18 & 1.19 \\
\hline 5 & 17.625 & 22.4 & 9128 & 0.56 & 0.17 & 1.09 \\
\hline 6 & 22.4 & 26.465 & 8084 & 0.51 & 0.15 & 1.00 \\
\hline 7 & 26.465 & 31.19 & 6696 & 0.47 & 0.12 & 0.88 \\
\hline 8 & 31.19 & 40.79 & 3479 & 0.52 & 1.49 & 3.02 \\
\hline 9 & 40.79 & 46.57 & 2145 & 0.32 & 0.85 & 1.76 \\
\hline 10 & 46.57 & 48.95 & 1703 & 0.13 & 0.05 & 0.27 \\
\hline
\end{tabular}

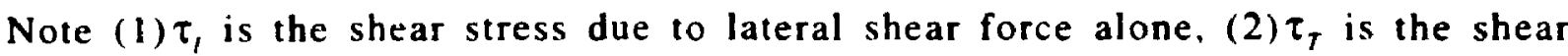
stress caused by torsional moment and $\tau_{\mathrm{s}}$ is the total shear stress. 
Table 5.8 Shear stress in East-West direction

\begin{tabular}{|c|c|c|c|}
\hline \multirow{2}{*}{ Level } & \multicolumn{2}{|c|}{ Elevation } & \multirow{2}{*}{$\tau_{s}$} \\
\cline { 2 - 3 } & Bottom & Top & $(\mathrm{MPa})$ \\
\hline 1 & 0 & 2.874 & 0.31 \\
\hline 2 & 2.874 & 6.705 & 0.31 \\
\hline 3 & 6.705 & 11.785 & 0.30 \\
\hline 4 & 11.785 & 17.625 & 0.30 \\
\hline 5 & 17.625 & 22.4 & 0.28 \\
\hline 6 & 22.4 & 26.465 & 0.30 \\
\hline 7 & 26.465 & 31.19 & 0.29 \\
\hline 8 & 31.19 & 40.79 & 0.52 \\
\hline 9 & 40.79 & 46.57 & 0.32 \\
\hline 10 & 46.57 & 48.95 & 0.09 \\
\hline
\end{tabular}

\subsubsection{Frame Model}

The frame model was subjected to the equivalent lateral force computed according to the NBCC 1990 and the artificially generated ground motions along two periendicular directions, namely the North-South and East-West direction. The dynamic analysis was carried out using the displacement mode superposition method assuming $3 \%$ modal damping. The response of the frame model was determined 10 the ground motions that contain high and low frequency content and repiesenting return period of 200,500 and 2000 year. Since the computer program ETABS outputs only member forces, a special computer program was required to calculate the resultant member stresses. The base shears corresponding to 500 return period were also computed and are listed in Table 5.9. The computed horizontal displacement along the height are listed in Tables 5.10 and 5.11. The resulting compressive, tensile and shear stress along the height are given in Table 5.12 to Table 5.17. The results are discussed in Section 5.4 


\section{Table 5.9 Computed base shear (MN) for 500 year return period ground motion}

\begin{tabular}{|c|c|c|c|}
\hline & $\begin{array}{c}\text { Equivlent } \\
\text { Static analysis }\end{array}$ & $\begin{array}{c}\text { High Frequency } \\
\text { Content }\end{array}$ & $\begin{array}{c}\text { Low Frequency } \\
\text { Content }\end{array}$ \\
\hline $\mathrm{N}-\mathrm{S}$ & $\mathbf{8 . 0 7}$ & 1.52 & 0.95 \\
\hline \multicolumn{3}{|l}{} & 1.01 \\
\hline E - W & 8.07 & 2.29 & \\
\hline
\end{tabular}

\section{Table 5.10 Maximum horizontal displacement obtained from frame analysis: North - South direction (Units: mm)}

\begin{tabular}{|c|c|c|c|c|c|c|c|c|c|c|}
\hline \multirow[t]{2}{*}{ Floor } & \multicolumn{2}{|c|}{$\begin{array}{c}\text { Elevation } \\
(\mathrm{m})\end{array}$} & \multirow[t]{2}{*}{ Material } & \multirow[t]{2}{*}{$\begin{array}{c}\text { Equivalent } \\
\text { Static }\end{array}$} & \multicolumn{3}{|c|}{$\begin{array}{c}\text { High Frequency } \\
\text { Content }\end{array}$} & \multicolumn{3}{|c|}{$\begin{array}{c}\text { Low Frequency } \\
\text { Content }\end{array}$} \\
\hline & Botton & Top & & & $2000 y$ & $500 y$ & $200 y$ & $2000 y$ & $500 \%$ & $200 y$ \\
\hline 1 & 0 & 2874 & Masonr & 0 & 0 & 0 & 0 & 0 & 0 & 0 \\
\hline 2 & 2874 & 6705 & Masonr & 0 & 0 & 0 & 0 & 0 & 0 & 0 \\
\hline 3 & 6705 & 11785 & Masoniy & 0 & 0 & 0 & 0 & 0 & 0 & 0 \\
\hline 4 & 11785 & 17625 & Masong & 0 & 0 & 0 & 0 & 0 & 0 & 0 \\
\hline 5 & 17625 & 224 & Masongy & 0 & 0 & 0 & 0 & C & 0 & 0 \\
\hline 6 & 224 & 26465 & Masonr & 110 & 040 & 020 & 010 & 050 & 010 & 000 \\
\hline 7 & 26465 & 3119 & Masonn & 450 & 170 & 110 & 030 & 220 & 070 & 020 \\
\hline 8 & 3119 & 4079 & Masonr & 1470 & 540 & 350 & 080 & 650 & 210 & 060 \\
\hline 9 & 4079 & 4657 & Masonry & 2050 & 790 & 490 & 110 & 920 & 300 & 090 \\
\hline 10 & 4657 & 4695 & Masonr & 2180 & 850 & 530 & 120 & 1000 & 320 & 100 \\
\hline 11 & 4895 & 5189 & Brick Wall & 2280 & 890 & 560 & 130 & 1040 & 330 & 100 \\
\hline Rool & 5189 & 8155 & $\begin{array}{c}\text { Steel } \\
\text { Angles }\end{array}$ & 7850 & 4310 & 4560 & 910 & 7480 & 2820 & 600 \\
\hline
\end{tabular}

\section{Table 5.11 Maximum horizontal displacement obtained from frame analysis: East - West direction (Units: $\mathbf{m m}$ )}

\begin{tabular}{|c|c|c|c|c|c|c|c|c|c|c|}
\hline \multirow[t]{2}{*}{ Floor } & \multicolumn{2}{|c|}{$\begin{array}{c}\text { Elevation } \\
(\mathrm{m})\end{array}$} & \multirow[t]{2}{*}{ Material } & \multirow[t]{2}{*}{$\begin{array}{c}\text { Equivalent } \\
\text { Static }\end{array}$} & \multicolumn{3}{|c|}{$\begin{array}{c}\text { High Frequency } \\
\text { Content }\end{array}$} & \multicolumn{3}{|c|}{$\begin{array}{c}\text { Low Frequency } \\
\text { Contert }\end{array}$} \\
\hline & Bottom & Top & & & $2000 y$ & $500 y$ & $200 y$ & $2000 y$ & $500 y$ & $200 y$ \\
\hline 1 & 0 & 2874 & Masonry & 0 & 0 & 0 & 0 & 0 & 0 & 0 \\
\hline 2 & 2874 & 6705 & Masonn & 0 & 0 & 0 & 0 & 0 & 0 & 0 \\
\hline 3 & 6705 & 11785 & Masonn & 0 & 0 & 0 & 0 & 0 & 0 & 0 \\
\hline 4 & 11785 & 17625 & Masonry & 0 & 0 & 0 & 0 & 0 & 0 & 0 \\
\hline 5 & 17625 & 22.4 & Masonry & 0 & 0 & 0 & 0 & 0 & 0 & 0 \\
\hline 6 & 224 & 26465 & Masonr & 040 & 030 & 030 & 000 & 030 & 010 & 000 \\
\hline 7 & 26.465 & 3119 & Masontr & 290 & 140 & 130 & 030 & 160 & 060 & 020 \\
\hline 8 & 31.19 & 4079 & Masonn & 13.30 & 470 & 4.50 & 090 & 590 & 240 & 0.80 \\
\hline 9 & 40.79 & 4657 & Masonry & 1890 & 700 & 640 & 120 & 820 & 340 & 110 \\
\hline 10 & 4657 & 4895 & Masonry & 2000 & 740 & 670 & 120 & 860 & 360 & 120 \\
\hline 11 & 4895 & 5189 & Brick Wall & 2090 & 7.90 & 710 & 130 & 910 & 380 & $13 n$ \\
\hline Roof & 51.89 & 8155 & Steel & 4770 & 2290 & 2010 & 330 & 2090 & 9.90 & 270 \\
\hline
\end{tabular}




\section{Table 5.12 Maximum compressive stress obtained from frame analysis: North-South direction (Units: MPa)}

\begin{tabular}{|c|c|c|c|c|c|c|c|c|c|c|}
\hline \multirow[t]{2}{*}{ Floor } & \multicolumn{2}{|c|}{$\begin{array}{c}\text { Elevation } \\
\text { (m) }\end{array}$} & \multirow[t]{2}{*}{ Material } & \multirow[t]{2}{*}{$\begin{array}{c}\text { Equivalent } \\
\text { Static }\end{array}$} & \multicolumn{3}{|c|}{$\begin{array}{c}\text { High Frequency } \\
\text { Content }\end{array}$} & \multicolumn{3}{|c|}{$\begin{array}{l}\text { Low Frequency } \\
\text { Content }\end{array}$} \\
\hline & Bottom & Top & & & $2000 y$ & $500 y$ & $200 y$ & $2000 \mathrm{y}$ & $500 \mathrm{y}$ & $200 y$ \\
\hline 1 & 0 & 2874 & Masonry & 042 & 0.37 & 0.36 & 034 & 038 & 035 & 034 \\
\hline 2 & 2874 & 6705 & Masonry & 140 & 1.25 & 122 & 1.15 & 127 & 120 & 116 \\
\hline 3 & .6705 & 11785 & Masonry & 1.22 & 108 & 1.05 & 098 & 110 & 1.02 & 098 \\
\hline 4 & 11785 & 17.625 & Masonn & 1.22 & 101 & 097 & 084 & 104 & 094 & 089 \\
\hline 5 & 17625 & 224 & Masonr & 431 & 351 & 236 & 299 & 362 & 323 & 300 \\
\hline 6 & 22.4 & 26465 & Masonry & 639 & 338 & 276 & 258 & 368 & 269 & 259 \\
\hline 7 & 26.465 & 3119 & Masonry & 566 & 3.80 & 282 & 225 & 387 & 253 & 214 \\
\hline 8 & 3119 & 4079 & Masenry & 500 & 287 & 221 & 141 & 310 & 186 & 136 \\
\hline 9 & 4079 & 46.57 & Masonry & 250 & 180 & 121 & 068 & 196 & 099 & 067 \\
\hline 10 & 4657 & 4895 & Masonn & 258 & 104 & 093 & 090 & 108 & 093 & 090 \\
\hline 11 & 4895 & 5189 & Brich $W_{\text {all }}$ & 362 & 180 & 165 & 107 & 217 & 130 & 103 \\
\hline roof & 5189 & 8155 & Steel & 8366 & 5737 & 6245 & 2080 & 9658 & +113 & 2169 \\
\hline
\end{tabular}

\section{Table 5.13 Maximum compressive stress obtained from frame analysis: East - West direction (Units: MPa)}

\begin{tabular}{|c|c|c|c|c|c|c|c|c|c|c|}
\hline \multirow[t]{2}{*}{ Floor } & \multicolumn{2}{|c|}{$\begin{array}{l}\text { Elevalion } \\
\text { (m) }\end{array}$} & \multirow[t]{2}{*}{ Material } & \multirow[t]{2}{*}{\begin{tabular}{|c|} 
Equivalent \\
Static
\end{tabular}} & \multicolumn{3}{|c|}{$\begin{array}{c}\text { H:gh Frequency } \\
\text { Content }\end{array}$} & \multicolumn{3}{|c|}{$\begin{array}{c}\text { Lou Frequency } \\
\text { Content }\end{array}$} \\
\hline & Bollom & Top & & & $2000 y$ & $500 \mathrm{y}$ & $200 y$ & $200(x)$ & 5001 & $2(1)$ \\
\hline 1 & 0 & 2.874 & Masonry & 028 & 0.37 & 033 & 034 & 037 & 0.36 & 0.34 \\
\hline 2 & 2.874 & 6.705 & Masonry & 0.91 & 1.08 & 1.08 & 1.15 & 1.28 & 121 & 1.15 \\
\hline 3 & 6.705 & 1178.5 & Masonry & 072 & 0.9 & 0.9 & 0.97 & 1.11 & 1.04 & 0.98 \\
\hline 4 & 11.785 & 17.625 & Masonry & 0.58 & 1.02 & 1.01 & 0.88 & 1.04 & 0.96 & 0.89 \\
\hline 5 & 17.625 & 22.4 & Masonry & 1.83 & 3.29 & 3.28 & 299 & 3.59 & 3.27 & 299 \\
\hline 6 & 22.4 & 26.465 & Masonry & 516 & 3.41 & 287 & 2.48 & 3.43 & 291 & 251 \\
\hline 7 & 26.465 & 31.19 & Masonry & 7.12 & 3.15 & 301 & 2.14 & 3.25 & 2.57 & 201 \\
\hline 8 & 31.19 & 4079 & Masonry & 7.82 & 2.11 & 2.1 & 1.2 & 251 & 1.46 & 12 \\
\hline 9 & 40.79 & 46.57 & Masonry & 3.16 & 1.43 & 1.07 & 074 & 128 & 089 & 0.74 \\
\hline 10 & 46.57 & 48.95 & Masonry & 389 & 161 & 1.28 & 096 & 1.55 & 1.15 & 096 \\
\hline 11 & 48.95 & 51.89 & Brick Wall & 167 & 1.49 & 1.16 & 1 & 121 & 1.07 & 0.96 \\
\hline Roof & 51.89 & 81.55 & Steel & 73.27 & 73.76 & 4169 & 2026 & 44.61 & 2916 & 21.75 \\
\hline
\end{tabular}


Table 5.14 Maximum tensile stress obtained from frame analysis: North-South direction (Units: MPa)

\begin{tabular}{|c|c|c|c|c|c|c|c|c|c|c|}
\hline \multirow[t]{2}{*}{ Floor } & \multicolumn{2}{|c|}{$\begin{array}{l}\text { Elevation } \\
(\mathrm{m})\end{array}$} & \multirow[t]{2}{*}{ Material } & \multirow[t]{2}{*}{$\begin{array}{c}\text { Equtvalent } \\
\text { Static }\end{array}$} & \multicolumn{3}{|c|}{$\begin{array}{c}\text { High Frequency } \\
\text { Content }\end{array}$} & \multicolumn{3}{|c|}{$\begin{array}{l}L \cdot w \text { Frequency } \\
\text { Content }\end{array}$} \\
\hline & Bottom & Top & & & $2000 \mathrm{y}$ & $500 y$ & $200 y$ & $2000 y$ & $500 y$ & $200 y$ \\
\hline 1 & 0 & 2874 & Masons & 014 & 011 & 012 & 012 & 011 & 012 & 012 \\
\hline 2 & 2874 & 6705 & Masonr & 048 & 083 & 085 & 088 & 081 & 086 & 088 \\
\hline 3 & 6705 & 11785 & Masonr & 122 & 091 & 094 & 098 & 089 & 096 & 098 \\
\hline 4 & 11785 & 17625 & Masons & 119 & 080 & 084 & 089 & $07 ?$ & 087 & 084 \\
\hline 5 & 17625 & 224 & Masonrs & 4116 & 320 & 306 & 285 & 330 & 294 & 087 \\
\hline 6 & 224 & 26465 & Misonry & 608 & 301 & 186 & $10 x$ & 331 & $13 x$ & 108 \\
\hline 7 & $26+65$ & 3119 & Masonr: & 162 & 067 & 0.57 & 047 & 074 & 052 & $0+7$ \\
\hline 8 & 3119 & 4079 & Masonrs & 415 & 167 & 102 & 024 & 190 & 066 & 018 \\
\hline 9 & $\$ 179$ & 4657 & Masors & 204 & $10 x$ & $04^{7}$ & 020 & 122 & 025 & 014 \\
\hline 10 & 4697 & +595 & Masonts & 241 & (1) 85 & 0) 63 & 053 & 044 & 056 & 052 \\
\hline 11 & 4895 & 5189 & Bnih $\mathrm{W}$ all & 387 & 183 & 153 & 043 & 202 & 117 & 089 \\
\hline $\mathrm{R}(1) 1$ & $51 \times 4$ & 8155 & Ste: & 65012 & $3 \times 10$ & $41 \times 5$ & 2744 & 7557 & 32511 & 2601 \\
\hline
\end{tabular}

Table 5.15 Maximum tensile stress obtained from frame analysis: East - West direction (Units: MPa)

\begin{tabular}{|c|c|c|c|c|c|c|c|c|c|c|}
\hline \multirow[t]{2}{*}{ Floor } & \multicolumn{2}{|c|}{$\begin{array}{c}\text { Eirvation } \\
(\mathrm{m})\end{array}$} & \multirow[t]{2}{*}{ Matertal } & \multirow[t]{2}{*}{$\begin{array}{c}\text { Equwialent } \\
\text { Statix }\end{array}$} & \multicolumn{3}{|c|}{$\begin{array}{l}\text { High Frequency } \\
\text { Contem }\end{array}$} & \multicolumn{3}{|c|}{$\begin{array}{l}\text { Low Frequency } \\
\text { Content }\end{array}$} \\
\hline & Bolton & Top & & & $200(1)$ & $500 \mathrm{~s}$ & $200 i 1$ & $2000 y$ & $500 y$ & 2001 \\
\hline 1 & 0 & $2 \times 24$ & Mysonn & (1) 10 & 011 & 011 & 012 & 011 & 012 & 012 \\
\hline 2 & $2 \times 74$ & 6705 & Mlasurnon & 070 & (1) $x=$ & $0 x=$ & $0+1$ & 038 & 040 & 088 \\
\hline 3 & 6,7115 & $11-145$ & Masunn & 072 & 1) $4(1$ & 040 & $119^{-}$ & 087 & 044 & 048 \\
\hline-4 & 11785 & 17625 & M1asonn & 0158 & 0174 & 081 & $0 \pi 8$ & 0177 & 085 & 084 \\
\hline 5 & 17625 & 324 & Masunts & 176 & 318 & 317 & 286 & 328 & 298 & 285 \\
\hline 6 & 224 & $2 n+105$ & Masinn & +51 & $1+4$ & 144 & 108 & $1+4$ & 108 & 108 \\
\hline $\bar{i}$ & $20+465$ & 3119 & Mavonn & 210 & $0 \mathrm{~ns}$ & 064 & 050 & 068 & 0.56 & (1) 49 \\
\hline 8 & 3119 & $40>9$ & Masunts & 718 & 041 & 086 & $01 \%$ & 127 & 023 & $n 0$ \\
\hline 4 & 4074 & +6.57 & Masunn & 205 & 069 & $0 \leq 0$ & 020 & 061 & 034 & 020 \\
\hline 10 & 46.57 & 4895 & Masonn & 231 & 152 & 123 & $0(x)$ & 147 & 087 & 060 \\
\hline 11 & 4845 & $51 \times 9$ & Brich Wull & 522 & 136 & 103 & 087 & 108 & 094 & 082 \\
\hline Ruw' & 5184 & 8155 & Sted & $797-$ & 76.22 & 3832 & $279 x$ & 4277 & 3044 & 2617 \\
\hline
\end{tabular}


Table 5.16 Maximum shear stress obtained from frame analysis: North-South direction (Units: MPa)

\begin{tabular}{|c|c|c|c|c|c|c|c|c|c|c|}
\hline \multirow[t]{2}{*}{ Floor } & \multicolumn{2}{|c|}{$\begin{array}{c}\text { Elevation } \\
\text { (m) }\end{array}$} & \multirow[t]{2}{*}{ Material } & \multirow[t]{2}{*}{$\begin{array}{c}\text { Equivalent } \\
\text { Static }\end{array}$} & \multicolumn{3}{|c|}{$\begin{array}{c}\text { High Frequency } \\
\text { Content }\end{array}$} & \multicolumn{3}{|c|}{$\begin{array}{c}\text { Low Frequency } \\
\text { Content }\end{array}$} \\
\hline & Bottom & Top & & & $2000 y$ & $500 y$ & $200 \mathrm{y}$ & $2000 y$ & $500 \mathrm{y}$ & $200 y$ \\
\hline 1 & 0 & 2874 & Masonry & 004 & 004 & 0.04 & 003 & 004 & 0.04 & 003 \\
\hline 2 & 2.874 & 6.705 & Masonry & 0.22 & 020 & 0.20 & 019 & 0.20 & 0.19 & 0.19 \\
\hline 3 & 6705 & 11785 & Masony & 0.26 & 0.23 & 0.22 & 021 & 0.23 & 0.22 & 021 \\
\hline 4 & 11.785 & 17.625 & Masonry & 0.28 & 0.22 & 0.21 & 020 & 0.23 & 0.20 & 019 \\
\hline 5 & 17.625 & 22.4 & Masonry & 0.68 & 0.56 & 0.54 & 0.50 & 0.58 & 052 & 0.50 \\
\hline 6 & 22.4 & 26465 & Masonry & 049 & 0.34 & 0.31 & 026 & 0.35 & 0.28 & 026 \\
\hline 7 & 26465 & 31.19 & Masonsy & 0.64 & 034 & 0.23 & 0.14 & 0.37 & 018 & 014 \\
\hline 8 & 31.19 & 40.79 & Masonry & 049 & 0.22 & 013 & 0.06 & 023 & 0.08 & 005 \\
\hline 9 & 40.79 & 4657 & Masonsy & 0.34 & 0.20 & 0.12 & 0.07 & 022 & 0.08 & 007 \\
\hline 10 & 46.57 & 48.95 & Masonry & 0.29 & 015 & 0.08 & 005 & 017 & 005 & 004 \\
\hline 11 & 48.95 & 5189 & Brick Wall & 029 & 0.15 & 0.06 & 005 & 019 & 006 & 005 \\
\hline Roof & 5189 & 8155 & Steel & 0.30 & 0.29 & 029 & 029 & 0.30 & 029 & 029 \\
\hline
\end{tabular}

Table 5.17 Maximum shear stress obtained from frame analysis: East - West direction (Units: MPa)

\begin{tabular}{|c|c|c|c|c|c|c|c|c|c|c|}
\hline \multirow[t]{2}{*}{ Floor } & \multicolumn{2}{|c|}{$\begin{array}{c}\text { Elevation } \\
(\mathrm{m})\end{array}$} & \multirow[t]{2}{*}{ Material } & \multirow[t]{2}{*}{$\begin{array}{c}\text { Equivaler } \\
\text { Static }\end{array}$} & \multicolumn{3}{|c|}{$\begin{array}{l}\text { High Frequency } \\
\text { Content }\end{array}$} & \multicolumn{3}{|c|}{$\begin{array}{c}\text { Low Frequency } \\
\text { Content }\end{array}$} \\
\hline & Bottom & Top & & & $2000 y$ & $500 y$ & $200 y$ & $2000 y$ & $500 \mathrm{y}$ & $200 y$ \\
\hline 1 & 0 & 2874 & Masonry & 003 & 004 & 004 & 003 & 004 & 004 & 003 \\
\hline 2 & 2874 & 6705 & Masonsy & 015 & 020 & 020 & 019 & 020 & 019 & $01^{\circ}$ \\
\hline 3 & 6705 & 11.785 & Masonry & 016 & 023 & 023 & 0.22 & 0.23 & 022 & 0122 \\
\hline 4 & 11785 & 17625 & Masonsy & 012 & 022 & 0.22 & 020 & 029 & 020 & 0120 \\
\hline 5 & 17625 & 224 & Masonr & 030 & 056 & 056 & 050 & 058 & 053 & 0.50 \\
\hline 6 & 224 & 26465 & Masonty & 055 & 032 & 030 & 026 & 031 & 027 & 026 \\
\hline 7 & 26465 & 3119 & Masonry & 1.11 & 027 & 0.22 & 012 & 025 & 012 & 012 \\
\hline 8 & 3119 & 4079 & Masonry & 097 & 016 & 013 & 004 & 017 & 0007 & 002 \\
\hline 9 & 4079 & 4657 & Masonry & 066 & 017 & 014 & 008 & 016 & 011 & 008 \\
\hline 10 & 46.57 & 4895 & Masons & 041 & 015 & 011 & 005 & 014 & 006 & 005 \\
\hline 11 & 4895 & 5189 & Brick W'all & 027 & 070 & 006 & 005 & 006 & 005 & 00.5 \\
\hline Roof & 5189 & 8155 & Steel & 029 & 032 & 030 & 029 & 031 & 029 & 1) 29 \\
\hline
\end{tabular}

\subsubsection{Finite Element Model}

For the finite element model. the dynamic analysis was carried out using the implicat time integration scheme with time step equal to $0.01 \mathrm{~s}$. In this case, the tower is assumed to have zero damping. Since the available post processor program does not yield the maximum values over the time history, a computer program was written to detect the maximum normal stress and shear stresses, acceleration and 
horizontal displacement along the elevation of the tower. The maximum lateral displacements and acceleration are given in Tables 5.20 and 5.21. Figures 5.5 and 5.6 display the computed frequency content of time history response at the top of the stone masunry and steel roof for 500 year return period with high frequency content using Fast Fourier Transform. The stresses are summarized in Tables 5.22 to 5.27 for the limestone and Tables 5.28 and 5.29 for the sandstone. Again the implications of these results are discussed next.

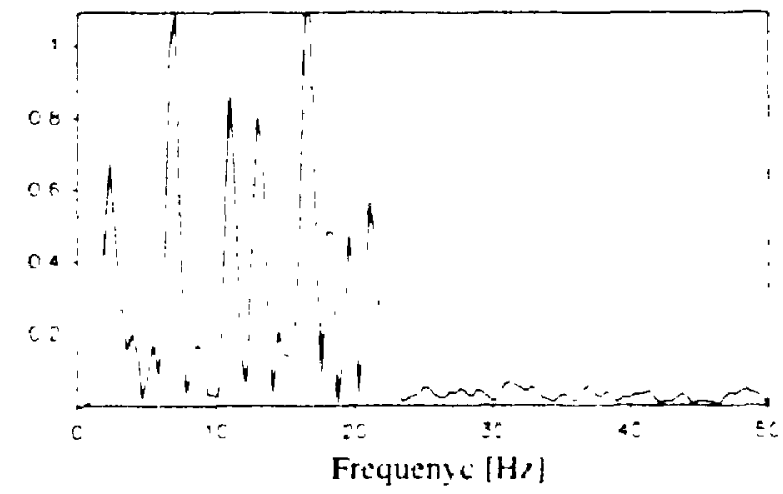

(a) East - West

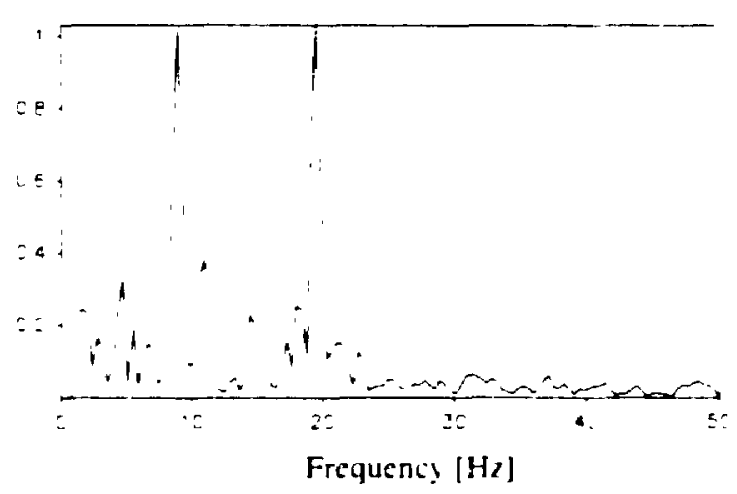

(b) North - South

Fig. 5.5 frequency content of time history response at the top of the stone masonry 


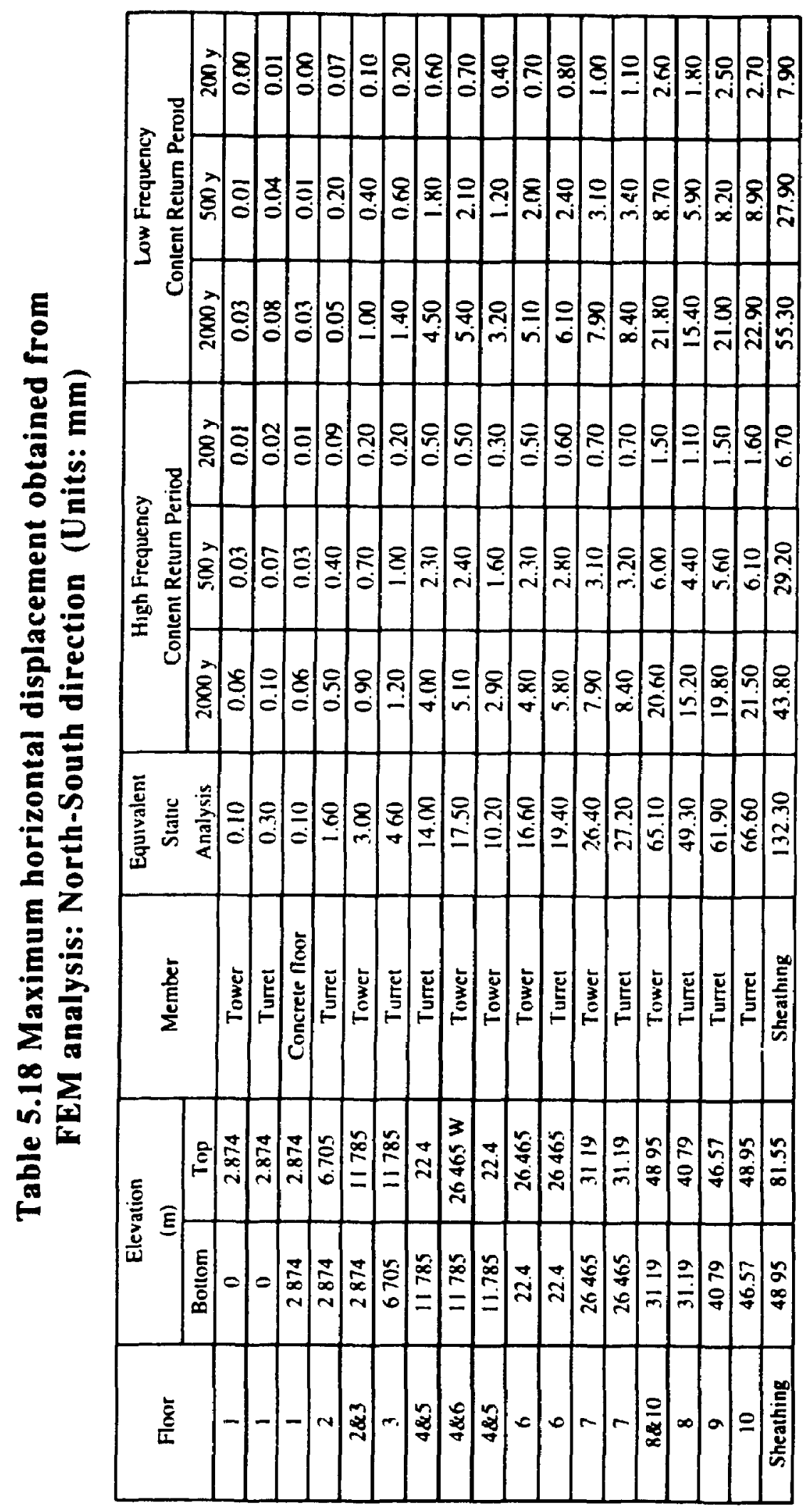




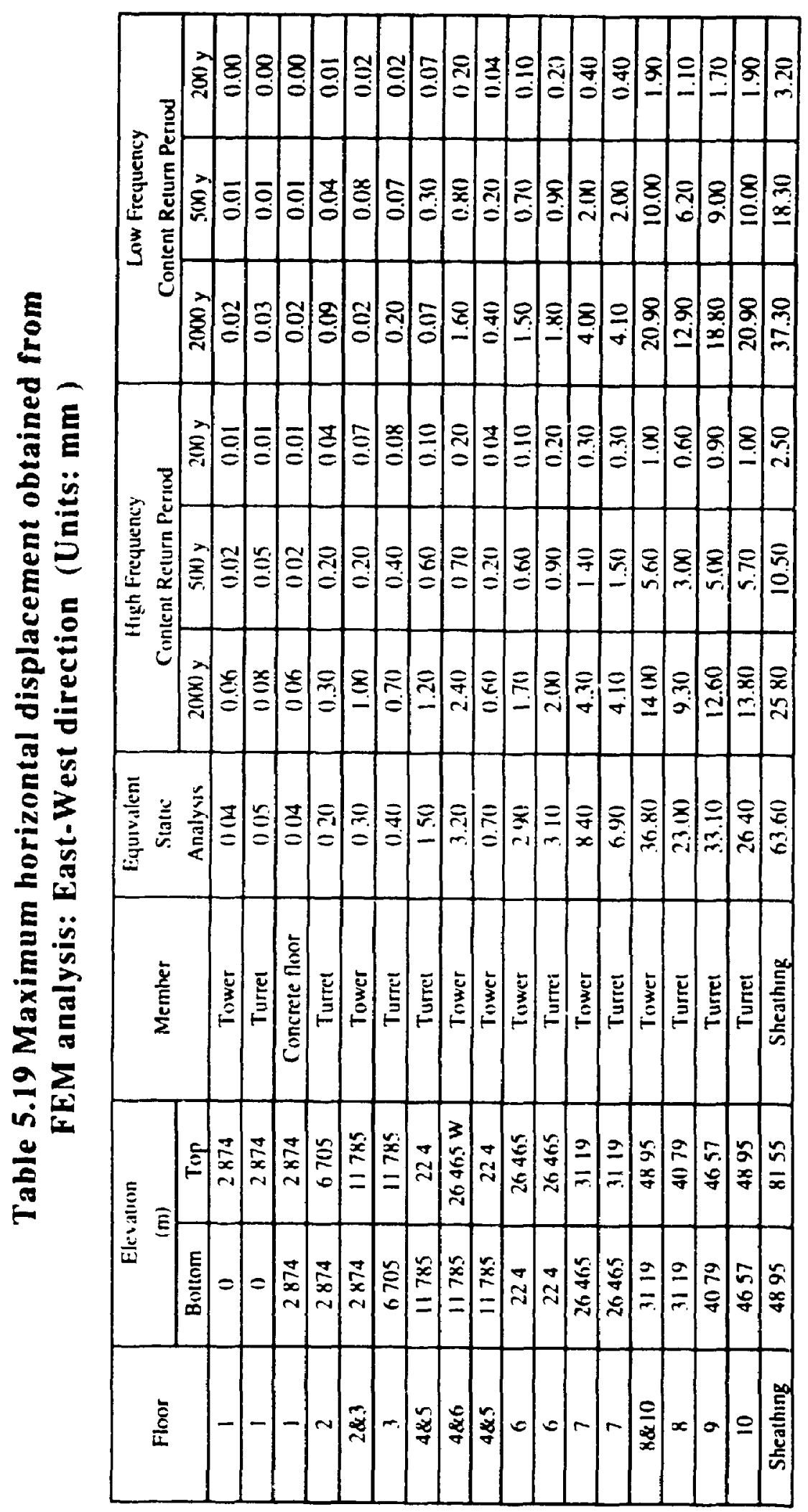




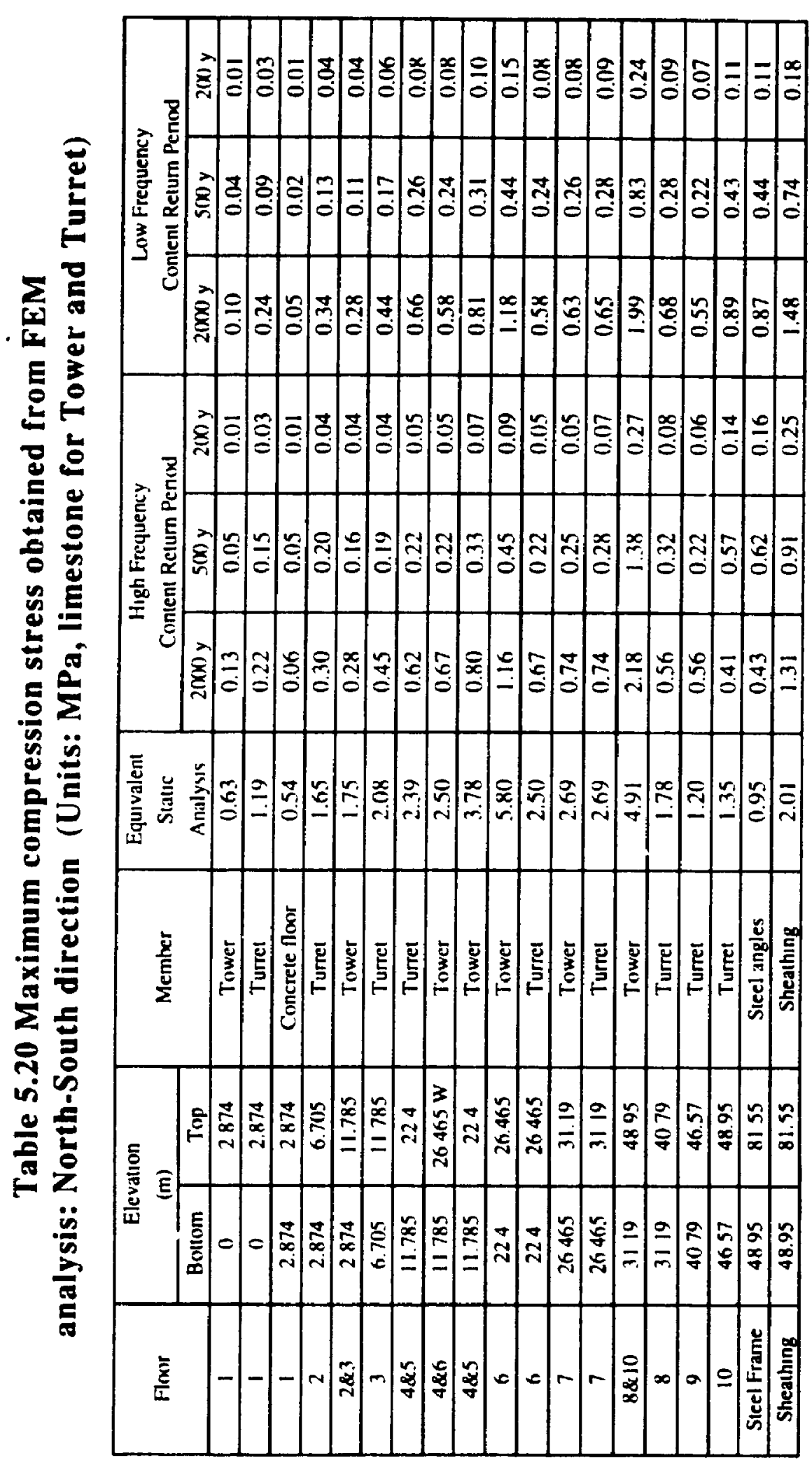




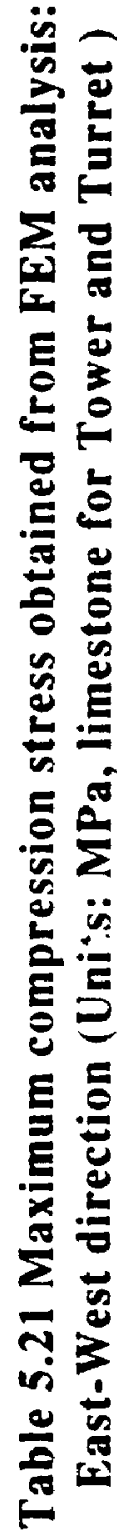

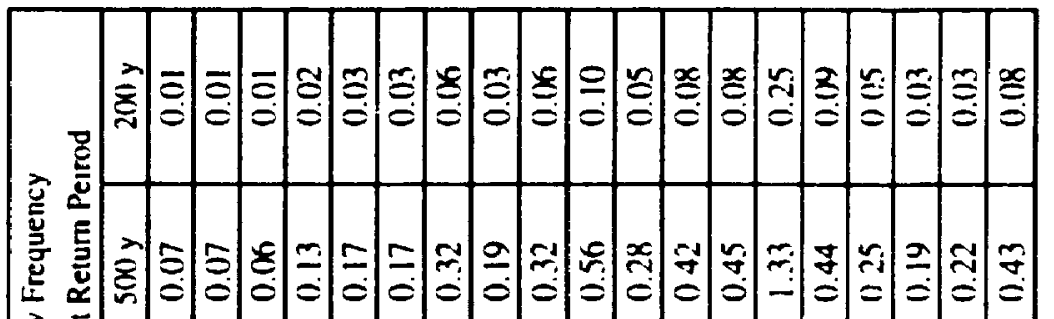

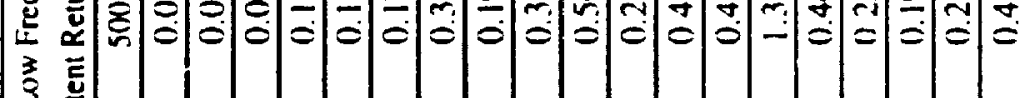

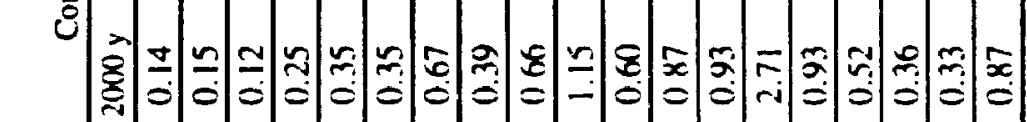

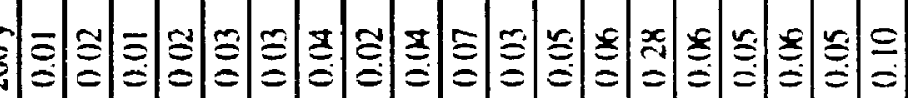
ह

उั

美到

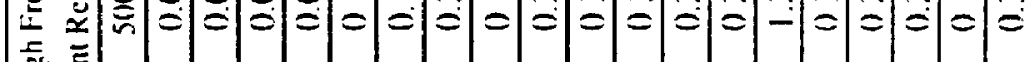

些

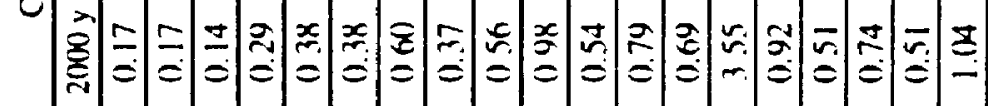

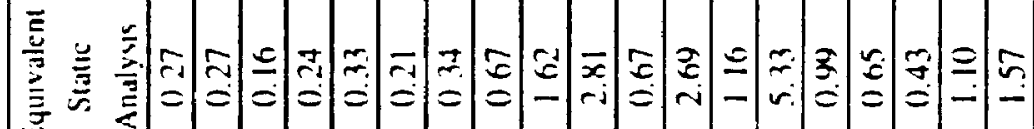
i

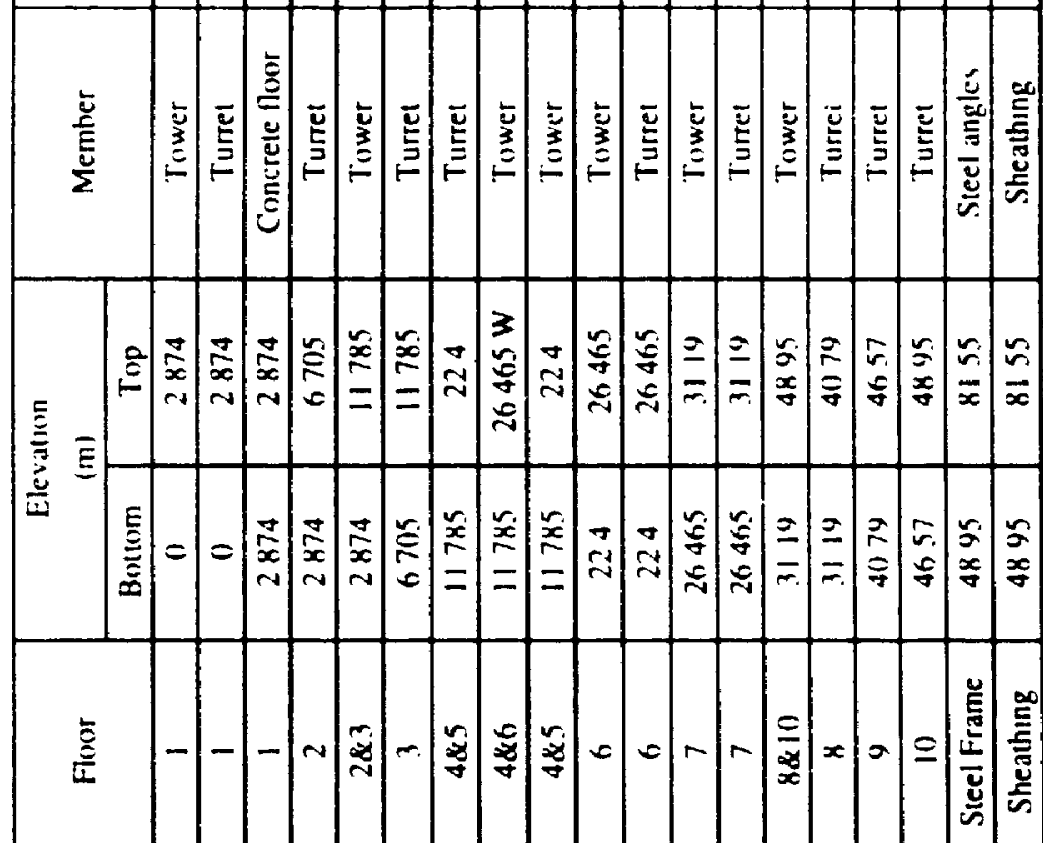




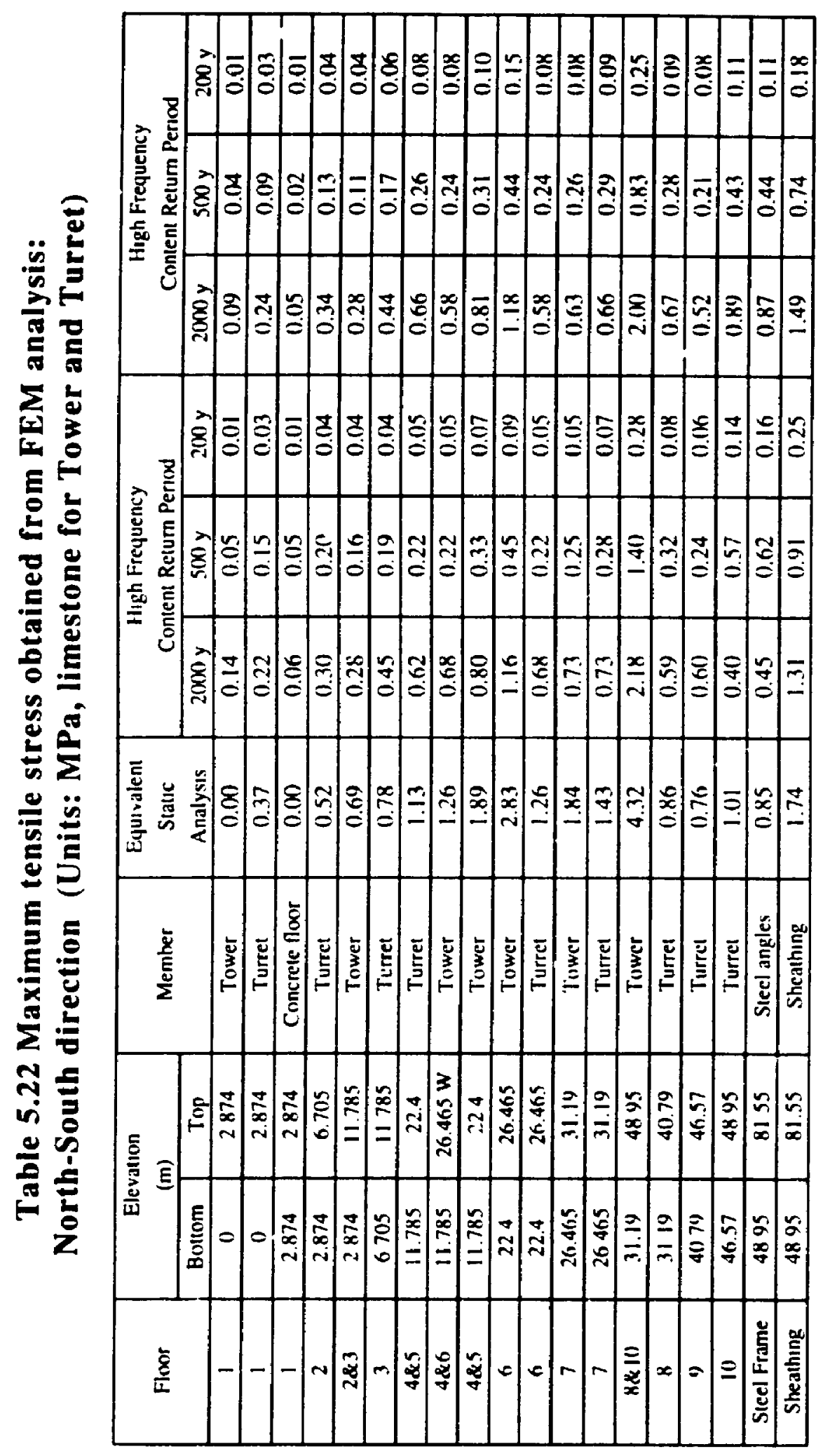




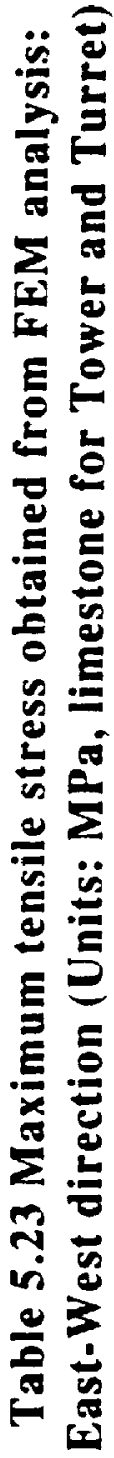

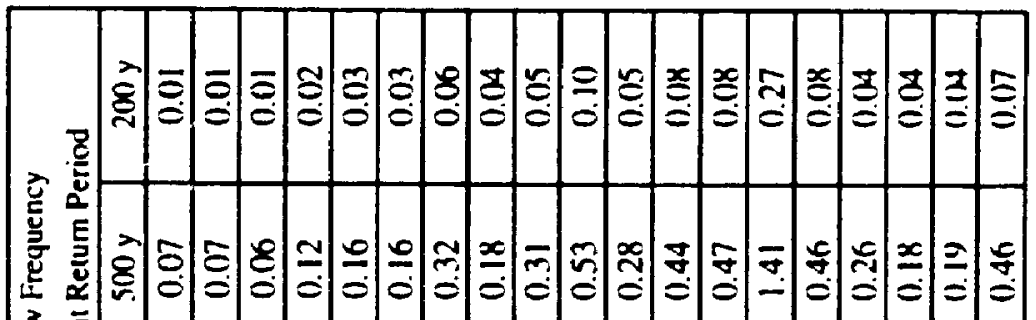

3 年

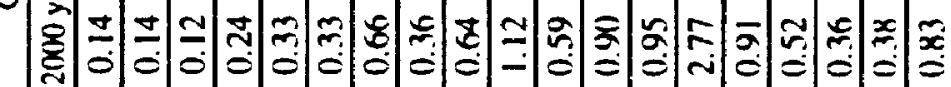

- 공

范

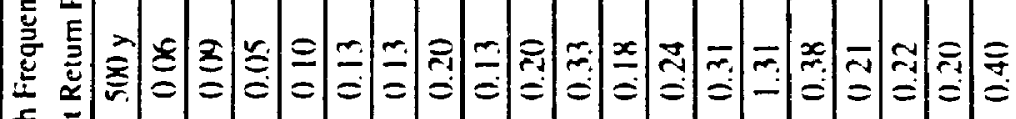
宓

工

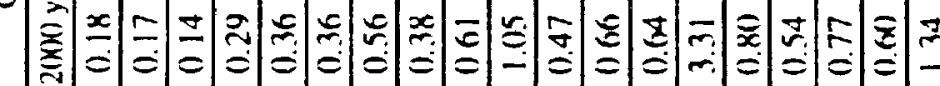

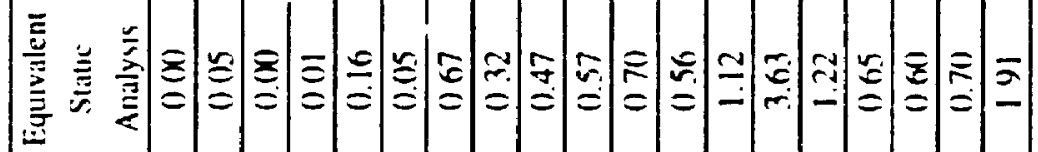

$\begin{array}{lllllllllllll} & & & & & & & & & & & & \end{array}$

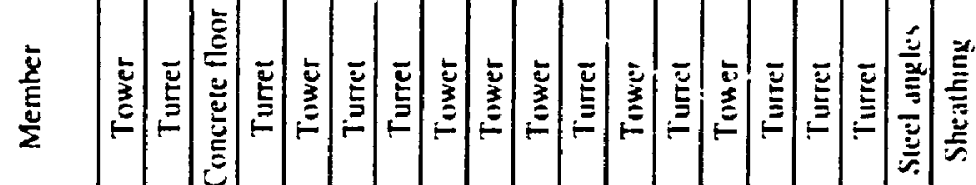

列

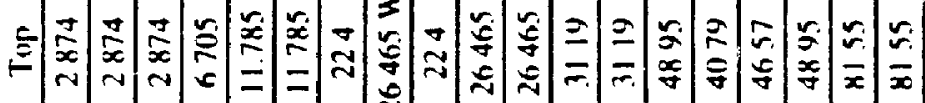

言

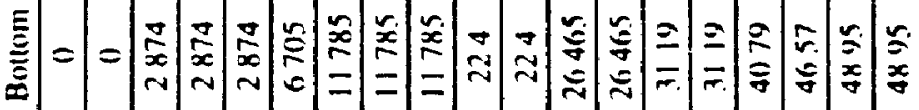

$\frac{\vdots}{5}$

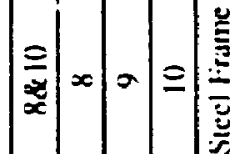




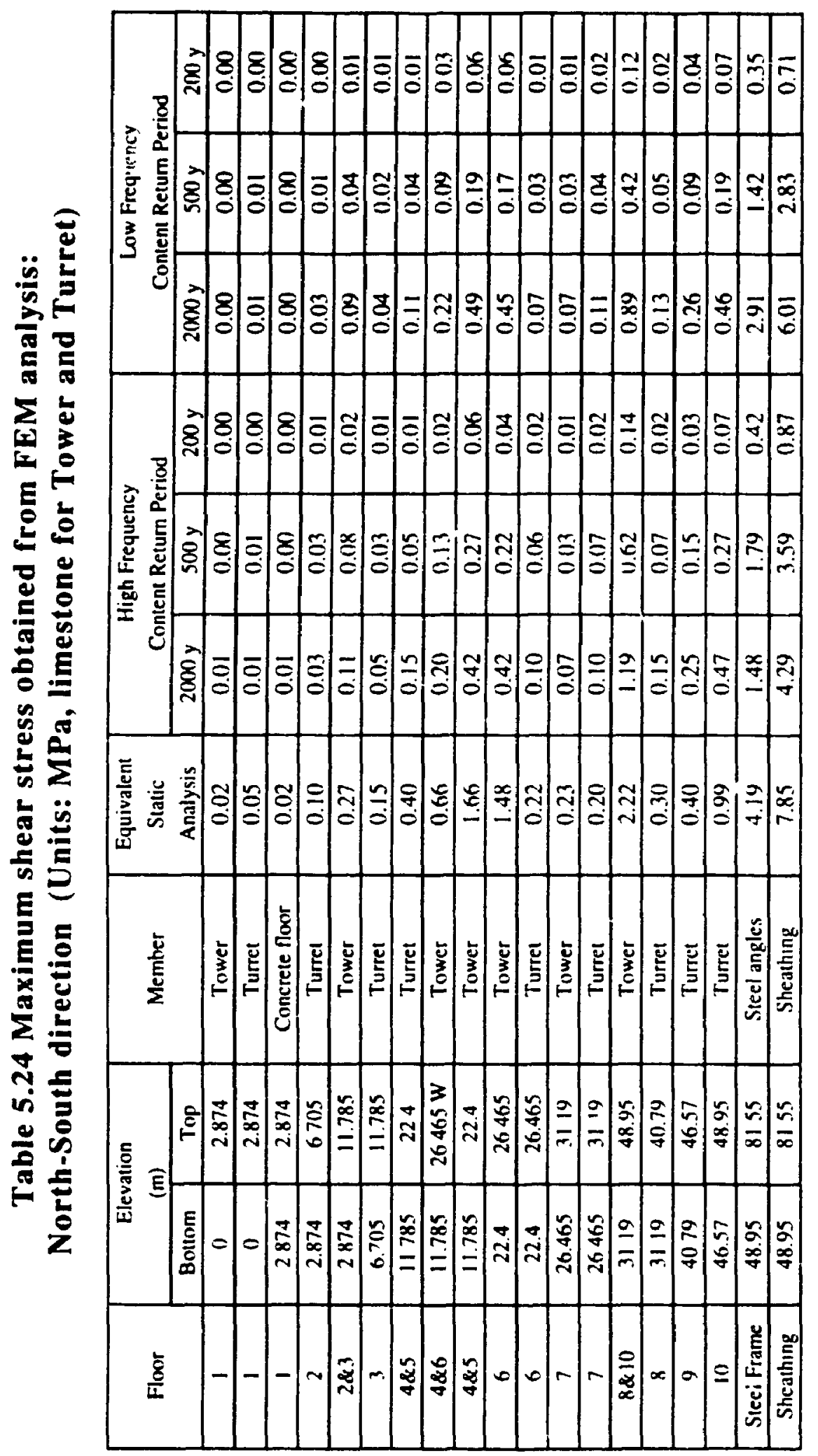




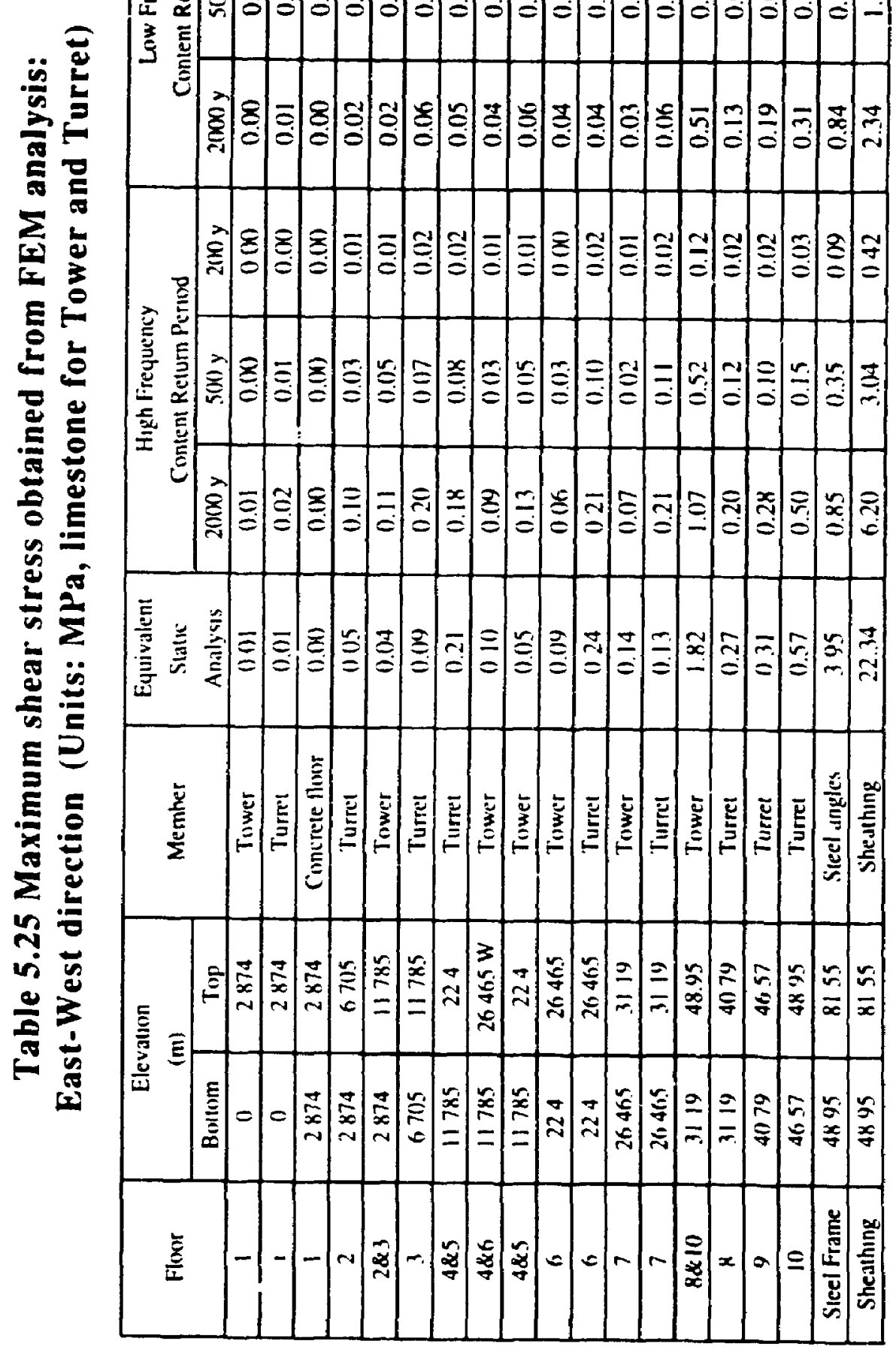

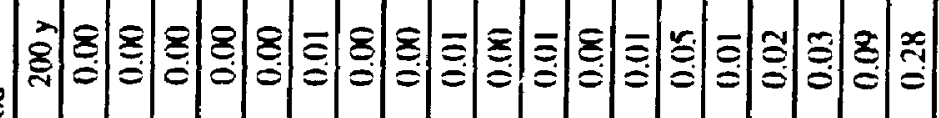

군

竞

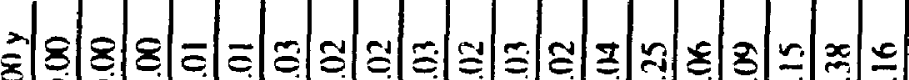

范

象

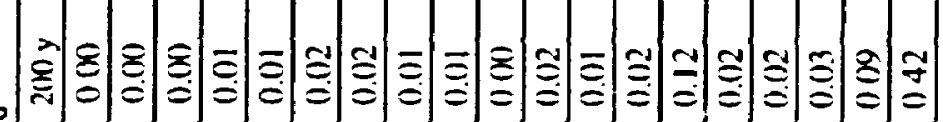




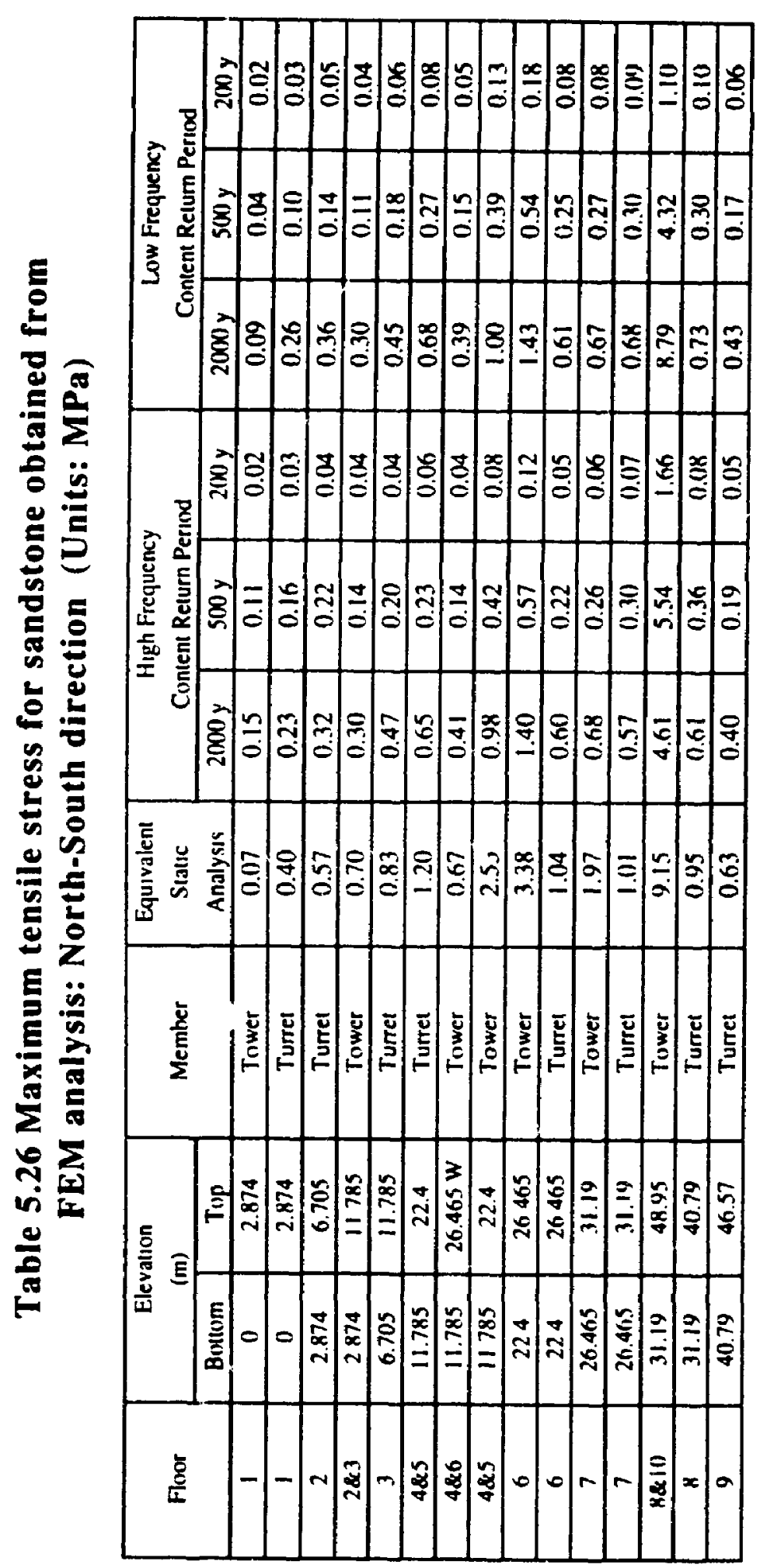




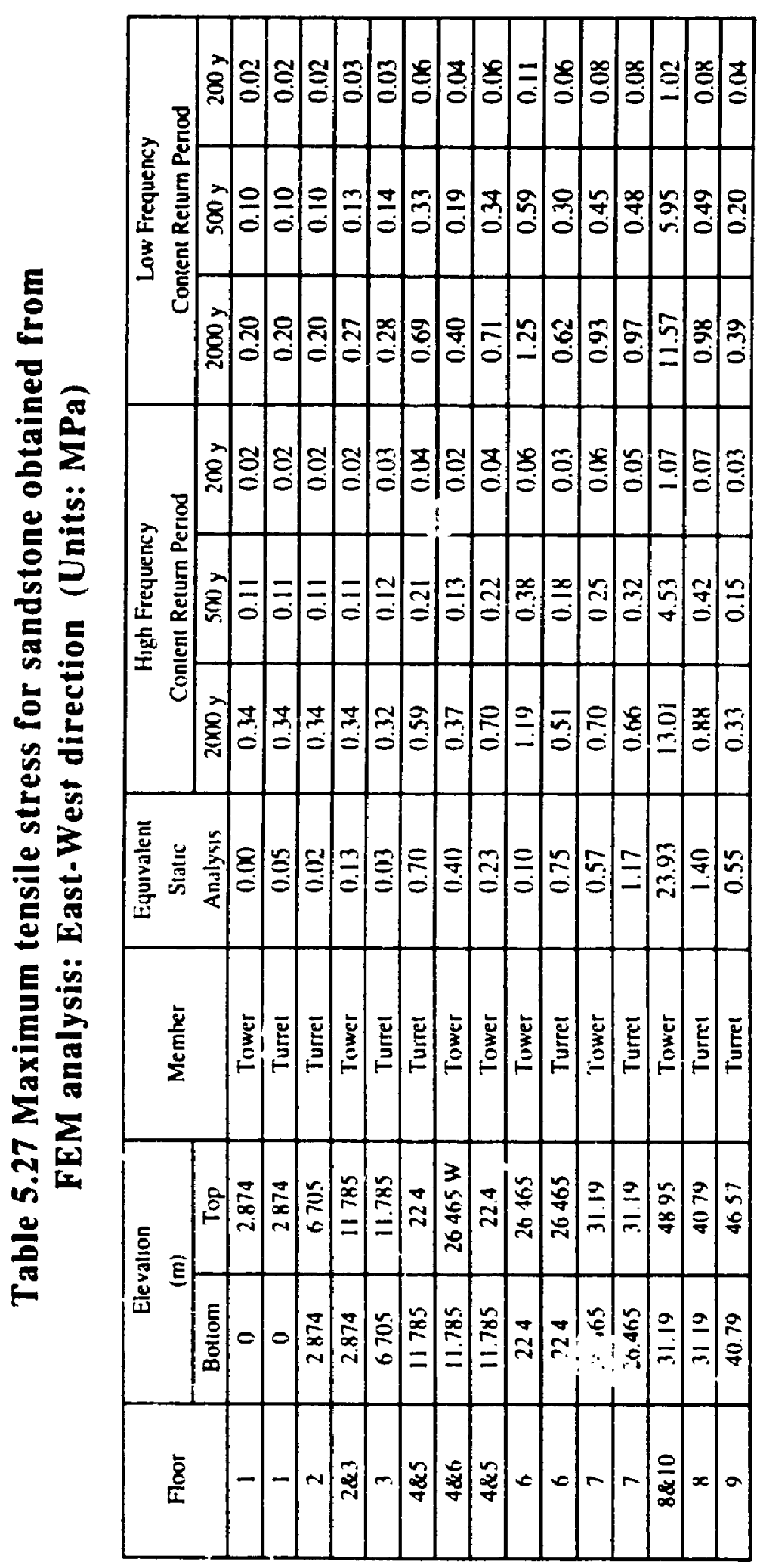




\subsection{Comparison of Results}

\subsubsection{Comparison of Lateral Displacement}

The computed horizontal displacements are the primary results of the tower's response to the equivalent static forces or the inertia forces generated by the ground motions. Their magnitude therefore corresponds to that of the lateral forces since the same mathematical model is used to perform the analysis. Since the stone part of the tower is expected to be restrained by the surrounding building in a rigid manner. the tower's response is evaluated at only three locations: the roof level of the surrounding building, the top of the masonry and the top of the steel roof frame.

\subsubsection{Displacement in the East-West Direction}

From Table 5.4, 5.10, 5.11. 5.18 and 5.19. the lateral displacement corresponding to 500 year return period is, compiled for all three models in Table 5.28. The equivalent static results reveal that the frame model yields substantially smaller values at the roof level. Further, at the top of masonry and steel roof, the finite element model gives the largest displacement to the equivalent lateral forces. The simplified model yields large lateral displacement at the top of masonry and sinall cnes at the top of steel roof in comparison to the frame model. This in attributed primarily to the crude representation of the steel roof in the simplifiad model.

From Table 5.28, the finite element equivalent static lateral displacements are significantly larger than its dynamic counterpart. By scaling the dynamic results to correspond to $0.1 \mathrm{~g}$ peak ground acceleration using Equation 5.10. the scaled displacements can be obtained. 


\section{Table 5.28 Horizontal displacement from three methods for $\mathbf{5 0 0}$ year return period (Units: $\mathbf{m m}$ )}

\begin{tabular}{|c|c|c|c|c|c|c|c|c|c|}
\hline \multirow[t]{2}{*}{ Direcuon } & \multirow{2}{*}{$\begin{array}{c}\text { Elevatuor } \\
(\mathrm{m})\end{array}$} & \multirow[t]{2}{*}{ Material } & \multicolumn{3}{|c|}{ Finite element model } & \multicolumn{3}{|c|}{ Frame model } & \multirow[t]{2}{*}{ Simplified } \\
\hline & & & Static & HFC & LFC & Static & HFC & LFC & \\
\hline \multirow{3}{*}{$\mathbf{E}-\mathbf{W}$} & 26.465 & Masonry & 3.20 & 0.90 & 0.90 & 0.40 & 0.30 & 0.10 & 3.60 \\
\hline & 48.95 & Masonry & 36.80 & 5.70 & 10.00 & 20.00 & 6.70 & 3.60 & 24.90 \\
\hline & 81.55 & Roof & 63.60 & 10.50 & 18.30 & 47.70 & 20.10 & 9.90 & 36.30 \\
\hline \multirow{3}{*}{$\mathbf{N}-\mathbf{S}$} & 26.465 & $\mathbf{M}$ & 19.40 & 2.80 & 240 & 1.10 & 0.20 & 0.10 & 7.60 \\
\hline & 48.95 & Masonry & 66.60 & 6.10 & 8.90 & 21.80 & 5.30 & 3.20 & 40.40 \\
\hline & 81.55 & Roof & 132.30 & 29.20 & 27.90 & 78.50 & 45.60 & 28.20 & 71.90 \\
\hline
\end{tabular}

HFC : High frequency content LFC : Low frequency content

$$
\delta_{,}=\delta \times 0.1 g / P G A
$$

where $\delta$, is the resulting scaled displacement. The results are given in Table 5.29.

The results from dynamic analysis with low frequency content are found to be close to those from equivalent static analysis, and the scaled up dynamic results corresponding to 500 year return period are now larger than those obtained using a ground motion corresponding to 2000 year return period as shown in Tables 5.18 and 5.19. The result in the latter tables correspond to a peak ground acceleration of $0.193 \mathrm{~g}$.

\section{Table 5.29 Scaled horizontal displacement for 500 year return period (Units: $\mathbf{m m}$ )}

\begin{tabular}{|c|c|c|c|c|c|c|c|c|c|}
\hline \multirow[t]{2}{*}{ Direction } & \multirow{2}{*}{$\begin{array}{c}\text { Elevation } \\
\text { (m) }\end{array}$} & \multirow[t]{2}{*}{ Material } & \multicolumn{3}{|c|}{ Finite element model } & \multicolumn{3}{|c|}{ Frame model } & \multirow[t]{2}{*}{ Simplified } \\
\hline & & & Static & HFC & LFC & Statie & HFC & LFC & \\
\hline \multirow{3}{*}{$E \cdot W$} & 26.465 & Masonry & 320 & 113 & 3.00 & 040 & 038 & 0.33 & 3.60 \\
\hline & 48.95 & Masonry & 36.80 & 713 & 33.33 & 20.00 & 8.38 & 12.00 & 24.90 \\
\hline & 81.55 & Roof & 6360 & 13.13 & 6100 & 47.70 & 25.13 & 33.00 & 36.30 \\
\hline \multirow{3}{*}{$N-S$} & & & 0 & & & & & & 760 \\
\hline & $\frac{26.465}{48.45}$ & $\frac{\text { Masonry }}{\text { Masonry }}$ & $\frac{19.40}{66.60}$ & $\frac{3.50}{7.63}$ & 300 & $\frac{1.10}{21 .}$ & $\frac{0.25}{6.63}$ & $\frac{033}{1067}$ & $\frac{7.60}{40.40}$ \\
\hline & 81.55 & Roof & 132.30 & $36 \overline{50}$ & 93.00 & $\overline{78.50}$ & 57.00 & 94.00 & 71.90 \\
\hline
\end{tabular}

HFC : High frequency content LFC : Low frequency content

To compare the results of the finite element to the frame method. the ratio of their maximum lateral displacement at the top of the masonry and the steel roof are listed in Tables 5.30 and 5.31 . The results reveal that the finite element model is 
generally 1.8 times more flexible than the frame model for the masonry portion of the tower but less flexible for the steel roof frame.

\subsubsection{Displacement in the North-South Direction}

At the roof level of the surrounding building, contrary to the East-West direction, the finite element equivalent static analysis results have yielded the largest horizontal displacement in comparison to the frame and simplified method. The equivalent static results indicate that the finite element model offers the least resistance followed by the simplified model. Again exceptions occur at the steel roof due to the crude modeling of the simplified method.

Table 5.30 Lateral displacement of the top of stone masonry relative to the roof of surrounding building from FEM and FA (L'nits: $\mathbf{m m}$ )

\begin{tabular}{|c|c|c|c|c|}
\hline \multirow[t]{2}{*}{ Direction } & \multirow{2}{*}{$\begin{array}{c}\text { Return Penod } \\
\text { year }\end{array}$} & FEM & $\mathbf{F A}$ & \multirow[t]{2}{*}{ FEM/FA } \\
\hline & & \multicolumn{2}{|c|}{ High Frequency Content } & \\
\hline \multirow{8}{*}{ West-East } & 2000 & 13400 & 7400 & 181 \\
\hline & 500 & 5400 & 6700 & $0 \times 1$ \\
\hline & 200 & 0960 & 1200 & 080 \\
\hline & & & & \\
\hline & & \multicolumn{2}{|c|}{ Low Frequency Content } & \\
\hline & 2000 & 20.500 & 8600 & 238 \\
\hline & 500 & 9800 & 2600 & 377 \\
\hline & 200 & 1850 & 1200 & 154 \\
\hline \multirow{9}{*}{ North-South } & & \multicolumn{2}{|c|}{ Hıgh Frequenc! Content } & \\
\hline & 2000 & 17700 & $8 S 00$ & 208 \\
\hline & 500 & 4400 & 5.300 & 08.3 \\
\hline & 200 & 1200 & 1200 & 100 \\
\hline & & & & \\
\hline & & \multicolumn{2}{|c|}{ Low Frequency Conteni } & \\
\hline & 2000 & 18600 & 10000 & 186 \\
\hline & 500 & 7500 & 3200 & 234 \\
\hline & 200 & 2.200 & 1000 & 220 \\
\hline
\end{tabular}

Tables 5.30 and 5.31 show a direct comparison of the maximum horizontal displacement obtained from the FEM model with the ones obtained from the FA(Frame analysis) model at the top of the stone masonry and steel roof. Similar 
with East-West direction, the results indicate that the finite element model has a more flexible masonry part and a stiffer steel roof.

Table 5.31 Lateral displacement at the top of the roof relative to the top of stone masonry from FEM and FA (Units: $\mathrm{mm}$ )

\begin{tabular}{|c|c|c|c|c|}
\hline \multirow[t]{2}{*}{ Direction } & \multirow{2}{*}{$\begin{array}{c}\text { Retum Period } \\
\text { (year) }\end{array}$} & \multicolumn{2}{|c|}{ High Frequency Content } & \multirow[t]{2}{*}{ FEM/FA } \\
\hline & & FEM & FA & \\
\hline \multirow{8}{*}{ West-East } & 2000 & 11.800 & 15500 & 0.76 \\
\hline & 500 & 4.900 & 13.400 & 0.37 \\
\hline & 200 & 1.500 & 2.100 & 0.71 \\
\hline & & \multicolumn{2}{|c|}{ Low Frequency Conient } & \\
\hline & & FEM & FA & \\
\hline & 2000 & 16400 & 12.300 & 1.33 \\
\hline & 500 & 8300 & 6.300 & 1.32 \\
\hline & 200 & 1.300 & 1.500 & 0.87 \\
\hline \multirow{10}{*}{ North-South } & Retum Period & \multicolumn{2}{|c|}{ High Frequency Content } & \multirow[t]{2}{*}{ Ratio } \\
\hline & (year) & FEM & FA & \\
\hline & 2000 & 23.200 & 34.600 & 067 \\
\hline & 500 & 23.200 & 40.300 & 0.58 \\
\hline & 200 & 5200 & 7.900 & 0.66 \\
\hline & & \multicolumn{2}{|c|}{ Lou Frequency Content } & \\
\hline & & FEM & FA & \\
\hline & $2000)$ & $2350(1)$ & 64800 & 0.36 \\
\hline & 500 & 19000 & 25000 & 076 \\
\hline & 200 & 5200 & 5000 & 104 \\
\hline
\end{tabular}

\subsubsection{Comparison of Base Shears}

Base shear corresponding to 0.002 annual probabilıty of exceedance were calculated using the frame analysis. The results have revealed that the lateral equivalent forces from the static method are at least 3.5 times larger than the ones computed from the dynamic analysis Recognizing that the peak ground motion acceleration differs between the two. the base shears are then normalized with their corresponding peak ground acceleration first and then normalized with the normalized equivalent static shear. Accordingly. 


$$
\mu_{r}=\frac{V_{d} / P G A}{V_{e} / P G A_{\text {equislent }}}
$$

where $\mu_{r}, V_{d}$ and $P G A$ are the resulted ratio, the base shear computed from the dynamic time history and the corresponding peak ground acceleration. Equation 5.11 yields values of $1.0,0.41,0.27,0.38$ and 0.36 for the equivalent static, the high frequency content in the E-W and N-S ground motion and the low frequency content in the E-W and N-S ground motion, respectively. This shows that on the average, the ratio of $1: 0.36$ exists between the equivalent static and the dynamic base shear.

\subsubsection{Comparison of Acceleration}

The horizontal accelerations along the height corresponding to a return pericd of 500 year are listed in Table 5.32 and 5.33 for the East-West and the North-South ground motion, respectively.

Table 5.32 Maximum absolute acceleration from FA and FEM model of 500 year return period: East-West direction (Units: g)

\begin{tabular}{|c|c|c|c|c|c|c|}
\hline \multirow{2}{*}{$\begin{array}{c}\text { Elevation } \\
(\mathrm{m})\end{array}$} & \multirow{2}{*}{ Material } & \multicolumn{2}{c|}{$\begin{array}{c}\text { High Frequency } \\
\text { content }\end{array}$} & \multicolumn{2}{c|}{$\begin{array}{c}\text { Fow Frequency } \\
\text { content }\end{array}$} \\
\cline { 5 - 7 } & & FA & FEM & FA & FEM \\
\hline Bottom & Top & & 0.08 & 0.03 & 0.01 \\
\hline 0 & 2.874 & Masonry & 0.08 & 0.27 & 0.03 & 0.04 \\
\hline 2.874 & 6.705 & Masonry & 0.08 & 0.35 & 0.03 & 0.04 \\
\hline 6.705 & 11.785 & Masonry & 0.08 & 0.35 & 0.03 & 0.07 \\
\hline 11.785 & 17.625 & Masonry & 0.08 & 0.40 & 0.03 & 0.07 \\
\hline 17.625 & 22.4 & Masonry & 0.08 & 0.40 & 0.03 & 0.07 \\
\hline 22.4 & 26.465 & Masonry & 0.07 & 0.40 & 0.03 & 0.12 \\
\hline 26.465 & 31.19 & Masonry & 0.07 & 0.43 & 0.04 & 0.23 \\
\hline 31.19 & 40.79 & Masonry & 0.09 & 0.66 & 0.04 & 0.23 \\
\hline 40.79 & 46.57 & Masonry & 0.09 & 0.66 & 0.05 & 0.25 \\
\hline 46.57 & 48.95 & Masonry & 0.09 & 0.66 & 0.05 & 0.62 \\
\hline 51.89 & 81.55 & Roof & 0.70 & 3.16 & 0.27 & \\
\hline
\end{tabular}




\section{Table 5.33 Maximum absolute acceleration from FA and FEM model of 500 year return period: North-South direction (Units: $g$ )}

\begin{tabular}{|c|c|c|c|c|c|c|}
\hline \multirow{2}{*}{$\begin{array}{c}\text { Elevation } \\
(\mathrm{m})\end{array}$} & \multirow{3}{*}{ Material } & \multicolumn{2}{c|}{$\begin{array}{c}\text { High Frequency } \\
\text { content }\end{array}$} & \multicolumn{2}{c|}{$\begin{array}{c}\text { Low Frequency } \\
\text { content }\end{array}$} \\
\cline { 5 - 7 } & & FA & FEM & FA & FEM \\
\hline Bottom & Top & & 0.09 & 0.03 & 0.01 \\
\hline 0 & 2.874 & Masonry & 0.08 & 0.15 & 0.03 & 0.04 \\
\hline 2.874 & 6.705 & Masonry & 0.08 & 0.03 & 0.03 & 0.06 \\
\hline 6.705 & 11.785 & Masonry & 0.08 & 0.19 & 0.03 & 0.08 \\
\hline 11.785 & 17.625 & Masonry & 0.08 & 0.25 & 0.03 & 0.08 \\
\hline 17.625 & 22.4 & Masonry & 0.08 & 0.25 & 0.03 & 0.09 \\
\hline 22.4 & 26.465 & Masonry & 0.06 & 0.25 & 0.03 & 0.10 \\
\hline 26.465 & 31.19 & Masonry & 0.06 & 0.28 & 0.03 & 0.17 \\
\hline 31.19 & 40.79 & Masonry & 0.05 & 0.50 & 0.04 & 0.17 \\
\hline 40.79 & 46.57 & Masonry & 0.06 & 0.50 & 0.04 & 0.17 \\
\hline 46.57 & 48.95 & Masonry & 0.06 & 0.50 & 0.04 & 1.78 \\
\hline 51.89 & 81.55 & Roof & 0.81 & 2.56 & 0.67 & \\
\hline
\end{tabular}

The absolute accelerations is seen generally to increase along the height except for the resulted obtained from the frame analysis model due to ground motion with high frequency content. From the frame analysis, it is found that the maximum acceleration of the stone masonry above the fifth floor to be less than the peak ground acceleration. In contrast. the results obtained from the finite element analyss using $0 \%$ damping exhbit a larger amplification to the peak ground acceleration and especially at the top of the steel rooi irame. At the top of stone masonry, the amplification of the ground acceleration is found to be 8.3 and 1.7 for the FEM model and the FA model, respectively.

The Fourier Spectrum was performed on the ume history response of the finite element model to determine the frequency content of the records. Fig. 5.5 and 5.6. The results, as expected, indicate that the first natural frequencies of the model were excited by the ground motion. Since the response of finite element model corresponds to the undamped structure, the effect of the $5 \%$ damping ratio 
was approximated using the pseudo spectra acceleration shown in Fig. 5.2. For a period of $0.565 \mathrm{~s}$, the ratio of undamped to $5 \%$ damping for $S_{a}$ is found to be 1.1 and 1.8 for the ground motion containing high and low frequency content, respectively. This shows that the finite element analysis yields larger acceleration than the frame analysis.

\subsubsection{Comparison of Maximum Normal and Shear Stresses}

From the previous section, it is apparent that the stress analyses have produced a large amount of data. To compare the results, some of the data is reproduced in graphical form, showing the distribution along the height. First, the maximum normal and shear stresses obtained from the three models due to the equivalent lateral loads are plotted in Fig. 5.7. The simplified model yielded compressive stresses that in general decrease along the height of the tower. On the other hand, both the frame and finite element show a maximum value at the 8 th floor and the 6th floor due to the East-West and North-South equivalent lateral forces, respectively. Further only the frame model showed significantly high compressive stress values occurring between the 5 th and 8 th floor. The finite element model clearly showed the high stress location at the 8 th floor for both directions and at the 6th floor for only the North-South direction.

For the tensile stress, the same decreasing trend is exhibited by the simplified model. For the equivalent lateral load in the North-South direction, both the frame model and the finite element model have indicated high stress values between the 5 th and the 10 th floor. However, for the equivalent lateral force in the East-West direction, the finite element model limits the high stress values between the 8th and 10th floor level whereas the frame model show the high stress region to extend from the 5 th up to 10 th floc: level. 
The simplified model showed that the 8th floor has the highest shear stress when subjected to an equivalent lateral force in the North-South direction which was also reproduced by the finite element analysis. On the other hand, the results from the frame analysis showed that the maximum shear stress occurs at the 5 th floor. The same pattern was also observed due to the East-West equivalent lateral force with the frame model yielding the maximum shear stress at the 7 th floor. These results show inconsistency in the frame model.

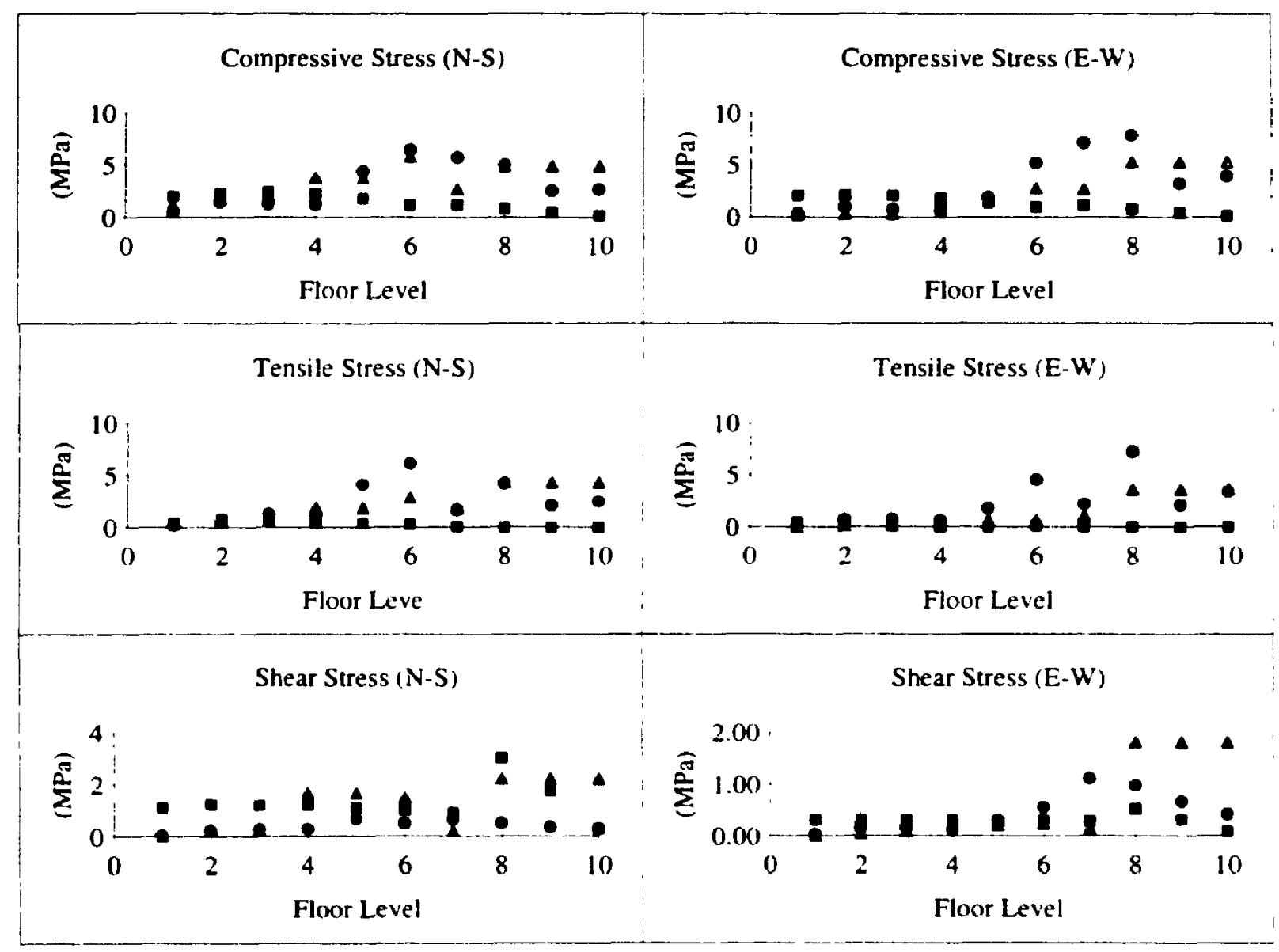

Simplified model

- Frame model Finite element model

Fig. 5.7 Maximum normal and shear stresses due to equivalent lateral forces 
The maximum stresses obtained from the frame model for different time history ground motions are reproduced in Fig. 5.8 and Fig. 5.9 for both high and low frequency contents, respectively. It can be seen that the location of the maximum compressive stress is always between the 5 th and the 7 th floor level whereas for the tensile stress it varied depending on the orientation of the ground motion. This again indicates the inconsistency in the results obtained from the frame model. The increase in stress values may be attributed to the sudden geometric changes at the seventh floor level vihere large openings exist and to the boundary condition imposed by the surrounding building at the fifth level. From the base of the tower to the fourth level, the value for the stress was found to be small and again is attributed to the imposed bountary condition which conztrain the diaphragm from any relative movement. Thus the use of a rigid diaphragm in the presence of a fixed boundary condition restrains the response of the structure.

From Figs. 5.8 and 5.9, it can also be observed that the maximum stresses from the three artificially generated ground motions follow the same trend and they increase with higher return period. On the other hand, the values of maximum stress, in particular the shear stress, obtained from the high frequency content record ase comparable to those obtained from the low frequency content record although the peak ground acceleration of the tower is 2.1 times larger than the latter as shown in Table 5.3. Also the changes in the stress values along the height of the tower are not linearly proportional with the increase in the return period. 


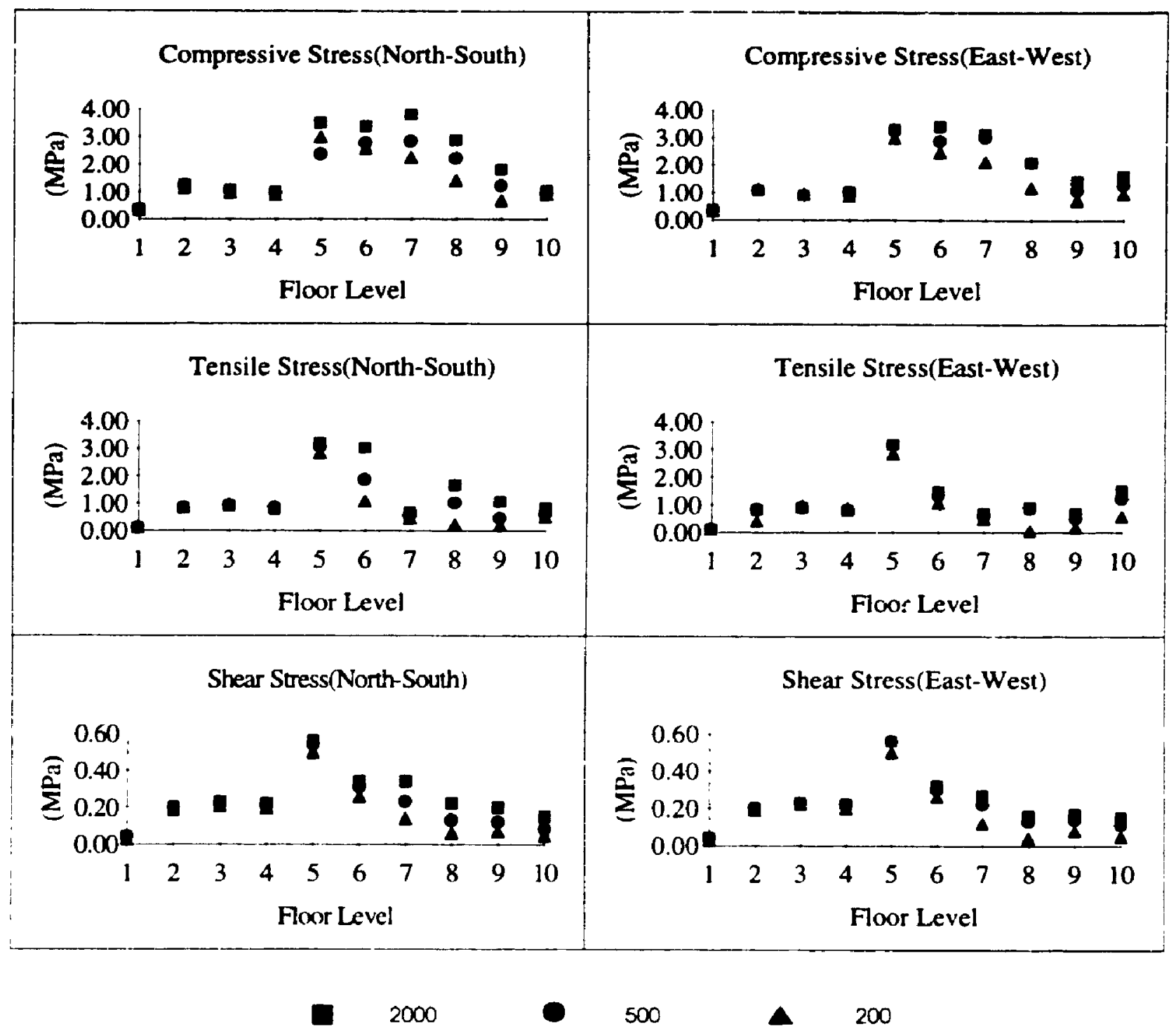

Fig. 5.8 Maximum stresses from high frequency content of time history ground motions (frame model)

The finite element analysis has yielded a stress distribution for the two layers of the shell representing the limestone and sandstone. The maximum stresses for the limestone are plotted in Fig. 5.10 and Fig. 5.11 for $\cdots$ high and low frequency content, respectively. In contrast to the results of the frame model, the distribution of the stresses for the finite element is consistent in that the maximum stress vaiues always occur at the eighth floor. This increase is expected due to the 
sudden geometrical changes and large openings in the walls. At the lower level, the magnitude of the stresses is found small and is partially due to the imposed boundary conditions. Further, it can be observed that generally the maximum stress obtained from the three different ground motions uniformly increases with the return period.

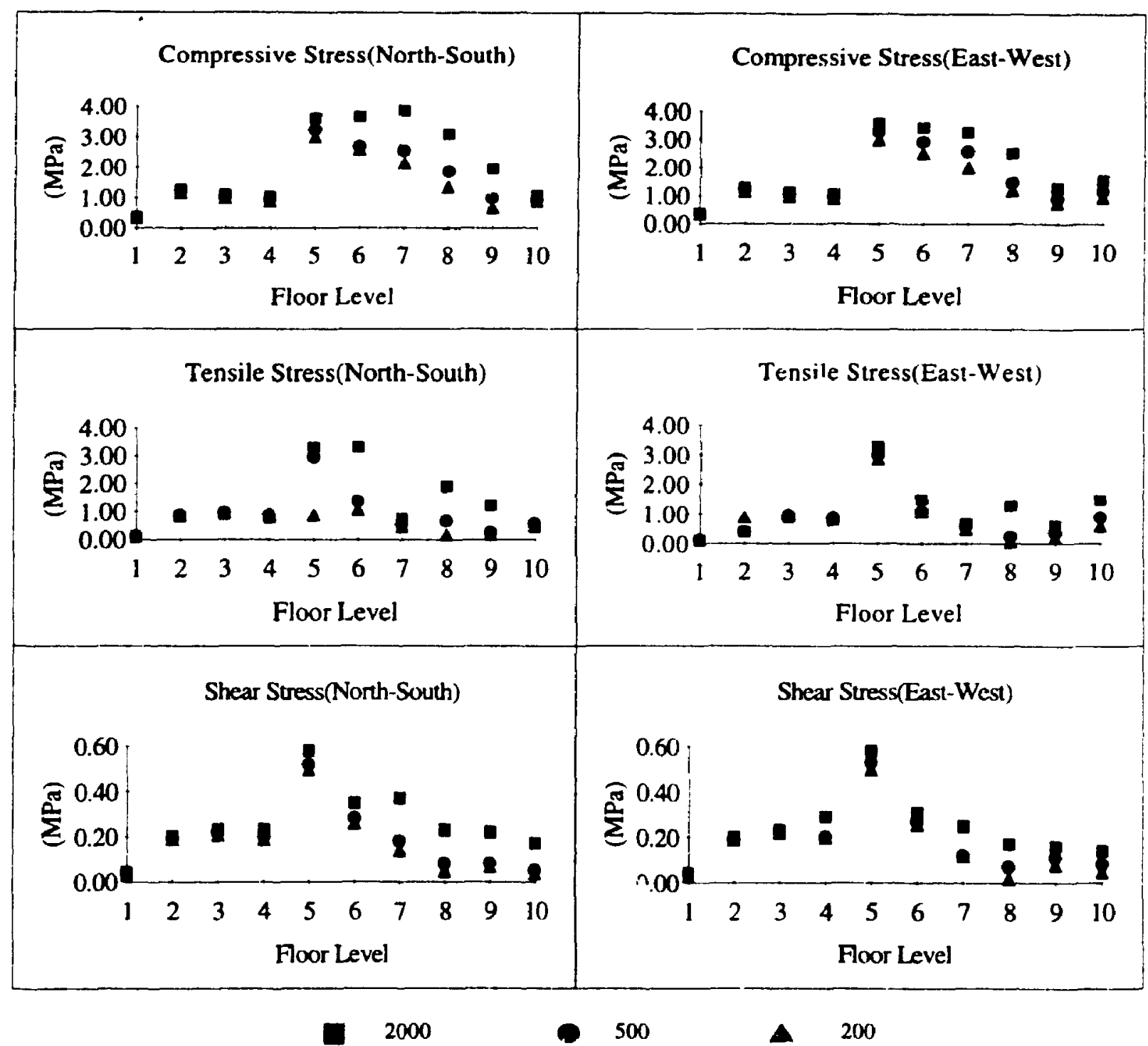

Fig. 5.9 Maximum stresses from low frequency content of time history ground motions (frame model) 


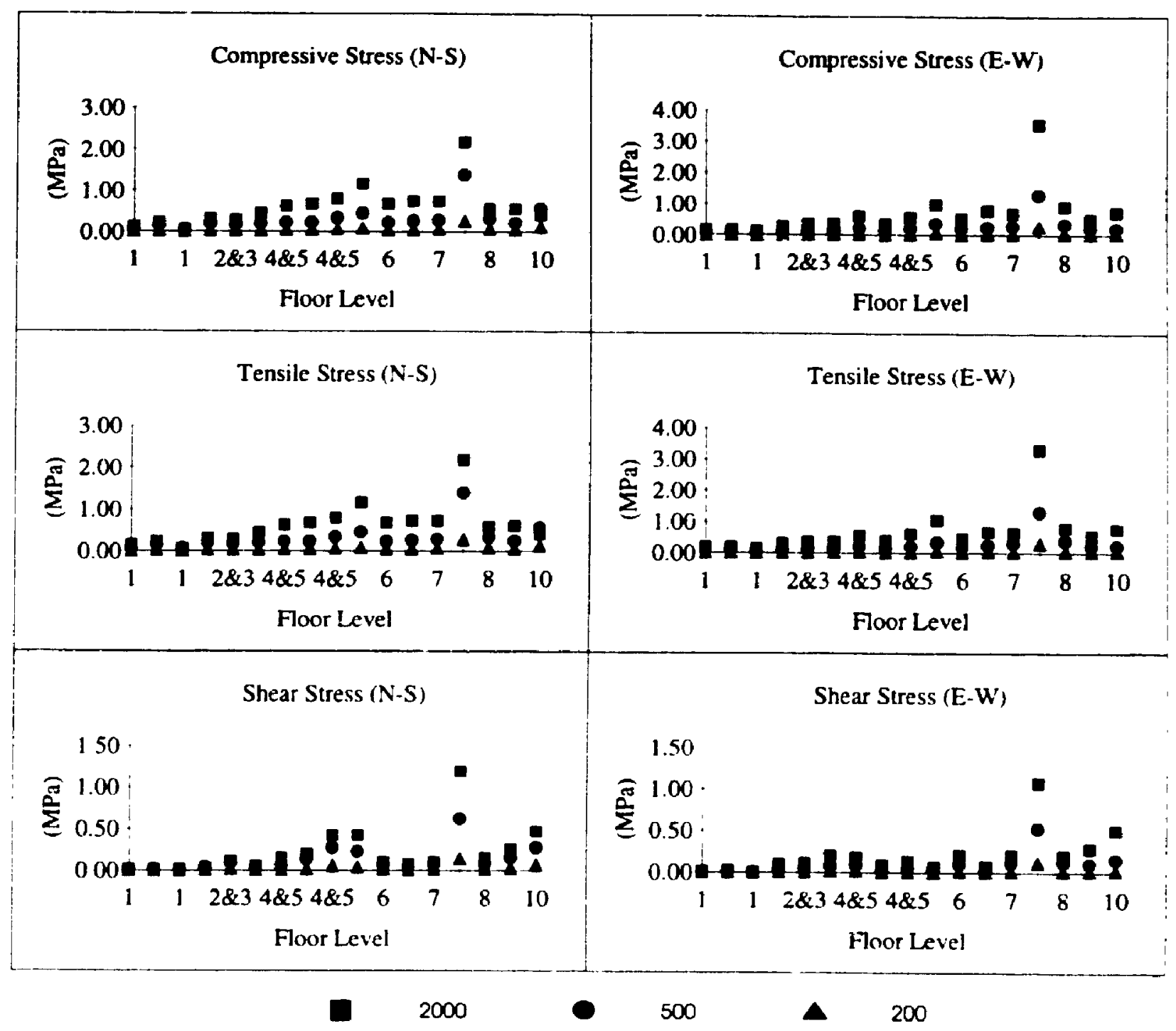

Fig. 5.10 Maximum stresses from high frequency content of time history ground motions (FEM model)

In contrast to the frame analysis. the finite element results indicated that the response of the tower is not the same for the high and low frequency content. From Figs. 5.10 and 5.11 , it is observed that the maximum values are not only dependent on the peak ground acceleration. 
The maximum tensile stresse.s for th.e layer of sandstone obtained from the finite element model are given in Table 5.26 and Table 5.27. It is found that the maximum stress value in sandstone is much higher than that in the limestone.

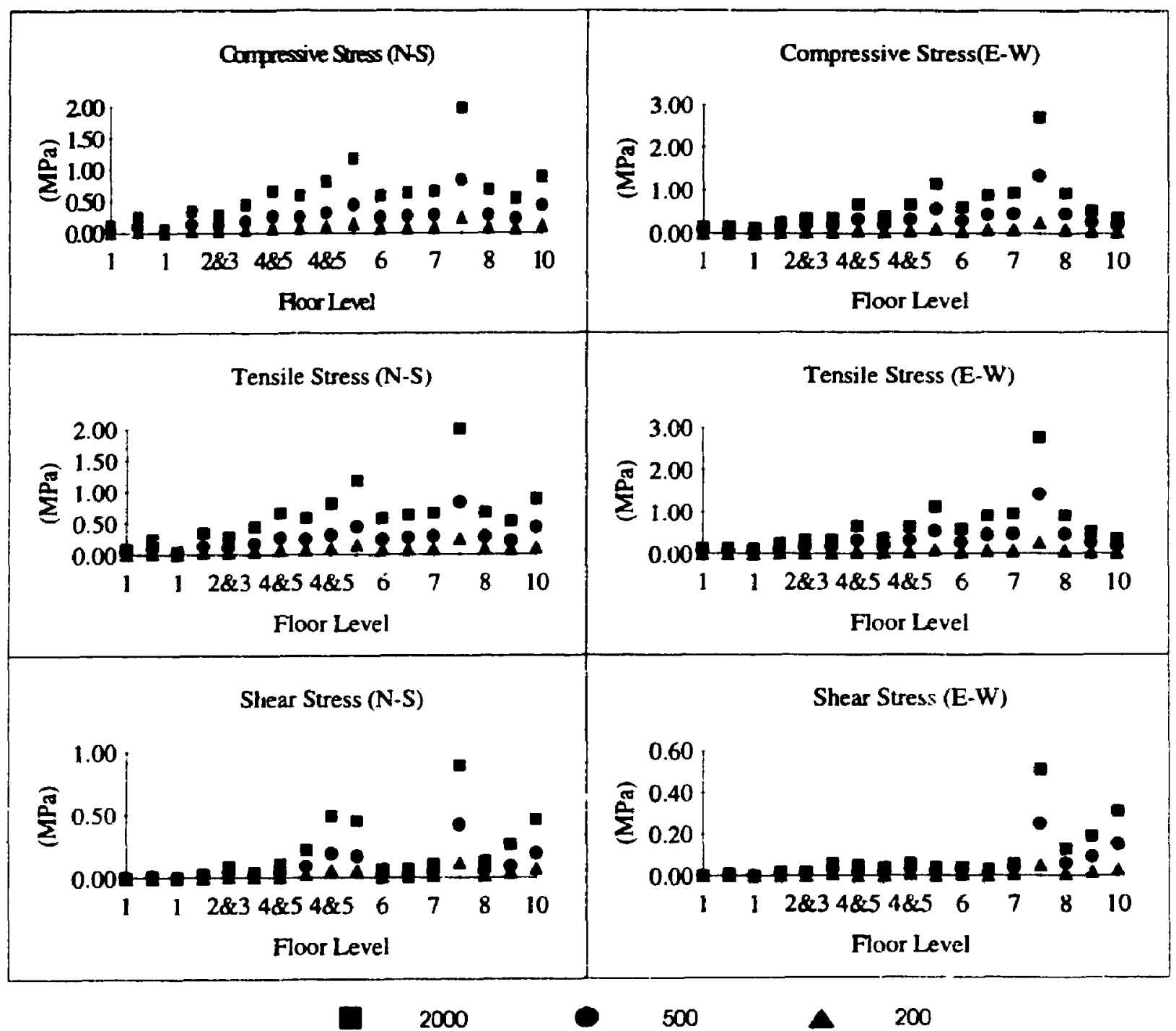

Fig. 5.11 Maximum stresses from low frequency content of time history ground motions (FEM model) 


\subsection{Observations}

The response of the stone masonry tower to the equivalent lateral forces and inertia forces due to ground motion was investigated using three different structural analysis models. From the comparative study, the following observations and interpretation are possible;

- The equivalent lateral forces were found to be at least 2.5 larger than the corresponding inertia forces.

- Only the results of the finite element method were found to be consistent.

- The simplified model failed to identify the location of high stress. The same observation can be made regarding the frame analysis. Also the computed stresses using the frame model are found inconsistent. This deficiency is believed to be caused by the presence of a fixed boundary condition and a rigid diaphragm.

- The results of the normalized base shear indicated that the peak ground acceleration is not the only dominant factor and that both the duration and the frequency content of the ground motion are equally important.

- Although the frame model is the most widely used structural analysis tool for modern buildings, its application to stone masonry structures with flexible diaphragm is unacceptable. 


\section{Chapter 6}

\section{CONCLUSIONS AND RECOMMENDATIONS}

\subsection{Conclusions}

An existing unreinforced stone masonry tower was used to investigate the impact of various existing analytical models on predicting the seismic response of unreinforced stone masonry structures. The results have revealed a major difference among the different analytical methods. First the magnitude of the modulus of elasticity obtained through the calibration procedure decreased as progressively refined methods of analysis were adopted. This implies that the lateral resistance increases as the methods of analysis become more refined..

The calibrated modulus of elasticity did not correspond to the values reported in the literature which range from 10 to $80 \mathrm{GPa}$ for limestone and 3 to 80 GPa for sandstone. In this study, the dynamic elastic modulus for limestone masonry was found in a range from $6 \mathrm{GPa}$ to $3.5 \mathrm{GPa}$. This implies that without the measured dynamic properties, the use of any mathematical model to predict the dynamic performance of a stone masonry structure is questionable.

In terms of base shears, the influence of the peak ground acceleration is not found to correlate linearly with the lateral seismic forces. This was clearly demonstrated from the results corresponding to the ground motion with 0.005 , 0.002 and 0.0005 annual probability of exceedance. Thus, the various methods of analysis which rely on the peak ground motion parameter and the first natural period of the structure do not yield representative seismic forces when compared to 
time history response analysis using artificially generated ground motions. This finding requires further study.

The impact of the modeling technique is found to be tremendous. The stiffness method mostly applied by structural engineers to study both static and dynamic analysis of structures yielded inconsistent results for lateral displacement and both normal and shear stresses. The requirement of the rigid diaphragm to lump the mass of the structure and the deficiency of the panel element for modeling openings in thick walls are the major contributors to the shortcomings of the frame model.

The simplified model which assumes the tower as a free standing structure produced lower displacements and stress values than the finite element model. This mcans that the simplified model may yield non-conservative results.

Although ETABS is suitable for the seismic analysis of many modern structures, the requirement of rigid diaphragm and the deficiencies of the panel element in this program yielded erroneous result for thick masonry structure with openings and flexible diaphragms.

In general, the finite element model was the only method capable of representing the dynamic properties of the tower. It was found to yield a consistent response of the tower when subjected to both equivalent lateral force and ground motion. The results of the FEM compared well with the ambient vibration tests both in terms of mode shape and frequency.

Although the FEM method has shown good promise to model the dynamic response of the stone masonry tower, such analysis requires extensive computer resources. 


\subsection{Recommendations}

Based on the findings of this study, further research is still required as listed below.

I. Modification of the frame program are required for properly modeling flexible diaphragms and thick masonry walls before it san be used for such structures.

2. A special post-processor needs to be developed which computes the average stress field along mortar joints which can reflect overail stress condition.

3 Ultimately, mathematical models are needed to identify the seismic vulnerability of existing structures where non-linear betavior is involved. The use of traditional finite element method in conjunction with non-linear material constitutive law is not economically viable. Thus fusther research to simplify the analysis is definitely needed in this area. 


\section{References}

1. ABY, A Joint Venture, (1981) Methodology for mitigation of seismic hazards in existing unreinforced masonry buildings, Categorization of buildings, ABK-TR-01, Seismic input, ABK-TR-02, Diaphragm testing, ABKTR-03, Wall testing, out-of-plane, ABK-TR-04,. EI Segundo, CA: Agbabian Associates

2. ABK, A Joint Venture, (1984) Methodology for mitigation of seismic hazards in existing unreinforced masonry buildings, "The Methodology," ABK-TR-08. El Segundo, CA: Agbabian Associates

3. Adham, S. A., Ewing, R. D. (1978) Interaction between unreinforced masonry structures and their roof diaphragms during earthquakes, Proceedings of the North American Masonry Conference, August, University of Coorado, Boulder, Colorado

4. Adham, S. A., Ewing, R. D., Kariotis, J. C. and Johnson, A. W. (1985)

Interaction between brick masonry building and their roof diaphragms during earthquakes. Proc. of the 7 th International Brick Masonry Conference, Vol. 2, pp 1153-1164

5. AFEMS (1992) Automatic Finite Element Modeling \& Solution, User's Operation Manual, FEM Engineering Corp., Inglewood, California CA 90304

6. Allen, D. E., Fontaine, L., Maurenbrecher, A. H. P. and Gingras, M. (1989) The 1988 Sequenay Earthquake: Damage to Masonry Construction, National Research Council, Canada, Internal Report, No. 584, p15

7. Angotti, F., Chiostrini, S. and Vignoli, A. (1988) Influence of Uncertainty of geometric and mechanical characteristic on ultimate lateral load of 
existing masonry building, Proc. 8th International Brick Masonry Conference, Dublin, Vol. 3, pp 1768-1778

8. Benedetti, D. and Benzoni, G. M.(1984) Experimental evaluation of seismic provisions for stone masonry buildings, Proc. 8th World Conference on Earthquake Engineering Vol. 1, San Francisco

9. Benedetti, D. and Castellani, A. (1980) Experimental determination of the seismic resistance of repaired masonry structures, Proc. 7th World Conference on Earthquake Engineering, Istanbul, Structural Aspects Part III, Vol. 6, pp 159-166

10. BRE (1979) Estimation of thermal and moisture movement and stresses: Part 2, Building Research Establishment Digest, Nov. 9, pp 2-3

11. Bruncau, M. and Boussabah, L. (1991) Literature survey on seismic performance of thick unreinforced masonry wall, internal report, Public Work of Canada

12. Bernal, D. (1992) Instability of buildings subjected to earthquake, Journal of Structural Engineering, Vol. 118, No. 8, pp 2239-2260

13. Carydis, Panayotis G., Tilford, N. R., Brandow, G. E. and Jirsa, J. O. (1982)

The central Greece earthquakes of February-March 1981, National Research Council, Springfield, Virginia and Earthquake Engineering Research Institute, Berkeley, p 160

14. Chidiac, S. E., Rainer, J. H. and Maurenbrecher, A. H. P.(1993) Internal Report No. A-8006.1, March 26

15. Chidiac, S. E., Rainer, J. H., Guan, W., Lu, Y. and Razaqpur, A. G. (1995)

A comparative study of modeling the dynamic characteristics of a solidstone masonry tower, Streama 95, Structural Studies, Repairs and Maintenance of Historical Buildings, Chania, Crete, Greece 
16. Chidiac, S. E., Rainer, J. H., Maurenbrecher, A. H. P. and Allen, D. E. (1995)

An approach to seismic evaluation of heritage buildings, Seventh Canadian Conference on Earthquake Engineering

17. Clough, R. W. and Penzien, J. (1993) Dynamics of Structure, ISBN 0-07011394-7, McGraw-Hill Inc.

18. Corley, W. G. (1991) Changes in American structural standards for concrete and masonry high rise building, Structural Engineering International, April 1991, pp 51-52

19. Dionisio, B. (1992) Instability of building subjected to earthquakes, Journal of Structural Engineering, Vol. 118, No.8, August, pp 2239-2260

20. Ergunay, O. and Erdik, M. (1984) Turkish experience on the earthquake performance of rural stone masonry building, International Conference on Natural Hazards Mitigation Research and Practice-Small buildings and Community Development, Oct. 1984, India, New Delhi

21. Erdik, M. (1990) The earthquake performance of rural stone masonry buildings in Turkey and Earthquake damage evaluation vulnerability analysis of building structures, A. Koridze, INEEC Series of Engineering Aspects of Earthquake Phenomena, V3, Omega Scientific

22. ETABS (1991) Building Analysis \& Design, users manual, Computer \& Structures Inc., Berkeley, California

23. FEMA (1989) A handbook for seismic evaluation of existing buildings (preliminary), Earthquake hazards reduction series 47, FEMA-178, June

24. Groci, G. (1992) Structural behavior of monuments: Knowledge and improvement, Porc. Conservation of Stone and Other Materials, RILEM, Paper No. 51.8 pages. 
25. Humar, J. L. (1990) Dynamics of Structures, Prentice Hall International Series in Civil Eng.

26. International Masonry Institute(undated) Mexico earthquake September, 1985, IMI, p 71

27. IRC-NRCC (1992) Guidelines for seismic evaluation of existing building, Ottawa, December

28. IRC-NRCC (1992) Manual for screening of buildings for seismic investigation, Ottawa, September

29. Karantoni, F. K. and Fardis, M. N. (1992) Computed versus observed seismic response and damage of masonry building, Journal of Structural Engineering, Vol. 118 , No. 7

30. Kariotis, J. C., Ewing, R. D. and Johnson, A. W. (1985) Predictions of stability for unreinforced brick masonry walls shaken by earthquakes, Proc. 7th International Brick Masonry Conference, Vol. 2, pp 1175-1183, Melbourne, Australia

31. Kidder, F. E. and Parker, H. (1931) Kidder-Parker architects ${ }^{\circ}$ and builders' handbook

32. Klingner, R. E., Beiner, R. J. and Amrhein, J. E. (1987), Performance of mortars for historical buildings, Proc. 9th International Brick/Block Masonry Conference, Berlin, Vol. 3, pp 1412-1419

33. Li, M. and Chou, J. (1985) Structural Mechanics of Bridge Engineering, Tongji University, Shanghai

34. Mann, W. and Muller, H. (1982) Failure of shear-Stress masonry--an enlarged theory, tests and application to shear walls. Proc. of the British Ceramic Society No. 30, pp 223-235 
35. Mayes, R. L. and Clough, R. W.

State-of-art in seisnuic shear strength of masonry - an evaluation and review, Earthquake Engineering Research Center Report No. EERC 75-21, University of California, Berkeley

36. Modena, C. (1989) Italian practice in evaluating, strengthening and retrofitting masonry buildings, Proc. International Seminar on Evaluating, Strengthening and Retrofitting Masonry Buildings, University of Texas at Arlington

37. NRC-CNRC (1990) National Building Code of Canada 1990, part 4 structural design pp 137-163 and Supplementary of National Building Code of Canada 1990, Commentary J, Effects of Earthquakes, 202-217

38. NRC-CNRC (1992) Guidelines for Seismic Evaluation of Existing Buildings, National Research Council of Canada, Ottawa

39. Seible, F. and Kingsley, G. R. (1991) Modeling of concrete and masonry structures subjected to seismic loading. Experimental and NLanerical Methods in Earthquake Engineering. pp 281-318

40. Sinha, B. P. (1978) A simplified ultimate load analysis of laterally loaded model orthotropic brickwork panels of low tensile strength. The Structural Engineering Dec. 1978. No. 4. Volume 56B

41. Tezcan, S. S., Yerlici, V. and Durgunoglu, H. T. (1978) A reconnaissance report for the Romanian earthquake of March 4, 1977. Earthquake Engineering and Structural Dynamics, Vol. 6, pp 397-421

42. Timoshenko, S. and Goodier, J. N. (1951) Theory of Elasticity

43. Tomazevic, M. and Anicic, D. (1989) Research, technology and practice in evaluating, strengthening and retrofitting masonry buildings: Some 
Yugoslavian experiences, Proc. International Seminar on Evaluating. Strengthening and Retrofitting Masonry Buildings, Arlington, p54

44. Tomazevic, M. and Sheppard, P. (1982) The strengthening of stonemasonry buildings for revitalization in seismic regions, Proc. 7th European Conference on Earthquake Engineering, Athens, Vol. 5, pp 275-285

45. Tomazevic, M. and Turnsek, V.(1982) Verification of the seismic resistance of masonry buildings, Proc. British Ceramic Society,, No. 30, Sept., Load-Bearing Brickwork (7), pp 360-369

46. Tomazevic, M. and Velechovsky, T. (1992) Some aspects of testing smallscale masonry building models on simple earthquake simulators, Earthquake . gineering and Structural Dynamics, Vol. 21, pp 945-963

47. Turnsek, V., Tercelj, S., Sheppard, P. and Tomazevic, M. (1978) The seismic resistance of stone-masonry walls and buildings, Proc. 6th European Conference on Earthquakc Engineering, Dubrovnik, Vol. 3, pp 255-262

48. UNESCO (1982 and 1983) Earthquake risk reduction in the Balkan region, UNDP Project-UNESCO

49. Vestroni, F., Giannini, R. and Grillo, F. (1991) Seismic analysis of an ancient church and a proposal of strengthening repair, Structural Repair and Maintenance of Historical Building, pp 77-88, Spain

50. Xia, J. and Chen, M. (1084) Experimental study on ceismic behavior of brick building. Proc. of 8 th World Conference on Earthquake Engineering, Vol. 6 


\section{APPENDIX -A}

\section{Natural Periods Computed According to NBCC}

\section{A Description}

\section{A.1 Geometry Consideration}

According to NBCC, the lateral force at each level shall be calculated directly proportional to the mass lumped at that level and the height of that level. Since the tower has walls continuously along its height and the mass of the floor is negligible compared with the mass of stone masonry wall, we would divide the tower into segments where each segme.nt will carry the lateral force according to its mass and the height where the mass is lumped. Primarily, we focus on the height and the thickness of the wall. The natural periods obtained from this computation is therefore based on the discrete model involving different segments where the geometry property changes rapidly.

The steel cap and clay brick are assigned only one degree freedom each because of their relatively small mass which also means small kinetic energy. The tower is considered with three degrees of freedom for the steel roof, the clay brick and the masonry stone, respectively. Second the stone masonry is divided into two equal length segments with the total number of degrees of freedom equal to ruur. Third, the stone masonry is divided into three segments due to the sudden large changes in the rection geometry. Again the stone masonry is divided into four segments according to the geometry changes. This time, the results is found to be 
less than $1 \%$ different from that of the preceding idealization one and thus is considered as converged result that will be used for further study.

The torsional mode was computed in a slight different way from how the first mode and second mode were calculated. Since the steel cap and clay brick wall are symmetrical in both directions, the torsional moment is zero for each of them. The tower was directly divided into three segments, namely from the base to sixth floor, from the sixth floor to the ninth floor and from the ninth to the tenth floor. For three of them, the first and third are considered as close section and second is modeled as an open section consisting of several walls and turrets.

\section{A.2 Material Property}

Material properties of the structure are listed in Table A 2.1

\section{Table A 2.1 Material properties applied in the simplified method}

\begin{tabular}{|c|c|c|c|}
\hline \multirow{2}{*}{ Material } & Modulus of Elasticity & Mass Density & Poisson's Ratio \\
\cline { 2 - 4 } & $(\mathrm{GPa})$ & $\left(\mathrm{kg} / \mathrm{m}^{3}\right)$ & \\
\hline Stone masonry & 6 & 2716 & 0.2 \\
\hline Steel & 200 & 7800 & 0.3 \\
\hline Brick wall & 28 & 1800 & 0.2 \\
\hline
\end{tabular}

\section{A.3 Computing Procedure}

\section{A.3.1 First two natural periods}

Step 1 Identify the segments

Step 2 Determine the mass and mass center of each segment 
Step 3 Determine the average moment of inertial of the segment

Step 4 Determine the lateral forc $s$, at each mass center $H_{i}$ (total lateral force is assumed $100,000 \mathrm{~N}$ )

Step 5 Determine the lateral flexural displacement at each mass center due to bending force applied at that level by using general flexural equation

$$
E I(x) \delta_{1,}^{n}=M(x)
$$

where $\delta_{i}$ is the lateral flexural displacement due to bending moment applied at floor $i, E$ is the modulus of elasticity, $I(x)$ and $M(x)$ are function of moment of inertia and applied moment along the height of interest.

Step 6 Determine the lateral shear displacement' at each mass center due to lateral force applied at that level according to equation $A 2.2$

$$
\delta_{1,}=\frac{Q_{1} H_{t}}{G A^{*}}
$$

where $Q_{1}, H$, are the applied shear force, height of segment for segment $i$ respectively. $G$ is shear modulus, and $A^{*}$ is to be computed as

$$
A^{*}=\frac{I^{2}}{\oint_{A}\left(S_{1} / t\right)^{2} d A}
$$

where $S_{1}, t$ and $I_{1}$ are the first moment of area integrated along walls. thickness of the wall and moment of inertia of segment $i$ respectively.

\footnotetext{
'Shear displacement of steel roof was not calculated
} 


\section{Close section:}

For a close section, first cut the section open at certain point on the edge, then from the free end integrate along the edge to find $S_{t_{0}}$, which is the first moment of area for opening section. By knowing $S_{t_{0}}, S_{t_{t}}$ can be calculated as

$$
S_{t_{1}}=\frac{\oint S_{t_{0}} \frac{d s}{t}}{\oint \frac{d s}{t}}
$$

finally, $S$ is obtained by add up the two components

$$
S_{1}=S_{t_{0}}+S_{t_{t}}
$$

\section{Open section:}

For section consisting of columns alone, $S_{X}$ can be easily obtained by directly integrating from the free end. By assuming all columns connected with rigid beam at both ends, the lateral force can be directly distributed to each column according to their total flexural and shear stiffness, $K$, which can be computed as

$$
K=\frac{G A^{*}}{L}+\frac{12 E I_{b}}{L^{3}}
$$

where $L$ is the length of the segment.

Step 7 Total displacement at each mass center can be computed by

$$
\delta_{1}=\delta_{1,}+\delta_{i_{s}}
$$

Step $^{\circ}$ Substitute the values into the equation (A 2.8) suggested by NBCC 19990 , the natural period can be obtained from 


$$
T=2 \pi \sqrt{\frac{\sum_{i=1}^{n} W_{i} \delta_{i}^{2}}{g \sum_{i=1}^{n} F_{i} \delta_{i}}}
$$

where $F_{1}$ represents any lateral force associated with weight $W_{i}, \delta_{i}$, is the elastic deflection due to the applied lateral force $f_{t}$ in storey $i$.

Step 9 Refine the segment division and go back to Step 1 through Step 6 until the results converge to the desired level.

\section{A.3.2 Period of Rotational Mode}

Step 1 Establish the segments

Step 2 Determine the nass and mass center of each segment

Step 3 Determine the average moment of inertia of each segment

Step 4 Determine the lateral force $f_{1}$ at each mass center $H_{1}$ (total lateral force is assumed $100,000 \mathrm{~N}$ )

Step 5 Determine the shear center of the section and the total eccentricity of the section. In this case, because of symmetrical geometry at north-south direction, the shear center is on the central line of west-east direction. 


\section{Close section:}

(1) Determine the center of mass

(2) Compute $S$, as suggested in Step 6 for the first period computation.

Apply a unit horizontal force through the mass center and obtain the shear flow along the wall as

$$
q_{i}=\frac{Q_{1} S_{1}}{I_{1}}
$$

where $q_{x}$ is the shear flow along the wall.

Find the moment due to a unit load about the center of mass

$$
M=e \times 1=\oint_{l} \frac{S_{l}}{I_{l}} R(l) d l
$$

integrate along the center of the wall where $R(l)$ is the perpendicular distance between the point where the shear flow acts and the shear center.

\section{Open section:}

(1) Find center of mass

(2) Find center of sectional rigidity according to equation A 2.6

(3) Eccentricity is the distance between those two centers.

The total eccentricity of the section suggested by NBCC is calculated as follows

$$
e_{x}=1.5 e+0.10 D_{n}
$$

where $D_{n}$ is the plan dimension of the building in the direction of the computed eccentricity and $e$ is the eccentricity of the interested direction.

Step 6 Find the torsional moment applied at each mass center

$$
M_{1}=F_{1} \times e_{x}
$$


Step 7 Determine the torsional constant $J$ at each segment. For close section, it is calculated as

$$
J=\frac{\Omega^{2}}{\oint \frac{d s}{t}}
$$

where $\Omega=2 A_{\iota}$ (area surrounded by center line of the wall).

$$
J=\frac{1}{3} \sum_{t=1}^{n} b_{t} t_{t}^{3}
$$

where $b_{1}$ is the length of the element and $t_{t}$ is the thickness respectively.

Step 8 Determine the twist angle due to torsional moment in each segment.

$$
\theta=\frac{M_{t} L}{G J}
$$

Step 9 Determine the rotational displacement due to torsional moment

$$
\delta_{1}=r_{1} \times \theta
$$

where $r_{1}$ is radius of gyration at segment $i$.

Step 10 Substitute the values into the equation A 2.17 which is equivalent to A2.8 suggested by NBCC 1990

$$
T=2 \pi \sqrt{\frac{\sum_{i=1}^{n} W_{i} \delta_{i}^{2}}{g \sum_{i=1}^{n} M_{i_{i}} \theta_{i}}}
$$

Calculated values are listed in Tables A 2.2 to $\mathrm{A} 2.4$ for the first period with the tower divided into five segments, and in Tables A 2.5 to A 2.6 for the torsional period. 


\section{A.4 Example}

\section{A.4.1 Fundamental Period}

The stiffness of the steel cap was obtained by idealizing the cap as a triangular truss structure pin ended at the top and the bottom with no horizontal link in-between. The section property of the truss model is the same as the actual member (the idealized model was checked by comparing its result with the complete space-truss steel cap model, and they were found to be less than $20 \%$ difference). A unit force was applied at the top of the cap while the bottom of the cap was held and the lateral displacement was calculated. The stiffness of the cap was obtained by finding the necessary force for a unit displacement at the same location. While the mass center of the cap is at 0.38 of its own height, the stiffness based on the assumption that the cap is a uniform section cantilever beam.

Table A 2.2 Flexural displacement

\begin{tabular}{|c|c|c|c|c|c|c|c|c|c|c|}
\hline $\begin{array}{c}\text { Storey } \\
\text { Level }\end{array}$ & Height & $\begin{array}{c}\text { Weight } \\
\text { per Storey } \\
(\mathrm{m})\end{array}$ & $\begin{array}{c}\text { Mass } \\
\text { Center } \\
(\mathrm{m})\end{array}$ & $\begin{array}{c}\text { I } \\
\left(\mathrm{m}^{4}\right)\end{array}$ & $\begin{array}{c}\text { Height } \\
\text { of Storey } \\
(\mathrm{m})\end{array}$ & $\begin{array}{c}\text { I of } \\
\text { Segment } \\
\left(\mathrm{m}^{4}\right)\end{array}$ & $\begin{array}{c}\text { W of } \\
\text { Segment } \\
(\mathrm{kN})\end{array}$ & $\begin{array}{c}\text { Height of } \\
\text { Mass Center } \\
(\mathrm{m})\end{array}$ & $\begin{array}{c}\text { Lateral } \\
\text { Force } \\
(\mathrm{N})\end{array}$ & $\begin{array}{c}\text { Lateral } \\
\text { deflection } \\
(\mathrm{m})\end{array}$ \\
\hline Steel Cap & 63.16 & 386.00 & 63.16 & & 11.27 & 0.04 & 386 & 63.16 & 1256 & $1.36 \mathrm{E}-04$ \\
Clay Brick & 51.89 & 2360.00 & 50.42 & 178.60 & 2.94 & 178.00 & 2360 & 50.42 & 6131 & $4.77 \mathrm{E}-05$ \\
10th & 48.95 & 3804.70 & 47.76 & 709.60 & 2.38 & & & & & \\
9th & 46.57 & 7458.10 & 43.67 & 680.80 & 578 & 684.66 & 22209 & 40.59 & 46174 & $1.47 \mathrm{E}-0.04$ \\
8th & 40.79 & 10946.10 & 35.99 & 680.80 & 9.60 & & & & & \\
7th & 31.19 & 6275.50 & 28.83 & 849.20 & 4.73 & & & & & \\
6th & 26.47 & 10242.70 & 24.43 & 951.90 & 4.07 & 952.00 & 36181 & 21.29 & 38588 & $1.62 \mathrm{E}-05$ \\
5th & 22.40 & 9412.20 & 20.00 & 934.70 & 4.78 & & & & & \\
4th & 17.63 & 10250.30 & 14.71 & 1049.40 & 5.84 & & & & & \\
3th & 11.79 & 9761.90 & 9.25 & 1196.80 & 5.08 & & & & & \\
2th & 6.71 & 11311.60 & 4.79 & 1259.80 & 3.83 & 1342.70 & 29692 & 5.28 & 7851 & $5.59 \mathrm{E}-08$ \\
Ith & 2.87 & 8618.50 & 1.44 & 1711.10 & 2.87 & & & & & \\
\hline
\end{tabular}


Table A 2.3 Shear displacement

\begin{tabular}{|c|c|c|c|c|c|c|c|c|c|c|}
\hline $\begin{array}{c}\text { Storey } \\
\text { Level }\end{array}$ & $\begin{array}{c}\text { Height } \\
(\mathrm{m})\end{array}$ & $\begin{array}{c}\text { Weight } \\
\text { of Storey } \\
(\mathrm{kN})\end{array}$ & $\begin{array}{c}\text { Mass } \\
\text { Center } \\
(\mathrm{m})\end{array}$ & $\begin{array}{c}\mathrm{I} \\
\left(\mathrm{m}^{4}\right)\end{array}$ & $\begin{array}{c}\text { Height } \\
\text { of Storey } \\
(\mathrm{m})\end{array}$ & $\begin{array}{c}\text { A of } \\
\text { Segment } \\
\left(\mathrm{m}^{2}\right)\end{array}$ & $\begin{array}{c}\text { W of } \\
\text { Segment } \\
(\mathrm{kN})\end{array}$ & $\begin{array}{c}\text { Height of } \\
\text { Mass Center } \\
(\mathrm{m})\end{array}$ & $\begin{array}{c}\text { Lateral } \\
\text { Force } \\
(\mathrm{N})\end{array}$ & $\begin{array}{c}\text { Lateral } \\
\text { Deflection } \\
(\mathrm{m})\end{array}$ \\
\hline Clay Brick & 51.89 & 2360.00 & 50.42 & 178.60 & 2.94 & 3.75 & 2360 & 50.42 & 6131 & $6.94 \mathrm{E}-06$ \\
10th & 48.95 & 3804.70 & 47.76 & 709.60 & 2.38 & & & & & \\
9th & 46.57 & 7458.10 & 43.67 & 680.80 & 5.78 & 2.08 & 22209 & 40.59 & 6225 & $4.07 \mathrm{E}-05$ \\
8th & 40.79 & 10946.10 & 35.99 & 680.80 & 9.60 & & & & & \\
7th & 31.19 & 6275.50 & 28.83 & 849.20 & 4.73 & & & & & \\
6th & 26.47 & 10242.70 & 24.43 & 951.90 & 4.07 & 19.56 & 36181 & 21.29 & 38588 & $1.68 \mathrm{E}-05$ \\
5th & 22.40 & 9412.20 & 2000 & 934.70 & 4.78 & & & & & \\
4th & 17.63 & 10250.30 & 14.71 & 1049.40 & 5.84 & & & & & \\
3th & 11.79 & 976190 & 9.25 & 1196.80 & 5.08 & & & & & \\
2th & 6.71 & 11311.60 & 479 & 1259.80 & 3.83 & 22.70 & 29692 & 5.28 & 7851 & $7.30 \mathrm{E}-07$ \\
1th & 2.87 & 8618.50 & 1.44 & 1711.10 & 287 & & & & & \\
\hline
\end{tabular}

Table A 2.4 Fundamental period(unit: second)

\begin{tabular}{|c|c|c|}
\hline $\begin{array}{c}\text { Total } \\
\text { Displacement } \\
(\mathrm{m})\end{array}$ & $W_{i} \delta_{i}^{2}$ & $\mathcal{}$ \\
\hline $1.34 \mathrm{E}-04$ & $6.93 \mathrm{E}-03$ & $1.65 \mathrm{E}+00$ \\
\hline $5.46 \mathrm{E}-05$ & $7.04 \mathrm{E}-03$ & $3.28 \mathrm{E}+00$ \\
\hline $1.88 \mathrm{E}-04$ & $7.85 \mathrm{E}-01$ & $8.51 \mathrm{E}+01$ \\
\hline $3.31 \mathrm{E}-05$ & $3.96 \mathrm{E}-02$ & $1.25 \mathrm{E}+01$ \\
\hline $7.86 \mathrm{E}-07$ & $1.83 \mathrm{E}-05$ & $6.05 \mathrm{E}-02$ \\
\hline Summation & $8.39 \mathrm{E}-01$ & $1.03 \mathrm{E}+02$ \\
\hline The Fundamental period: & $\mathrm{T}=$ & $5.68 \mathrm{E}-01$ \\
\hline
\end{tabular}




\section{A.4.2 Period of Rotational Mode}

\section{Table A 2.5 Torsional displacement}

\begin{tabular}{|c|c|c|c|c|c|c|c|c|c|c|c|}
\hline $\begin{array}{l}\text { Storey } \\
\text { Level }\end{array}$ & $\begin{array}{c}\text { Story } \\
\text { Weight } \\
\text { (kN) } \\
\end{array}$ & $\begin{array}{c}\text { Mass* } \\
\text { Center } \\
\text { (m) }\end{array}$ & $\begin{array}{c}\text { Storey } \\
\text { Height } \\
\text { (m) }\end{array}$ & $\begin{array}{c}J \text { of } \\
\text { Segment } \\
m^{4}\end{array}$ & $\begin{array}{c}\mathrm{W} \text { of } \\
\text { Segment } \\
(\mathbf{k N})\end{array}$ & $\begin{array}{c}\text { Lateral } \\
\text { Force } \\
\text { (N) }\end{array}$ & $\begin{array}{c}\text { Eccentricity } \\
\text { (m) }\end{array}$ & $\begin{array}{c}\text { Torsional } \\
\text { Moment } \\
(\mathrm{N}-\mathrm{m})\end{array}$ & $\begin{array}{c}\text { Radius of } \\
\text { Gyration } \\
\text { (m) }\end{array}$ & $\begin{array}{c}\text { Rotationl } \\
\text { Angle }\end{array}$ & $\begin{array}{c}\text { Rotational } \\
\text { Displacement } \\
(\mathrm{m})\end{array}$ \\
\hline 10th & 3805 & 47.76 & 2.38 & 743.9 & 3805 & 9216 & 3.02 & -49791 & 3.66 & $-6.4 E-08$ & $-2.33 \mathrm{E}-07$ \\
\hline 9th & 7458 & 43.67 & 5.78 & & & & & & & & \\
\hline 8th & 10946 & 35.99 & 9.60 & 23.5 & 24680 & 45674 & 3.56 & 221292 & 3.42 & $7.6 E \cdot 05$ & 2.59E-04 \\
\hline 7th & 6276 & 28.83 & 4.73 & & & & & & & & \\
\hline 6th & 10243 & 24.43 & 4.07 & & & & & & & & \\
\hline 5th & 9412 & 20.00 & 4.78 & & & & & & & & \\
\hline 4th & 10250 & 14.71 & 5.84 & 1144.7 & 59597 & 37839 & 3.90 & -390000 & 3.79 & $-3.6 \mathrm{E}-06$ & $-1.37 \mathrm{E}-05$ \\
\hline 3th & 9762 & 9.25 & 5.08 & & & & & & & & \\
\hline 2th & 11312 & 4.79 & 3.83 & & & & & & & & \\
\hline 1th & 8619 & 1.44 & 2.87 & & & & & & & & \\
\hline
\end{tabular}

Table A 2.6 Torsional period (unit: second)

\begin{tabular}{|c|c|c|c|}
\hline $\begin{array}{c}\text { RotationL } \\
\text { Angle }\end{array}$ & $\begin{array}{c}\text { Rotational } \\
\text { Displacement } \\
(\mathrm{m})\end{array}$ & $W, \delta_{1}^{2}$ & $g M, \theta_{1}$ \\
\hline$-6.37 \mathrm{E}-08$ & $-6.40 \mathrm{E}-05$ & $1.56 \mathrm{E}-02$ & 0.03 \\
\hline $7.56 \mathrm{E}-05$ & $1.34 \mathrm{E}-04$ & $4.43 \mathrm{E}-01$ & 164.02 \\
\hline$-3.61 \mathrm{E}-06$ & $-6.21 \mathrm{E}-06$ & $2.30 \mathrm{E}-03$ & 13.70 \\
\hline \multicolumn{2}{|c|}{ Summation } & $4.61 \mathrm{E}-01$ & 177.84 \\
\hline The torsional period & $\mathrm{T}=\mathrm{0.32}$ \\
\hline
\end{tabular}




\section{A.4.3. Results}

The first three natural frequencies calculated through the previous section are listed in Table A 2.7

Table A 2.7 Natural frequencies obtained from the simplified method

\begin{tabular}{|c|c|}
\hline Mode & $\begin{array}{c}\text { Natural Period } \\
(\mathrm{sec})\end{array}$ \\
\hline North-South direction & 0.568 \\
\hline East-West direction & 0.475 \\
\hline Rotational direction & 0.32 \\
\hline
\end{tabular}



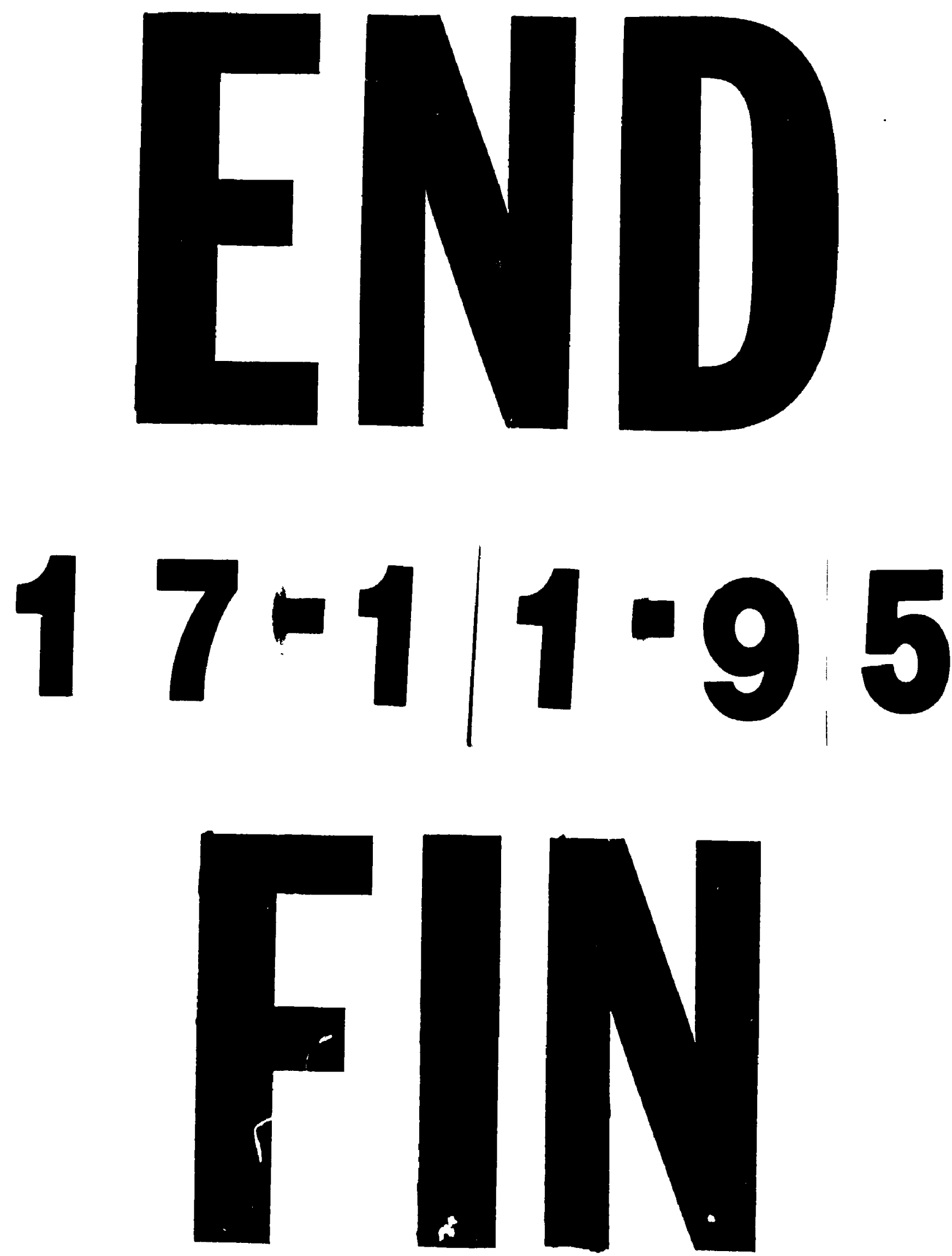